Research for Development

Paola Pucci

Matteo Colleoni Editors

Understanding

Mobilities for

Designing

Contemporary

Cities

Fondazione

Politechico

di Millano

Springer 


\title{
Research for Development
}

\author{
Series editors
}

Emilio Bartezzaghi, Milano, Italy

Giampio Bracchi, Milano, Italy 
More information about this series at http://www.springer.com/series/13084 
Paola Pucci · Matteo Colleoni

Editors

\section{Understanding Mobilities for Designing Contemporary Cities}

第 Springer 


\section{Editors}

Paola Pucci

DAStU

Politecnico di Milano

Milan

Italy
Matteo Colleoni

Università di Milano Bicocca

Milan

Italy
ISSN 2198-7300

Research for Development

ISBN 978-3-319-22577-7

DOI 10.1007/978-3-319-22578-4
ISSN 2198-7319 (electronic)

ISBN 978-3-319-22578-4 (eBook)

Library of Congress Control Number: 2015950898

Springer Cham Heidelberg New York Dordrecht London

(C) Springer International Publishing Switzerland 2016

This work is subject to copyright. All rights are reserved by the Publisher, whether the whole or part of the material is concerned, specifically the rights of translation, reprinting, reuse of illustrations, recitation, broadcasting, reproduction on microfilms or in any other physical way, and transmission or information storage and retrieval, electronic adaptation, computer software, or by similar or dissimilar methodology now known or hereafter developed.

The use of general descriptive names, registered names, trademarks, service marks, etc. in this publication does not imply, even in the absence of a specific statement, that such names are exempt from the relevant protective laws and regulations and therefore free for general use.

The publisher, the authors and the editors are safe to assume that the advice and information in this book are believed to be true and accurate at the date of publication. Neither the publisher nor the authors or the editors give a warranty, express or implied, with respect to the material contained herein or for any errors or omissions that may have been made.

Printed on acid-free paper

Springer International Publishing AG Switzerland is part of Springer Science+Business Media (www.springer.com) 


\section{Acknowledgments}

This book brings together contributions from a cycle of seminars held at the Politecnico di Milano on "Mobilities. Policy and projects" organised in association with activities for the Ph.D. Course in Urban Planning, Design and Policy (UPDP), Politecnico di Milano, and for the Ph.D. Course in Urban and Local European Studies (URBEUR), University of Milano Bicocca.

We owe thanks for their collaboration to all the colleagues who participated in the cycle of seminars with expertise and interest, as well as the Ph.D. candidates who enlivened debates on the issues of spatial mobility, urban transformations and the construction of urban policies.

The interdisciplinary contributions arising from the experience have proved essential for this publication. 


\section{Contents}

Part I Mobilities and the Transformations of Contemporary Cities

Mobility Practices as a Knowledge and Design Tool for Urban Policy . . . . . . . . . . . . . . . . . . . . .

Paola Pucci

A Social Science Approach to the Study of Mobility:

An Introduction.

Matteo Colleoni

Putting Territory to the Test of Reversibility . . . . . . . . . . . . 35

Vincent Kaufmann

Populations and Rhythms in Contemporary Cities . . . . . . . . . . . . 49

Gabriele Pasqui

Part II Mobility Practices, Policy and Project

Planning in Motion. The New Politics of Mobility in Munich. . . . . . . 67

Sven Kesselring

In Search of an Integrated Mobility Project . . . . . . . . . . . . . . . . 87

Arturo Lanzani and Antonio Longo

Plug\&Play Places: Subjective Standardization of Places

in Multilocal Lifeworlds. . . . . . . . . . . . . . . . . . . . . . . . . . . . . . . . . . . 109

Robert Nadler

Inhabiting Simultaneous Lives: Analysing Process

of Reversibilization of Mobility Practices in Italy . . . . . . . . . . . . . . . 129

Bruna Vendemmia 
Part III Mobilities, Inequalities and Conflicts

Temporal Efficiency, Temporal Justice and Urban Mobility . . . . . . . 151

Dietrich Henckel and Susanne Thomaier

Transport Disadvantage, Car Dependence and Urban Form . . . . . . . 171

Giulio Mattioli and Matteo Colleoni

Resident and Non-resident Populations: Types of Conflicts . . . . . . . . 191

Giampaolo Nuvolati

Part IV Mapping Mobility Practices

Metropolitan Dynamics and Mobility Flows: A National

Comparative Study (1991-2011) . . . . . . . . . . . . . . . . 207

Mario Boffi and Matteo Colleoni

Mobility Practices in Peri-Urban Areas: Understanding Processes of Urban Regionalization in Milan Urban Region . . . . . . . . . . . . . . 231

Paola Pucci

Mobile Phone Data in Reading Mobility Practices. . . . . . . . . . . . . . . 253

Fabio Manfredini, Paola Pucci and Paolo Tagliolato

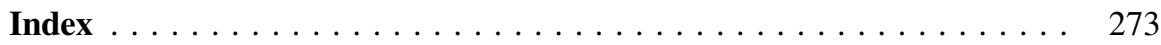




\section{Introduction}

The book focuses on spatial mobilities and explores the study of the topic as a key for understanding practices that both frame and generate contemporary everyday life in cities. At the same time, the book deals with the challenges raised, thanks to an interpretation of mobility as a socio-spatial phenomenon, both in social sciences and in urban studies as well as in reference to transport projects and urban policy. Thanks to the contribution of sociologists (Kesselring, Kaufmann, Nuvolati, Mattioli, Colleoni and Boffi), economists (Henckel and Thomaier), urban planners (Lanzani, Pasqui and Pucci), architects (Vendemmia and Longo), mathematician (Tagliolato) and geographer (Nadler, Manfredini), the book tries to understand how spatial mobilities bring about diversified uses of cities, different rhythms and life practices and unexpected and unplanned uses and conflicts on urban spaces.

The book is organised as four parts:

- Mobilities and the Transformations of Contemporary Cities;

- Mobility Practices, Policy and Project;

- Mobilities, Inequalities and Conflicts;

- Mapping Mobility Practices.

The four parts lead us towards a broader understanding of mobilities in relation to the capacity of analysing, planning and designing contemporary cities. Many of the essays undertaken in the book show the results of practical experiences (research projects, surveys), with the intent of giving an operational content to the overall theoretical debate on the issue.

The first part ("Mobilities and the Transformations of Contemporary Cities") introduces the debate on spatial mobilities by means of the contribution of scholars working in different countries and with dissimilar disciplinary approaches. This part introduces the concept of mobility as a complex system of social economic and spatial interactions; furthermore, it opens up, on the one hand, to new views towards mobilities, on the other hand, to new mobility scenarios for cities.

Chapter "Mobility Practices as a Knowledge and Design Tool for Urban Policy" by Paola Pucci puts forward the analysis of the different processes giving centrality to mobility as a cognitive key for understanding socio-spatial changes in 
contemporary cities. The author suggests an interpretation of mobility both as knowledge and as policy tool for understanding and regulating the process of transformation of contemporary cities. The identification of three interpretive keys for declining the role of mobility in contemporary cities-mobility as a socio-spatial phenomenon, mobility as a social capital and a common good and mobility as a project-allows to examine its role for both the analytical and the normative dimensions.

Chapter "A Social Science Approach to the Study of Mobility: An Introduction" by Matteo Colleoni presents the main theories proposed by social scientists on daily mobility. After an introductory section, aimed at describing mobility from a sociological point of view, the essay explains the reason of the increased daily mobility in contemporary cities. Following the chapter depicts the history of city changes as an image of the evolution of mobility and investigates the relationship between mobile populations and new urban morphology. The problematic coexistence of different populations, in urban areas characterised by the scattering of settlements and by the difficulty to access goods and services, is examined in the last part of the chapter related to the theories on the relationship between mobility, accessibility and social exclusion.

"Putting Territory to the Test of Reversibility" is the title of the third chapter by Vincent Kaufmann aimed at understanding territories through mobilities of different individual and collective actors. After a first section in which the reasons of the growing influence of travel and movement on our everyday lives are explored, the author investigates the changes of our relationship to space and time and the meaning of mobility in contemporary societies. Particular attention is devoted to the concept of motility, defined as "the wide range of possibilities when it comes to the relationship between movement in space and social change". The chapter aims to understand the logics of action that underlies actors' movements and mobilities and to consider not only changes in lifestyles (pluralism, individualism, etc.), but also the new technical and social forms that drive them and ensuing new forms of inequality, opportunity, physical tensions and socio-cultural conflicts.

The last chapter of the first part ("Populations and Rhythms in Contemporary Cities" by Gabriele Pasqui) focuses on the concept of rhythms, defined as the time of movement and on the use of urban space by temporary populations. These last are "groups of subjects that-temporarily and intermittently-share practices of daily life". Attention is devoted, in the central part of the essay, at analysing the movement of urban populations according to their space-time trajectories. The last part of the chapter, assuming urban populations not as users of policies but as potential generators of common goods, focuses on the representation of the pluralisation of identities in a public context.

The second part of the book explores the operational effects related to an interpretation of mobilities as a socio-spatial phenomenon. The contributions are designed to restore critical positions aimed at opening the black box of infrastructure projects and mobility policy to explore how infrastructures are linked to a co-evolution of cities, society and technical networks, and to the development of individual strategies of mobility. Using this theoretical frame, the authors analyse 
different projects and practices of mobilities, approaching different issues: the use of car in everyday life and its impacts on public space; the transformation of landscape by a new infrastructure project; the combined use of different means of transport and communication in order to deal with dispersed activities; and the consequences generated by this new mobility behaviours on the relation between people and territory.

This second part begins with the chapter on "Planning in Motion. The New Politics of Mobility in Munich" by Sven Kesselring. The essay deals with the issue of the new politics of mobility, paying particular attention to the Inzell Initiative, a deliberative platform on the future of mobility and transport founded in Munich in 1995, in order to solve conflicts and to enable collaborative planning among stakeholders. After an introductory section devoted at analysing the issue of urban planning processes in contemporary cities (notably smart urbanism), the author brings forward the historical development and the contents and the influence of the Inzell Initiative on strategical planning. By doing so, the author considers the initiative as a new form of deliberation and participation and as an indicator for emerging urban mobility regime, although its strong orientation on the maintenance of power should be thoroughly questioned. In the chapter, the initiative will be discussed "as a deliberative practice on a low level of democratic legitimacy, but on a high level of efficiency in regional governance".

Chapter "In Search of an Integrated Mobility Project" by Arturo Lanzani and Antonio Longo puts forward an investigation on the relationship between infrastructure projects for mobility and territorial projects in Italy, with particular attention to the project for environmental integration of the "Autostrada Pedemontana Lombarda", a motorway system in the North of Milan. Drawn on planning research carried out between 2005 and 2013 by a group of researchers from Politecnico di Milano, the essay is aimed at offering numerous keys to interpret the relationship between design, research and action in Italy, going beyond the specific case under discussion. Following a description of the historical process of infrastructure construction in Italy, the chapter goes into the experience of Autostrada Pedemontana, presenting the direct and indirect results of the design experience.

Described as a phenomenon midway between daily commuting and permanent migration, multi-locality is the way of life of an increasing number of people in contemporary cities, analysed by Robert Nadler in the chapter entitled "Plug\&Play Places: Subjective Standardization of Places in Multilocal Lifeworlds". More in detail the essay puts forward a study of "plug\&play" as a specific property of places in multi-local lifeworlds. After a first section, aimed at offering an overview of the literature on the standardisation of places, the author depicts objectives, method and main findings of a research on mobile lifestyles and subjective processes of standardisation of places of a sample of creative knowledge workers. The final section of the chapter will indicate fields of interest for future research interested in the spatiality of mobile lives.

The analysis of multi-local lifestyles carries on in the chapter with the essay by Bruna Vendemmia on "Inhabiting Simultaneous Lives: Analysing Process of 
Reversibilization of Mobility Practices in Italy". Using biographies of a sample of high-mobile people (long distance commuters, shuttles, overnighters...), the author analyses the relationship between people and environment and identifies the territorial profiles of people living simultaneous lives. The use of maps enables to represent the unstable, temporary and multi-scalar spaces that are the interviewees' everyday territories. After briefly introducing the ongoing process of reversibilisation of mobility practices, the essay will present the methodology of the research and first empirical results.

The third part ("Mobilities, Inequalities and Conflicts") deals with inequalities and conflicts related to mobility practices and projects. The growth of mobility has profound implications in the dynamics of social inequality and social exclusion. The topic of inequalities addresses the broader fields of the relation between the distribution of resources in the city, the accessibility and the temporal costs, as well as between transport supply and social equity.

The first issue will be treated by Henckel and Thomaier's chapter ("Temporal Efficiency, Temporal Justice and Urban Mobility") aimed at dealing with concepts of urban rhythms, temporal efficiency of cities and the impact of temporal inefficiency on temporal/social justice. Particular attention will be paid to the impact of the building structures of the city, the organisation of public and private transport and the organisation of other infrastructures on access to services and on the social and spatial distribution of accessibility. The provision of public services is often inefficient and leads to time losses. The main cause of temporal stress and higher temporal stress is not necessarily a time shortage but rather an unequal distribution of resources and choices to organise daily time uses.

The relation between transport supply and social equity is the topic of the second chapter of this section on mobility-related transport disadvantage ("Transport Disadvantage, Car Dependence and Urban Form"). Devoting attention to a comprehensive literature review and to the findings of international research, the authors, Giulio Mattioli and Matteo Colleoni, analyse the relation between transport disadvantage and social exclusion. As in most developed countries the car is the dominant mode of transport, the essay puts forward a typology of different types of car-related transport disadvantage, notably car deprivation, car-related economic stress, oil vulnerability and car-related time poverty. In order to bring to light the spatial dimension of transport disadvantage, the chapter continues with a more in-depth analysis of the relationships between transport disadvantage, urban structure and built environment. A review of the policy options to address these issues will conclude the essay.

The analysis of inequalities and conflicts is discussed also in chapter "Resident and Non-resident Populations: Types of Conflicts" by Giampaolo Nuvolati. Given the fact that our cities have become places where people go to work, consume, visit and where the amount of commuters is growing, the essay focuses on the different types of metropolitan populations. Paying attention to data from official sources, the essay estimates the amount of temporary population in Italian metropolitan cities 
and puts forward an innovative criterion for sub-diving the city based on the different combinations of resident and non-resident populations at different times during the day. The analysis of different conflicts between residents and non-residents and of public policies aimed at tackling these conflicts will be treated in the last part of the essay.

The fourth part of the book focuses on different quantitative approaches and data sources to analysing and mapping mobility and urban practices.

An innovative method to identify metropolitan areas based on census data on mobility flows is put forward in the chapter on "Metropolitan Dynamics and Mobility Flows: A National Comparative Study (1991-2011)" by Mario Boffi and Matteo Colleoni. After a preliminary analysis of long- and medium-term Italian urban demographic dynamics aimed at describing the socio-territorial processes that have led to the formation of Italian urban and metropolitan areas, the essay focuses on the different methods to identify their territorial collocation and socio-demographic structures. Combining criteria of homogeneity, interdependence and morphology and paying particular attention to the concentration of metropolitan functions, the chapter studies the evolution of the metropolitan areas in Italy over the last twenty years. Mobility is considered by the authors as a fundamental dimension of metropolitan areas, helping to define the shape of the area and draw its borders, more than an accessory function that supports the other activities.

The interest in the analysis of the interrelation between mobility practices and urban form is shared by chapter on "Mobility Practices in Peri-Urban Areas: Understanding Processes of Urban Regionalization in Milan Urban Region” by Paola Pucci. According to a recent literature-introduced in the opening section of this chapter-peri-urban areas are conceived not simply as transitional areas located between town and country, but rather as "new and emerging forms of urbanity that bring into play new lifestyles, new mobility behaviours and new urban issues". An overview of the perspectives on the peri-urban settlement in Italy enables the author to investigate the relationship between mobility patterns and processes of urban transformation in Milan Urban Region. Integrating traditional data with mobile data network, the essay puts forward the analysis of the correlations between housing density and mobility density.

The aim of the last chapter of the book is to understand the potential of mobile phone data in reading urban practices and rhythms of usage of the contemporary city. Chapter "Mobile Phone Data in Reading Mobility Practices" by Fabio Manfredini, Paola Pucci and Paolo Tagliolato brings forward the findings of two researches promoted by Telecom Italia and carried out in Lombardy Region (Italy), aimed at studying the potential and usefulness of cellular network data in urban studies and mobility. After a section focused on the explanation of the methodological approach, the chapter introduces the main findings, devoting particular attention to the spatial representation of space-time patterns of mobility practices. 
Explaining how different types of mobile phone data can provide new knowledge about urban dynamics, the chapter introduces a reflection on methods able to integrate mobile phone data with conventional data sources, as well as on their role for supporting and increasing the efficiency of urban policies and mobility services.

Milan

Paola Pucci

July 2015 Matteo Colleoni 


\section{Part I \\ Mobilities and the Transformations of Contemporary Cities}




\title{
Mobility Practices as a Knowledge and Design Tool for Urban Policy
}

\author{
Paola Pucci
}

\begin{abstract}
The chapter introduces two processes that endow mobility with centrality as a cognitive key for understanding socio-spatial transformations in the contemporary city. The first process is part of broader critical reflection on the role of spatial mobility in describing and assessing socio-urban changes. The second process interprets the contemporary city as a "site of sociability" (Amin and Thrift 2002), which can be understood by tracking the routinization of site practices that follow their own rhythms of appearance and disappearance. This leads us toward the heuristic value of interpretation of the rhythms of usage of the contemporary city, well provided by mobility practices. Working along these two lines, in this chapter we try to reconstruct how we can consider mobility as both a knowledge and a policy tool for understanding and regulating the process of transformation of the contemporary city. Through study of mobility practices, we argue that it is possible to recognise temporary populations generating new claims, but also new common goods. In the conclusion we will briefly consider two paradoxes raised by the excessive rhetoric on mobility: the link between mobility and rootedness, and the link between mobility and speed.
\end{abstract}

Keywords Spatial mobilities - Mobility policy • Social capital · Socio-spatial transformations

In the literature and in policy documents, urban mobility is identified as one of the toughest challenges that cities face: over the last twenty years, mobility has represented a framework of significance not only in relation to the changes in the dynamics of spatial mobility and their spatial and social impacts, but also because it has become a useful fact-finding tool to describe urban transformations in times and in places, according to personal social life and work programmes, as well as constituting a structural element of contemporary cities.

There are two processes that endow mobility with centrality as a cognitive key for understanding socio-spatial transformations in the contemporary city.

\footnotetext{
P. Pucci $(\square)$

DAStU, Politecnico di Milano, Milan, Italy

e-mail: paola.pucci@polimi.it
} 
The first process is part of broader critical reflection on the role of spatial mobility in describing and assessing socio-urban changes. A consolidated body of knowledge in the social sciences ${ }^{1}$ has, for some years, suggested that mobility can be interpreted as a "total social phenomenon (...), as the action at the heart of social processes of operation and change" (Bassand 1986, p. 25), because it is cause and consequence of changes in the organisation of everyday life (Urry 2000). In doing so, the attention paid to the role of spatial mobility as a means for "understanding the connections, assemblages, and practices that both frame and generate contemporary everyday life" 2 has given rise to conceptual and methodological renewal of the analytical approaches in social science, and in transport engineering, too.

The second process interprets the contemporary city as a "site of sociability" (Amin and Thrift 2002), which can be understood by tracking the routinization of site practices that follow their own rhythms ${ }^{3}$ of appearance and disappearance.

This leads us toward the heuristic value of interpretation of the rhythms of usage of the contemporary city, well provided by mobility practices.

Sharing the position proposed by Amin and Thrift implies reading the city from the space-time variability of the practices that take place within it, rather than understanding the city as configured by "enclaves" (fixed and bounded sites) and "armatures" (infrastructure channels and transit spaces) (Shane 2005), or by a sedentary/nomad dichotomy (passive layered morphologies vs. multiple flows, interactions and linkages).

In the words of Jensen (2009, p. 147), social agents appropriate places in a process of "social spatialisation" (Shields 1991) where they use the environment and artefacts as requisites for the complex identity-building process.

Based on this, it is "the mobile sense-making, experiencing and meaningful engagement with the environment that makes mobility", the object of study. "It includes a notion of a relational understanding of place, a networked sense of power and a re-configuring of the way identities and belonging is being conceptualized" (Jensen 2009, pp. 139-140).

Working along these two lines, in this chapter we try to reconstruct how we can consider mobility as both a knowledge and a policy tool for understanding and regulating the process of transformation of the contemporary city.

In the first part of the chapter we will argue that mobility, being "part of the process of social production of time and space" (Cresswell 2006, p. 5)-both (space and time) rarely addressed within an integrated perspective by public policies-represents $a$ knowledge tool because it is able to describe urban rhythms and the space-time

\footnotetext{
${ }^{1}$ Ehrenberg (1995), Urry (2000), Urry (2007), Kaufmann (2002), Ascher (2004), Bourdin (2005), Sheller and Urry (2006), Cresswell (2006).

${ }^{2}$ Interview with John Urry by Adey and Bussel (2010, p. 2).

${ }^{3}$ Borrowing from the work of Lefebvre (2004), Amin and Thrift argue that the rhythms of the city are "the coordinates through which inhabitants and visitors frame and order the urban experience" (Amin and Thrift 2002, p. 17).
} 
dimensions of the practices in using a territory. The users' practices and spatial mobilities can help to achieve a better understanding of the complexity of behaviour in human activities, and indeed of urban spaces (Cresswell 2013; Jensen 2013).

In the second part of the chapter we introduce mobility as a policy tool by virtue of the possibility that it provides to root policy in the basis of observation of molecular daily practices, so as to construct policies coherent with the emerging demands being made by urban populations ${ }^{4}$ (Martinotti 1993), using the city and its services, at varying rhythms and intensities.

This is because, according to Amin and Thrift (2002, p. 158), "much of what goes on in the everyday spaces of the city is not about participation in politics with a conventional capital. Rather, it is about new kinds of molecular politics which vie for public attention, sometimes succeeding in creating wider social and political effects." In this framework, through study of mobility practices and their "territorialisation" as configuration in space, we argue that it is possible to recognise temporary populations generating new claims, but also new common goods, as well as communities of practice ${ }^{5}$ (Wenger 1998) and the intensities with which they utilise territorial services and infrastructures. In this perspective, we view urban populations not as users of policies but as potential generators of common goods (Pasqui 2008), partially detected on the evidence of mobility practices.

\section{Mobility as a Knowledge Tool: Three Interpretative Keys}

By reconstructing the conceptual evolution of mobility (Bourdin 2005; Gallez and Kaufmann 2009), as well as the positions emerging in the literature from the social sciences and transport engineering, we can identify at least three interpretive keys for representing the role of mobility in contemporary city:

- Mobility as a socio-spatial phenomenon;

- Mobility as a social capital and a common good;

- Mobility as a project.

\footnotetext{
${ }^{4}$ Moving away from the classical approach of social ecology, Martinotti (1993, pp. 137-139) suggests we "conceptualize metropolitan development and emerging social morphology as the progressive differentiation of four populations (inhabitants, commuters, city users, Metropolitan businessmen) that characterise the metropolis". The four urban populations proposed by Martinotti (1993) are nonetheless static entities that do not afford an understanding of the variable roles that may be played by an individual during the course of a day.

${ }^{5}$ The term communities of practice is employed to focus attention on the fact that urban populations cannot be reduced to predefined and fixed categories. Urban populations are not as static categories (inhabitants, commuters, city users, etc.), but they are "groups of subjects that, temporarily and intermittently, share practices of daily life" (Pasqui 2008, p. 148). Hence they can be considered "communities of practice" that generate particular space-time geographies.
} 


\subsection{Mobility as a Socio-spatial Phenomenon}

Over the past twenty years, mobility has been subjected to reconceptualization, redefining its meaning and role, superseding simplified interpretations as movement through space in geography, social change in sociology, flows between an origin and a destination in traffic engineering.

Mobility, being the focus of many theoretical reflections, ${ }^{6}$ has undergone progressive "slippage" towards a more complex conceptualization with important consequences in the evolution of approaches, especially in the social sciences, where mobility research combines social and spatial theory in new ways (Sheller 2011), providing a transformative nexus for explaining the role of mobility as a "social product" (Cresswell 2006), and an "indisputable process of urbanogenesis", (Lévy 1999).

These - mobility as a social product and mobility as an unquestionable process of urbanogenesis - are two different perspectives, characterised by a shared conceptualization of mobility.

As a social product, mobilities of people, goods, ideas are a central concept of contemporary sociology "because the contemporary world is defined by the circulation of goods, more than by stable structures and organisations" (Urry 2000, p. 17).

In The New Mobilities Paradigm by Sheller and Urry (2006), which considers mobility as an all-inclusive concept with a number of interrelated notions (Elliott and Urry 2010), including the "network capital" concept and diverse types of connections, as well as in so-called "mobilities turn" (Cresswell 2006), the focus is on how 'moves' make social and material realities.

At the same time, working with the material conditions of mobility and associated practices, Vincent Kaufmann in Re-thinking mobility (2002) proposes a conceptualization of mobility as "the intention and realisation of an act of movement in physical space that involves social change" and, therefore, analysis of mobility tells us about the composition of and changes in a society.

These approaches, focusing on the relationship between space and social practices, also open up interesting perspectives on the quality of the spaces of contemporary mobilities that are often "staging places". In Staging Mobilities Jensen (2013), explores the mobile sense-making, experiencing and meaningful engagement with the environments that "makes mobility", drawing attention to the process of design and planning that give rise to and shape urban mobilities. In this perspective, design and planning processes are tasked with creating new potentials, capacities and experiences.

\footnotetext{
${ }^{6}$ See, in this book, the essay by Colleoni (Chapter "A Social Science Approach to the Study of Mobility: An Introduction").

${ }^{7}$ My translation from "la mobilité constitue aussi une technique incontestable de "urbanogenèse" et non un problème externe aux pratiques urbaines les plus fondamentales, c'est à dire à ce qui fait d'une ville une ville, à son urbanité" (Lévy 1999, p. 157).
} 
From this content of mobility as a new relationship between space and social practices, involving a wide range of social phenomena (Mincke and Montulet 2010), mobility has become a tool that must be well-defined and fine-tuned to be able to "read" a society (Kaufmann 2014).

As an indisputable process of urbanogenesis (Lévy 1999), "mobility is not only a technical tool for linking places. Insofar as the accessibility between places is a condition of existence of the city itself", mobility becomes an "act of territorialisation" (Raffestin 1980).

This interpretation surpasses, in intensity, the positions recognising the heuristic value of mobility practices to interpret urban transformations, because it ascribes to mobility a constitutive role for urban spaces.

According to Soja (2004, p. 176), the transformations of the contemporary metropolis toward a "post-metropolitan" model can be better understood not as a decline in the importance of the geography of sites with respect to the "space of flows", but as an accelerated reorganisation and restructuring of the geography of movements that define the spatiality of human societies. In addition, analysing urban transformations through mobility allows for movement across various scales of observed phenomena, "from the small-scale bodily movements, through infrastructural and transport aided movements to global flows of finance or labour" (Cresswell 2011, p. 552).

In both perspectives, mobility represents an "analyser" (Bourdin 2005) useful for describing urban life and identifying "mobile communities" (Le Breton 2006), because, according to Cresswell (2013, p. 92) "we are simultaneously part of different groups, we live our lives across a number of spaces as we move through the splintered city. We belong to many groups that rarely intersect. It may be the case that our identity as a national citizen is increasingly likely to be the less important one".

The challenge is not to analyse mobility as such, but to analyse contemporary society through the realities of mobility (Bourdin 2005).

Within this context, in transport engineering and in econometric modelling approaches the social dimension of mobility, which focuses on people, their attitudes, behaviour and well-being, appears to be the "poor relation" (Jones and Lucas 2012, p. 4).

According to Gallez and Kaufmann (2009), there are two major shifts in the conceptualization of mobility in transport engineering: from quantitative assessment of the flows to the focus on the notion of displacement in the 1970s and later, to a conceptualization of movements as "derived demand".

In the 1970s, with the new research field on the socio-economics of transport, particular attention was paid to individual mobility behaviour as a condition serving for analysis of mobility demand, although still treated at the aggregate level and according to a rationale based on minimization of costs and travel times.

\footnotetext{
8“"Groupes sociaux définis à partir de leurs inscriptions territoriales, de leurs pratiques de mobilité, des dispositifs techniques qu'ils mettent en oeuvre" (Le Breton 2006, p. 26).
} 
Introducing the criterion of modal choice, traffic patterns reconstructed parameterizations based on the individual utility function (socio-economic characteristics, income, residential location), resulting in a greater adherence to the actual conditions that characterise the spatial mobility.

The gradual shift from displacement to mobility allowed for conceptualization of movements as "derived demand" with consequences in terms of the need to know in detail the social interactions lying behind the movements. At the same time, the displacement constraints (accessibility, skills, availability of means and resources, as well as the spatial organisation of settlements) represent a framework for explaining the dynamics of mobility (Vincent-Geslin and Kaufmann 2012, p. 31).

This evolution challenges the traffic models, built on the assumption of temporal stability of behaviours and formalizing a state of equilibrium, in a short-term perspective.

The need to understand more about human spatial travel behaviour and its temporal variability in relation to a myriad of different social issues (Jarv et al. 2014, p. 122), hardly reflected in the daily travel patterns derived from traditional data, calls into question the available analytical tools and data sources because they must describe different patterns of mobility in the form of "active biographies" (Nuvolati 2003, p. 71).

Although social interactions or changes of position in social space are taken into account only through the attention to the effect (i.e. the movement), statistical models supported by new empirical data (i.e. mobile phone and digital data) open up perspectives to investigate the time-space variability of urban populations (Sevtsuk and Ratti 2010; Pucci et al. 2015), as well as the relationships between location coordinates of mobile phones and the social identification of the people carrying them (as Social Positioning Method proposed by Ahas and Mark 2005).

The experimental and operational studies on new data sources able to describe various urban rhythms and identify different mobile populations offer an useful framework to operationalise the notion of mobilities as a socio-spatial phenomenon, given by theoretical reflection in the social sciences.

According to Sheller and Urry (2006, p. 217) "the new mobilities paradigm" calls for new research methods "on the move" and able to "simulate intermittent mobility".

\footnotetext{
${ }^{9}$ The "Mobile methods" proposed by Sheller and Urry (2006) include: interactional and conversational analysis of people as they move; mobile ethnography involving itinerant movement with people, following objects and co-present immersion in various modes of movement; after-the-fact interviews and focus groups on mobility; keeping textual, pictorial, or digital time-space diaries; various methods of cyber-research, cyber-ethnography and computer simulations; imaginative travel using multimedia methods attentive to the affective and atmospheric feeling of place; tracking affective objects that attach memories to places; and finally methods that measure the spatial structuring and temporal pulse of transfer points and places of in-between-ness in which the circulation of people and objects is slowed down or stopped, or facilitated and speeded up (Sheller 2011, p. 7).
} 
This is also because new forms of mobility are emerging in the contemporary city and have intensified the density and typologies of movements that traditional sources are unable to describe with continuity (Pucci 2013a, b; Jarv et al. 2014).

These mobility practices result from the combination of physical and virtual mobility, leading to new and mixed forms of daily, residential and travel mobility (Flamm and Kaufmann 2006).

If long-distance travel for leisure, occupational or social interaction has become part of the daily activity of many people (Limtanakool et al. 2006), work-related or mandatory travel is increasingly characterised by spatial and temporal variability, describing "a reversible use of territories and networks" (Vincent Geslin and Kaufmann 2012, p. 40).

No longer referable to traditional categories of commuting, ${ }^{10}$ these new forms of mobility are always work-related trips, even if they take more complex forms and timeframes. These mobilities - defined by Kaufmann (2005) as "reversible"-are the result of two combined processes: the evolution of the labour market, which requires ever more flexibility and is subject to increasing unpredictability, and the performance of the territorial, transport and communication networks, doing away with physical distances.

Even if the process of identification of new mobile practices has been tested and updated, ${ }^{11}$ the impact that they have on the relation between people and territory is still uncertain.

These transformations of mobility practices open up operational challenges in transport and, indeed, in sociological inquiry (Büscher and Urry 2009). The aggregate methods (traffic census, O/D matrices of flow) to study mobility as geographic displacement, predominantly based on short periods and on proportional relations between utility and cost/time of movement, are unable to account for the complexity of mobility as a spatialized form of social interactions, depending not only on the availability of transport and communication services, but also on the personal projects, attitudes, habits, abilities and preferences related also to the so-called mobility biographies (Lanzendorf 2010).

A different research perspective is also to be seen in travel behaviour studies, usually based on the utility maximisation axiom: working on the mode switching issue, departing from the mode choice concept as defined some decades ago in the classical 4-step transport model, some research studies behavioural changes, not only in response to modifications in the transport supply, but also on the basis of personal characteristics, showing the added value of considering them jointly.

\footnotetext{
${ }^{10}$ Daily commuters, city users, businessmen, tourists, but also long-distance commuting and multiple residences.

${ }^{11}$ The EU research "Job mobilities and Family Lives in Europe" (http://www.jobmob-andfamlives.eu/) identifies among the new forms of daily mobility: Long-Distance Commuters (LDC); Overnighters spending at least 60 overnights away from home during the last 12 months for occupational reasons; Recent Relocators over a distance of at least $50 \mathrm{~km}$; Long-Distance Relationships (LDR). See also Viry and Kaufmann (2015).
} 
Through the new basic idea of "co-modality" and "modal diversion" (i.e. identification of the best ambits of use of transport modes on the basis of different real-life constraints), some recent research (Diana and Pronello 2010) assesses the importance of the behavioural mechanisms that are involved in a modal diversion process in helping to tackle the complex issues of contemporary transport systems.

Opening interesting new perspectives in terms of new empirical and analytical orientations, this research considers mobility as a complex pattern of paths and activities in space and time and the outcome of the interconnections between individual and external (environment and social structure) factors (Pred 1984; Jarv et al. 2014).

\subsection{Mobility as Social Capital and a Common Good}

If mobilities become a useful research tool for understanding transformations in times, places, social life and work programmes structuring contemporary cities (Ascher 2004; Bourdin 2005; Sheller and Urry 2006; Cresswell 2006), at the same time mobility is a resource and a value because it creates and introduces differences, according to the possibilities of each subject, in relation to their own personal projects and capabilities (both economic and cultural) to select the more effective way to ensure "the right to mobility" that belongs within a modern conception of human rights (Bauman 1999).

The "right to mobility" is not the "right to transport", but is a matter of the possibility to have more flexibility, connectivity, reversibility and the best ubiquitous access to different resources and possible destinations.

Ascher (2004, p. 23) considers the "right to move" a sort of "droit générique" which implies many other rights because of the role that mobility carves in contemporary society. He distinguishes two types of right to move: the "liberty rightdroit-liberté" (the right of individuals to move) and the "droit-créance - credibility right" (the right to have the effective means, practical and cultural, to move).

In the literature, many authors have, for years, considered mobility as a key resource for social inclusion, a value that also produces new forms of social differentiation (Kaufmann 2002; Orfueil 2004; Le Breton 2005; Cresswell 2006; Cass et al. 2005), related to the greater or lesser possibility of each to choose between alternative forms of mobility.

Therefore, mobility can be considered as "social capital" (Tarrius 2000; Orfueil 2004) that depends on the availability, quality, diffusion, access to transportation and communication supplies, but also on the capacity of each subject to appropriate them.

The concept of motility, proposed by Kaufmann (2002), as well as the "network capital" notion introduced by Urry (2007) form part of this assumption, but in two different perspectives.

Network capital is the capacity to engender and sustain social relations with people who are not necessarily proximate, generating emotional, financial and 
practical benefit (although this often entails various objects and technologies or the means of networking) (Elliott and Urry 2010, pp. 57-59). It is indicative of the real and potential social relations that mobilities afford, highlighting a specific condition, which is based on the ability to create contacts, from resources such as time, objects, access, emotions, differently distributed (Elliott and Urry 2010, p. 58).

The concept of motility proposed by Kaufmann (2008) refers specifically to "the manner in which an individual or group appropriates the fields of possibilities, relate to movement and uses them" (pp. 37-56), defining the potential of mobility as disposition to mobility that depends on social conditions of access (the conditions on which supply can be used), on skills (required to use a urban service), and on mobility projects (the actual use of the service affording mobility).

In doing so, "motility leads to the conclusion that between supply and demand is the actor, who captures the possibilities offered and he turns them into travel demand according to its own logic"12 (Kaufmann 2012).

However some authors (Borja et al. 2012, 2013) call into question the possibility of referring to "mobility capital". On the basis of the definition of the capital concept in social sciences as a "dispositional" one, Simon Borja, Guillaume Courty and Thierry Ramadier argue that the capital concept implies much more than a simple matter of ownership of the subject under discussion. If "to move is to move one's dispositions" (Wagner 2010), the type of mobility in question "reveals the type and specificities of the forms of capital (cultural, economic, social and symbolic) that are available to someone. This in turn leads us to consider movement as something that is actually carried out by the forms of capital that a person already has available" (Wagner 2010, p. 89). In doing so, mobility is no longer geared to the presence or absence of specific "skills", but to the greater or lesser possibility of living within the imposed norm (mobility), such as having the possibility to choose and design one's own displacement. If moving depends on our social position and is based on the challenges and socio-spatial contexts we encounter, according to Borja et al. (2012), the point should not be "mobility capital", but considering "mobility" on the one hand as an "effect of forms of capital", and on the other hand as "a new form of domination, one that is both spatial and social at the same time".

Nevertheless, if we understand mobility in terms of a "field" in which unexpected opportunities arise and come into play, and capital - according to the definition of "social capital" by James Coleman (1990) — as "a resource for action (...) present in the structure of relations between two or more people, mobility practices mobilise capital but, at the same time, thanks to the various forms of interaction triggered, they in turn generate new capital" (Coleman 1990, p. 302).

In this direction, the mobility practices express new needs and sometimes alternative solutions, and they can be examined starting from the capital they mobilise.

\footnotetext{
${ }^{12}$ Available in URL: http://en.forumviesmobiles.org/arguing/2012/12/11/mobility-capitalsketching-arguments-533.
} 
At the same time, the behaviour of individuals can play a key role in generating positive externalities for both the individual and the community and, from this viewpoint, capital mobility can become a reference both to promote the virtuous behaviours already in place, and to support alternative practices.

This condition seems to foreshadow a new way of thinking about mobility policies, from "micro" moving towards "macro", opening up to the combination of different resources, not least because, according to Crosta (2010), practices always have a political aspect: they can advance claims and produce collective goods, developing bottom-up policies.

In the former case, the relevance of the practices lies in their very existence, which enables specific forms of appropriation of space, while the latter case refers to the possible "social production of public goods, or in other words (the possibility of) having public assets thanks to social practices rather than policies" (Donolo 2005, p. 47).

In this perspective, the manifold mobility practices entail a potential asset of collective goods that individuals and groups can contribute to, whether they use existing services in unforeseen ways, or create new possibilities for movement through specific solutions (Vecchio 2015).

\subsection{Mobility as a Project}

Mobility, being a means of social interaction, constitutes a form of capital that is not simply a combination of someone's income, educational achievement and social networks, actually produces new capital itself, starting from the interactions it makes possible.

Because mobility is not just the ability to move, some authors have introduced a distinction between "potential mobility" (which depends on the knowledge of space and social relationships) and "effective mobility".

According to Ehrenberg (1995) and Orfueil (2004), effective mobility presupposes a "mobility project". This project depends on the abilities, skills, acquired knowledge, organisational capacity and social bonds that are themselves reinforced or weakened by our practices.

The above-mentioned concepts of motility (Kaufmann 2002; Kaufmann et al. 2007), network capital (Urry 2007), potentiality of mobility (Orfueil (2004) can be useful tools to understand how to build a mobility project and what relations there may be between it and mobility practices as movements in space.

Several studies, aiming to "measure" motility (Viry et al. 2009; Canzler et al. 2008; Kesselring 2006), have shown in an exploratory way ${ }^{13}$ that it seems to be

\footnotetext{
${ }^{13}$ While these studies remain exploratory in that they have not yet come up with a recognised standard of measurement, they have revealed many kinds of aptitude for movement.
} 
vaguely related to income and levels of education rather than preferences and habits, differentiated in social and spatial terms.

Working on habits, rethinking the researches of Dewey (1921), enables us to investigate how individuals make strategic and tactical choices involving their rationality, feelings, ethics and aesthetics, combining or not combining different opportunities: habits "are not deliberately formed", they are "active means, means that project themselves" (Dewey 1921), as "intersecting rhythms" (Lefebvre 2004).

Interest in the habit notion as a form of life central to community formation, in negotiation with the governing rules and laws, enters into analytical experimentation in a specific way: any evaluation methodology must focus not only on behaviour change as such, but also on the more subtle changes in attitudes and perceptions underlying the behaviour change process. The ethnographic dimension of research on mobility will lead to a better understanding of the end user and the situational conditions creating opportunities and obstacles for the mobile subject on the move. The "view from below" afforded by mobile ethnographic approaches will be helpful in connecting the larger datasets and aggregated mobility data to the real-life situations governing this new urban condition (Vannini et al. 2012).

This perspective is also adopted in the transport model research that studies behavioural change in relation to the use of different transport modes, when both a set of new technology options and the different regulatory and marketing actions are implemented. With the aim to clarify the relationship between behavioural changes in terms of modal diversion and the range of possible interventions that can be implemented in different disciplinary ambits, new structural equations modelling frameworks are experimented to mix mobility and attitudinal surveys (Diana 2010), also for the purpose of working on the new and powerful decision support policy tool.

\section{Mobility as a Policy Tool}

Studying mobility practices plays an important role in both the analytical and the normative dimensions: producing knowledge about mobility patterns and behaviours, we produce an analytical framework describing habits and lifestyles which have influence on urban transformation processes as well as on the implementation of urban policy.

Three main perspectives are proposed to define how understanding mobility practices can improve the effectiveness of urban policy, governing spatial dynamics of social changes and urban form as shapers of mobility.

The first perspective concerns the importance of a real-time knowledge of mobility needs, possible also through a more widespread use of networked technologies, as drivers of area-wide implementation of innovative urban policy and transport supply.

Unsatisfactory results in the case of modal diversion strategies, despite the wealth of research activities and policy actions, difficulty to affect established 
behaviour by mobility policy, difficulty to intercept different behaviours needs from territories, and with them, to find effective solutions, confirm the need to a shift the paradigm from the prevailing focus on daily travel patterns in terms of flows and the related "mode choice" concept, which is commonly used in mainstream transport planning activities, to the understanding and managing the mobility behaviours and habits.

In this framework, new opportunities are offered to planners and policy makers by digital sources and mobile phone data, as well as the new wave of technology developments that is likely to change our lifestyles and mobility habits radically. The networked technologies at work are producing data on the use of the city with a spatio-temporal resolution difficult to obtain from traditional data and surveys "that urban planners may well make use of in their attempts to monitor and track the city and its dynamics (...)". In addition, "these technologies offer new opportunities for engaging with the public, to facilitate new public participation processes and involve segments of the city's population that are not normally very vocal in urban planning processes" (Jensen 2015, p. 230).

The research and the operating results in this field show promising results: the outcomes of approaches for estimating human movements through urban spaces using ICT and mobile phone data (Ahas and Mark 2005; Ratti et al. 2006; Kwan et al. 2007; Reades et al. 2007) have gained ground to the point of being able to identify fine-grained variations in urban movements and information on the real use of cities. These studies, providing a "longitudinal perspective" on the variability in human travel activities (Jarv et al. 2014) through geographical mapping of mobile phone usage at different times of the day (Ratti et al. 2006), offer interesting representations of the intensity of urban activities and their evolution through space and time. $^{14}$

Since the observed individual traces and aggregated telephone traffic are the result of individual behaviours and habits, the maps - produced with these datarepresent the molecular mobility patterns. In so doing, the maps processed in these studies (Ahas and Mark 2005; Sevtsuk and Ratti 2010; Reades et al. 2007; Soto and Frías-Martínez 2011) highlight the places where these practices occur recursively, providing significant data to improve the effectiveness of urban policies (Pucci 2014; see in this book Chapter "Mobile Phone Data in Reading Mobility Practices").

${ }^{14}$ Three are the main outcomes:

- Showing the relationships between location coordinates of mobile phones and the social identification of the people carrying them (as Social Positioning Method and its possible applications in the organisation and planning of public life proposed by Ahas and Mark 2005);

- Describing the relationships between mobile phone measures (the volume of call activity in mobile network cells as Erlang) and population distribution in cities (Sevtsuk and Ratti 2010);

- Classifying urban spaces, according to mobile phone uses (Reades et al. 2007; Soto and Frías-Martínez 2011), in which different "basic" profiles of city usages can concur to identify different profiles of use and consumption. 
In addition, the same data raise questions about particular theoretical interpretations of the erratic and nomadic behaviour ${ }^{15}$ of metropolitan populations that characterise urban practices, already confirmed by well-known studies (Song et al. 2010): the marked recursion path in all the remarkable density of daily movements highlights the fact that we tend to do so along familiar and habitual paths.

In this way, the challenge in detecting behaviour changes is met by integrating traditional and new data sources and developing research protocols and a methodological toolkit capable of improving real-time investigation into the time-space variability of mobility patterns. The production of knowledge of mobile practices through approaches easily usable and replicable also by the local authorities and by the end users can support appropriate policy and regulatory actions and lead to considerable advancement in the sphere of mobility policy design and governance, in relation to urban mobility needs.

The second perspective is related to the valuable support offered by mobility practices, to "re-scale" urban policy and assist in the construction of geographies of partnerships between different stakeholders, as a tool for supporting and increasing the efficiency of urban policies and mobility services (Pucci et al. 2015).

Deforming institutional boundaries, mobility practices define new geographies that can vary over time, even within one and the same urban area, showing how "all territorial governments exist in a condition of permanent dissociation between citizens, inhabitants and city users" (Estèbe 2008, p. 17).

"The structural effects (or destructuring effects) of spatial mobility on institutional boundaries" "16 (Estèbe 2008, p. 6) expose a clear discrepancy between fixed jurisdictions and "mobile factors", and call into question the perimeters of the institutional policies. This is why through mobilities we can better explain the dynamics of the "erosion" of institutional boundaries and indeed of the boundaries of public and private life, making possible to "re-scale" the hierarchies of intervention and the territories of urban and mobility policies.

Mobility trends can, by offering new maps of site practices and information on temporary populations and city usage patterns, serve as a basis for reading interscalar urban processes and defining relevant boundaries to deal with the variability of urban practices and their relationships which the institutional boundaries fail to take into account.

While there is a consensus in the spatial planning debates on the need to build relevant boundaries as a resource of institutional capital through which new initiatives can be pursued rapidly and legitimately (Healey 1998, p. 1531), questions are being raised about the practical impact of this shift.

A different articulation of skills and resources that will improve the regulation of practices and help to generate the new frameworks required for institutional

\footnotetext{
${ }^{15}$ For example, in the influential work of Gilles Deleuze and Felix Guattari (1980), or Paul Virilio's (1997) texts on dromology.

${ }^{16}$ Our translation from "Les effets profondément structurants (ou déstructurants) de la mobilité des personnes sur les territoires politiques" (Estèbe 2008, p. 6).
} 
innovation, calls for identification of variable boundaries. If notions like "soft spaces"- such as transversal spaces - and "fuzzy boundaries"- such as fluid perimeters, suggest the need for "new post-devolution spaces of planning" (Haughton et al. 2010), the operational impact of these spaces on the institutional perimeters, representing the "formal hard spaces of governmental activity" (Haughton et al. 2010, p. 52) remain uncertain. This is also because in the relationship between fuzzy boundaries and institutional spaces, problems related to the temporal variability of the practices that lie behind fuzzy perimeters, such as the mechanisms of political representation of temporary populations, remain unresolved.

Nonetheless, the "re-scaling" processes brought about by mobile practices can highlight forms of cooperation, not necessarily or forcibly linked to institutional frameworks.

The challenge is that the informal boundaries defined by mobile practices may become part of an institutional landscape, generating new models of public involvement and actions capable of intercepting and responding more effectively to the emerging social demands that can be inferred from these practices.

The third perspective is related to the possibility to affect forms of inequality in access to goods and services through mobility.

According to Cresswell (2004, p. 145), mobility has never been synonymous with freedom and citizenship, but if "movement makes connections (....) connections make inequalities" (Urry 2012, p. 24).

As argued by Amin and Thrift (2002, p. 26) mobilities are never free and unfettered, but are "striated by a whole series of rules, conventions and institutions of regulation and control (...) a systematized network". In this sense, inequality in access to goods and services is more than mere lack of transport supply: it is associated with conditions which limit physical, at-distance connections.

The link between the individual and universal scales, between personal and societal constraints defines "the degrees of connection" of each one and relates to the concept of motility (Kaufmann 2002) and network capital (Elliott and Urry 2010), already mentioned because they point to the real and potential social relations that mobilities afford.

The difficulty in translating these concepts into operational reality has so far limited their application in urban policies as tools serving not only to identify the forms and causes that restrict travel, good meetings, bodily co-presence, but also to prompt approaches of use in assessing their effectiveness.

The distinction between the right of individuals to move and the right to have the effective means, practical and cultural, to move (Ascher 2004), helps to distinguish between having access to the means enabling to movement (physical and immaterial) through the provision of universal services as well as adjustment of conventions and institutions of regulation and control, and a more complex and integrated devices answering to heterogeneous and complex demands.

These are related to the obligation of autonomy, also for the "invisible maintenance workers" (Aubenas 2010), and indeed to the demand for "reflexivity" (Ascher 2002) and "reversibility" (Kaufmann 2005) as conditions connected with 
transformations in in the labour market and social life with development based on weak links and short-term contracts links.

In the spread-out spaces and temporalities, it is not a matter of providing equitable services to all regions with modes that are accessible to everyone, because this is economically unsustainable, but also ineffective with respect to the molecular size of mobility demands.

According to Orfeuil (2011), it is a matter of offering a "credibility right, a duty that is fulfilled with varying degree of ambition, for political and/or economical reasons and whose implementing implies a contributory responsibility for citizen" (Orfeuil 2011, p. 50).

This contributory responsibility for citizens can also happen in terms of services co-created by a small number of employee-facilitators and end users, as innovative ways to close the gap between cost and yield, resulting in the need for public founding, but also to support local capabilities to produce self-organised solutions capable of coping with problems that public policies appear unable to deal with.

Highlighting the potentials and scalability of such forms of social innovation, the challenge concerns the possibility to support and propagate the processes by which territories produce goods and services.

In all three perspectives, mobility becomes a policy tool according to its properties: as a social product inherent to the world we live in, according to the way we interact with space and with other persons.

\section{Paradoxes: The «Dark Sides» of Mobilities}

In the debate that places mobility at the centre of a new interpretative and planning paradigm that cuts across various disciplines (from town planning and geography to sociology and transport planning, etc.), many authors have also pointed out the perverse effects of hyper-mobility (Rosa 2010) and the contradictions inherent to heterogeneous deployment of mobility phenomena (Kaufmann 2008; Castaigne et al. 2003).

With a background of excessive production, unsustainable consumption of carbon and oil, fragmentation of settlement patterns and the manifold polarisation deriving from the differentiation and specialisation of places, individuals become "multi-centred" (Rémy 1996). Thus the need arises to rethink the ways of regulating the various forms of mobility, and at the same time to address certain paradoxes raised by the excessive rhetoric on mobility. Of these, I will briefly consider two: the link between mobility and rootedness, and the link between mobility and speed.

As for the former, in contrast with the literature that had, back in the 1980s (Virilio 1990), stressed the possibilities opened by the new mobilities to transform a one-way link with space into manifold links, creating the conditions for a "multi-territorialisation of people" (Deleuze and Guattari 1980), the current mobility practices raise doubts about this idea of "uprootedness". Often, in fact, the conditions of mobility are experienced as a constraint, and not a choice. 
A consequence of the flexibilisation of the labour market, together with economic crisis driving people far and wide in search of jobs while family bonds remain rooted in particular places, is that people often have to travel over considerable distances to get to work, and the friction between mobility as freedom and mobility as constraint is rekindled. At the same time, communication networks offer us the possibility to become rooted in some particular place, but often fail to substitute commuter routines.

As for the link between mobility and speed: if certain forms of mobility are possible only because the speed of material and immaterial connections has been greatly boosted, it is equally true that the speed achieved with the creation of increasingly efficient networks and infrastructures has not meant a saving of time, that has often contributed to using up space, bringing in new forms of inequality in access to territorial opportunities, restructuring the hierarchies in the territory on the basis of the new connections. This is also because, according to Lévy (2011), "the three major methods for handling distance (co-presence, telecommunications, mobility) do not replace one another bur rather have a "co-petitive relationship", meaning they are at once competitive and complementary, used separately or together as tools for overcoming distance" (Lévy 2011, p. 28).

\section{References}

Adey, P., \& Bussel, D. (2010). Mobilities, meetings, and futures: An interview with John Urry. Environment and Planning D: Society and Space, 28, 1-16.

Ahas, R., \& Mark, U. (2005). Location based services: New challenges for planning and public administrations? Futures, 37, 547-561.

Amin, A., \& Thrift, N. (2002). Cities. Reimagining the urban. Cambridge: Polity.

Ascher, F. (2002), La société hypermoderne. Paris: L'Aube.

Ascher, F. (2004). Les sens du mouvement: modernité et mobilités dans les sociétés urbaines contemporaines. In S. Allemand, F. Ascher, \& J. Lévy (Eds.), Les sens du mouvement (pp. 2134). Paris: Belin.

Aubenas, F. (2010). Le quai de Oustreham. Paris: L'Olivier.

Bassand, M. (1986). La mobilité spatiale, une phénomène macroscopique. Sociologie pluraliste et pluralisme sociologique. Neuchâtel: Université de Neuchâtel, EdES.

Bauman, Z. (1999). Liquid modernity. Cambridge: Polity press.

Borja, S., Courty, G., \& Ramadier, T. (2012). La mobilité serait un capital: doutes et interrogations. Forum Vies Mobiles. URL: http://en.forumviesmobiles.org/arguing/2012/12/ 11/mobility-capital-sketching-arguments-533. Accessed in March 16, 2015.

Borja, S., Courty, G., \& Ramadier, T. (Eds.). (2013). Approches critiques de la mobilité. Regards sociologiques (pp. 45-46). Strasbourg: Association Regards Sociologiques. ISSN: 1164-0871.

Bourdin, A. (2005). Les mobilités et le programme de la sociologie. Cahiers internationaux de Sociologie, CXVIII, 5-21.

Büscher, M., \& Urry, J. (2009). Mobile methods and the empirical. European Journal of Social Theory, 12(1), 99-116.

Canzler, W., Kaufmann, V., \& Kesselring, S. (Eds.). (2008). Tracing mobilities. Towards a cosmopolitan perspective. Aldershot: Ashgate.

Cass, N., Shove, E., \& Urry, J. (2005). Social exclusion, mobility and access. Sociological Review, 53(3), 539-555. 
Castaigne, M., et al. (2003). Droit et mobilité. Namur: Presses Universitaire de Namur.

Coleman, J. (1990). Foundations of social theory. Cambridge: Mass.

Cresswell, T. (2004). Justice sociale et droit à la mobilité. In S. Allemand, F. Ascher, \& J. Lévy (Eds.), Les sens du mouvement (pp. 145-153). Paris: Belin.

Cresswell, T. (2006). On the move: Mobility in the modern western world. London: Routledge.

Cresswell, T. (2011). Mobilities I: Catching up. Progress in Human Geography, 35(4), 550-558.

Cresswell, T. (2013). Citizenship in worlds of mobility. In O. Söderström, et al. (Eds.), Critical mobilities (pp. 81-100). Lausanne: EPFL Press.

Crosta, P. L. (2010). Pratiche. Franco Angeli, Milano: Il Territorio è 1'Uso che Se ne Fa.

Deleuze, G., \& Guattari, F. (1980). Traité de nomadologie. La machine de guerre. Capitalisme et schizophrénie. Paris: Minuit.

Dewey, J. (1921). Habits and Will. Excerpt from Human Nature and Conduct In Collected works of John Dewey. Middle works (Vol. 14, pp. 21-32). Carbondale: Southern Illinois University Press. Available in http://www.alexandercenter.com/jd/johndeweyhabits.html.

Diana, M. (2010). From mode choice to modal diversion: A new behavioural paradigm and an application to the study of the demand for innovative transport services. Technological Forecasting and Social Change, 77(3), 429-441.

Diana, M., \& Pronello, C. (2010). Traveler segmentation strategy with nominal variables through correspondence analysis. Transport Policy, 17, 183-190.

Donolo, C. (2005). Dalle politiche pubbliche alle pratiche sociali nella produzione di beni pubblici? Osservazione su una nuova generazione di policies. Stato e mercato, 73, 33-65.

Ehrenberg, A. (1995). L’individu incertain. Paris: Calmann-Lévy.

Elliott, A., \& Urry, J. (2010). Mobile lives. London, New York: Routledge.

Estèbe, P. (2008). Gouverner la ville mobile: la ville en débat. Paris: Puf.

Flamm, M., \& Kaufmann, V. (2006). Operationalising the concept of motility: A qualitative study. Mobilities, 1(2), 167-189.

Gallez, C., \& Kaufmann, V. (2009). Aux racines de la mobilité en sciences sociales. In M. Flonneau \& V. Guigueno (Eds.), De l'histoire des transports à l'histoire de la mobilité? (pp. 41-55). Rennes: Presses Universitaires de Rennes.

Haughton, G., \& Allmendinger, P. (2008). The soft space of local economic development. Local Economy, 23(2), 138-148.

Haughton, G., et al. (2010). The new spatial planning: Territorial management with soft space and fuzzy boundaries. London: Routledge.

Healey, P. (1998). Building institutional capacity through collaborative approaches to urban planning. Environmental and Planning A, 30(9), 1531-1546.

Jarv, O., Ahas, R., \& Witlox, F. (2014). Understanding monthly variability in human activity spaces: A twelve-month study using mobile phone call detail records. Transportation Research Part C: Emerging Technologies, 38(1), 122-135.

Jensen, O. B. (2009). Flows of meaning, cultures of movements-Urban mobility as meaningful everyday life practice. Mobilities, 4(1), 139-158.

Jensen, O. B. (2013). Staging mobilities. London, New York: Routledge.

Jensen, O. B. (2015). The will to connection: A research agenda for the "programmable city" and an ICT "toolbox" for urban planning. In: A. de Souza e Silva \& M. Sheller (Eds.), Mobility and locative media: Mobile communication in hybrid spaces (pp. 224-237). London: Routledge.

Jones, P., \& Lucas, K. (2012). The social consequences of transport decision-making: Clarifying concepts, synthesising knowledge and assessing implications. Journal of Transport Geography, 21, 4-16.

Kaufmann, V. (2002). Re-thinking mobility. Contemporary sociology. Burlington: Ashgate.

Kaufmann, V. (2005). Mobilités et réversibilités: vers des sociétés plus fluides? Cahiers Internationaux de Sociologie, 8(118), 119-135.

Kaufmann, V. (2008). Les paradoxes de la mobilité. Lausanne: Presses polytechniques et universitaires romandes. 
Kaufmann, V. (2012). Mobility as capital. Sketching the arguments, Mobile Lives Forum. Connnexion on 17th of September 2015, http://en.forumviesmobiles.org/arguing/2012/12/11/ mobility-capital-sketching-arguments-533.

Kaufmann, V. (2014). Mobility as a tool for sociology. Sociologica 1: doi: 10.2383/77046.

Kaufmann, V., Max Bergman, M., \& Joye, D. (2007). Motility: Mobility as capital. International Journal of Urban Regional Research, 28(4), 745-756.

Kesselring, S. (2006). Pioneering mobilities: New patterns of movement and motility in a mobile world. Environment and Planning A, 38, 269-279.

Kwan, M. P., Dijst, M., \& Schwanen, T. (2007). The interaction between ICT and human activity-travel behaviour. Transportation Research Part A: Policy and Practice, 41(2), 121124. Available at: http://linkinghub.elsevier.com/retrieve/pii/S0965856406000255. Accessed in May 9, 2012.

Lanzendorf, M. (2010). Key events and their effect on mobility biographies: The case of childbirth. International Journal of Sustainable Transportation, 4, 272-292.

Le Breton, E. (2005). Bouger pour s'en sortir. Paris: Arman Colin.

Le Breton, E. (2006). Homo mobilis. In M. Bonnet \& P. Aubertel (Eds.), La ville aux limites de la mobilité (pp. 23-32). Paris: Puf.

Lefebvre, H. (2004). Rhythmanaysis. Space, time and everyday life. Continuum, London and New York (or. pub. 1992).

Lévy, J. (1999). Le tournant géographique. Paris: Editions Belin.

Lévy, J. (2011). Modèles de mobilité, enjeu de société/Mobility Models: Society and Stake. In C. Gay, V. Kaufmann, S. Landriève, \& S. Vincent-Geslin (Eds.), Mobile immobile (Vol. 2, pp. 27-39). Paris: Editions de l'Aube, Forum Vie Mobile.

Limtanakool, N., Dijst, M., \& Schwanen, T. (2006). The influence of socioeconomic characteristics, land use and travel time considerations on mode choice for medium and longer-distance trips. Journal of Transport Geography, 14, 327-341.

Martinotti, G. (1993). Metropoli: la nuova morfologia sociale della città. Bologna: Il Mulino.

Mincke, C., Montulet, B. (2010). L'idéologie mobilitaire. Politique, revue de débats. La nouvelle obsession de la mobilité. 64. www.politique.eu.org.

Nuvolati, G. (2003). Resident and non-resident populations: Quality of life, mobility and time policies. The Journal of Regional Analysis and Policy, 33(2), 67-83.

Orfeuil, J. P. (2011). Le "droit à la mobilité" aujourd'hui et demain/The « Right to Mobility » In: C. Gay, V. Kaufmann, S. Landriève, \& S. Vincent-Geslin (Eds.), Mobile immobile (Vol. 1, pp. 48-59). Paris: Editions de l'Aube, Forum Vie Mobile.

Orfueil, J. P. (2004). Transports, pauvretés, exclusions: pouvoir bouger pour s'en sortir. Paris: L'Aube.

Pasqui, G. (2008). Città, popolazioni, politiche. Milano: Jaca Book.

Pred, A. (1984). Place as historically contingent process: Structuration and the time-geography of becoming places. Annals of the Association of American Geographers, 74, 279-297.

Pucci, P. (2013a). Dati di traffico telefonico e politiche per la mobilità. Tema, 6(3), 325-340.

Pucci, P. (2013b). Fuzzy boundaries per comunità mobili: Disegnare territori contingenti nella Regione Urbana Milanese. Planum, 27(2), 139-149.

Pucci, P. (2014). Identifying communities of practice through mobile phone data. Urbe. Revista Brasileira de Gestão Urbana_Brazilian. Journal of Urban Management, 6(1), 75-97.

Pucci, P., Manfredini, F., \& Tagliolato, P. (2015). Mapping urban practices through mobile phone data. Heidelberg, New York, Dordrecht, London: SpringerBriefs in Applied Science and Technology, Springer.

Raffestin, C. (1980). Pour une géographie du pouvoir. Paris: LITEC.

Ratti, C., et al. (2006). Mobile landscapes: Using location data from cell phones for urban analysis. Environment and Planning B: Planning and Design, 33, 727-748.

Reades, J., Calabrese, F., Sevtsuk, A., \& Ratti, C. (2007). Cellular census: Explorations in urban data collection. IEEE Pervasive Computing, 6(3), 30-38. 
Rémy, J. (1996). Mobilité et ancrages: vers une autre définition de la ville. In: M. Hirschorn \& J. M. Berthelot (Eds.), Mobilités et ancrages. Vers un nouveau mode de spatialisation? (pp. 135-153). L'Harmattan, Paris.

Rosa, H. (2010). Accélération, une critique sociale du temps. Paris: La Découverte.

Sevtsuk, A., \& Ratti, C. (2010). Does urban mobility have a daily routine? Learning from the aggregate data of mobile networks. Journal of Urban Technology, 17(1), 41-60.

Shane, D. G. (2005). Recombinant urbanism. Conceptual Modelling in Architecture, Urban Design, and City Theory. Wiley: Chichester.

Sheller, M. (2011). Mobility. Sociopedia.isa. Available at: http://www.sagepub.net/isa/resources/ pdf/Mobility.pdf. Accessed in August 8, 2013.

Sheller, M., \& Urry, J. (2006). The new mobilities paradigm. Environment and Planning A, 38, 207-226.

Shields, R. (1991). Places on the margin. Alternative geographies of modernity. London: Routledge.

Soja, E. (2004). Le temps des nodalités post-métropolitaines. In S. Allemand, F. Ascher, \& J. Lévy (Eds.), Les sens du mouvement (pp. 175-181). Paris: Belin.

Song, C., et al. (2010). Limits of predictability in human mobility. Science, 327, 1018.

Soto, V., \& Frías-Martínez, E. (2011). Automated land use identification using cell-phone records. In Proceedings of the Third ACM international workshop on MobiArch (pp. 17-22).

Tarrius, A. (2000). Les nouveaux cosmopolitismes: mobilités, identité, territoires. Paris: La tour d'Aigues, l'Aube.

Urry, J. (2000). Sociology beyond societies: Mobilities for the twenty-first century. London: Routledge.

Urry, J. (2007). Mobilities. Cambridge: Polity.

Urry, J. (2012). Social networks, mobile lives and social inequalities. Journal of Transport Geography, 21, 24-30.

Vannini, P., Budd, L., Jensen, O. B., Fisker, C., \& Jirón, P. (Eds.). (2012). Technologies of mobility in the Americas. New York: Peter Lang.

Vecchio, G. (2015). Mobilitarsi per muoversi. Pratiche periurbane e capitali di mobilità nell'area metropolitana di Milano, In Conferenza SIU, Venezia, 11-12 Giugno.

Vincent Geslin, S., \& Kaufmann, V. (Eds.). (2012). Mobilité sans racines: Plus loin, plus vite... plus mobile?. Paris: Descartses \& Cie.

Virilio, P. (1977). Speed and politics: An essay on Dromology. New York: Semiotext(e).

Virilio, P. (1990). L'inertie polaire. Paris: C. Bourgois.

Viry, G., Kaufmann, V., \& Widmer, E. (2009). Social integration faced with commuting. In T. Ohnmacht, et al. (Eds.), Mobilities and inequalities (pp. 121-143). Aldershot: Ashgate.

Viry, G., \& Kaufmann, V. (Eds). (2015). High mobility in Europe. Work and personal life. New York: Palgrave Macmillan.

Wagner, A.C. (2010). Le jeu de la mobilité et de l'autochtonie au sein des classes supérieures. Regards Sociologiques, 40, 89-98.

Wenger, E. (1998). Communities of practice: Learning, meaning and identity. Cambridge, MA: Cambridge University Press. 


\title{
A Social Science Approach to the Study of Mobility: An Introduction
}

\author{
Matteo Colleoni
}

\begin{abstract}
The chapter introduces the foremost theories put forward by social sciences on daily mobility, notably in urban societies. After a preliminary part aimed at defining spatial mobility from a sociological point of view, the paper puts forward an overview of explanations related to factors associated with daily mobility and its growth, particularly following the invention and diffusion of motorised means of transport from the second half of the nineteenth century. The relationship between mobile populations and new urban morphology is dealt with in the subsequent part of the chapter aimed at describing the history of city transformations as a reflection of the evolution of mobility. The coexistence of different populations, in urban areas characterised by the increasing scattering of settlements and by the difficulty to access goods and services, it is the basis for the last group of theories, outlined in the final part of the chapter related to the issue of the relationship between mobility, accessibility and risks of social exclusion.
\end{abstract}

Keywords Daily mobility - Urban mobility - Motorised means of transport • Mobility time $\cdot$ Urban morphology $\cdot$ Accessibility

\section{Introduction}

The study of mobility has become an object of interest for social sciences, particularly following the invention and diffusion of motorised means of transport, from the second half of the nineteenth century. Despite societies always having been mobile, suffice to think of migration, mechanical transport changed the way that the population moved and lived, generating hitherto unknown levels of mobility. The diffusion of private mechanical means of transport gave mobility an ordinary connotation lacking in eras when travel was associated with the extraordinary aspect of

\footnotetext{
M. Colleoni $(\bowtie)$

University of Milan Bicocca, Milan, Italy

e-mail: matteo.colleoni@unimib.it 
migration or the drama of exile. The car turned mobility into a private daily activity, expanding the range of places that could be reached quickly and enabling working, consuming, purchasing and social relations in increasingly more distant, diverse contexts from the habitual ones. The presence of private mechanical mobility in societies that came about at the turn of the twentieth century was so pervasive that it has become a habit, in social sciences, to call them automobile or automobility societies (Urry 2000). This expression refers not only to the fact that in these societies travel is mainly by car, but also to the consequences that this has had on relationships between people and organisation of space.

Recurrent use of private transport means, together with that of the new communication technologies, has been interpreted in various ways by social sciences, in some cases highlighting the positive aspects, with reference to the expansion of exchange, opportunities for interaction, accessibility to urban resources and social inclusion (Kwan 1999; Dijst et al. 2002; Le Breton 2005; Seu 2006; Preston and Rajé 2007; Colleoni et al. 2012). In other cases, a critical interpretation prevails of the consequences that the excess of vehicular mobility has on the poor quality of urban environment (Schäfer et al. 2009), on the loss of spatial proximity in interaction and spatial-temporal references of social formations (the so-called processes of de-territorialisation, Giddens 1985; Mela 2006) or on the risks of social alienation of subjects excluded from possession and use of the car (Kenyon et al. 2002; Lucas 2004). The following pages introduce the main theories put forward by social sciences on these issues, many of which will be analysed in the papers in this book.

\section{Spatial Mobility in Social Sciences: Definitions and Foremost Explanations}

It is opportune to start this introductory review by recalling that social sciences define spatial mobility as the subjective and objective inclination to be mobile via any method with the aim of reaching the places where social activities take place. This is a fairly broad definition that includes the different forms of mobility, deliberately excluding actions that do, however, not entail physical movement inherent to the activity. Action aside, reference to the inclination is justified by the interest in seeing mobility as a property of subjects rather than a characteristic of places. This perspective sees insertion of studies by Dijst on the concept of space of action (2002) and those by Kaufmann on the capital of mobility (Kaufmann et al. 2004). The space of action shifts attention from places and services that must be reached to the possibility of the person being able to do so, where reference to the concept of potentiality refers to the possession of different kinds of individual resources. Resources that are included, together with more traditional ones (gender, age, family condition, income...), in the definition of capital of mobility proposed by Kaufmann and which will be analysed, with reference to the theme of 
reversibility, in Chapter "Putting Territory to the Test of Reversibility". According to the latter, an individual's mobility behaviour is to be considered as the combined result of the factors that represent his mobility capital (or motility), including competences.

It is known that, of social sciences, economic sciences includes in mobility only physical travel that enables places to be reached where activities occur that generate an indirect differential benefit (or usefulness) (Musso and Burlando 1999). However, some sociologists highlight the perception that the presence of an indirect benefit represents an important, yet not always necessary, motivation for travel. Mobility can have direct usefulness simply as a result of travel for pleasure, visiting environments other than habitual ones (Flamm 2005). Otherwise there would be no explanation for tourism, which represents one of the most important forms of mobility in contemporary society, in particular in its interpretation of mobility motivated by the pleasure of the travel experience (Cohen 1979).

Reference to travel for pleasure or tourism, reminds that there are different forms of mobility. The classifications of kinds of mobility proposed by social sciences include the particularly successful one proposed by Kaufmann in 2004. This sorts mobility depending on the length of the time of travel and exit or not from the life context. The combined use of the two variables allows the author to identify four kinds of mobility: everyday mobility and travel in short temporality, residential mobility and migration in long temporality.

The importance assumed by daily mobility has led social sciences, on the one hand to dedicated increasing attention to it and on the other to study the hybrids resulting from a combination of the different forms of mobility. Cases are known of daily mobility or tourism that turns into voluntary residential mobility; in the first case, to reduce home-work travel times and in the second, to benefit from a holiday home. Less frequently analysed, despite being more and more frequent, are those hybrid recursive forms of mobility which Beck calls polygamies of place (1997), evident for example in existential tourism and multi-localism. In the former, characterised by the adhesion to values of the hosting context, the tourist lives in separate worlds, that of ordinary life without meaningful values and the chosen one of tourist life (Cohen 1979). Whereas with multi-localism, the player lives in different places and homes, developing individual strategies to adapt to the environment and acquiring a multi-place personality in order to maintain social relations and cognitively combine the different places (Weichhart 2009). In this sense, he is different from the better-known cosmopolitan, the citizen who lives in various places in the world, while not actually belonging to any of them. He is different from this latter multi-place individual, also due to the longer period of time he spends in the places - such as some contemporary cities (Sassen 1994; Duclos 1999) — where gradual specialisation of production, financial and service functions calls for the presence of highly qualified works willing to work and live temporarily in various places without having a fixed abode in any of them. In addition to the paper by Kaufmann on the theme of reversible and irreversible mobility (Chapter "Putting Territory to the Test of Reversibility"), this matter is also covered by Nadler in his essay on multi-local life-words (see Chapter "Plug\&Play Places: 
Subjective Standardization of Places in Multilocal Lifeworlds") and by Vendemmia in his study on inhabiting simultaneous lives (see Chapter "Inhabiting Simultaneous Lives: Analysing Process of Reversibilization of Mobility Practices in Italy"). The fact that daily mobility accounts for almost all travel in contemporary cities has led social sciences, in the same way as urban sciences, to analyse the causes and formulate theories on relative consequences. Many factors have been studied to find the reasons for this increase in daily mobility, for which it is difficult to establish the direction of causality. Paper by Pasqui, in the Chapter "Populations and Rhythms in Contemporary Cities", offers in-depth analysis of this aspect.

Separation of family life spaces from working spaces, marking the passage from the peasant society to that of urban industry, is the first historic reason considered to be at the base of the increase in daily mobility. A separation that for citizens translated into the practice, at first unusual, of having to travel to work and to purchase goods or access service. Moving into cities and subsequently between cities, was not just a necessity, it was also an opportunity that allowed players to multiply and differentiate contexts of life and respective social roles. For modern citizens, being able to choose where to go became a condition for deciding what to do and who to be, in those cases where moving, beyond being an activity, is the expression of a citizen's right. Individuals who have also had positive collective effects, in particular that of having enabled movement of the labour force and scientific-technological competences, ensuring the success of cities and territories that received them and exploited them to its advantage in national and international competitions (Jones 1981).

Another important phenomenon that social studies associate with daily mobility is the insertion of women in the job market and relative consequences on mobility. The question is addressed in a growing number of international studies (Walsh 2007) and community and national policies (OECD-International Transport Forum; World Bank-Transport and Gender, Transport of London 2007). These studies agree in saying that in the past, female mobility was not absent but limited to the restricted spaces and hermetic times of home life and in the residual and, for a long time inaccessible to women, leisure time. Sources provide information about the presence of mobility profiles characterised by short times and distances, regular flexible rhythms and slow pace, which was suitable to the lifestyle of women in post-war societies. Short travel times and distances, to guarantee their presence, necessary to the running of the home; regular flexible rhythms to compensate for the rigid working hours of husbands and school hours of children; a slow pace, to meet the family's requirements for attention and care. Characteristics that we still find in the daily mobility profiles for females, together however, with others that are increasingly similar to those for males and characterised by a reduction in time spent at home and by an increase in that spent on travel.

Reference to the question of times has allowed social sciences to address a third macro phenomenon associated with the increase in daily mobility, which consists of an increase in daily activity. The results of surveys into time use carried out in different countries over the past thirty years, provide scientific support for the experience common to growing numbers of people of being increasingly busier 
with different activities and having to travel to reach places in order to do them (Gershuny 2000, 2011; Fisher and Robinson 2011).

For sociology and economic geography, the increase in daily mobility can also be traced back to the transformations that have occurred in the production sector of goods and services. Acceleration in the production cycle of modern post-Fordism enterprise has been enabled by the gradual automation of companies' in-house functions, but also by organisational changes for the management of production decentralisation and management of just-in-time warehouses (Harvey 1990). From a territorial point of view, this has translated into the spreading of production and trade functions, previously located in just a few industrial areas, thanks also to the parallel development of the two technological macro-systems of physical and immaterial communications. Diversification of territorial localisation of company divisions and desynchronisation and differentiation of production times has resulted, on the one hand, in an increase in the average level of integration of the overall system (Chiesi 1989; Colleoni 1994), and on the other, in an increase in the number of atypical work relations out of the total labour force. The greater functional interdependence of activities by the individual parts, primarily in the production system and then in the service system, has resulted in an increase in the average level of mobility of human resources and increasingly more delocalised materials.

This overview of explanations regarding the factors associated with daily mobility cannot draw to a conclusion without addressing the main cause for this increase in travel, the availability of the car. Its origins, as it is known, date back to the period after World War Two, when a greater disposable income of families and the still low price of cars and fuels considerably increased the demand for cars, frequently leading to automobile dependence. This issue essentially refers to two traditional studies; the first is by Newman and Kenworthy (1999), who during the 1980s and 1990s carried out a survey on approximately 50 cities around the world with a view to analysing the relationship between urban density, use of the car and energy consumption. Analysis by these authors is introduced by an interesting historic reconstruction of types of cities, starting with:

- walking city, which dominated until the mid-nineteenth century, characterised by a combination of small size, high density, mixed use of territory and narrow streets;

- transit city, established in industrialised countries from the second half of the nineteenth century, distinguished by the co-presence of more extended territorial size, average density, increase in the population and the presence of linking rail and tram ways;

- automobile city: historic evolution of the previous city, characterised by big size, decentralisation and scattering of settlements, low demographic density and territorial separation of urban functions (zoning).

Allowing home to be kept separate from the workplace, the car had the result of influencing the structure of settlements and services, with greater scattering of the latter than increasing use of the car, creating the conditions for automobile dependency. To justify this theory, the authors show that where there are low-density 
levels, like in North American and Australian cities, consumption of energy for transport is very high, with the worst consequences on depletion of energy resources, on climate change and urban sustainability.

The theme of automobile dependency is also addressed by a second traditional theory from the English sociologist John Urry and his studies on automobility (2000, 2004, 2006). According to the author, social sciences have always undervalued the influence of the car on urban life and the causes should be looked for in the trend either to consider the car as a mere technological invention or to highlight only the negative consequences on the quality of life and urban spaces. To obviate this limit, he proposes the word automobility to describe the car as a kind of society based on its use and dependency that goes beyond a mere means of transport. "Complex amalgam of interlocking machinery, social practices and ways of dwelling which have reshaped citizenship and the public sphere via the mobilisation of modern civil societies" (Sheller and Urry 2000, p. 73, 2006). On the one hand, the word automobility refers to the ability of individuals to move autonomously and on the other, it indicates the ability for movement of objects and machinery (automatic) and finally, it refers to the possibility of self-directed movement free from the constrictions of transport on rails. Automobility therefore represents a self-fuelling system that constantly generates the conditions for its expansion through its effects on social organisation of space and time. The reference to space and time allows the author to highlight the main characteristic of automobility, which consists of being simultaneously flexible and coercive. Flexible, allowing multiple activities to be carried out at freely chosen times; coercive, because territorial organisation of activities founded on the car obliges use of the car for ever longer travel.

\section{Daily Mobility and Urban Societies}

Social science studies into factors traditionally associated with the increase in daily mobility have more than once reminded that this has come about and developed in urban societies. The urban connotation has, in fact, been since the beginning associated with mobility because it is in cities that people become accustomed to moving every day to connect the different sectors of life, starting with those in which they live and work. It has mainly been urban sociology, out of the social sciences, and urban planning, out of territorial sciences, that have studied the relationship between mobile populations and new urban morphology, as part of an approach that sees the history of city transformations as a reflection of evolution of the flows that run through them. From this perspective, Martinotti elaborated the theory of urban populations and development process of metropolises $(1993,1999)$, picked up and updated by many authors, including, in this book, Nuvolati (2007) and, of urbanologists, Pasqui (2005). The theory is very well known and represents the conceptual point of reference for a large number of contemporary urban studies. 
Here, we limit ourselves to presentation of the contribution this offers studies into urban scattering and those into conflict and inequality associated with mobility.

The historical evolution from traditional city to new-gen metropolis (in other words from resident population city to that where the population lives alongside the ever more numerous temporary populations), comes from the theory by Martinotti summarised in the formation process of today's scattered (or borderless) cities. According to the author, the scattering of settlements has led to the formation of increasingly more extended urban areas in which the continuum of housings, businesses and services no longer allows the city to be distinguished from its surrounding area. Many words have been used to define the new urban realitiesmegalopolises, scattered cities, urban regions and metropolitan areas-whose variability indicates the difficulty in identifying their distinctive traits. Over recent years, some authors have suggested calling them meta cities, cities that have gone beyond both the classic morphology of the metropolises that dominated the twentieth century and also traditional administrative control by local bodies in the area, and even the sociological reference to the resident population alone. However you want to call them, they are clearly visible in the immense urban areas where most of the world's population lives today. In Europe, they are recognisable in the urban continuum of the London area, that of Paris or in the Hanseatic megalopolises in the Netherlands and Lombardy in Italy (see Chapters "Mobility Practices in Peri-Urban Areas: Understanding Processes of Urban Regionalization in Milan Urban Region" and "Metropolitan Dynamics and Mobility Flows: A National Comparative Study (1991-2011)"), but also along the axes that link coastal cities in the South of France and along the Spanish and Italian Mediterranean coasts. Their borders often do not coincide with those of the administrative units and they are similar to corridors in shape, places for residential, production and service settlements and increasingly spaces of flows (Castells 1996; Martinotti 2004). In the new urban areas, the scattering of settlements has brought with it that of mobility, with the consequent further increase in movement of temporary populations. That of commuters, drawn by the larger number of available jobs in the metropolises and also of city users, attracted by the concentration and better quality of goods and services in urban centres. A meeting of populations that has resulted in a change in the morphology and quality of life in the cities that house them and that, in many cases, as covered in the paper by Nuvolati (see Chapter "Resident and Non-resident Populations: Types of Conflicts "), may cause conflict and new forms of urban inequality. The reference to the newness of these conflicts depends on the fact that compared to the past, they do not involve just the social classes that live in the cities, but the populations that inhabit them, visit them and more in general use their places and services.

Coexistence of different populations, in urban areas characterised by the increasing scattering of settlements and often, by the difficulty to access goods and services, is the basis for the last group of theories by social sciences, which we introduce here, regarding the question of the relationship between mobility, accessibility and risks of social exclusion (Colleoni 2011). The argument is covered by a large number of authors belonging, and not only, to the dominion of social sciences, in this book in the paper by Mattioli and Colleoni, with reference to 
sociology, and in the paper by Henckel and Thomaier, with attention to the new theme of efficiency and urban temporal justice. These studies share the assumption that the relationship between mobility and accessibility is complex and not unidirectional and that in a society constructed around the assumption of high mobility and the availability of a means of private transport, the insufficient or inadequate mobility of weaker subjects may compromise access to goods, services and social networks, compromise participation in economic, political and social life and as a consequence, cause their social exclusion (Kenyon et al. 2002). As will be explained in detail in the papers, the lack of accessibility (better known in international literature as transport disadvantage, Naess 2006; Currie and Delbosc 2011; Jones and Lucas 2012), is the result of the combination of four macro factors: the resources of the individuals and families, the characteristics of the context in which we live (land use, infrastructure, density and distance from services...), the supply and quality of the transport system and the social obligations of interaction that require players to be mobile (in literature summarised by the term compulsion to proximity, Cass et al. 2005). To these factors must be added those that come in the field of capital of mobility, or motility, mentioned by Kaufmann and which we have already introduced on the previous pages, which represents the mobility potential of subjects in terms of resources for access, competence and cognitive appropriation (Dijst and Vidakovic 1997; Kaufmann et al. 2004). Attention to the relationship between mobility, accessibility and social exclusion has over recent years extended to that with the theme of well-being and quality of life. Starting with a consideration of the differences between subjective, objective and psychological well-being (Vella-Brodrick 2011), many studies highlight the direct and indirect relationships that exist between inaccessibility, social exclusion and well-being (Vella-Brodrick and Delbosc 2011) while others emphasise its complex interrelations with the concept of social capital (Viry et al. 2009; Stanley et al. 2010).

\section{Conclusions}

From pioneer studies by the French and Chicago schools (McKenzie 1927), to those by Sorokin (1927) and of urban sociology in the seventies, social sciences have looked to spatial mobility with increasing interest. Studying the way in which people and populations move, they have given, on a macro social level, a better understanding of the morphology of societies and their transformations. But also on a micro level, the study of mobility has provided much information to social sciences, enabling a revision of the theories on which explanations for social and spatial interaction between people and the sentiment of social-territorial identity were based. A structural, and not only contextual, element of social interaction, mobility is studied to better understand how society has changed. As Urry says, it has a paradigmatic value that goes beyond the field of social sciences to meet the more general one of the sciences involved in knowing the forms assumed by societies in their distribution in space. Sciences that, as we will see in the papers, 
consider the cities as the spatial formation where the flows of movement define their identity in a way that is increasingly more liberated from characteristics of centrality, compact morphology and behaviour style traditionally associated with urban life. As Simmel (1907/1986) had already observed at the turn of the last century (1907), mobility is a key to interpreting modernity and, we add, an important analytical tool for integrated, spatial and social interpretation of urban phenomena (Bassand and Brulhardt 1980; Bourdin 2005; Gallez and Kaufmann 2009). An integrated interpretation of social-spatial practices that lend shape to daily life in urban contexts that, as we will see, represents the element of continuity for the papers in this book.

\section{References}

Bassand, M., \& Brulhardt, M. C. (1980). Mobilité spatiale. St-Saphorin (Lavaux): Georgi.

Beck, U. (1997). Was ist Globalisierung?. Irrtümer des Globalismus: Antworten auf Globalisierung. Suhrkamp, Frankfurt a.M.

Bourdin, A. (2005). Les mobilités et le programme de la sociologie. In: Cahiers internationaux de sociologie, 1/2005 (Vol. 118, pp. 5-21).

Cass, N., Shove, E., \& Urry, J. (2005). Social exclusion, mobility and access. The Sociological Review, 53(3), 539-555.

Castells, M. (1996). The information age: Economy, society and culture. Oxford: Blackwell.

Chiesi, A. (1989). Sincronismi sociali: l'organizzazione temporale della società come problema sistemico e negoziale. Bologna: Il Mulino.

Cohen, E. (1979). A phenomenology of tourist experiences. In Sociology, 13, 179-201.

Colleoni, M. (1994). I tempi sociali: Teorie e strumenti di analisi. Roma: Carocci.

Colleoni, M. (2011). Urban mobility, accessibility and social equity. A comparative study in four European Metropolitan Areas. In G. Pellegrino (Ed.), The politics of proximity: Mobility and immobility in practice (pp. 121-132). London: Ashgate.

Colleoni, M., Castrignanò, M., \& Pronello, C. (2012). Muoversi in città: Accessibilità e mobilità nella metropoli contemporanea. Milano: Franco Angeli.

Currie, G. (Ed.). (2011). New perspectives and methods in transport and social exclusion research. Bingley: Emerald Group Publishing Ltd.

Currie, G., \& Delbosc, A. (2011). Transport disadvantage: a review. In G. Currie (Ed.), New perspectives and methods in transport and social exclusion research. Bingley: Emerald.

Dijst, M., Schenkel, W., \& Thomas, I. (2002). Governing cities on the move, functional and management perspectives on transformations of European urban infrastructures. Urban and regional planning and development. Aldershot: Ashgate.

Dijst, M., \& Vidakovic, V. (1997). Individual action space in the city. In D. Ettema \& H. J. Timmermans (Eds.), Activity-based approaches to travel analysis (pp. 117-134). Oxford: Pergamon.

Duclos, D. (1999). La nascita dell'iperborghesia. In G. Martinotti (Ed.), La dimensione metropolitana (pp. 175-187). Bologna: Il Mulino.

Fisher, K., \& Robinson, J. (2011). Daily life in 23 countries. Social Indicators Research, 101, 295-304.

Flamm, M. (2005). A qualitative perspective on travel time experience. Paper for the 5th Swiss Transport Research Conference, Monte Verità, Ascona (Ch).

Gallez, C., \& Kaufmann, V. (2009). Histoire de la sociologie face à la mobilité. In M. Flonneau \& V. Guigueno (Eds.), Histoire de la mobilité. Rennes: PUR. 
Gershuny, J. (2000). Changing times: Work and leisure in post industrial society. Oxford: Oxford University Press.

Gershuny, J. (2011). Time-use surveys and the measurement of national well-being. UK: Centre of Time-use Research, Department of Sociology, University of Oxford.

Giddens, A. (1985). Time, space and regionalisation. In D. Gregory \& J. Urry (Eds.), Social relations and spatial structures (pp. 265-295). London: Macmillan.

Harvey, D. (1990). The condition of the postmodernity. Oxford: Basil Blackwell.

Jones, E. J. (1981). The European miracle: environments, economies and geopolitics in the history of Europe and Asia. Cambridge: University Press.

Jones, P., \& Lucas, K. (2012). The social consequences of transport decision-making: Clarifying concepts, synthesising knowledge and assessing implications. Journal of Transport Geography, 21, 4-16.

Kaufmann, V., Bergman, M. M., \& Joye, D. (2004). Motility: Mobility as capital. International Journal of Urban and Regional Research, 28(4), 745-756.

Kenyon, S., Lyons, G., \& Rafferty, J. (2002). Transport and social exclusion: Investigating the possibility of promoting inclusion with through virtual mobility. Journal of Transport Geography, 10, 207-219.

Kwan, M. P. (1999). Gender and individual access to urban opportunities: A study using space-time measures. The Professional Geographer, 51(2), 210-227.

Le Breton, E. (2005). Bouger pour s'en sortir. Mobilité quotidienne et intégration sociale. Paris: Armand Colin.

Lucas, K. (Ed.). (2004). Running on empty. Transport, social exclusion and environmental justice. Bristol: The Policy Press.

Martinotti, G. (1993). Metropoli: La nuova morfologia sociale della città. Bologna: Il Mulino.

Martinotti, G. (1999). La dimensione metropolitana. Bologna: Il Mulino.

Martinotti, G. (2004). The rise of meta-cities. Mobility and the new metropolitan europe. In Move, international, non governmental, permanent, observatory on sustainable mobility in Metropolitan Areas, Final Technical Report (pp. 9-37).

McKenzie, R. D. (1927). Spatial distance and community organization pattern, Social Forces,5(4), 623-627.

Mela, A. (2006). Sociologia delle città. Roma: Carocci.

Musso, E., \& Burlando, C. (1999). Economia della mobilità urbana. Torino: Utet.

Naess, P. (2006). Accessibility, activity participation and location of activities: Exploring the links between residential location and travel behaviour. Urban Studies, 43(3), 627-652.

Newman, P. W. G., \& Kenworthy, J. R. (1999). Sustainability and cities: Overcoming automobile dependence. Washington, DC: Island Press.

Nuvolati, G. (2007). Mobilità quotidiana e complessità urbana. Firenze: Firenze University Press.

Pasqui, G. (2005). Territori: progettare lo sviluppo. Teorie, strumenti, esperienze. Roma: Carocci.

Preston, J., \& Rajé, F. (2007). Accessibility, mobility and transport-related social exclusion. Journal of Transport Geography, 15, 151-160.

Sassen, S. (1994). Cities in a world economy. Thousand Oaks: Pine Forge Press.

Schäfer, A., Heywood, J. B., Jacoby, H. D., \& Waitz, I. A. (2009). Transportation in a climate-constrained world. Cambridge, Massachusetts: The MIT Press.

SEU. (2006). The social exclusion of older people: Evidence from the first wave of the English longitudinal study. Final report. London: Office of the Deputy Prime Minister.

Sheller, M., \& Urry, J. (2000). The city and the car. International Journal of Urban and Regional Research, 24(4), 737-757.

Sheller, M., \& Urry, J. (2006). The new mobilities paradigm. Environment and Planning, 38, 207-226.

Simmel, G. (1907/1986). The philosophy of money. London: Routledge.

Sorokin, P. (1927). Social mobility. New York: Harper \& Brothers.

Stanley, J., Stanley, J., Vella-Brodrick, D. A., \& Currie, G. (2010). The place of transport in facilitating social inclusion via the mediating influence of social capital. Research in Transportation Economics, 29, 280-286. 
Transport for London. (2007). Gender Equality Scheme 2007-2010. Mayor of London.

Urry, J. (2000). Sociology beyond societies: Mobilities for the twenty-first century. London: Routledge.

Urry, J. (2004). The system of automobility. Theory, Culture \& Society, 21(4/5), 25-39.

Urry, J. (2006). Inhabiting the Car. The Sociological Review, 54(s1), 17-31.

Vella-Brodrick, D. A. (2011). Contemporary perspectives on well-being. In G. Currie (Ed.), New perspectives and methods in transport and social exclusion research (pp. 45-59). Bingley: Emerald Group Publishing Ltd.

Vella-Brodrick, D. A., \& Delbosc, A. (2011). Measuring well-being. In G. Currie (Ed.), New perspectives and methods in transport and social exclusion research. Bingley: Emerald Group Publishing Ltd.

Viry, G., Kaufmann, V., \& Widmer, E. D. (2009). Social integration faced with commuting: More widespread and less dense support networks. In T. Ohnmacht, A. Maksim, \& M. Bergman (Eds.), Mobilities and inequality. Farnham: Ashgate.

Walsh, M. (2007). Gender in the history of transportation services: A Historiographical perspective. Business History Rewiev, 81, 545-562.

Weichhart, P. (2009). Multilokalität - Konzepte, Theoriebezüge und Forschungsfragen. In Informationen zur Raumentwicklung, 1/2, pp. 1-14. 


\title{
Putting Territory to the Test of Reversibility
}

\author{
Vincent Kaufmann
}

\begin{abstract}
In this chapter, we will argue that territories (urban areas included) can be understood based on the movement and mobility of their actors, as the result of the enmeshment of different actors' (individual and collective) motilities with the receptiveness of a given environment. Actors have and use their highly specialized skills and creativity to appropriate technical systems, and to use them for personal and/or collective projects. The major challenge when it comes to regulating motility, more so than policies, therefore consists of having tools that are capable of identifying, describing, and analyzing motility and its social and spatial implications to develop means for controlling it-ideally without adverse regional, economic, social, or environmental consequences. A return to the underlying logics of action that govern mobility and movement naturally leads to an exploration of their political and social consequences, thereby allowing us to analyze the structure and functioning of modern societies in detail. In other words, we must consider not only changes in lifestyles (pluralism, individualism, etc.), but also the new technical and social forms that drive them (the development of economic structures, technical innovation, and changes in customs) and ensuing issues (new forms of inequality, opportunity, physical tensions, socio-cultural conflicts, etc.).
\end{abstract}

Keywords Territory $\cdot$ Sociology $\cdot$ Mobility $\cdot$ Motility

\section{Introduction}

Given the multiplication and diversification of speed potentials, the gradual disappearance of the fixed boundaries between city and countryside, only to be replaced by urban sprawl, is an indication of changes in the relationship between

\footnotetext{
V. Kaufmann ( $₫)$

Laboratoire de Sociologie Urbaine, Ecole Polytechnique Fédérale de Lausanne,

Lausanne, Switzerland

e-mail: Vincent.kaufmann@epfl.ch

(C) Springer International Publishing Switzerland 2016

P. Pucci and M. Colleoni (eds.), Understanding Mobilities

for Designing Contemporary Cities, Research for Development,

DOI 10.1007/978-3-319-22578-4_3
} 
service infrastructures, urban morphologies, and lifestyles. Motility, now primordial for actors when it comes to realizing plans in a world of hyper-choice, is a result of this multiplication and diversification. In keeping with this approach is the idea that a city can be more or less mobile (mobility as we have defined motility, relative to change) and thus more or less city, in much the same way that people constitute a society.

In this chapter, we will argue that territories (urban areas included) can be understood based on the movement and mobility of their actors, as the result of the enmeshment of different actors' (individual and collective) motilities with the receptiveness of a given environment.

Using this approach means having a clear idea of what an environment (i.e., a city, region, or territory) is, how it is built up over time, what makes a city a city and how that has changed. Such is our goal in this chapter. This will also allow us to analytically define the contemporary city which, contrary to what certain authors have posited, has not dissolved in the urban (Le Galès 2002; Ascher 1995). A simple analysis of actors' motilities and their impact on the surrounding environment will help us rightfully restore it to its place.

\section{Why This Influence of Movement in Our Daily Lives?}

Travel and movement in general has a growing influence on our everyday lives in different ways. Let us explore this influence in order to better understand the reasons.

The first is that some trips have replaced others. On an average, time spent travel time budgets has long remained constant. Yet, this seeming stability actually concealed a rather radical structural change in motives. Work-related travel, still dominant thirty years ago, today represents only $20-30 \%$ of trips. Nowadays, full-time employees do not go home for lunch, which cuts the number of daily trips into half. While the so-called "leisure" travel has increased considerably, the approximate balance of this substitution of one pattern for another has been upset in recent years, as the number of work-related trips is no longer decreasing and the number of leisure trips continues to increase. Add to this a significant increase in "trip chaining," meaning the grouping of activities outside home without returning home in between. This does not reflect changes in transportation technology, but rather deep changes in mobility patterns and society, be it structural (female labor is closely linked to the decrease in trips home at lunchtime), cultural (the importance of leisure activities and free time), or perceptual (it is now considered dangerous to let children go to school alone).

A second explanation for this increase in what we could call "travel time budgets" is the decoupling of transportation speed and mobility. Transport networks long offset the increase in distance traveled by gains in speed. However, this compensatory equation no longer works. Those who travel the fastest and the furthest are also those who spend most time "on the road." Even more 
fundamentally, there is a segment of the population that commutes for more than two hours a day (Joly et al. 2006). Why? Perhaps because markets are expanding, thereby requiring people to travel further for work. Dual-earner couples, whose workplaces are far from one another are forced to compromise when it comes to choosing a residential location. Traffic jams are increasing on roads at peak hours, thus counteracting the gain in speed provided by infrastructure.

The third explanation for this sudden increase in travel time budgets has to do with changes in how we move. The distinction between daily mobility, travel, and residential mobility has been blurred by the emergence of new forms of travel. The latter two are less innocuous and conventional than they seem at first glance. The first is long-distance commuting in countries characterized by a multipole spatial organization, like Germany, Belgium, and The Netherlands (Van Wee et al. 2006; Mokhtarian and Chen 2004). The second is overnighting, i.e., having two or more residences several hundred miles apart (Pierre 2006; Duchêne-Lacroix 2014).

These emerging lifestyles were initially misinterpreted as epiphenomena; we thought that they only concerned elites, who distinguish themselves by their frequent use of train and plane travel and who work by cell phone and/or laptop while traveling. Such practices indicate considerably high-time budgets and raise survey averages, even though they represent only 5-6\% of the population (as was the case in Switzerland in 2000). While these forms may still appear as a caricature of modern times, they are rapidly increasing, such that one wonders if they are not a foreshadowing of the mobility of tomorrow. The question is quite controversial. Without attempting to judge, it is interesting to note that, for long-distance commuters and overnighters, travel time is no longer wasted time but rather a social time in its own right, whose quality is worth analyzing (Vincent-Geslin and Kaufmann 2012).

In summary, we have observed that the distance and time spent traveling is increasing, that these increases reflect new forms of travel, and that personal perceptions of travel time should be explored.

\section{Our Relationship to Space and Time Has Changed}

By traveling further and for longer time periods, are we truly more mobile? Behind the increase in travel-in terms of distance and time-lurk more fundamental changes in our relationship to time and space. These may be expressed by the terms "connexity" and "reversibility."

Widespread use of telecommunications and motorized transportation has led to changes in the way individuals integrate socially, meaning their ability to "move" in space via a technical intermediary. Actors have, for the most part, been keen to understand, appropriate, and make use of these new possibilities. Connexity marks the shift from social integration - based on differentiations of space and time - to a more "mixed" model (Lévy 1999; Kaufmann 2011), and is closely linked to the increase in daily commute distance and the resulting "archipelization" of lifestyles. 
Until 1960s, modern societies were characterized by a separation of functions in social space (gender division in the workplace, the importance of socio-professional categories for individual identity, etc.) and physical space (spatial differentiation of activities). Changing roles typically implied changing locations. This model has now become more or less obsolete, making way for a more spatial and temporal superposition of roles (Larsen et al. 2005). The gradual erasing of gender roles (women's work, "stay-at-home" dads, etc.) and changes in how free time is, both seen and used, has broadened social mobility on the horizontal axis without necessarily increasing spatial mobility. Many people use telecommunication and transportation technologies to increase the number of activity spheres in their daily lives and the speed with which these activities can be done. Thus, for instance, home is no longer merely a domestic or family space; rather, it is increasingly becoming a space of leisure and work (thanks in great part to home computers and the Internet). As a result, a kind of melding of the public and private spheres and telescoping of free time and constraints ensues. This dividing of activities spheres also results from the interruption of one activity by another, an increasingly frequent issue in the age of cell phones. Nonetheless, one of the most flagrant examples of this superposition is the installation of video surveillance cameras in US daycares, whereby parents can observe their children at any given moment via Internet from home, work, or wherever they may be.

Spatially speaking, connexity develops both near and far, i.e., in the home via information technology and in this archipelago of spaces brought together by the speed with which transportation gets us from one place to another.

The impact of the use of telecommunications and motorized transport has also led to a reversal of movement and mobility. Like connexity, actors typically take advantage of this potential often by using transport and telecommunications technology to nullify the effects of travel and commuting on social life.

Let us first look at how more irreversible forms of movement (migration and relocation) are being replaced by more reversible forms (daily mobility, commuting, and travel). Such is the case for rapid transit and telecommunications systems, used by those who live far from their places of work as a way of avoiding relocation (Schneider et al. 2002; Green et al. 1999), and the various forms of multiple residency we have already looked at, when the distance is too far to travel on a daily basis (Meissonnier 2001). These forms of substitution replace long-term spatial temporalities with shorter ones. More important is how travel and commuting impact social relationships. By traveling instead of migrating and commuting instead of relocating, networks and social attachments can be more readily maintained. Studies on mobility also emphasize a reversal among the forms of mobility themselves. Now more than ever are we able to limit the impact of distance and even those who do migrate can stay in touch with families and friends by phone or email (Kesselring 2005). Hence migrating no longer means a definitive break, and even less so with the speed potential of modern transport, making it possible for us to travel and/or receive visits. By the same token, relocation often goes hand in hand with habits and practices transposed from the old neighborhood and lifestyle to the new one, making it possible to not relocate in a certain manner. Reversal also 
has to do with commute time, which is increasingly used as a social time during which a variety of work and leisure activities can be done.

\section{A Paradox: Those Who Move to Be Sedentary}

The behaviors described above led to an observation that was both unexpected and contrary to popular belief: extensive use of speed potential serves to maintain a sedentary lifestyle. New ways of traveling are therefore not necessarily indicative of "hypermobility"; rather they point to an attempt as to preserve our environment and our attachments.

To better understand this paradox, a survey was recently conducted in Switzerland among long-distance commuters, i.e., people who work more than $80 \mathrm{~km}$ from home (Kaufmann 2008), and confirmed that this practice is linked to a quest for a sedentary lifestyle. People who are strongly attached to their place of residence often choose to long-distance commute. Thus, we observed a highly localized social attachment for Sonia, an employee whose company headquarters transferred from Basel to a suburb of Bern, and who thus became a long-distance commuter. She explained: 'I'm originally from Basel. I've always lived there and that's where my circle of friends is. That's why under no circumstances do i imagine moving to be closer to my workplace."

This attachment can also be based on strong attachment to a home, neighborhood, or city. Christine, for instance, is very attached to a farm she renovated. She explains her decision to long-distance commute: "I completely renovated my house myself. Even if I have to travel two hours a day, I want to live in it."

Alexandre has strong ties with an old area of Geneva. The air he breathes there reminds him of Proust's Madeleine: "I'm attached to the neighborhood where I grew up. I no longer have a lot of friends in the neighborhood because I left for several years...but I have a lot of memories."

Such interviews also highlight different ways of using travel time as a time for working, connecting socially, or relaxing.

Long-distance commuters tend to be individuals who are attached to their habits and social and spatial ties, thus highly "localized." In no way desirous to uproot themselves from this fixity, they will accept a job provided that it is possible to not move. The speed of transport systems offers them the sedentary lifestyle they seek. In this way, we can say that they experience their extensive travel as reversible.

Are we really more mobile? We have just discovered the paradoxical answer to this question: we move more and more, and yet are less mobile. This has two important consequences.

First, the crossing of space, in terms of speed and distance, should not be used as an indicator to describe mobility. As we have attempted to stress, mobility cannot be reduced to transport. Transport is first and foremost a demand that is derived from the lifestyles and plans of actors. Our movement is born of obligations, constraints, or windows of opportunity that open to us. 
The second consequence of this pseudo-mobility is that the increase in travel time budgets is no longer experienced as wasted time, but is increasingly becoming a social time in its own right.

\section{In Search of the Meaning of "Mobility"}

The aforementioned considerations raise the question of the definition of mobility and travel.

Along with Dietrich (1990), we propose to consider mobility as a phenomenon that is likely to take different, sometimes overlapping forms, each of which reflects specific "social times." By this we mean days and weeks for activities and roles, months and years for trips, years and life cycles for moves and professional mobility, and life histories for migrations and family histories. These different forms, all of which are events, mutually impact one another. Certain forms of mobility reflect longer temporalities (e.g., life cycles and life histories) and invariably have an impact on forms of mobility resulting from shorter timeframes. Our daily mobility naturally changes after a move, the birth of a child or change of jobs, as the space of our daily existence changes. Moving to another country changes not only our daily mobility, but can also result in additional travel to visit friends and family, as well as specific residential mobility in the new country of residence (first as a tenant and later as an homeowner), etc. This interpretation of mobility reveals a system based on social temporalities, or systems of temporal interlocking, and not strictly as spatial forms of movement. As such, we considerably pare down the process.

Based on this idea of interlocking temporal systems, we propose an approach to mobility organized around three analytical dimensions.

The field of possibilities. Regarding mobility, each context offers a specific range of opportunities: the available networks and their development; performance and conditions of access; road, highway, and rail networks; airports; and telecommunications amenities. We must also consider geographical areas and their configurations (urban development, functional centralities, institutional territories, etc.). Add to this the employment market, along with opportunities for training, the unemployment rate, and the institutions and laws that in one way or another govern human activity (family policy, housing and property assistance, and immigration policy). In short, our analyzes must take into account the social relationships and success models proposed by a given society and the trials to which it subjects its actors in order to succeed.

Aptitude for movement. Each individual and group is characterized by a more or less marked propensity to move in geographical, economic, and social space. This set of skills has been termed "motility," in reference to the biological definition of this term (Kaufmann 2002). Motility is defined as all those factors which enable us to be mobile in space, i.e., physical capacities, income, aspirations for mobility or immobility, telecommunication and transport systems and their accessibility, and 
acquired skills (e.g., training, driver's license, international English for travel, etc.). Motility thus refers to accessibility factors (the conditions in which the offer may be used broadly speaking), skills (required to use the offer), and appropriation (actual use of the offer to realize plans). Ultimately, motility is how an individual or group appropriates and uses the realm of possibilities to move. We wish to stress that motility implies both intent and action.

Movement. This refers to all that moves. Movement can be guided, taking place between an origin and one or more destinations, or can be random, with no clear origin or destination, like rhizomes in biology. Movement does not only involve people. In general, objects, ideas, and information all move.

Together, phenomena stemming from these three dimensions may produce mobility. However, we must not limit ourselves to preconceived ideas about how they relate to one another. A "field of possibilities" offering highly efficient networks and widespread access does not automatically lead to appropriation or given uses. Similarly, highly developed motility in a given population can serve to anchor it to an area rather than to change statuses. A population that moves a lot does not necessarily have a "field of possibilities" that is favorable to movement.

The whole point of this conception is precisely that it allows us to identify the relationships between the field of possibilities, motility, and movement. Each context offers a specific field of possibilities, and thus different mobility conditions. In this sense, city centers versus suburbs and north countries versus south countries have strong differences.

In addition, the three analytical dimensions proposed here allow us to deconstruct the synonymy between movement and mobility and to consider three possible ideal type arrangements.

Moving without being mobile. In the first case, movement in space does not change the actor's state. However, this movement does not change the actors' state. The world in which their activities take place is a globalized bubble that offers no relationship to otherness. Hence, they are socially immobile.

Not moving and being mobile. Intensive telecommunications users (Internet, email, Skype, etc.) may correspond to this example, provided that their social practices lead them to frequent specific and different social worlds, in the same way that readers who mentally escape into the world of a novel are mobile without moving.

Moving and being mobile. In this case, spatial mobility is social mobility. The crossing of geographical space goes hand in hand with a journey in social space. This example, well documented in sociology, supposes the existence of territorialized, hierarchical societies, with the specificity of their spatial and daily workings.

\section{Actors' Motility and Its Translation in Time and Space}

Motility highlights the wide range of possibilities when it comes to the relationship between movement in space and social change. This diversity has increased considerably over the past few decades, spurred by advances in telecommunications 
and transport technology. Nonetheless, we must be careful not to make a deterministic analysis here; the fact that a technical solution exists does not necessarily mean that people make use of it. In other words, simply describing spatio-temporal practices does not offer insight into the motives that underlie them.

Thus, a person who works $80 \mathrm{~km}$ away from home and commutes by train each day is, by definition, sedentary residentially speaking. He or she is, however, a sedentary person who moves a great deal and, though their motility is more strongly geared toward movement than mobility, is able to use the transport system in different ways. Another example: a company's (i.e., a collective actor) development strategy consists in expanding the market for its existing products, a strategy typical of the automobile industry in emerging economies over the past fifteen years or so. Here too does the company's motility consist in movement, in this case by expanding its markets spatially rather than changing its products. Its strategy is therefore one of movement rather than mobility and, like in our first example, is not dictated by transport means, thanks to other possible strategies.

In terms of choice with regard to appropriating technical systems, we can also cite examples of mobility-oriented motility. A family that chooses to live in the city to enjoy the wide range of services and conveniently located facilities there essentially has mobility-oriented motility. By the same token, a company whose development strategy consists in using technology to improve its products also has mobility-oriented motility. In both cases, rapid transit serves not as a means of escape, but rather a way of willingly investing in proximity.

Actors' choices, when it comes to utilizing these technological opportunities, are critical to the composition and structuring of the environment. Two aspects of our relationship to space and time determine how motility comes to be and how it is used: attitudes toward connectivity and feelings regarding reversibility.

A more or less connexity and the degree of reversibility allow us to describe motility in terms of movement and mobility. Scientific literature, while still in its infancy as far as this topic goes, nonetheless indicates that connectivity and reversibility redefine these highly differentiated movement- or mobility-oriented relationships to space.

At the individual level, for example, this results in the identification of three logics of spatial constitution of social networks:

- The logic of maintaining local social anchoring goes part and parcel with motility aimed at nullifying the effects of movement as much as possible. This behavior leads to a degree of residential sedentariness and daily "hyper-commuting” practices (Schneider et al. 2002; Meissonnier 2001). In this context, social networks develop only marginally as a result of commuting or the travel experience itself. Connectivity thus serves to reverse the effects of distance and limit mobility, while actors attempt to counteract the effects of their movement on social inclusion.

- A recursive logic, wherein each travel or commute experience enriches the actor's social network by aggregation, thus changing the actor. Spatially 
speaking, social attachment in this case is multiple, with motility geared toward building and maintaining new relationships during these movements despite the distance, by staying in touch via one or multiple modes of communication (Kennedy 2004; Kesselring 2005). This logic is contrary to that of the first example: opportunities for connectivity and reversibility serve both the ability to be mobile (by allowing individuals to develop their social networks) and moving to maintain established relationships (so as not to have to change the fabric of one's social relationships).

- A logic whereby each movement produces a spatial recomposing of the social network, and whereby the old network is gradually abandoned requires motility, as it means being able to uproot and reroot elsewhere (Tarrius 2000). The preferred forms here are residential mobility and migration (i.e., irreversible forms). Connectivity and reversibility are to some extent rejected, as a balance is found between movement and mobility. Physical movement in this logic is inevitably mobility.

Regarding attitudes toward connectivity and reversibility, it is worth noting that the decision to practice a certain type of mobility over the others is not necessarily a choice; room for maneuver is, in fact, often limited. By remembering this and keeping it a central focus in our approach, we can dismiss theories that herald the radical fluidification of Western societies, which will become a-stratified and function individualistically according to the binary modalities of inclusion and exclusion (we are thinking in particular of the works of Bauman (2000), when he contrasts the dominant, who have high mobility, with the dominated, who are attached to a very local area).

As its role in determining the density and diversity of a territory is so instrumental, different types of mobility can in fact produce different cities and different urbanity. Nevertheless, we must try and keep a unilateral vision of the effects of these different forms of mobility on a given environment, in which movement with weak mobility is associated with something anti-urban, and movement with strong mobility with urbanity par excellence. Fundamentally, the degree of mobility offered by a given trip is ambivalent with regard to its effect on the surrounding territory.

Let us also mention that movement with strong mobility and movement with weak mobility often tend to couple with - rather than exclude - one another. To reuse the example of long-distance commuting, we can easily travel or commute great distances each day in order to continue living in a city center-for its diversity, richness, and "otherness" - and still have weak mobility.

Let us also note another critical point: mobility projects and movement may be favored or thwarted by a territory's receptiveness. A territory (and this point is imperative), the material product of the sedimentation of successive acts by individuals and public and private sector over time, is not merely a blank slate. 


\section{Potential Receptiveness as a Vehicle for Constant Transformation}

What defines the scope and extent to which a given territory is receptive to motility is largely linked to the material artifacts that structure it. All action takes place within a context, which supposes that the environment provides the footholds (opportunities, etc.) necessary for them to exist (Gibson 1979).

Material artifacts are critical to a territory's receptiveness to projects and aspirations; more fundamentally, they affect the emergence and definition of these projects. That the diversity of urban forms (their appearance, ambiance, the way they lived and used, their price, etc.) defines a territory's receptiveness is obvious. By the same token, the inherent potential of transport systems also defines this receptiveness, as do travel and commuting, and cultural, sporting, and economic institutions.

We would like to go even one step further and suggest that the impact of all the material artifacts that together constitute a given territory has an impact on the very presence of the actors' plans and their nature. The existence of industrial wastelands or defunct workshops in a city tends to stimulate projects of rehabilitation. The possibility of living without a car, thanks to efficient public transportation, makes this lifestyle more attractive and thus more adoptable. The existence of auditoriums gives rise to festival-type projects. And the list goes on.

We can sum up this observation by saying that not all plans and aspirations can find the footholds they need to be realized in a given environment. Some territories are more receptive to certain projects than others depending on their morphological characteristics, the laws in effect, their accessibility, etc.

A field of possibilities limits the potential for movement and their more or less mobile nature. At first glance, it would seem that this potential differs from region to region and from country to country based on characteristics such as infrastructures and transportation services. A downtown area does not offer the same opportunities in terms of movement as does a suburban one, nor a north country offer the same ones as a south one. Most importantly, every context does not offer the same opportunities for mobility; job markets, leisure activity offerings, etc., all differ greatly according to geographical scale-from the local to the continental and, of course, the national which, nowadays, we tend to consider as having dissolved into triumphant cosmopolitanism. Let us recall that living in London as a Brit and in Nairobi as a Kenyan are radically different in terms of revenue, even for the same profession, social welfare, career opportunities, the right to travel the globe without a visa, and a great many other things.

What is more, the more or less open and pluralistic nature of a context is itself contextualized. In other European countries (or in some cases other French cities, if we adhere to Wiel's (1999) analyzes of housing complexes), cities have developed according to different types of urbanization, producing different systems of opportunities and constraints. Thus, for instance, a family that wishes to live in a townhouse close to the city center will have no trouble finding something that suits it in Great Britain, a country where the housing market consists primarily of 
terraced and semi-detached houses. On the other hand, this same family looking to live in a single-family home will have a harder time finding this in Great Britain, where such residential opportunities are rare, than in France. We can use this same line of reasoning with regard to cars. In Switzerland, where public transportation networks are efficient and serve the country's many agglomerations both spatially and temporally, it is easier to live without a car on a daily basis than in France.

The importance of receptiveness and artifacts with regard to a city's substance and urban dynamics should not obscure the fact that individual and collective action also gives rise to unexpected and undesired consequences.

The impact of different actions on an environment is rarely the one sought, or rather is rarely the only one sought. This has to do with the fact that a given action at a given level leads to other actions often at other levels. Territorial dynamics are the result of the ensemble of individual and collective actions conceptualized and realized via motility. Thus can a territory be likened to a dynamic milieu in constant flux, mutating and reconfiguring itself based on human action. This transformation, which in turn affects an environment's receptiveness to new action, stimulates the genesis of actors' plans and aspirations.

The various forms that the meeting of motility and receptiveness constitute the core of environmental dynamics.

\section{Configurations of the Meeting Between Actors and Environment}

Let us now focus on how the meeting between motilities and receptiveness transpires.

The social sciences distinguish three levels of analysis (typically known as scales): the personal level, the interpersonal level, and the collective level. For a long time, these scales were conceptualized by contrasting the "micro" and "macro." Yet, this dichotomy merits rethinking. For one, it stifles the "meso," or intermediate level. What is more (and more important), these levels are very much enmeshed and interconnected, and need not be contrasted as each encompasses a part of the other two. These three levels of action should be seen as three possible approaches to society, each encapsulating an irreducible level of the human experience. Society results of the interaction of the two and the framework for action that they provide.

\subsection{Linking the Different Scales}

For an actor, linking the three levels of human experience is a delicate operation, one that requires specific skills, giving rise to power struggles and domination. 
It consists of configuring the four dimensions of territory identified earlier (the dwelling, social, functional, and commercial spaces) into working arrangements. In a modern world characterized by the differing speeds at which we move, forging this link has become a key task that, for actors, is a constant exercise.

Many great examples can be used here. For instance, we expect a jobseeker who finds a job far from home to find a way to accept the position, regardless of his or her personal situation (in Switzerland, it is the law). Similarly, an executive sent to Tokyo for three months to train a team in a new software must, from his company's viewpoint, be willing to meet this demand, regardless of the constraints of his private life (as a father or as partner in a couple in which both individuals work, for instance). Along these same lines, in a shared custody divorce scenario, both parents must find residences suitable for hosting the child or children, despite their own personal goals. A family that wants to live in town must find a residential solution outside the mechanisms of the real estate market. In all of these cases, motility and the way it is transformed into movement and/or mobility is an attempt to solve the issues and tensions that arise from the discrepancy between the three levels of human experience in a context where leeway is often limited. These tensions are reveling of an environment's receptiveness. ${ }^{1}$

By linking the three levels, several strategies aimed at reducing these issues and tensions become apparent:

Dissonance leading to resignation. In this first case, the possible arrangements of the four dimensions of the territory allow actors to realize their plans only with great difficulty. Actors therefore must scale down their goals and lower expectations to escape this catch. Cécile Vignal's study on mobility arrangements subsequent to the relocation of production for a factory in a small town in the east of France aptly illustrates this phenomenon (Vignal 2005). While some adapted easily to the multi-residential or long-distance commuting solutions they were forced to adopt, others preferred to leave their job in order to maintain local ties; others divorced in order to keep their job. In either case, refusal to reconcile the four dimensions of environment is itself a form of resignation.

Shaping leading to conformity. The socially valued, preferred arrangements among the four dimensions of the territory serve here as a kind of cookie cutter when it comes to making decisions. This second process is common when a "good life"is defined by society's prevailing models of success. Ownership of a single-family home (once one has a family) is undoubtedly emblematic of this. Many families in fact comply with such values for these reasons alone, and not because it is truly their aspiration (Kaufmann 2002).

\footnotetext{
${ }^{1}$ We must differentiate between tensions among the different levels and the conflicts that arise within each level which, strictly speaking, are not our concern here. By this we mean the personal conflicts arising from cognitive dissonance that can lead, in their extreme, to suicide. Interpersonal conflict leads to disputes that can be settled by law; societal conflicts have to do with political controversies and are typically settled by laws and institutions and, in extreme cases, by war. The tensions among the three levels are essentially characterized by the fact that they are not governed by the law as they tend to fall outside of it rather result from social justice.
} 
Alternative plans leading to innovation. In this third arrangement, the limits of the possible arrangements of the four dimensions are pushed and ultimately rejected. Often, the energy spent looking for new strategies or arrangements gives rise to this third scenario. Pugnacity and the time and effort spent on difficultly realizable residential aspirations are good examples of this. The collective movement behind squatting in Geneva (a pioneer project stemming from the desire to rethink the privatization of housing that was made "official" by a partnership with the local authorities in the 1990s based on contracts of trust) is yet another. This movement has led to new forms of collective living since the start of the new millennium (Pattaroni 2006).

These different arrangements are central to actors'-both individual and collective satisfaction (Schneider et al. 2002; Kaufmann 2011) and thus have an impact on their dynamism.

\section{Conclusion}

In this chapter, we have looked at the profound transformations urban areas are undergoing based on the types of movement and mobility found in them.

Reestablishing the state's authority with regard to the transformation of cities and regions in this context implies regulating the motility of different actors. In order to do so, it is essential understand the logics of action that underlie actors' movements and mobilities beforehand. Actors have and use their highly specialized skills and creativity to appropriate technical systems, and to use them for personal and/or collective projects. The major challenge when it comes to regulating motility, more so than policies, therefore consists in having tools that are capable of identifying, describing, and analyzing motility and its social and spatial implications to develop means for controlling it-ideally without adverse regional, economic, social, or environmental consequences.

A return to the underlying logics of action that govern mobility and movement naturally leads to an exploration of their political and social consequences, thereby allowing us to analyze the structure and functioning of modern societies in greater detail. In other words, we must consider not only changes in lifestyles (pluralism, individualism, etc.), but also the new technical and social forms that drive them (the development of economic structures, technical innovation, and changes in customs) and ensuing issues (new forms of inequality, opportunity, physical tensions, socio-cultural conflicts, etc.).

In this endeavor, it is important not to limit analyzes to the transportation field and telecommunications systems which, be it objects or individuals, are more often than not a by-product of human activity. Our investigations have clearly demonstrated that actors' motility is largely based on domains that are only indirectly linked to transportation or telecommunications. Regulating mobility thus requires impacting things such as cultural dynamism, early childhood policies, the social diversity of neighborhoods, and many more. 


\section{References}

Ascher, F. (1995) Métapolis ou l'avenir des villes. Jacob, Paris: éditions Odile.

Bauman, Z. (2000). Liquid modernity. London: Polity.

Dietrich, W. (1990). Mobilité et renouvellement local de l'emploi. Thèse EPFL no 831: Lausanne.

Duchêne-Lacroix, C. (2014). Habiter plusieurs logements habituels: éléments conceptuels et typologiques d'une pratique plurielle. In P. Hamman, M. Blanc, C. Duchêne-Lacroix, T. Freytag, \& C. Kramer (Eds.), Questionner les mobilités résidentielles à l'aune de la multilocalité (pp. 33-60). Strasbourg: Neothèque.

Gibson, J. J. (1979). The ecological approach to visual perception. Boston: Houghton Mifflin.

Green, A. E., Hogarth, T., \& Shackleton, R. E. (1999). Longer distance commuting as a substitute for migration in Britain: A review of trends, issues and implications. International Journal of Population Geography., 5, 49-67.

Joly, I., Littlejohn, K., Kaufmann, V. (2006). La croissance des budgets temps de transport en question: Nouvelles approaches. Final report. LET—LaSUR: Lyon, Lausanne.

Kaufmann, V. (2002). Re-thinking mobility. Aldershot: Ashgate.

Kaufmann, V. (2008). De l'espace au temps: ces mobilités hybrides qui transforment la ville. In F. Paulhiac \& Y. Chalas (Eds.), Actes des deuxièmes rencontres internationales de l'urbanisme de Grenoble. Lyon: Collections du CERTU.

Kaufmann, V. (2011). Re-thinking the City. Routledge/EPFL Press: London, Lausanne.

Kennedy, P. (2004). Making global society: Friendship in networks among transnational professionals in the building design industry. Global Networks, 4(2), 157-179.

Kesselring, S. (2005). New mobilities management. Mobility pioneers between first and second modernity. Zeitschrift für Familienforschung, Heft, 2, 129-143.

Larsen, J., Urry, J., \& Axhausen, K. (2005). Mobilities, networks, geographies. Aldershot: Ashgate.

Le Galès, P. (2002). European cities, social conflicts and governance. Oxford: Oxford University Press.

Lévy, J. (1999). Le tournant géographique. Belin, Paris.

Meissonnier, J. (2001). Provinciliens: les voyageurs du quotidian. Paris: éditions de L'harmatta.

Mokhtarian, P., \& Chen, C. (2004). BTT or not BTT that is the question: a review and analysis of the empirical literature on travel time (and money) budget. Transportation Research Part A, 38 (9), 643-675.

Pattaroni, L. (2006). La ville plurielle: quand les squatters ébranlent l'ordre urbain. In M. Bassand, V. Kaufmann, \& D. Joye (Eds.), Enjeux de la sociologie urbaine. Lausanne: Presse Polytechniques et Universitaires romandes.

Pierre, M. (2006). L'invention d'un système bi-résidentiel. Un choix de vie pour couple retraité aisé, Les annales de la recherche urbaine, 100, 107-113.

Schneider, N. F., Limmer, R., Ruckdeschel, K. (2002). Mobil, flexible, gebunden. Familie und Beruf in der mobilen Gesellschaft, Campus, Frankfurt am Main.

Tarrius, A. (2000). Nouvelles formes migratoires, nouveaux cosmopolitismes. In M. Bassand, V. Kaufmann, \& D. Joye (Eds.), Enjeux de la sociologie urbaine. Lausanne: Presses polytechniques et Universitaires Romandes.

Van Wee, B., Rietveld, P., \& Meurs, H. (2006). Is average daily time expenditure constant? In search of explanations for an increase in average travel time. Journal of Transport Geography, $14,109-122$.

Vignal, C. (2005). Injonctions à la mobilité, arbitrages résidentiels et délocalisation de l'emploi. Cahiers internationaux de sociologie. CVIII: 101-117.

Vincent Geslin, S., Kaufmann, V. (Eds.) (2012). Mobilité sans racines. Plus loin, plus vite... plus mobile. Paris: Descartes \& Cie.

Wiel, M. (1999). La transition urbaine. Spirmont: Margada éditions. 


\title{
Populations and Rhythms in Contemporary Cities
}

\author{
Gabriele Pasqui
}

\begin{abstract}
The chapter focuses on the importance to consider mobility practices characterising contemporary cities in the perspective of urban populations. Starting from the interpretation of mobility practices by different populations in terms of urban rhythms, the chapter analyse temporary populations as "groups of subjects that, temporarily and intermittently, share practices of daily life". Urban populations, exactly because of their variety and considering the impossibility to constrain themselves into logics of identity and representation, may in fact generate new claims, but also new common goods, without necessarily operating as intentional actors in public policies. In this perspective, it is crucial to construct mobility policies that match up to the degree of mutation and complexity of the city, of the territories and of their relationship with living worlds, and with the radical irreducibility and plurality of spatial and temporal patters of urban populations.
\end{abstract}

Keywords Urban rhythms • Urban populations • Pluralization

\section{Rhythm: Time of Movement}

What is the "time" of movement? To what extent can mobility practices characterising the contemporary city be conceived as temporal practices?

The first claim I would like to put forward is that the time of urban movement is rhythm. This means that any interpretation of mobility practices should lead us to consider the nature and characteristics of urban rhythms.

In an essay written more than twenty years ago, which admirably anticipated much of the more recent literature on liquid and flexible modernity, the Italian sociologist Alberto Melucci addressed the radical transformations occurring to the archetypes of time in our era. Melucci underlined the contradictions between linear and social time, vis-à-vis the "multiple and discontinuous" time of subjective

G. Pasqui $(\bowtie)$

DAStU, Politecnico di Milano, Milan, Italy

e-mail: gabriele.pasqui@polimi.it 
experience (Melucci 1996). The former is characterised by the continuity and uniqueness of events, which follow each other in a single direction of travel and is therefore irreversible. The latter, on the other hand, is both cyclical and simultaneous; it is the time of our day-to-day experience, featuring its own variable rhythms. In contemporary cities, forms and practices related to mobility assume a rhythmic nature characterised by the repetition of our daily practices.

In his last book Rythmanalyse, Henri Lefebvre put great stress on the central position occupied by the rhythmic dimension in the interpretation of everyday experience, and more broadly with regard to analysis of contemporary society (Lefebvre 2004). The literature on urban studies then explicitly addressed the issue of the city rhythms in relation to the changes affecting the very nature of urbanity (Amin and Thrift 2002; Henckel et al. 2013; Smith and Hetherington 2013).

But what do we mean by rhythm? In general terms, rhythm is repetition within diversity. Accordingly, rhythm here is understood as the very condition of possibility of linear and chronological time. Time can emerge as a measure of distance only through rhythm. Distance already contains and is itself rhythm, and it is here that time finds, literally, space and place (Sini 1989). From this perspective, practices related to everyday experience are the first and foremost rhythmic practices; starting from all practices related to movement. Even the simple act of walking defines a rhythm, through the alternate setting down and raising of the legs and the entire body. On the other hand, rhythm has not only to do with movement: stationary urban activities, too, are characterised by their own rhythms, with regard to practices related to work, consumption and free time. As noted by Amin e Thrift, cities are primarily defined by rhythms. "The rhythms of the city are the coordinates through which inhabitants and visitors frame and order the urban experience" (Amin and Thrift 2002, p. 17).

If we look at the city from the perspective of everyday life, the experience that each of us has of the city is a rhythmic one. This proves to be the case with regard to the day cycles (day and night, light and darkness, work and rest and sleep and waking) and the cycle of the seasons, but also in relation to the events in the calendar that year after year mark the life of a city (national holidays, vacations, fairs and big showcases or sporting events). To live in a city is to move not only in space, but also within its plural rhythms that define for us the conditions of possibility and the constraints of our daily doings.

When we observe rhythm from a phenomenological point of view, we are dealing with the return of the same (rhythm is always connected to the upbeat and the downbeat) in its diversity; with the repetition of everyday life practices as part of their constant transiting.

From this viewpoint, practices related to movement are no exception. They, on the one hand, build their own rhythm and through such rhythm define their own maps and their peculiar space-time geographies. On the other hand, they intertwine with already existing and diverse rhythms that are knitted together and that sometimes overlap.

Rhythmic is the movement (systole/diastole) characterising the breathing of the city. Because cities breathe, and it is in this breathing that the conditions of 
possibility of rhythm for the different populations which inhabit or go through them open up. Here, we will confine reference to the analyses of movement describing and mapping daytime and night-time rhythms, which stress the linkage between rhythms and geographies (Henckel et al. 2013).

Rhythmic are the patterns of the movement of a large number of urban populations, not only those of commuters, but also of all people that experience the city only in some parts of the day, or certain periods of the week, the month or year. During the weekend, in summer months, cities empty. In the length of time between academic terms, non-resident students go back to their hometowns and cities. Migrants and refugees spend shorter or longer period of time in cites because of policy choices and in view of complex life plans.

Rhythmic is the organisation of activities and functions, which in turn informs the very structure of urban spaces. From this angle, the key turning point explored by an extensive multidisciplinary literature and discussed in many contributions contained in this volume has to do with the transition from the industrial to the contemporary city. Here, activities and functions cluster together over time in plural and disorderly ways, giving rise to trajectories that seem increasingly to depart from the rhythm of daily commuting between home and work or home and school (Stavrides 2013).

Clearly, such journeys are still paramount, both quantitatively and qualitatively, but they can no longer be considered the sole spatiotemporal thread making-up the city rhythm. Tracing and mapping urban rhythms is not a simple task, as these are becoming more complex and intertwined with life practices, which are themselves becoming increasingly disorderly (Mareggi 2013). It is not only the crisis of the Fordist model related to the organisation of production we are dealing with. More radically, it is a temporal and spatial pluralisation that challenges and calls for radical redefinition of what we mean by urban; also in light of cultural and social changes and of ground-breaking technological innovations (Brenner 2014; Soja 2000).

In this context, thinking of movement in the city means recognising the rhythms that characterise it, which overlap with each other creating a polyrhythmic pattern. The analyses of movement contained in this volume attest to the fact that new movement practices are in fact characterised by their breaking free from the singularity of the urban rhythm, (which had been a prominent feature of the industrial twentieth century city). They are distinctive in that they generate a polyrhythmic pattern giving rise to the trajectories of spatiotemporal practices that shape everyday life.

\section{The Passing by of Urban Populations}

How can we describe the rhythm of movement characterising the contemporaneity city? The second hypothesis I propose is that a fruitful perspective to interpret mobility practices in contemporary cities, lies in observation and interpretation of urban populations. 
The understanding of urban population that I wish to articulate here is based on the observations of the Italian sociologist Guido Martinotti, but it differs from them with regard to one fundamental feature. As we know, from the sociological point of view, Martinotti's contemporary city encompasses four types of populations that perform their activities (living, working and consuming) in different areas in or outside the city (Martinotti 1993, 1999). Simplifying Martinotti's analysis to the extreme, we could say that Residents work and "consume" in the city, and may or may not work there. Commuters live elsewhere, but definitely work in the city and may also perform activities related to consumption there. City users come from outside, do not work in the city but perform activities related to consumption. Finally, businessmen work and consume in the city without living there. If the city of the residents and commuters is that of the first generation, consumption is of the second generation and businessmen are of the third generation. The interaction between the four populations is then destined to shape the future of the large metropolitan regions around the world, also through the generation of new conflicts and government challenges (Martinotti 1992).

The remarks made by the Italian sociologist can be seen as a good starting point. They legitimise the assumption that urban populations stand out among the most distinctive features of the changes occurring to the contemporary city. Moreover, Martinotti explicitly foresaw some crucial questions related to interpretation of the aporetic and ultimately paradoxical nature of urban populations and in the first place the complex relationships that populations entertain with time and with the different dimensions of temporality that are at play. Second, the manifold relationship with space, that becomes the subject matter of activities (of everyday life practices) and which can no longer be understood as a neutral platform. Third, the link between population and policies, of which they become the focus of, in relation to the use and abuse they make of the city. Fourth, the disarticulation between places of life, vis-à-vis the realm of political representation. Finally, there is the coexistence of different and potentially conflictual practices related to use between populations, in both space and time.

The development of Martinotti's analyses, as for example done in the writings of Nuvolati (2002), allows us to draw a more articulated and complex portrait of urban populations. Without getting bogged down in details, we can observe that the writings of Martinotti and Nuvolati offer a number of important insights with regard to the considerations presented here. The work of Martinotti, in particular, paves the way to an understanding of some phenomena that are key in the interpretation of the contemporary city; phenomena that cannot be attributed to traditional analytic categories.

Thinking of the contemporary city through the lenses of urban populations in fact enables us to reflect adopting an interesting perspective akin to what Bernardo Secchi has recently referred to as "the new urban question". This underlines how new social disparities have a strong spatial connotation, precisely stemming from the phenomena linked to the rearticulation of the urban populations in space and to their "access" to movement. According to Secchi, there are three aspects that lie behind the new urban question: the intensification of spatial disparities, which 
redesigns the geography between the city of the rich and the city of the poor; the aggravation of risks related to climate change and the dilapidation of natural and environmental resources; and the growing inequality among populations with regard to their capacity to move (namely their motility), understood as a form of citizenship (Kaufmann et al. 2007).

Each of these aspects, forming part of the new urban question, is characterised by the central role played in them by urban populations; with the latter understood as forms of densification of socio-spatial practices in the contemporary city.

There are therefore at least two reasons to leave Martinotti's approach behind and proceed on a different path. To start with, and indeed with all due caution, for Martinotti (and his school of thought), there is a recognisable relationship between urban rings (i.e. between a given description of the urban form) and populations inhabiting them, which operates according to a spatial logic that moves from the urban core areas to the outer regions. Second, Martinotti's approach does not fully account for the fundamental issue of "multiple belonging", that is to say, the possibility for an individual to belong to more than one population. The Italian scholar Pier Luigi Crosta commented on Martinotti's approach suggesting that his perspective ultimately assumes a specific viewpoint, (which is that of public administrations that have to think in terms of the diverse categories of city-users). "The coming into being of the "city users" concept occurs, in fact, "on the side on the city", in that (Martinotti's) question asks: "what kind of people use the city?", rather than "what kind of city (or region) is used by people?" The difference lies in conceiving the city as something given (and its administration as a "given"), and the "migrant" populations (which move in the region) only as migrants (different, temporary, cyclical, occasional...). The obvious question that is not formulated is: "what else do they do, and where do they do it, those who migrate to many places and take care of themselves? [...] Not to raising such a question is tantamount to selecting the single viewpoint of the administrations" (Crosta 2003, p. 15).

Multiple belonging means, simply, that each of us can belong, because of choice or necessity, to more than one urban population. We can be students commuting in and out during weekdays, and during weekends, become part of the youth population adhering to a musical subculture, who in view of this uses and moves across the city along well-established routes. We can be activist cyclists, taking part in initiatives organised by "Critical Mass" (Carlsson 2002) and mediating our relationship with urban space and with movement with use of a bicycle, while at the same time fully belonging to the night crowd which has its own iconic places.

If we assume the perspective of multiple belonging, we cannot accept that there are only the four metropolitan populations that Martinotti conceives as sociological categories to which any individual could in principle be attributed to. Phenomenological observation of the rhythmic practices of urban populations prompt us to conceive populations not in terms of categories, but rather as a bundle of practices, and thus potentially open to a temporary and partial "transit" of different individuals at a variety of times and in different localities.

My definition of urban population therefore differs on at least three fundamental issues. To start with, urban populations build their own identities and together 
generate and regenerate identities for individuals belonging to them. Belonging to a population can indeed be more or less intentional. Sometimes, it is the result of a choice (where the population is configured as a community of practice). Sometimes, it is the result of a number of bonds and constraints that limit the subject's range of action. In other terms, each individual is in a given relationship to others, enveloped in practices that characterise a population, and in belonging together to these practices the individual develops as part of his/her identity, which is therefore fragmented, contingent and partial, precisely because of the transient nature of the practices that we considered in the first section. Hence, it is through practices that individuals and populations belong together and shape each other as part of their transient identity.

Second, this belonging to an urban population always features the hallmarks of contingency and temporality. In everyday life practices that characterise urban populations, we can actually identify the thickening and the thinning of interactions along a line that takes in the pluralization and the virtualisation (which, by no means implies a lack of spatial differentiation) of the living worlds.

It is at this point that the paradox of sharing unfolds, namely the aporia according to which belonging to a population is never configured as a form of sharing, even when the single individual joins the other precisely in view of what happens to be done together. The community of populations, if it can still be called so, is without communion, without sharing, without any form of co-fusion, and nonetheless it generates strong bonds. Finally, as the individuals' belonging to populations can be plural (we belong to more than one population), this, from a spatial as well as temporal point of view, is always temporary and selective.

We have already noted how the time of populations configure itself in relation to the rhythm of the city. In other words, the time experienced by urban populations is a construct that draws a specific polyrhythm. Such "polyrhythmicity" implies a linkage between populations' movements, pace and temporality. The spatialisation of urban population flows is not merely a matter of "thickening" — of "lumps" that get created and that in turn constitute places (permanent or temporary) in which social practices (related to work, care, consumption, fun, but also to waiting and to movement itself) are nested in space. It is also a matter of speed and intensity-speed of movements and intensity of flows, which are themselves intertwined with the nature of the practices.

In short, as already anticipated, what we are dealing with is (not only) time, but more than anything else rhythms - rhythms of daily or weekly routines, work and care rhythms, rhythms of our own body and the body of the world.

Urban populations therefore give us rhythms that are spaces; spaces that are velocity and intensity of movement. The rhythm of children or the elderly; the rhythm of foreigners, who are constantly on the move and hang out in specific places, often colonising and taking possession of them. The youngsters' rhythm on weekend nights; the rhythm of new workers: all of these rhythms mark space, twist it (as on the shrunk or stretched out maps showing travel times), they fluidify and thicken it with variable intensity.

An interesting avenue, running in this direction, starts from the remarks on deterritorialization and reterritorialization made by Deleuze and Guattari. In One 
Thousand Plateaux the two French thinkers draw cartographies (Deleuze and Guattari 1980), consisting of plain level fields (plateaus) and layers (accumulations, coagulations, sedimentations and wrinkles) on the body of the earth. On the layers, concatenations are at work which are always territorial and which are themselves set in a relationship with deterritorialization phenomena.

We cannot follow Deleuze e Guattari along their path. It is just worth noting that deterritorialization and reterritorialization are phenomena related to flow, to the intensity and pace of the populations (see the chapter contained in One Thousand Plateaux titled "1730. Becoming-Intense. Becoming-Animal. BecomingImperceptible"). Deleuze e Guattari write: "The territory itself is inseparable from vectors of deterritorialization working it from within: either because the territoriality is supple and "marginal", in other words itinerant, or because the territorial assemblage itself opens onto and is carried off by other types of assemblage. Second, deterritorialization is in turn inseparable from correlative reterritorializations. Deterritorialization is never simple but always multiple and composite: not only because participates in various forms at the same time, but also because it converges distinct speeds and movements on the basis of which one may assign at a given moment a "deterritorialized element" and a "deterritorializing" element" (Deleuze and Guattari 1980, p. 509). What does this mean? It means that the deterritorialization of the populations is never pure; rather, it is interweaved with local reterritorializations, which themselves bring into play new cartographies, new localised "diagrams". It is a matter of rhythms and speed, hence of a swinging temporality that goes beyond spatiality. It is in the chiasmus between multiple temporalities and unsteady spatialities that populations and their practices related to the use of urban space can be found.

In the practices of rhythm, populations also build their space. The latter therefore is not neutral and isomorphic. On the contrary, it is made of places that constitute themselves as such in light of the population's behaviours. Populations produce geographies and cartographies: geographies since they mould space, which is together a constraint and an opportunity; cartographies since they depict space in maps (real or virtual) that are produced and used by the populations themselves.

The populations' space is thus a space that is built and "framed" by phenomena that are more or less intentional, connected to practices of use, made of resistances and fractures. It is a deformed space, different from that of planning and from that of physical and political geography. It is a space that, marked and streaked as it is by practices, absolutely cannot be reduced to administrative boundaries. Hence the paradoxes of time and space give us a temporality that is rhythmic and intermittent; a constructed spatiality that defines variable geographies. Within this temporality and spatiality, we can read not only innovative processes characterising ways of experiencing the contemporary city (from the invention of public space to the fragmentation and conflict linked to collective uses), but also more traditional phenomena characterising the urban experience, beginning with those related to movement.

Starting from these partially paradoxical aspects that characterise urban populations, we can tentatively put forward the following definition, which should be 
first and foremost understood as an operative definition (i.e. as a strategic construct, in the sense given to this term by Michel Foucault). Urban populations can be looked at as sets of individuals who, in a temporary and intermittent way, share everyday life practices; who constitute themselves as subjects of such practices and who generate specific spatiotemporal geographies according to the hooks and resistances of the "champs" within which their practices are transiting.

\section{Movement of Urban Populations}

Adopting this definition of urban populations, we can reflect more in depth on the movement characterising them, starting in this instance from one hypothesis: some of the features characterising polyrhythmic movement in the spaces making-up the city are a direct consequence of the complexity and plurality of urban population practices, as I have tried to define them.

We have already seen that one of the distinguishing feature of urban populations is movement (Balducci et al. 2011). Mobility phenomena stand in effect as one of the epiphenomena of the contemporary city, not only in relation to the movement of people and goods from one point in space to the other, but also with regard to the reinvention of time that the multiple mobility phenomena engender. Any description of the contemporary city cannot fail to underline the centrality of movement as a key feature of the urban experience (Kaufmann 2002; Urry 2007). People and populations move about for many reasons; they undertake shorter or longer trips, according to routines or exceptional circumstances, for the most diverse reasons. Several scholars have highlighted how little this pluralisation of the forms of movement is captured by official statistics, and therefore how difficult it is nowadays to gain access to up-to-date reliable data on different movement patterns (Pucci et al. 2015).

On the other hand, mobility is nowadays characterised by an extraordinary variety of opportunities and movements. Clearly, we commute to go to work or to get where we study, but we also move to consume and for leisure purposes, to meet other people, to move between houses in which we divide our lives.

In short, populations are on the move. They move along trajectories that are more or less regular, more or less elliptical and more or less wide-ranging. At the same time, they also stand still, they move in tight spaces, and have a reduced range of action. Accordingly, stillness can be framed as a "defective mode" of movement, which can be seen as the proprium of the urban experience and more specifically of the action of populations.

Let us try to single out some of the constitutive features of the movement of urban populations, adopting as a point of reference a series of empirical investigations undertaken during the past few years in the Milan metropolitan region.

First of all, as already said, urban populations' movements are rhythmic in character and are connected to a polyphonic multiplicity of urban rhythms. Commuters go from their homes to places of work according to a daily rhythm, 
which relates to the organisation of work. The youngsters taking part in the nightlife move among the areas of the city where the activities related to the so-called "movida" are denser. Skaters and other youth populations cut across the city to reach places where the activities characterising them are concentrated. Some foreign populations move in the urban region during weekends to get to public places (parks and gardens) where parties and other collective activities are organised. People attending events (in Milan for example, there are the Furniture Exhibition and the Fashion Week), move among the different locations where the event is taking place. These are just examples, which however bring to the fore the polyrhythmic nature of movement, namely the fact that the movement of urban populations is characterised by a specific temporality that cannot be reduced to that of linear time.

Second, urban populations' movements take on an erratic nature, drawing peculiar spatiotemporal trajectories. Precisely because the movement of urban populations display the features of being intermittent, temporal and contingent, the movements of individuals who are part of a population are characterised by marked pluralisation. To move within an urban environment means drawing specific geographies, which give rise to coalescences connected to non-linear practices and trajectories. Urban populations linked to specific life styles and consumption habits, for example, define specific places where certain activities are clustered: places of commerce or leisure, where members of different populations temporarily share and exchange. This is also true of more traditional populations, such as commuters. Railway stations and train coaches become physical spaces where different shared practices coalesce, even though not necessary intentionally. The movement of urban populations, precisely on account of their contingent and temporary nature, displays the typical features of erraticism.

Finally, urban population movements are typically characterised by accelerations and decelerations. In other words, they are movements that display stronger or weaker intensity in relation to the practices that characterise populations in a specific time-space segment. The temporal trajectories studied many years ago by the space-time geography are therefore characterised by an intensity of movement that varies over time (Hägenstrand 1975). Initiatives such as that of "Critical Mass" appear from this point of view paradigmatic. The intensity of movement of the many cyclists that cruise along the city streets in the evening hours is dependant upon the specific practices that define the nature of the urban population.

Essentially, the movement of urban populations and that of the single individuals who are part of them in a more or less temporary and contingent way, has a rhythmic nature. It is neither linear nor erratic, but rather displays intensities that vary in relation to geographies linked to the specific nature of the practices characterising each population.

Ultimately, many of the phenomena characterising mobility in the contemporary city, also as debated in this volume, can fruitfully be considered in view of some urban populations' features: rhythmicity, contingency, pluralisation of practices, definition of new geographies and new mappings of the city. 


\section{Mobility Policies and Populations Policies}

What are the effects on public policy, and more specifically on mobility policies, that such an understanding of the rhythmic movement of urban populations bring about?

On the basis of the points made so far, we can consider finally, the multifaceted and evasive nature of a perspective that we could call policy (and policies) for the urban populations. Multifaceted, as such policies cannot be reduced to any traditional kind of formalisation, and ultimately challenge the ordinary way through which public policy definition and implementation occurs. Evasive, since in any case it is sui generis policies we are dealing with, policies that cannot be linked to a single domain and that resist any form of sectoral and territorial classification.

Population policies, from the perspective of practices adopted in this chapter, cannot simply be policies for urban populations, but must also be polices produced (directly or indirectly, intentionally or less so) by urban populations. The nexus between populations and movement practices becomes, then, an exemplar terrain on which to reflect both on the efficiency and possibility to produce and reproduce public and urban common goods "via policies", and indeed on the quality and the meaning of the democratic process.

If urban populations are a strategic construct effective in thinking in terms of urban policy, this is also due to the significance of the urban populations' viewpoint in the construction of an urban agenda, that is to say, of the issues that in a public arena are deemed to be key by policy-makers, the media and the citizens.

The centrality of the mobility theme (and of the problems stemming from urban congestion and pollution), stands as a challenge that to date has proven almost untreatable through public policies, and as a crucial crossroads for the redefinition of a new citizenship profile (Estèbe 2008). This appears to be the case in large metropolitan areas in western countries, as well as, and perhaps even in a more acute way, in the new Asian and South American megacities.

As we have seen, the spatial and temporal articulation of movement forms and practices is in fact strictly connected to the populations' pluralisation phenomena related to the variety of movement patterns and rhythms specific to individuals and groups. Individuals and groups are themselves characterised by having complex relationships with mobility (Amin and Thrift 2002).

The right to mobility and the potential trade-off between mobility and quality of life (in light of pollution and congestion phenomena that represent a formidable problem that keeps growing) is therefore a central item in the city political agenda. This trade-off brings into play the phenomena related to the spatial and temporal articulation characterising urban population practices (i.e. the extension of movements to cover the entire length of the day and the proliferation of the rhythms characterising them, but also the impossibility to mainstream defined movement trajectories with regard to their rationale as well as the means of transport utilised).

Once we assume the viewpoint of urban populations, the issue of mobility, from a functional point of view as well as from a citizenship perspective, is then, 
articulated and expressed in a radical, aporetic and conflictual way. Also in light of this fact, the theme of urban populations policy can be seen as a litmus test, precious to reflect more generally upon the critical issues and potentials of urban policy.

The cumbersome presence of urban populations within the public agenda has deep roots lying in the radical breakdown of the ordinary principles of territorial sovereignty, namely of the usually one-to-one relationship between exercise of power and the government of an institutionally delimited geographical space.

This is not only about globalisation phenomena and the new contradictions between local and global. More simply, it has to do with the "voting paradox" that Guido Martinotti referred to, whereby urban populations live substantial parts of their lives and use public services in cities (controlled by local authorities) of which however they are not residents, nor vote there (Martinotti 1992).

There is no need to point to the demand for urban services generated by commuters that express their political rights in communities different from where they work. Suffice it to consider how in a city like Milan, sizeable urban populations such as non-resident students or the relatives of hospitalised people pose enormous new challenges in terms of accommodation and service needs of a temporary nature. Likewise, communities of practices related to youth habits required of the city, a set of services and facilities of a necessarily flexible and temporary nature against a supply that often proves inelastic over time and space.

Such examples are provided simply to show how the voting paradox calls into question the very concept of territorial representation. Even more radically, the urban populations' aporias and paradoxes show us that the problem is not limited to commuters or city users. It also encompasses urban populations who, through their intensive but selective use of the city in relation to a limited field of practices, place demands on urban policy in a way that cannot respond to any traditional notion of public interest.

Along this line, it is therefore possible to prompt urban policies observing them from the point of view of urban populations and in relation to some key dimensions, which also stands out as a potential agenda for a policy (and policies) centred on urban populations. They are dimensions strictly related to each other: the tie between representation and being represented; the centrality of everyday life; the attention to mechanisms related to the reproduction of common goods; and the perspective of habitability in the relationship between place-based policies and policies related to flows.

First, an urban populations policy cannot be reduced to a policy of representation for the reasons already mentioned, that is to say, the plural nature of territorial belonging that ties each of us to a multiplicity of places which are institutionally controlled and subdivided, delivering us de facto to a multitude of political constituencies. At the same time, it is also because territorial representation requires stability in the form of a series of preconditions (about interests, problems and worldviews) which the urban populations constantly call into question and overturn.

The link between city and policy hence needs to be reconsidered in view of this pluralisation, of this suspension of territorial sovereignty that detaches governors 
from the governed. The new and radical impossibility to reduce the problems of local government to problems "of" the local is therefore a key aspect of a wider difficulty experienced in defining and delimiting governmental activities within fixed boundaries. The very idea of territorial representation, the cornerstone of local democracy as understood in modern times, is called into question and with it the very concept of representation, which loses its necessary connection with the democratic rationale, without thereby gaining automatic access to a perspective centred on direct democracy.

In this context, we can understand how the subsumption of problems and queries raised (directly or indirectly, explicitly or implicitly) by urban populations aimed at city policies (and at urban policy) within the boundaries of new forms of representation (including more or less dialogical and inclusive forms of deliberative democracy) appears to elude the problem.

However, it is an illusion systematically pursued by (not only local) governments in their (not frequent) attempts to address the policy problems posed by urban populations. Such attempts are in fact largely made in the direction of redefinition of the traditional forms of political representation through the establishment of mechanisms of representation based on functional interests, in accordance with a model akin to that used in the social consultation between capital and work force. From here then, to come back to urban mobility issues, roundtables (national and local) are set up where commuter associations discuss with railway operators and other public transport providers.

In all the instances cited, we have devices aimed at building new modalities of representation based on a twofold assumption: urban populations can be represented through the construction of more or less traditional collective entities capable of bringing to the table, where institutions and other stakeholders sit, share queries and requests. The demands that populations place on institutions and politics can be traced back to the realm of social demands, along the path of a clear distinction between the producers and the consumers of policies.

Both such premises are almost entirely questionable. Although important, subjects representing (or pretending to represent) populations have features setting them aside from other, more traditional umbrella organisations (e.g. the trade unions). They are characterised by a marked volatility; they display clear signs of temporality and flexibility, and have at best a reduced capacity, which has to be constancy renegotiated to secure through clear mechanisms the representativeness of single individuals belonging to a certain population. For example, an empirical analysis of the commuters associations in Italy shows these to be very peculiar political actors, at least if considered within the traditional logic of the representation of vested interests.

On the other hand, many urban populations make no demands to politics; they neither directly nor indirectly express a social demand. In spite of this, because the practices that characterise them can generate public and common goods, they are often seen as key actors within the realm of public policies. Hence, in many instances deliberative logics become irrelevant, as simply there is nothing to decide upon. This is because policies are at most tasked with creating the conditions for 
"representation" (i.e. the visible presence on the urban scene through the creation of spaces, physical and institutional, and of freedom), rather than with representativeness.

The second dimension that it is worth considering is that of the link between urban policy and everyday life. Observed from the angle of everyday life, urban populations' practices exert pressure to calibrate policies in tune with what Amin and Thrift call the "everyday city" (Chapter "Mobility Practices as a Knowledge and Design Tool for Urban Policy"). The two authors describe their approach programmatically as an attempt to: "come close to the phenomenality of practices, without relapsing in a romanticism of the everyday, and of action for itself" (Amin and Thrift 2002, p. 21). This remark is important in that in light of it we can firmly state that the adoption of an everyday life perspective does not imply a refusal to tackle structural issues related to some of the crucial problems experienced by urban populations, starting with the problems arising over mobility.

Furthermore, to frame population policies as everyday life policies, also means considering more carefully the role that urban populations perform directly or indirectly, and more or less intentionally, as producers of common goods.

Urban populations, precisely because of the variety and paradoxes that characterise them, from the impossibility to reduce them to an identitarian and representative logic, to their radical dependence on the practices which they are subject to, can generate common goods (or evils), without thereby having to be intentional actors of public policies.

Individuals who belong to urban populations, according to this notion, should therefore not be understood as "policy takers" that make some demands on the institutions and politics, but rather as implicit makers of "factual policies", as producers of urban common goods.

Ultimately, if we question policies from the angle of their possible relationship with ordinary practices (i.e. the fabric of day-to-day experience), and if we conceive urban populations as producers of common goods and not as users of policies, we understand how a changed perspective over the ordinary and traditional links between political-administrative space and "social events occurring in space" calls for a renewed capacity to embed experience into policy. It also calls for the need to ground the "what" and the "how" in the fine-grain texture of everyday life, exploiting the unregulated and unintentional mechanisms related to the regeneration of common goods.

With regard to urban populations, they comprise everyday makers (Bang and Sorensen 1999). This means that it would be useful to leave behind the logic of political demand as demand for policies, in order to move towards a radical politicisation of everyday life. If this is how things stand (everyday life is politics: it is the politics of the quotidian), and if we can thus view daily practices "as" policies, then it will be even more the case that the main issue at stake is not really the classic one of representation, but rather of the production and reproduction (through daily life) of (urban) common goods occurring as part of life practices (i.e. what people do).

From the everyday life perspective, finding adequate ways to represent the urban populations' widespread interests (which cannot be clustered) is not all that 
important. It is much more important to create the conditions (able to work on resistances and hooks, hence on real and virtual places and spaces) that make the action of everyday makers possible, and indeed their production of public goods through what they ordinarily do (and not exclusively in light of the role they play in the decision-making arena).

To conclude, populations policy is both a field of social practices that indirectly and unintentionally generate common goods and a set of permeability devices open to the threads of practice and capable of making their full articulation possible. However, what are, practically speaking, the common goods we refer to? What is the exposure of urban populations? How can population policies, also through careful work undertaken in term of policy design, be able to accrue (and not reduce) the production and reproduction of such goods?

An urban populations policy, understood for example as a policy for liveability in relation to movement practices, implies a continuous interplay between policies for places and policies for flows. In other words, between attentions to everyday practices, which have to do with objects, things, localities and the capacity to relate to the immaterial and virtual nature of new relationships among individuals and with regard to populations.

If we try connecting these general considerations on population policies to the theme of mobility, we can put it thus: A mobility policy that takes into account the perspective of urban populations must be, one of representativeness and not of representation, able to enhance and support the production of common goods in the context of movement practices, while improving the liveability of places of movement within the perspective of everyday life. In this way, we can attempt to construct a mobility policy (and policies) that match up to the degree of mutation and complexity of the city, of the territories and of their relationship with living worlds, and with their radical irreducibility and plurality.

\section{References}

Amin, A., \& Thrift, N. (2002). Cities: Reimagining the urban. Cambridge: Polity Press.

Ascher, F. (2004). Les sens du mouvement: modernité et mobilités dans les sociétés urbaines contemporaines. In S. Allemand, F. Ascher, \& J. Lévy (Eds.), Les sens du mouvement (pp. 2134). Paris: Belin.

Bang, H. P., \& Sorensen, E. (1999). The everyday maker: A new challenge to democratic governance. Administrative Theory \& Praxis, 21(3), 325-341.

Balducci, A., Fedeli, V., \& Pasqui, G. (2011). Strategic planning for contemporary urban regions. London: Ashgate.

Brenner, N. (Ed.). (2014). Implosions/explosions: Towards a study of planetary urbanization. Berlin: Jovis.

Carlsson, C. (2002). Critical mass: Bicycling's defiant celebration. Edinburgh: AK Press.

Crosta, P. L. (2003). Reti traslocali. Le pratiche d'uso del territorio come 'politiche' e come 'politica'. Foedus, 3(7), 5-18.

Deleuze, G., \& Guattari, F. (1980). Mille plateux. Paris: Minuit.

Estèbe, P. (2008). Gouverner la ville mobile: la ville en debat. Paris: PUF. 
Hägenstrand, T. (1975). Space, time and human condition. In A. Karlquist, L. Lundquist, \& F. Snickars (Eds.), Dynamic allocation of urban space (pp. 3-12). Westmead: Saxon House. Henckel, D., et al. (Eds.). (2013). Space-time design of the public space. Berlin: Springer.

Kaufmann, V. (2002). Re-thinking mobility. Aldershot: Ashgate.

Kaufmann, V., Berger, M., \& Joye, D. (2007). Motility: Mobility as capital. International Journal of Urban and Regional Research, 28(4), 745-756.

Lefebvre, H. (2004). Rhythmanaysis. Space, time and everyday life. London and New York: Continuum (or. ed. 1992).

Mareggi, M. (2013). Urban rhythms in contemporary city. In D. Henckel, et al. (Eds.), Space-time design of the public space (pp. 3-20). Berlin: Springer.

Martinotti, G. (1993). Metropoli. La nuova morfologia sociale della città. Bologna: Il Mulino.

Martinotti, G. (1999). A city for whom? Transients and public space in the second-generation metropolis. In R. A. Beaurgard \& S. Body-Gendrot (Eds.), The urban moment. Cosmopolitan assays in the late-20th century city (pp. 155-183). London: Sage.

Martinotti, G. (2005). Social morphology and governance in the new metropolis. In Y. Kazepov (Ed.), Cities of Europe: Changing contexts, local arrangements, and the challenge to urban cohesion (pp. 90-108). Oxford: Blackwell Publishing.

Melucci, A. (1996). The playing self. Person and meaning in the planetary society. Cambridge: Cambridge University Press.

Nuvolati, G. (2002). Popolazioni in movimento, città in trasformazione. Abitanti, pendolari, city users, uomini d'affari e flâneurs. Bologna: Il Mulino.

Pasqui, G. (2008). Città, popolazioni, politiche. Milano: Jaca Book.

Pucci, P., Manfredini, F., \& Tagliolato, P. (2015). Mapping urban practices through mobile phone data. Berlin: Springer.

Secchi, B. (2010). A new urban question. Territorio, 53, 8-18.

Sini, C. (1989). La storia, il tempo e la parola. Sini C. Il silenzio e la parola. Luoghi e confini del sapere per un uomo planetario (pp. 73-97). Genova: Marietti.

Smith, R. J., \& Hetherington, K. (Eds.). (2013). Urban rhythms: Mobilities, space and interaction in the contemporary city. New York: Wiley.

Soja, E. (2000). Postmetropolis. Critical studies on cities and regions. Oxford: Blackwell.

Urry, J. (2007). Mobilities. Cambridge: Polity. 


\section{Part II \\ Mobility Practices, Policy and Project}




\title{
Planning in Motion. The New Politics of Mobility in Munich
}

\author{
Sven Kesselring
}

\begin{abstract}
Since more of twenty years Munich is a sort of laboratory for the new politics of mobility in Germany. The so-called Inzell Initiative has been founded in 1995 to solve conflicts and to enable collaborative planning in the major city in the south of Germany. The initiative is a powerful stakeholder network which has been influencing and shaping local mobility politics significantly. The article reconstructs the rise of the network and analyzes its current activities in planning and envisioning the future of mobility in one of the most powerful economic metropolitan region in Europe. By doing so the author critically asks if there has been progress in transgressing the 'technocentric planning paradigm' towards a mobilities paradigm that puts social cohesion in the centre of attention instead of technological feasibility. In fast it seems that the new politics of mobility leads to a re-strengthening of technocentric visions, not at least through the rise of the smart city and mobility discourse.
\end{abstract}

Keywords Governing mobilities - Mobile risk society - Local networks • Future of mobility - Smart urbanism

\section{Introduction}

Twenty years ago, the City of Munich and BMW, the Bavarian car producer, started a deliberative platform on the future of mobility and transport in Munich, the so-called Inzell Initiative. It is a stakeholder network from politics, administration, science and civil society gathered under the slogan "Solving Traffic Problems Together". During the past twenty years this deliberative practice has become a key player that is shaping the mobility politics in the most important city in southern Germany. Its influence on strategical planning is significant. Many decisions in the

\footnotetext{
S. Kesselring $(\bowtie)$

Nürtingen-Geislingen University, Geislingen, Germany

e-mail: sven.kesselring@hfwu.de 
field of mobility and transport have been prepared and pre-structured through debates within some of the initiative's forums, working groups and plenary meetings.

Here I will discuss the initiative as a deliberative practice on a low level of democratic legitimacy but on a high level of efficiency in regional governance. For a certain time there was an optimism that Inzell could function as an innovative discursive practice to think-through and conceptualize the transition towards sustainable and a socially coherent politics of mobility on the local and regional scale. The analytical 'proof case' for this is the later discussed result of a discussion process organized by the Inzell forum dedicated to the future of mobility. It was headed by the then Lord Mayor of Munich ${ }^{1}$ and the result of this process has been called 'Vision Mobility 2050 in the Munich Area'. The future forum is one out of six forums which are dealing with questions of traffic flow, public transport, transportation demand management, and the relations between the city and its region.

The research on these topics grounding this article started in 1995 with some expert interviews. One was with a manager from BMW, who was responsible for environmental affairs. We talked about sustainable mobility and the role of BMW in the regional urban context. Again and again, he mentioned the Inzell Initiative which was named after a quaint village in Upper Bavaria. Today, two decades later, it has become an established term for planners, policy makers, and urban researchers also beyond Munich.

Inzell can be seen as a sort of role model for the attempt of cities to initiate sustainable mobility (Beck and Kesselring 1998; Hajer and Kesselring 1996, 1999; Kesselring et al. 2003; Kesselring 2001; Bauman 2000). To investigate the initiative I attended numerous meetings, forums and plenary sessions since 1996 to date. ${ }^{2}$ Besides active participation in the meetings more than 25 qualitative interviews with stakeholders have been conducted and analyzed. Also strategical meetings between scientists from the Technische Universität München, planners, public authorities and representatives from industry and NGOs have been part of the research.

\section{Discursive Practices and 'Smart Urbanism'}

Urban planning is a social rather than a technical process. This might sound like a truism. But in many stakeholder dialogues and planning debates it is often forgotten and neglected. Hajer therefore emphasizes that 'cities are social organisms. You cannot just 'pop the hood' and fix them' (Hajer and Daasen 2014, p. 43).

\footnotetext{
${ }^{1}$ Munich had elections for its city parliament on March 16th in 2014.

${ }^{2}$ For documentation see: http://inzell-initiative.de/links_infos/links_infos.htm (last approach on 07/06/2015).
} 
In contemporary planning it sometimes seems the most important question is how to get the best data and how to measure developments better and more efficiently. But the fixation on data often leads to disorientation. Actors often forget that planning needs good data but it is also a communicative process where the social interaction between stakeholders is the basis for the social construction of problems as well as solution strategies. Data itself has to be contextualized and can only be used for the good in society when cities have a concept how to organize and structure the process of consensus finding and decision making. The conceptual turn from government to governance as the guiding principle in modern politics and planning is also a strong lea for the involvement and participation of not only within the political system but also urban stakeholders and the urban societies in their complexity. In other words, cities need a specific social construction, a discursive framework where data can feed in and become politically meaningful. In Munich, for many years, this was the discursive frame of 'compact, urban and green' from the spatial development plan. It was the guiding idea for the interpretation and the judgement of data, trends and developments. This slogan, taken from the late 1990s urban development plan, grounded the so-called 'Perspektive München', the city's guidelines for sustainable development. But in the 'age of second modernity' (Beck et al. 2003) the plea for governance and 'collaborative planning' (Healey 1997) and for sustainable urban development becomes louder step by step. It stands for the criticism of modern technocentric planning strategies. A technocratic planning paradigm as it has been strong in the 1950s-70s has lost much of its legitimacy. Too obvious it is that it has been generating a huge amount of unintended side effects that cannot be handled by only applying more and better technologies. The car-oriented city (autogerechte Stadt, see Reichow 1958) stands paradigmatic for this. In the 'risk society' (Beck 1992) experts and politicians have lost much of their power to plan cities. The boost of new governance concepts on the regional and national scale reveals that it has become a political issue what is the right knowledge and who has the power to shape urban futures and conditions. It becomes more and more obvious that the economic, ecologic and social challenges of climate change, 'splintering urbanism' and global competition are threatening modern urbanism (Graham and Marvin 2001; Urry 2011). To sustain and survive better collaboration and institutional innovations in between city representatives, planners, stakeholders from industry and civil society and the citizens are unavoidable. Sustainability is a common good. It can only be provided in a common social process that is using existing capacities, expertise and resources (Healey 2012; Dryzek and Hendriks 2012). But instead of using the new institutional capacities and the chances that lie in new cross-sectoral and interdisciplinary collaboration it seems that politics and planning have lost even more orientation. Their approach to envisioning the future of cities seems to be blocked and the new belief in 'big data' and smart solutions could also be misleading and counterproductive. Paradox enough, and I will come back to this later, technology becomes again the bringer of hope to the cities. Not any more as large-scale systems but as smart technologies and intelligent transport systems that promise a new sustainable use of infrastructures and is supposed to generate rational behaviour. 
But maybe this is the re-birth of the old utopia transportation engineers are dreaming of: the free flow of traffic without any congestion and unnecessary losses of energy and time (Schmucki 2001). In fact, planners, engineers and politicians never had full control over urban space and its developments (Lenger 2013). It was rather an ideology but powerfully persuasive. As long as people and institutions believed in it, it generated some sort of certainty, legitimacy and orientation for planning decisions. The modernist discursive construction of the role of planning was instrumental and linear: first, problem identification; second, data collection (survey); third, thorough analysis; and fourth, functional plans for the implementation of solutions. Increasing complexities in planning through globalization processes and shrinking room for manoeuvre (in terms of financing, decision-making and regulations) made the modern concepts of problem solving progressively precarious (Beck et al. 2003; Castells 2008; Sieverts 2003; Flyvbjerg 2006). Modern strategies that consider planning as a straight road from problem identification to regulation and to the implementation of measures must fail (Beck 1988; Graham and Marvin 2001; Kaufmann 2011). In a world of globally networked urban mobilities the interdependencies of planning processes are constantly increasing. Urban planning becomes the art of dealing with uncertainties, insecurities and the unintended consequences of political, economic and societal decision-making (Bertolini 2010). Problems of 'decision' and 'boundary management' become crucial. Giving answers to these questions becomes a daunting task: Who, where and with whom shall decisions be made on the future of urban regions, their economic development, their infrastructural layout, their social structures and social cohesion? Insurgent urbanism fighting against the rebuilding and retrofitting of train stations in the inner parts of cities, numerous conflicts on airport expansions, etc. show that the power to define what 'good solutions' are and to decide on infrastructures have been spread throughout societies and urban spaces (Kesselring 2009; Deckha 2003, Stone 1989; Hou 2010, 2015). A flood of scientific literature on governance has been produced throughout the last two decades since Rhodes article on 'governance without government' (1996). Politics and planning as a common task, as a public-private partnership - not in economic terms but in terms of social responsibility — has become a sort of master frame, a striking metaphor for contemporary analyses of policy processes.

The fundamental transformations occurring in the political sphere have made risk, uncertainty and ambivalence unavoidable elements of contemporary politics and planning and key concepts in policy analysis (Fischer and Forester 1993; Beck et al. 1999; Hajer and Kesselring 1999; Kesselring 2001; Hajer and Wagenaar 2003). Instead of complaining about the loss of clear-cut centres of decision-making I consider this an essential condition of the reflexive modernization of modern societies and as the historical chance to develop new discursive practices for planning the future of cities. New governance models on the regional, national and transnational scale have brought about a 'politics of ambivalence' (Junge 2000) implying a wealth of opportunities when not neglected and pushed away. It is the paradox in this that the ambivalence as well as the opportunities derives from the same place: the diversity of the stakeholders and the competing power structures 
that come together. Modern boundaries between disciplines, systemic rationalities and epistemologies have been challenged by this and one of the main questions here is: Is this the rise of a 'reflexive rationality', of a new form of political culture, 'reflexive governance' that is able to deal with the new complexities instead of trying to eliminate and purify them? (Voß and Kemp 2006; Beck 2006).

Already in the late 1990s an emerging new governance network on the regional urban scale has been visible in Munich. It had its origins in the 1980s but came along and got strengthened throughout the works on the new spatial development plan Perspektive München, which has been developed since 1998. It is probably too strong to call it a stand-alone case. Much more it has been part of a general development towards the institutionalization of regional governance structures (Rhodes 1996; Jessop 1998) in many democratic counties. But it became a role model for interpreting institutional innovations and the social transformations from separated spheres of power (politics, planning, economy) towards a networked urbanism where diverse actors share the access to power and the responsibilities for initiating urban developments (Switzer et al. 2013). Also in Munich the field of planning on mobility and transport diversified significantly. Discursive practices such as the Local Agenda 21, the Perspektive München, a referendum on building new road tunnels (1996) or the new politics of biking in the city belong to the broad field of 'governing mobilities'. The deliberative stakeholder network of Inzell Initiative was the paradigmatic case for what has been called the 'new politics of mobility' (Hajer and Kesselring 1999; Kesselring 2001). In these publications sustainable mobility has been considered demanding for a fundamental reframing of transport and paradox enough, the least democratic practice of the Inzell Initiative actually proved as being the most relevant. The way in which the footing of mobility policy was changed came closest to the way in which mobilities researchers at this time tended to rethink mobility (Urry 2000; Kaufmann 2002).

At this time a significant semantic change had happened in the scientific debate on mobility from talking about transport to talking about mobility. This occurred not only within the scientific community of social science based researchers. Also among practitioners in administration, politics and business the term 'mobility' was on the rise while before transport was the dominating term and paradigm (Petersen and Schallaböck 1995; Banister 2008). Rethinking and reframing of mobility and transport was not offered much attention in transportation research and planning. In Germany the push rather came and still comes from social sciences (Canzler and Knie 1994, 1998; Tully 1999; Jahn and Wehling 1999; Bonß and Kesselring 2001; Rammler 2001; Canzler et al. 2008). But the strongest boost came from the UK (Lash and Urry 1994; Urry 2000). Today, the 'mobilities turn' in social science has significant influence also on transportation research and engineering. In the late 1990s the literature on the 'new mobilities paradigm' (Sheller and Urry 2006; Hannam et al. 2006) had not yet been published. But increasingly it became a story line on how to re-think mobility in terms of mobility potentials of people, organizations and institutions. The quantitative and positivistic paradigm of measuring movements from A to B in kilometres and cargo loads has been challenged by the 
question of how mobility contributes to social cohesion and integration and the quality of urban living conditions.

Books such as Urry (2000, 2007), Bauman (2000), Cresswell (2006), Canzler et al. (2008) and others had not been available, but the semantic change was already obvious.

In many ways the new politics of mobility in Munich was recognized as an interesting case worthwhile to be studied from different perspectives (Kesselring 2001; Baumann and Stuart 2012; Switzer et al. 2013). It seemed that a new urban mobility regime was on the rise that had a number of similarities with 'cooperative management regimes'. Those were defined as practices that 'display a certain continuity over time, include representation from a plurality of concerned interests and proceed from a clear identification of problems and participants' (Lafferty and Meadowcroft 1996, p. 258). In the Munich case a complex network has been built originating in the attempts of the 1980s to set up a framework for an improved traffic management (Kooperatives Verkehrsmanagment, KVM). From 1995 onwards the deliberative practice of the Inzell Initiative has been set up aiming for a better quality and consensus finding in local mobility politics and planning. This network was expected to reframe ecological problem definitions and solution strategies on a less technocratic level than it was the case within the so far predominant modernist planning paradigm and its incremental technocentrism. The Inzell Initiative was considered to have a potential for initiating an innovative local planning culture. In many ways it had a number of characteristics pointing towards a deliberative politics 'beyond left and right' (Giddens 1994). In line with Dryzek's 'discursive democracy' (1990) Inzell was considered to be a crucial deliberative practice and a trajectory for new thoughts on mobility and urbanism.

This paper aims at proving, that the institutional innovation of Inzell still works as a practice for the re-thinking of problems and strategies. Planning in the modernist paradigm means that 'money will be spent on 'default' options and will simply extend the way we thought about urban planning over the last century, making an outdated model more efficient' (Hajer and Daasen 2014, p. 13). But the 20th century modern agenda is deeply problematic. Cities like Munich are facing significant challenges, most of them somehow connected with mobilities. The urban metabolism needs to be reconfigured; the city's flows - energy, waste, people (as workers, tourists, residents, business travellers, deliverers, refugees, etc.), information and so forth - need to be sustainable, if its future shall be sustained. In a situation like this the Inzell Initiative could provide the space and the institutional capacities for re-thinking mobility and towards a sustainable future for the city.

But so far, the contemporary urban metabolism is highly unsustainable. Data on the sustainability of cities and urban regions show that there is no city in the world that can proclaim ability to sustain in the current form for more than one or two generations. In this situation much hope lies on the visions of 'smart cities'understood as smart technologies, smart energy and so forth. But the most concepts of 'smart cities' are again 'technocentric' (Miciukiewicz and Geoff Vigar 2012). Instead of thinking about social innovations and qualitative growth them underly the predominant ideology that an increase in efficient use of technologies will lead 
to a more efficient use of energy and to sustainable lifestyles and mobility practices. In this sense this paper investigates if there is progress in setting up an agenda beyond 20th century modernist planning. The Inzell Initiative in particular will be used here to learn more about 'smart urbanism' (Hajer and Daasen 2014) as a planning and design practice that re-conceptualizes mobility as a matter of social cohesion rather than a technological and instrumental issue. Smart urbanism re-connects planning practice to people's lives and experiences. It breaks with the common idea that efficient technologies will pave the way to the sustainability of society. Smart urbanism argues for using the intellectual capacities of urban societies and social networks to figure out how liveable and just cities can look like instead of putting too fast the most feasible policies and marketable technologies, products and services centre stage.

(...) it is most likely that a new blend of social innovations, new technologies, and new business models will provide the 'disruptive' force needed to change the dominant modern system. One may think of the combined effects of a shift to the driverless car (..), a business model that moves from car ownership to mobility as a service, and the value shift from the car being the life structuring status symbol towards a life structured by the smart phone (Hajer and Daasen 2014, p. 37).

Against this background a politics of disruptive mobilities that breaks up with current path dependencies demands for the mobility and flexibility of politics itself. Urban politics and planning need to gain the capacities to act for a conception that understands mobility rather as a social fact and process than only as the effect of optimized travels from A to B. Urban mobility networks

are critical in framing the mobility opportunities of individuals and this in shaping social practices and networks of human interaction within various spheres of city life (Miciukiewicz and Geoff Vigar 2012, p. 1941).

This has a good point by saying that there is a need for a 'holistic conceptualization of urban mobility' which breaks with the modernist thinking that cities can be shaped sustainably when all systems from energy to waste and transport to health are efficiently organized and technologically advanced. In a holistic concept of mobility transport

serves individuals and social groupings not only as a utilitarian means of access to goods and services, but also as a crucial determinant of connectedness to diverse human networks and spaces of social integration (Miciukiewicz and Geoff Vigar 2012, p. 1942).

Travel time savings i.e., one of the most important goals of modernist transport planning, stands in a different light. Research on travel time use inspired from the mobilities turn shows that for many people travel time savings don't have the highest priority (Lyons et al. 2007; Elliott and Urry 2010). The quality of traveling and the question of what social interaction and individual benefits derive from traveling weighs higher. By emphasizing social cohesion as the most important aspect of urban life Miciukiewicz and Geoff Vigar (2012) point to the essentials of mobility. Transport is not a purpose in itself, it is a serving function in society. And 
mobility is a completely different thing, it is the capacity of individuals, groups and societies to make decisions about the course of developments (see Bonß and Kesselring 2001).

\section{Historical Developments}

Soon after its foundation in 1995 the Inzell Initiative developed into a lynchpin of Munich's regional mobility policies. The initiative has become a source of inspiration for other policy fields as well. Hardly any major political decision in the area of mobility and transport has been made without consulting the Initiative since then. I.e. the implementation of a new parking scheme for the inner city has been designed by the initiative in its main features. The text approved by the city council is identical word by word with the concept the initiative presented before (Kesselring et al. 2003). Currently more than 60 'influential movers' (Kesselring and Freudendal-Pedersen 2014) are participating in four active forums (two are inactive by 2015).

\subsection{On Blue Zones, BMW, and Old Friendships}

One key moment in the history of Inzell was the visit paid by BMW's former CEO Eberhard von Kuenheim to the Lord Mayor's office around 1992. He wanted to discuss solutions for pressuring local problems caused by increasing car traffic. Kuenheim promoted the "Blaue Zone München" (Blue Zone Munich; Janssen 1993), a BMW concept. It was supposed to reduce the pressure on the historic centre of Munich. At that time, Munich's city centre had only 9000 people living there but about 90,000 workplaces and moreover located the most attractive shopping facilities. Despite Munich being structured into many functionally mostly independent neighbourhoods developed from old village structures, its transport infrastructure follows a monocentric logic. All public transport fast tracks concentrate into one so-called "Stammstrecke" (trunk route) between Pasing in the West and Ostbahnhof in the East. The capacities of the trunk route, once built for the Olympic Games in 1972, were almost exhausted already in the beginning of the 1990s.

The Blue Zone Munich followed a fairly technocentric rational. It should convince the city planners to increase the inner city's appeal by protecting it through the construction of all in all ten automated parking garages with 600 parking spaces each around the inner city area. This fully automated computer-controlled parking system named AUTOPARK was dismissed, not least due to its massive impact on real-estate prices. The Munich transport planners responded with an article that critically presented the weaknesses of the BMW model (Schlüter and Schwerdtfeger 1993). However, this debate marks the first blurring of boundaries between urban planning and the industry in Munich. It started an exchange of ideas 
on transport planning. In some respects, it was an incubator for the later deliberative practice between industry and the municipality. It paved the way for cooperation that would have been unthinkable just a few years earlier. The meeting mentioned above led to a re-thinking of the city's public-private relations. Finally, it also had consequences for the political culture as a whole, on the political mobility culture in particular, and on Munich's governance processes (Baumann 2013).

Munich's Lord Mayer Christian Ude stated that "obviously, both sides can learn from each other" (author's interview). While BMW could offer expertise, resources and creative potential in the areas of mobility, traffic, and environment, the city's experts had this but also added their tacit knowledge on the interdependencies between mobility and urbanity, quality of life, the specific cultural conditions of policy making and participation, and so forth. At that time in Munich, industrial experts had only little access to urban complexities. They considered mobility and transport mainly functionalist and as a matter of technology. The holistic and interdependent perspective on the urban society and its complexity was new at that time. In 1993, when Wolfgang Pischetsrieder became BMW's new CEO, Ude revitalized the contact to his former classmate. He was campaigning the collaboration with BMW as an overdue step towards stable and trustful collaborations with industry partners. This is coinciding with some theoretical developments in the theory of democracy where "second-generation deliberative democrats" (Elstub 2010 , p. 291) argued for a more practical orientation in theory and practice and for the institutionalization of deliberation. Interestingly enough, the institutionalization of a collaborative planning culture in Munich has never been explained through any conceptual considerations. As the next part will show it's rather been a story about taking advantage from personal relations, social networks and emerging chances for restructuring the discourse coalitions around mobility and transport.

\subsection{A Journey into the Wild Blue Yonder: To the Mountains and to Fresh Pastures...}

Initial must have been another meeting with the new CEO in 1993. Under the former Lord Mayor (Ude was elected in 1992) sitting down with a powerful industrial figure, reflecting on the future of mobility in the biggest Southern German city would have been unimaginable. The meeting would have been affected by mutual distrust and fear of the exercise of compliance and of influence by the industry on political decision-making. Instead, the Lord Mayor and his staff and the people from BMW talked on equal terms. Each side acknowledged the other's expertise, even if they did not share the other's analysis and conclusions in its entirety. In other words, everybody paid respect to the other, even though the earlier debate on Blue Zone had shown that there were great differences regarding favoured strategic orientations. 
In the end, mutual recognition and the acceptance of different problem definitions formed the basis for collaborative planning. These conditions made it possible to compile a sort of SWOT analysis, an analysis of the strengths and weaknesses of the Munich mobility policy with its key message: at this time the Munich mobility policy was lacking effective instruments and the potential for action in order to solve the then most pressing problems like congestion, pollution, noise, and the enormous pressure on the city centre due to cars searching for parking space. Already at this time the ongoing rationale of deliberative planning was formulated:

\begin{abstract}
We decided that we don't want to get lost in fundamental debates on transport policies anymore. We wasted so much time and money and energy in debating utopian projects such as a car-free city centre or an uninterrupted motorway ring road around Munich. Instead we wanted to become action-oriented and go for the doable and the solvable. We wanted to invent a new thing to build up consensus and efficient collaboration (author's interview with a city representative).
\end{abstract}

In 1995, the Lord Mayor called for a "new conflict culture". Spaces and practices should be developed in which traffic problems could be jointly analyzed and common solutions be found. Moreover, these approaches should be directly incorporated into political organization and implementation. In doing so, the idea of a possible consensus, of a solution viable and feasible for all, should always be in the foreground. For the 10th anniversary of the initiative Ude wrote in 2005:

Within the Inzell Initiative representatives from politics, economy, science and administration concerned with traffic concepts are leading high-quality dialogues on traffic problems of the Munich urban area. The partners are jointly developing solutions and convert them into strategies. ${ }^{3}$

An article in the members' journal of the Munich Green Party (Schreiner 1995) can be considered prototype for the rise of a new pragmatism. The author campaigned for the abandonment of the denial mode that characterized especially green mobility policies of the early 1990s in Munich. Instead, it was time to do "business"; one should compromise in certain areas (even if that is painful for the green clientele) in order to succeed in others. This was a strong argument for a new Machiavellian approach to gain progress instead of being stuck in inertia. In order to enforce for example multimodal concepts, corporate mobility management, and innovative concepts for road safety education, the author advised the green members that they should not oppose purely technocentric concepts of traffic management and control but mix them up with soft policies. Beck (1993) labelled this strategy once "subpolitical" and characteristic for reflexive modernization. Reflexive strategies can secretly generate positive outcomes through collaboration in seemingly negative projects. This was a huge challenge for the 1990s green party in Munich, because it sounded opportunistic. In concrete, what the author in the green magazine suggested was to support automobile policies (i.e. in Inzell) to introduce sustainable policies for bikers, alternative pedagogical approaches or

\footnotetext{
${ }^{3}$ Documentation of the 10th anniversary of the Inzell Initiative (2005, p. 1); accessed on 18/12/2014 at www.inzellinitiative.de.
} 
better public transport. Instead of playing the power game in order to eliminate competing solutions and concepts, he argued for a reflexive strategy of opening up for a multiplicity of solutions. ${ }^{4}$

Contemporary planning means coping with "irreducible uncertainties" about "goals and the means of achieving them. The existence of both disagreement about goals and uncertainty about means results in 'chaos', and 'order' and must somehow "be discovered" (Bertolini 2010, p. 417). And as no one in Munich could definitively offer an optimum solution for complex mobility problems this discursive strategy described above was highly rational and matched with the anyway new pragmatism in local politics.

The discussions during the early phase of deliberation resulted in 1995 in a future workshop in Inzell. At the end of a two-day workshop conducted in line with Jungk and Müllert's methodology (1987), the participants agreed on setting up the initiative and the name "Inzell Initiative". Apart from BMW representatives and the Lord Mayor of Munich, the following stakeholders participated: different departments of the municipality (including heads of departments), representatives from local parties, the Chamber of Industry and Commerce, the Bavarian Ministry of the Interior's Supreme Building Authority, the Regional Planning Association, the German Railways, the National Association of Bavarian Retail, one trade union, the two Munich public transport authorities (MVV and MVG), and two professors from the Technische Universität München, department of civil engineering. Besides putting the initiative on track the most important result of the workshop was a list of eleven planning principles for the future of mobility in the Munich region:

1. The development of settlement patterns has to be oriented toward or geared to the public transport network.

2. The nearer the centre, the less car traffic.

3. The transit traffic has to be kept away from densely populated areas.

4. If residential areas are to have traffic calming, the traffic has to be concentrated on main arteries.

5. The capacity of traffic systems is increased and improved by cooperative traffic management.

6. Public transport has priority.

7. The Park + Ride system for linking up modes of transport is to be improved.

8. A concept for parking space management has to be developed for the City of Munich.

9. Regarding individual traffic, commercial transport has priority.

10. The transport of goods has to be optimized by fostering logistic systems.

11. Traffic is to be avoided by increasing the grade of occupancy in car traffic.

Seen from today, none of these principles sounds absolutely path-breaking. Today, most of it can be considered common sense in contemporary transport ${ }^{4}$ Elsewhere I put this as multiple-best-way-solutions instead of one-best-way-solutions (Kesselring
2008, p. 91). 
planning. But in 1993 it was a somehow historical achievement to reach agreement among stakeholders who had been in conflict for more than a decade. Only in 2013, almost twenty years later, the question was raised at the tenth Inzell plenary, if the time has come to redraft the eleven principles and update them to contemporary social and political realities and state-of-the-art in planning.

Probably part of this upcoming demand for a revision of the planning principles was the attempt of one of the forums to develop a long-term perspective for the Munich region. In 2012 the youngest forum on future mobility started a process of developing a vision for the year 2050.

\subsection{Envisioning the Future of Mobility}

In December 2012 the forum started debating how to develop 'guidelines and action plans for the development of mobility in Munich' (Wulfhorst 2013, p. 1). In three parallel working groups the forum elaborated a 'Vision Mobility 2050 in the Munich Area'. But in this sense the title of the Vision is somehow misleading. The vision doesn't tell a story on how the mobility of people in 2050 might look like. It seems that the question of how mobile urban lives could look like has not been on the agenda. Instead it has been the goal to elaborate possible pathways for future planning activities and for closer collaboration between public and private actors in the field. This pragmatic character of the forum's work on the Vision 2050 is already mirrored in the topics chosen for the working groups: the first concentrated on accessibility planning and how to reach better functionality in the Munich region's transport systems. The second group asked about future user expectations in public transport and how to collect reliable data on travel behaviour. It also asked how to use data for a mobility marketing that takes individualization processes and the diversification of transport demand into account. The third group concentrated on technical aspects and means, infrastructures and better operation in traffic systems.

The three groups met separately and developed their individual ideas within the specific fields. In a one-day workshop at the Munich Chamber of Commerce the synthesis of the three working groups was generated in mid-2013. It was organized in preparation of the tenth plenary workshop in June. Based on the documentation of the working groups and the minutes from the one-day workshop the Munich based firm Innovationsmanufaktur $\mathrm{GmbH}$ made the visualization in Fig. 1.

I consider this picture a key document of the local mobility discourse. As mentioned before, the initiative works as a key discursive and deliberative practice in local planning. The main actors in the field are gathered in the network and have been part of the process of envisioning future strategies and action plans. It can be interpreted as a discursive mind map, materializing different story lines on how to think into the future of mobility in Munich. Comparable with the eleven planning principles (see above) the vision represents the state-of-the-art on how the future of mobility has been discussed in 2013. It gives record on the discursive mind-map of 


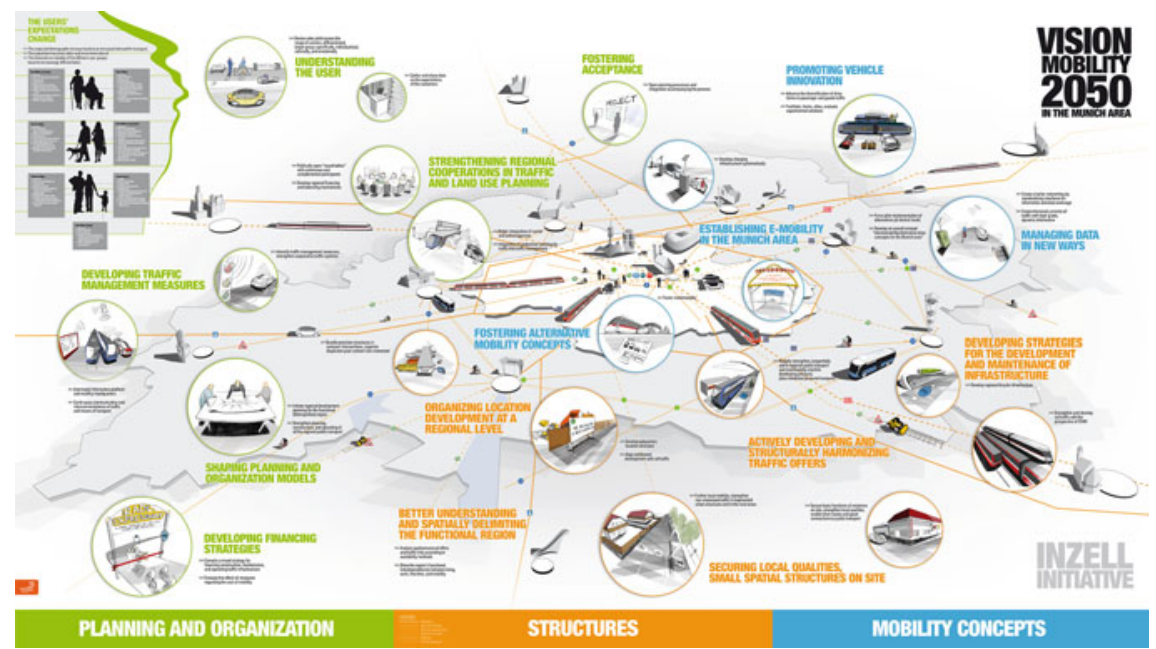

Fig. 1 Vision 2050 (Source Innovationsmanufaktur GmbH)

local mobility perception and shows the still strong functionalist and technocentric orientation of the initiative's discussions on future mobility planning.

After having thoroughly analyzed the materials from the working groups the Innovationsmanufaktur identified three dominant story lines: planning and organization; structures and mobility concepts. I will briefly summarize the three dimensions of local mobility discourse.

Planning and organization (green) encloses activities dealing with the organizational structures of transport management and the planning of future measures in transport. On the one hand how planning processes work or should work is mentioned and the role of planning in fostering acceptance for political decisions is highlighted. The strengthening of regional cooperative structures in traffic and land use planning is emphasized specifically. On the other hand it comprises the development of concrete measures for better traffic management (i.e. an intermodal information platform, the implementation of mobility service stations where people can get high quality information and support in modal choices and a user friendly management of traffic data in general). But it also includes research activities for a better understanding of users, their needs and expectations in traffic and new financial strategies for the building, maintenance and operation of transport systems. The planning and organization story line represents a strong engineering and functional approach and focuses on optimizing existing structures of collaboration between public authorities, public transport authorities, the industry and science. It is strongly driven by the intention to operationalize the 'right' interpretation of the region as a networked spatial and infrastructural layout. The discussion on the 'functional region' and the 'strengthening (of) regional cooperation in traffic and land use planning (see visualization) represents this discursive framing. This refers to the discussions if the planning region 14, which includes Munich, is the 
appropriate spatial and organizational structure for managing the traffic in the Munich region. Competing concepts argue for the metropolitan region as the better fitting structure as urban sprawl and suburbanization demands for the restructuring of administrative responsibilities. The working group on accessibility argued for a better understanding of regional interdependencies and networked structures (regionale Verflechtungen).

The second story line was called structures (orange) and even strengthens the first story line's strongly instrumental approach. It comprises the analysis of spatial structures for a more appropriate conceptualization of the region and the spatial definition of functional boundaries and administrative responsibilities (delimiting the functional region). It also encloses social and institutional relations between stakeholders and the civil society and for the prioritization of regional economies and cultures (organizing location development at a regional level; securing local qualities, small spatial structures on site). It seems that the predominant problem definition expressed here is that it needs new and better infrastructures to solve transport and traffic problems in the region. The topic 'developing strategies for the development and maintenance of infrastructures' goes in line with the planning and organization story line and concentrates on more efficient cooperative structures and effective measures to handle regional transport problems. It is driven by the attempt to build up institutional capacities through governance that was once formulated as the major goal of the Inzell Initiative.

Interestingly enough the third story line of mobility concepts (cyan) has been the less elaborated throughout the data. This is actually the place where one expects the most innovative ideas of a vision. But the picture only summarizes two more general perspectives and two, which orientate towards concrete aspects: The first general topics are 'fostering alternative mobility concepts' and 'promoting vehicle innovation'; the second, more concrete, are called 'establishing e-mobility in the Munich area' and 'managing data in new ways'. It might be the case that the industry has been reluctant to write their most promising concepts into a paper like this. But it could also be that it has been strategic considerations addressed to politics that played a role. One of the bullet points under promoting vehicle innovations says: 'facilitate, foster, allow, evaluate an experimental solution'. This points to the fact that many of these innovations in mobility, today, like free-floating car sharing, public bikes or sharing economy concepts, etc. are on-site experiments. The urban space is the laboratory where new business models and services need to be tested under live conditions. New mobility concepts can't be proved and evaluated in an experimental situation. They need to go out in public. And this needs collaboration and support from public authorities and politics. Against this background it seems to be a strategic moment in concentrating on the above-mentioned aspects and the story line has a strong political dimension addressed to politics to provide better conditions for entrepreneurial activities for new mobility concepts.

By presenting these results from data analysis it becomes visible that the forum's subject has not been mobility in a broader, sociological sense. The Vision 2050 has a strong instrumental and functionalistic approach. It is less the technocentric outset 
that shows up strongly in the data. Rather it is the instrumental planning approach and the idea that collaboration, organization and regional cooperation need to be optimized to provide better conditions and opportunities for sustainable mobility. In this sense it reconfirms results from a study on 'cooperative mobility politics' (Kesselring et al. 2003) where the Munich field of actors in mobility and transport was described as a policy network that follows the rationale of 'modernizing collaborative interaction structures and harmonizing working cultures. Seen from today the Vision represents the actors' attempts of setting up regional governance structures and providing the ground for sustainable mobility politics. But without failing in an over-interpretation of the data of the Vision 2050 it can be summarized that so far the energy and the resources are concentrated on this. The Vision 2050 doesn't give any guideline and perspective for sustainable mobility practice in the future. It puts together concepts that have been already in the air and widely discussed before. The expectations formulated for the forum's work haven't been delivered and the work on the future of mobility instead of the future of collaborative planning is still missing and needs to be done.

\section{Conclusions}

As mentioned above the Munich Inzell Initiative shows a couple of similarities with Lafferty and Meadwocroft's 'cooperative management regimes' (1996). The data presented before showed the strength of the initiative is not its innovative potentials and the capacity to envision future developments in mobility. Instead it seems to be a common sense among the stakeholders that the modernization of planning and organizational structures is more important and promising for the development of sustainable mobility action plans and policies. Against this background it seems to be relevant to investigate the question if we are witnessing the rise of a new urban mobility regime in Munich, which is about to gain power on the future shape of urban transport and mobility policies. Stone (1989) considers urban regimes as semi-institutional structures, sometimes also labelled 'organisms' (Mossberger and Stoker 2001, p. 812), that mediate between urban problems and policy outcomes. In the case of Inzell we can see the emerging structure as mediating transport and environmental problems, such as missing acceptance for policies, etc. and the local and regional political institutions. Inzell pre-structures the mobility discourse in a way that solutions favoured by the initiative can be built on discursive legitimacy that helps to find majorities amongst the members of the city parliament. The before-mentioned case of the new Munich parking scheme was a pilot case for this. Lessons learned from twenty years of experiences in mediating conflict, organizing majorities and finding consensus in an extra-political space can be studied in the social construction of the Vision 2050 documents. As Stone (1989) describes, the power sought by urban regimes is the 'power to' or the 'capacity to' act and decide and to build up institutional resources for policies. It is not the application of power to define the exact character or utopian potential that i.e. Jungk and Müllert (1987) 
demand for urban planning and policy making. David Harvey once coined the metaphor that modern societies need to envision the 'port we want to sail to' to be able to distinguish between futures that are possible but not sustainable and those which are desirable, because of being sustainable, just and liveable. The Inzell Initiative's will to power seems to be the one that keeps on track and not the one that wants to break up path dependencies. If it wasn't that the process of generating the Vision 2050 needed to be organized in a different way. In one of the documents analyzed for this article the author refers to Jungk and Müllert's future workshop methodology (Wulfhorst 2013, p. 1). But one of the characteristic elements of this approach in future research is that the policies, strategies and projects developed in the realization phase of the workshop imply a significant utopian potential and the method challenges for the participants' capacities to think out of the box and fly high in some sense. But the specific quality of the future forum's vision consists in the pragmatic spirit and the concentration on practicability and potentials for implementation.

Against this background Inzell must be considered as a new form of deliberation and participation and can be characterized as an indicator for an emerging urban mobility regime. But its strong orientation on the maintenance of power must be questioned fundamentally. Instead of administrating current power structures the Initiative should prioritize its innovative potentials and societal responsibility for bringing up new mobility policies and planning initiatives. Since 1995, Inzell has reached a high level of acceptance and influence. The challenge is now to work on the transition towards sustainable mobilities for the region of Munich.

\section{References}

Banister, D. (2008). The sustainable mobility paradigm. Transport Policy, 15, 73-80.

Bauman, Z. (2000). Liquid modernity. Cambridge: Polity Press.

Baumann, C. (2013). Making better choices-An investigation of collaborative stakeholder dialogue as catalyst for consensus building and learning in the transport policy process (Ph.D. thesis). University of Technology, Sydney: Institute for Sustainable Futures, Sydney.

Baumann, C., \& Stuart, W. (2012). Making better choices: A systematic comparison of adversarial and collaborative approaches to the transport policy process. Transport Policy, 24, 83-90.

Beck, U. (1988). Gegengifte. Die organisierte Unverantwortlichkeit. Frankfurt: Suhrkamp.

Beck, U. (1992). Risk society. London: Sage.

Beck, U. (1993). Die Erfindung des Politischen: Zu einer Theorie reflexiver Modernisierung. Frankfurt: Suhrkamp.

Beck, U. (2006). Power in a global age: A new global political economy. Oxford: Blackwell.

Beck, U., Bonß, W., \& Lau, C. (2003). The theory of reflexive modernization: Problematic, hypotheses and research programme. Theory, Culture and Society, 20(2), 1-34.

Beck, U., Hajer, M., \& Kesselring, S. (Eds.). (1999). Der unscharfe Ort der Politik. Opladen: Leske + Budrich.

Beck, U., \& Kesselring, S. (1998). Mobilitätspolitik unter den Bedingungen der reflexiven Modernisierung. Eine Untersuchung der Mobilitätspolitik in der Landeshauptstadt München. Schlußbericht an das Bundesforschungsministerium (BMBF). München: unpublished manuscript. 
Bertolini, L. (2010). Coping with the irreducible uncertainties of planning: An evolutionary approach. In J. Hillier \& P. Healey (Eds.), The ashgate research companion to planning theory: Conceptual challenges for spatial planning (pp. 413-424). Ashgate: Farnham.

Bonß, W., \& Kesselring, S. (2001). Mobilität am Übergang von der Ersten zur Zweiten Moderne. In U. Beck \& W. Bonß (Eds.), Die Modernisierung der Moderne (pp. 77-90). Frankfurt: Suhrkamp.

Canzler, W., Kaufmann, V., \& Kesselring, S. (Eds.). (2008). Tracing mobilities: Towards a cosmopolitan perspective. Aldershot: Ashgate.

Canzler, W., \& Knie, A. (1998). Möglichkeitsräume. Grundrisse einer modernen Mobilitäts- und Verkehrspolitik. Wien: Böhlau.

Castells, M. (2008). The networked city. In G. Pflieger \& M. Castells (Eds.), The social fabric of the networked city, Urbanism (pp. V-XIII). Routledge: London. ([u.a.]).

Cresswell, T. (Ed.). (2006). On the move: Mobility in the modern western world. New York: Routledge.

Deckha, N. (2003). Insugent Urbanism in a railway quarter: Scalar citizenship at king's cross, London. ACME, An International E-Journal for Critical Geographies 1(2): 33-56. http:// www.acme-journal.org/vol2/Deckha.pdf.

Dryzek, J. S. (1990). Discursive democracy: Politics, policy and political science. New York: Cambridge University Press.

Dryzek, J., \& Hendriks, C. M. (2012). Fostering deliberation in the forum and beyond. In F. Fischer \& H. Gottweiss (Eds.), The argumentative turn revisited: Public policy as communicative practice (pp. 31-57). Durham: Duke University Press.

Elliott, A., \& Urry, J. (2010). Mobile lives: Self, excess and nature. International library of sociology. London: Routledge.

Elstub, S. (2010). The third generation of deliberative democracy. Political Studies, 8(3), 291-307.

Fischer, F., \& Forester, J. (Eds.). (1993). The argumentative turn in policy analysis and planning. London: Duke University Press.

Flyvbjerg, B. (2006). Making organization research matter: power, values and phronesis. The Sagehandbook of organization studies, (pp. 370-387)

Giddens, A. (1994). Beyond left and right: The future of radical politics. Cambridge: Polity Press.

Graham, S., \& Marvin, S. (2001). Splintering urbanism: Networked infrastructures, technological mobilities and the urban condition. London: Routledge.

Hajer, M., \& Daasen, T. (2014). Smart about cities: Visualizing the challenges for 21st century urbanism. Rotterdam: Nai010 Publishers.

Hajer, M. A., \& Wagenaar, H. (Eds.). (2003). Deliberative policy analysis. Understanding governance in the network society. Cambridge: Cambridge University Press.

Hajer, M., \& Kesselring, S. (1996). Sustainable mobility in munich. Final report for the centre for european social research, Münchner Projektgruppe für Sozialforschung e.V. Cork, München.

Hajer, M., \& Kesselring, S. (1999). Democracy in the Risk Society? Learning from the New Politics of Mobility in Munich. Environmental Politics, 8(3), 1-23.

Hannam, K., Sheller, M., \& Urry, J. (2006). Mobilities, Immobilities and Moorings. Mobilities, $1(1), 1-22$.

Healey, P. (Ed.). (1997). Collaborative planning: Shaping places in fragmented societies. London: Palgrave Macmillan.

Healey, P. (2012). Performing place governance collaboratively: Planning as a communicative process. In F. Fischer \& H. Gottweiss (Eds.), The argumentative turn revisited: Public policy as communicative practice (pp. 58-83). Durham: Duke University Press.

Hou, J. (2010). Insurgent public space. Kentucky: Taylor and Francis.

Hou, J., Spencer, B., \& Way, T. (Eds.). (2015). Now Urbanism: The future city is here. London: Taylor and Francis, Routledge.

Jahn, T., \& Wehling, P. (1999). Das mehrdimensionale Mobilitätskonzept-Ein theoretischer Rahmen für die stadtökologische Mobilitätsforschung. In J. Friedrichs \& K. Hollaender (Eds.), Stadtökologische Forschung (pp. 127-141). Analytica, Berlin: Theorien und Anwendungen.

Janssen, L. J. (1993). Blaue Zone München. München: BMW. Unveröffentlichtes Manuskript. 
Jessop, B. (1998). The rise of governance and the risks of failure: The case of economic development. International Social Science Journal H, 155, 29-45.

Junge, M. (2000). Ambivalente Gesellschaftlichkeit. Die Modernisierung der Vergesellschaftung und die Ordnungen der Ambivalenzbewältigung. Opladen: Leske + Budrich.

Jungk, R., \& Müllert, N. (1987). Future workshops: How to create desirable futures. London: Institute for Social Inventions.

Kaufmann, V. (2002). Re-thinking Mobility. Aldershot and Burlington: Ashgate.

Kaufmann, V. (2011). Rethinking the city: Urban dynamics and motility (1st ed.). Milton Park, Abingdon, Oxon, New York, NY, Lausanne, Switzerland: Routledge; EPFL Press.

Kesselring, S. (2001). Mobile Politik: Ein soziologischer Blick auf Verkehrspolitik in München. edition sigma. Univ., Diss-München, 2000, Berlin.

Kesselring, S. (2008). The mobile risk society. In W. Canzler, V. Kaufmann, \& S. Kesselring (Eds.), Tracing mobilities: Towards a cosmopolitan perspective (pp. 77-102). Aldershot: Ashgate.

Kesselring, S. (2009). Global transfer points: The making of airports in the mobile risk society. In S. Kesselring \& J. Urry (Eds.), Aeromobilities, ed. Saulo Cwerner (pp. 39-60). International Library of Sociology, Routledge: London, New York NY.

Kesselring, S., \& Freudendal-Pedersen, M. (2014). Mobilities, futures and the city: Towards a reflexive methodology for urban planning in the mobile risk society. Paris: Forum des Vies Mobiles.

Kesselring, S., Moritz, Eckehart F., Petzel, Wolfram, \& Vogl, G. (2003). Kooperative Mobilitätspolitik: Theoretische, empirische und praktische Perspektiven am Beispiel München und Frankfurt, Rhein-Main. München: IMU; IMU-Inst.

Lafferty, W. M., \& Meadowcroft, J. (1996). Democracy and the environment: Problems and prospects. Cheltenham: Elgar.

Lash, S., \& Urry, J. (1994). Economies of signs and space. London: Sage.

Lenger, F. (2013). Metropolen der Moderne: eine europäische Stadtgeschichte seit 1850. Munich: Beck.

Lyons, G., Jain, J., \& Holley, D. (2007). The use of travel time by rail passengers in Great Britain. Transportation Research Part A, 41(1), 107-120.

Miciukiewicz, K., \& Geoff Vigar, G. (2012). Mobility and social cohesion in the splintered city: Challenging technocentric transport research and policy-making practices. Urban Studies, 49 (9), 1941-1957.

Mossberger, K., \& Stoker, G. (2001). The evolution of urban regime theory the challenge of conceptualization. Urban Affairs Review, 36(6), 810-835.

Petersen, R., \& Schallaböck, K. O. (1995). Mobilität für morgen. Birkhäuser, Berlin: Chancen einer zukunftsfähigen Verkehrspolitik. u.a.

Rammler, S. (2001). Mobilität in der Moderne: Geschichte und Theorie der Verkehrssoziologie. Berlin:edition sigma.

Reichow, H. B. (1958). Die autogerechte Stadt. Ein Weg aus dem Verkehrschaos. Hannover: Bauen undWohnen $\mathrm{GmbH}$.

Rhodes, R. A. W. (1996). The new governance: Governing without government. Political Studies, $44,652-667$.

Schlüter, T., \& Schwerdtfeger, W. (1993). Blaue Zone München: Ein Diskussionsbeitrag. Ein Konzept mit blauen Augen. Internationales Verkehrswesen 45(9):502-06.

Schmucki, B. (2001). Der Traum vom Verkehrsfluss: Städtische Verkehrsplanung seit 1945 im deutschdeutschenVergleich. Frankfurt: Campus.

Schreiner, M. (1995). Kooperatives Verkehrsmanagement. Die Grüne Mamba Nr., 63, 14-15.

Sheller, M., \& Urry, J. (2006). The new mobilities paradigm. Environment and Planning A, 38(2), 207-226.

Sieverts, T. (2003). Cities without cities: An interpretation of the Zwischenstadt. English language ed. Spon Press : London, New York.

Stone, C. N. (1989). Regime politics: Governing Atlanta, 1946-1988. Studies in government and public policy. Lawrence Kan: University Press of Kansas. 
Switzer, A., Bertolini, L., \& Grin, J. (2013). Mobility transitions 1945-2012. Working paper. Amsterdam: Centre for Urban Studies.

Tully, C. (1999). Erziehung zur Mobilität. Campus, Frankfurt/Main: Jugendliche in der automobilen Gesellschaft.

Urry, J. (2000). Sociology beyond Societies: Mobilities of the Twenty-First Century. London: Routledge.

Urry, J. (2007). Mobilities. Cambridge: Polity Press.

Urry, J. (2011). Climate change and society. Cambridge: Polity.

Voß, J. P., \& Kemp, R. (2006). Sustainability and reflexive governance: Introduction. In J. P. Voß., D. Bauknecht \& R. Kemp (Eds.), Reflexive governance for sustainable development (pp. 3-28). Cheltenham: Elgar.

Wulfhorst, G. (2013) Vision 2050. Strategiepapier der Arbeitsgruppe Erreichbarkeit im Forum Zukunft der Mobilität. Munich: Technische Universität München. 


\title{
In Search of an Integrated Mobility Project
}

\author{
Arturo Lanzani and Antonio Longo
}

\begin{abstract}
The essay draws on planning research conducted between 2005 and 2013 at DAStU by a team formed of Alessandro Alì, Arturo Lanzani, Antonio Longo and Christian Novak with Daniela Gambino, Alessandro Giacomel, Anna Moro and Lara Valtorta. Federico Zanfi was jointly in charge of research for the reformation of open spaces and productive areas in the Province of Monza and Brianza conducted in 2012 and 2013. Specific credits: Arturo Lanzani, paragraphs 6.2, 6.5, 6.6; Antonio Longo paragraphs $6.1,6.3,6.4,6.7$.
\end{abstract}

\begin{abstract}
This essay reflects on the relationship between infrastructure projects for mobility and territorial projects in Italy, on the basis of the authors' own experience in research and planning of projects for environmental integration of the Autostrada Pedemontana Lombarda road system. Difficulty integrating mobility projects into territorial development and reform projects is very accentuated and deeply rooted in Italy. The country's traditional attitude to technology, focused on separation of knowledge from know-how and characterised by weak administrative structures, has in fact added to the importance of institutions and agencies created for the purposes of specific projects which, outside of ordinary practice and normal administration, have temporarily represented a point for integrating knowledge and technique capable of producing potentially innovative territorial projects. This inevitably weak condition has also had some impact on the Autostrada Pedemontana Lombarda affair. The difficulties linked with poor quality planning, the role of the design agencies, the contractors and the expectations of the areas involved cast light on a number of original and difficult aspects of territorial integration of mobility projects. Beginning with a number of considerations on the Italian context, this essay looks at various aspects of the project and how it has been approached through development of the management process, and reports on its
\end{abstract}

\footnotetext{
A. Lanzani $\cdot$ A. Longo $(\bowtie)$

DAStU, Politecnico di Milano, Milan, Italy

e-mail: antonio.longo@polimi.it
}
A. Lanzani
e-mail: arturo.lanzani@polimi.it
(C) Springer International Publishing Switzerland 2016
P. Pucci and M. Colleoni (eds.), Understanding Mobilities
for Designing Contemporary Cities, Research for Development,
DOI 10.1007/978-3-319-22578-4_6 
direct and indirect results. In conclusion the essay offers a number of keys to interpretation of the relationship between design, research and action in Italy, going beyond the specific case under discussion and the limits of practice in Italy.

Keywords Infrastructure project - Environmental integration - Autostrada Pedemontana Lombarda

\section{Introduction}

This essay reports on the attempt, promoted by a group of Politecnico di Milano researchers, to begin an extensive process of territorial reform to the north of the Milan Urban Region, taking advantage of the opportunity to collaborate in the design of a new motorway and the related environmental compensation projects. This was a process of reflective practice involving territorial studies, the practice of urban planning and landscape design in relation to a real, living, reactive context. In one of Europe's biggest and most complex urban areas, characterised, like much of Italy, by serious environmental problems and inadequate infrastructure, this project of limited scope centring around a major infrastructure offered an opportunity to add to our knowledge in several areas: the methods and defects with which major infrastructure projects are developed in today's urban areas, the characteristics and dynamics (territorial, political and institutional) of the territories they pass through, and the scope and potential of landscape projects for producing extensive and systemic effects through partial actions.

The essay is divided into six parts. The first part (Sect. 2) describes the historical process of infrastructure construction in Italy and its specific features. The second part looks at the context of the specific case presented (Sect. 3), urban development to the north of Milan and the motorway that passes through the area. The essay then goes into the experience in which the authors were involved (Sect. 4). This part describes the client's request and the attitude inspiring the response. The generic demand to improve the quality of the Autostrada Pedemontana project, integrating it better with the territory and the landscape, took the specific form of a request to orient economic resources for environmental compensation through a particular strategy. This demand targeted a group of academics and designers with in-depth knowledge and familiarity with the area north of Milan on both the personal and scientific levels, a fact which had a major impact on the course of the project. In the subsequent parts (Sects. 5 and 6), the essay offers an assessment "in progress" of the direct and indirect results of the design experience. These results apply to the relationship between the different project areas, "landscape design", "territorial planning" and "infrastructure engineering", and the relationship between design technique and political decision-making processes. The conclusion (Sect. 7) summarises the most characteristic and specific aspects of the design process. 


\section{Context: The Problem of Large-Scale Projects in Italy}

\subsection{Italian Soil: Modern Infrastructure, Ancient Fabric}

Two processes took place in Italy between the late nineteenth century and the 1970s. A minute, capillary infrastructure was developed in southern Italy, culminating in the land reclamation, agricultural reform and infrastructure resulting from pre-industrialisation policies in the 1950s. At the same time, the whole country saw construction of a new and bigger network of infrastructure: the beginning of construction of national highways (in the nineteenth century), railways (between the late nineteenth century and the First world war), and finally motorways (between the 1920s and the 1970s). This was a new network which, in certain parts of the country, especially the flatlands of the Po Valley, was densely interwoven with large and small pre-existing works. In this process of formation, however, connections between the two networks, the smaller and the larger one, were weakened with the passage of time. While these connections are still significant in the national highways and railways, thanks to smaller and regional connecting railway lines, and in municipal and inter-municipal routes to new stations, they are definitely weaker in the motorways. What this meant was that in the middle of the last century new, abstract lines began to be drawn over the map of a country, which had been reduced to a blank slate with very few points of reference.

Not until Giolitti's time (1900-1915), with the completion of the railway and national highway networks and the first significant stage in construction of urban infrastructure, was the only attempt made to give the country a new face consistent with its age-old human settlement, combining protection of the ancient landscape with intentional construction of a new landscape. With the beginning of construction of the motorway grid and definitively after the second world war, all attempts to redraw the country's "face" in a manner that would be consistent with its past heritage of landscape and infrastructure were dropped (Moretti 1996).

\subsection{The Progressive Specialisation}

The country's subsequent history is one of progressive specialisation and growing self-referentiation of the knowledge and skills guiding construction of infrastructure. Starting from the 1950, in Italy the know-how that contributed to infrastructure planning in other European countries at the time of the growth was marginalised. The economist's "strong" knowledge was not truly involved in assessment of costs and benefits. And the country ignored the weaker but no less important bearers of knowledge, such as the geographer, the urban planner, the geologist, the naturalist, the landscape architect, or the architect who might - as they had done in different 
ways in France, Germany and Great Britain - make a transportation project into a true work of infrastructure: a project supporting a variety of different activities and bringing together different natural and anthropic elements. (Ambrosini 2002; Angrilli 2002; Gasparrini 2003; Waldheim 2006; Körner et al. 2012; Nucci 2012; Secchi 2010; Fabian and Pellegrini 2012).

The term infrastructure contains the Latin prefix "infra", which refers to "that which is below", that which is not seen and acts as a support, but also to "that which is between", intermediating between different elements at different locations in space. The declared potential of the very meaning of the term infrastructure is however reduced to a mix of technical rationality with political habit. This marked the beginning of a complicated age of useless patronage projects implemented on the whim of powerful local politicians, and the awarding of the contract became more important than the project itself. The focus was on the economic results of the work, not of the structure itself. And so it should come as no surprise that the golden age of motorway construction in Italy includes an number of projects which are incomprehensible in terms of both existing and potential demand for mobility, that is, in terms of the dynamics of economic development and construction that they pursue and that they might support (Lanzani 2003; 2011).

\subsection{Two Basic Features: Growth Without Civilisation and the Domination of Special Players and Agencies}

This history of infrastructure explains two of the most widespread features of the country. The first has been defined by a number of historians as "modernisation without development" or growth without development, or better yet as growth "without civilisation" (Sapelli 2005; Bevilacqua 2008). What these expressions refer to is in short the rapid, radical intrusion of modernity into the country. Italy led the way in motorway construction in Europe.

In some ways we might say that the wise Italy rushed into a post-modern condition moulded by radical individualism and technical rationality. The experience of early modernity, however significant, developed in too short a time in history and affected only limited portions of the country. A second characteristic feature of the country is the strong role played in this situation by special parties, agencies separate from ordinary public administration. In post-war, Italy it was not so much the presence of private capital in the construction of the motorways that was the problem, but the increasingly decisive and exclusive role it played in planning and operating the network, clearly outside of a systematic approach consistent with controlled, limited investment goals. 


\subsection{Landscape and City Versus Infrastructure}

The last 25 years have seen a clear worsening of this chronic situation and the contradictions are becoming more and more evident. As available resources shrink, the split is widening between poorly built new large-scale infrastructure that will have to be maintained and managed in the future and the inheritance of great capillary landscape and historic infrastructure works that have supported the country's urban development. In the meantime, the care and maintenance of this heritage is getting worse and worse as a result of more and more drastic spending cuts in funds for the local institutions in charge of maintaining them. But it is not merely a matter of poor division of resources between large-scale projects and widespread infrastructure; at this point, after a long series of mediocre new infrastructure projects and rapacious exploitation of a fixed amount of social capital, it is also a matter of the total cost of maintaining these projects.

This process has also led to a serious cultural consequence, which is perhaps more general and not only Italian, to a break between landscape interpreted in terms of "image" and landscape interpreted in terms of "reality". The "image" of the Italian landscape has defensively retracted into the shell of its past, the memories of the beautiful landscape recorded by travellers and guides between the late eighteenth century and the early twentieth century: a landscape that should be protected wherever this is still possible. The landscape as "reality" and part of the contemporary city becomes primarily a superficial phenomenon formed as a result of individual transformations responding to sectorial rationality and individual interests, a condition far from the most advanced international experiences and reflections (Shannon and Smets 2010; Tiberghien and Desvigne 2009) (Fig. 1).

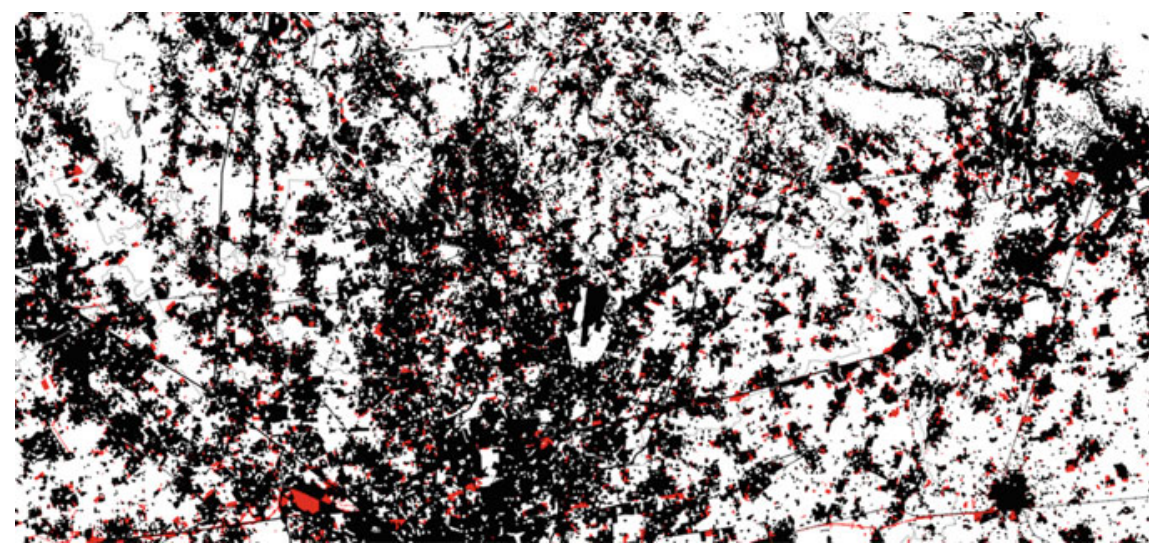

Fig. 1 The urbanization in the Milan urban region in the last decade. (Source Dastu Politecnico di Milano 2013) 


\section{North of Milan: The Planned Motorway System in the Foothills of the Alps}

\subsection{Milan: A City Without Quality}

The metropolitan area to the north of Milan has a population of more than 4 million. It is a complex urban system product of the overlapping in the second half of the twentieth century of two great dynamics of urbanisation: the first dynamic is the result of radial and concentric growth of the city of Milan along the major roads to national and European destinations; the second dynamic is generated by a closely knit landscape network, characterised by many cross routes intersecting the main river valleys that cross the upper Po Valley. The continuous conurbation, which is the result of overlapping of these two scenarios and their growth dynamics, does not have a name on the map: "city region", "diffuse city", "infinite city", "city of cities" are only a few of the expressions coined in an attempt to describe its history and dynamics (De Carlo 1966; Lanzani 1991; Boeri et al. 1993; Lanzani 1996; Ischia 1999; Bonomi and Abruzzese 2004; Balducci et al. 2011).

Decentralised development is the product of an economy centring around small enterprises, exploitation of the land and the process of accumulation of local capital. In less than 50 years the 423 small municipalities making up the area have grown to occupy almost half the available land, with a rate of intensification in the years following 2000 of consumption of more than 1000 ha of farmland a year, producing what might be called an unconscious metropolis devoid of quality.

Each municipality proudly maintains its own administrative independence and continues to determine its own development policies, independently of all the others and of the weak structural policies for governance of the territory by the Region and the Provinces, now abolished. The regional urban planning law promulgated in 2005 (L.R.L. 12, 2005, http://www.territorio.regione.lombardia.it/) after the Italian nation delegated responsibility for territorial planning to the regions, definitively sanctioned the assignment of all decisions regarding planning to the individual municipalities, including assessment of their own plans and programmes. These methods of development have had a very serious impact, especially on the quality of the environment and on mobility: two key factors in determining the liveability of a settlement (Fig. 2).
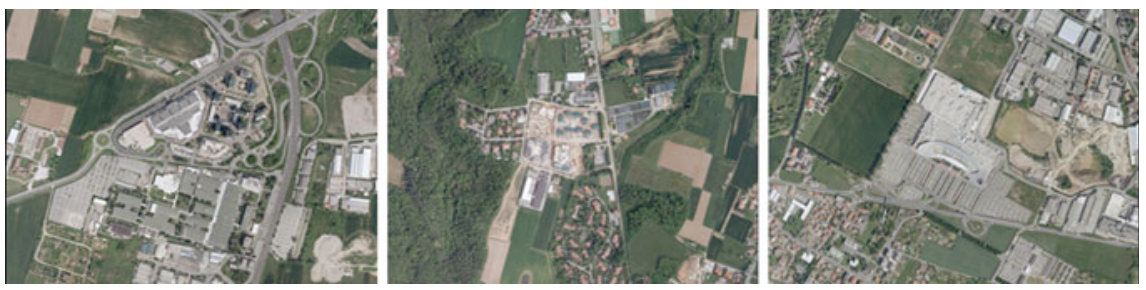

Fig. 2 New and old infrastructures and settlements in the Milan urban region. (Source Regione Lombardia DBT 2011-12) 


\subsection{The Need for an East-West Connection System: Autostrada Pedemontana Lombarda}

The idea of a bypass around the city and a direct connection from Bergamo to the road leading to the San Gottardo tunnel has been tossed around since the early 60s (Lanzani et al. 2013) as a unitary motorway solution. Many proposals have been made since then, with progressive adaptation of the routes and technical features of the infrastructure to the new needs of the area and to the changes that have taken place in the meantime: from cross corridor to road for crossing and distribution of the territory linked with a complementary road system. The 2003 preliminary project was developed in view of national legislation tying large-scale infrastructure projects to special goals, with special terms for financing, planning and procedures. The project proposed a system including $87 \mathrm{~km}$ of motorway and $70 \mathrm{~km}$ of local roads which not only cross the area between Bergamo and Varese but provide two ring roads for Varese and Como, intended to facilitate direct access to these cities and to the secondary border crossings with Switzerland. This was a major territorial infrastructure project worth 3.8 billion Euro. A company was set up for the purpose of the project, Autostrada Pedemontana Lombarda Spa (APL), a mixed public/private undertaking that has produced the plans and administrated the calls for tenders for the concession with project financing for two functional segments. But the project, which, for the reasons set forth above, could have represented an opportunity for extensive redevelopment of the foothills of the Alps, was born with an "original sin" that largely compromises its potential: the plan is to build a motorway, technically suited to cutting across the area, rather than a city road, which would be more suitable for a territory which has in the meantime become saturated and where travel is primarily local. Local road-building would be dealt with by individual city authorities, traded off for consent for construction of the main motorway, not with a view to optimising mobility but as a work of urban development and local enhancement. Thus the frequency of access, geometry and slope of the road and the planned speed limits would be those characteristic of a motorway designed to cut across an uninhabited area, not those suitable for an urban road such as this will actually be, and another opportunity to rationalise mobility by road in the foothills of the Alps has been missed.

The motorway has taken more than 10 years to plan, from the earliest drawings to the opening of the first section and of the Varese ring road, and it is not yet finished. Over the years the limits and anachronisms of the project have gradually become clear, and awareness of this and of the need to deal with its consequences has also emerged, along with a number of potential opportunities for action, which we will describe below (Fig. 3). 


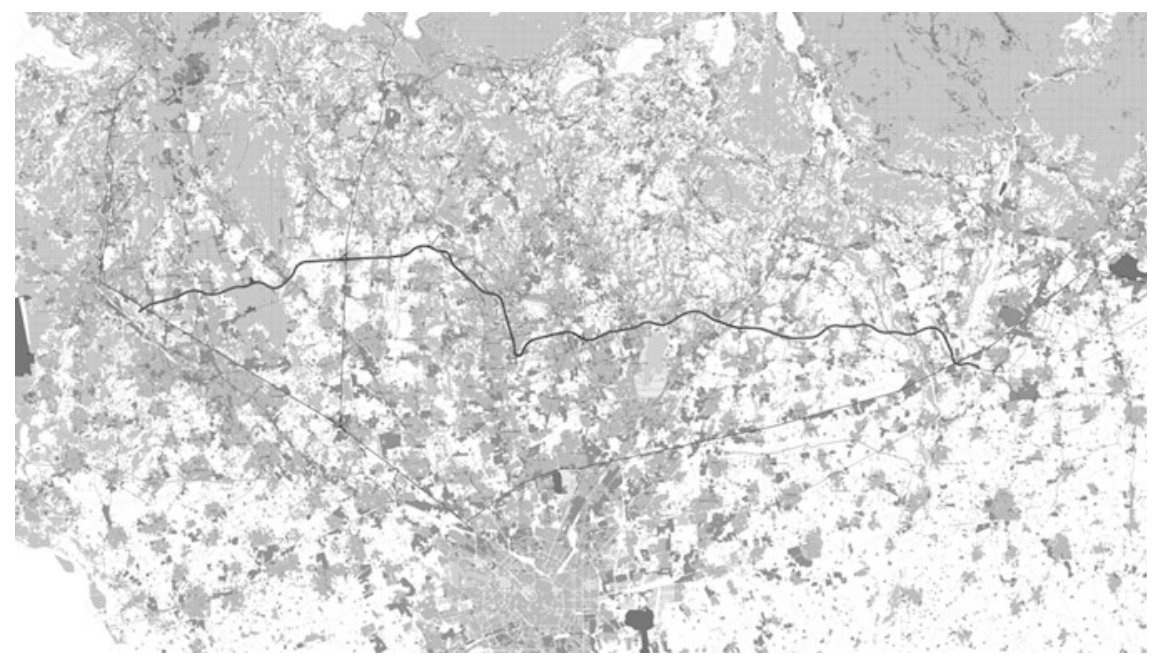

Fig. 3 Milan urban region and the layout of the Pedemontana Motorway. (Source Dastu Politecnico di Milano 2013)

\subsection{Anachronisms in the Economic System}

The first and perhaps the most serious anachronism is the one separating the project's economic and financial scenario from real market conditions, the nature of enterprise and development of planning in the territory. The "Legge Obiettivo", the legislative framework that accompanied the construction of the motorway (L. 443 2001, http://www.camera.it/parlam/leggi/014431.htm) has in fact facilitated procedures for awarding the work on a competitive basis to general contractors for long-term concessions in relation to which the enterprises take on all the costs and benefits of planning and implementation of the project followed by its operation for a number of decades.

It is not only the financial crisis that has underlined the limitations of this method. The initial results of the construction not only of the first section of the Pedemontana but, dramatically, in the case of another major motorway in Lombardy, the "Brescia Bergamo Milano" motorway, demonstrates how scenarios of use produced for technical and financial feasibility studies are guided by incorrect estimates based on obsolete urban dynamics and, perhaps above all, by the urgent need to find arguments to justify funding for the project. Let us not forget that the core business of the competing Italian general contractors is infrastructure construction (a certainty) rather than future management and maintenance, which is on the other hand the concern of political financial circuits in which the future can always been renegotiated. And so, where it has been possible to obtain complete financing and implementation of the project, the constructions built (a first section A, from the Malpensa international hub to the existing Milano-Como motorway in 
an integrated contract of tender) still have few users, and in the remaining parts financial uncertainty makes them dependent on the central government's intention to support them.

\subsection{Technical and Territorial Anachronisms}

A second set of anachronisms and inadequacies pertains not only to the relationship between the road's route and the territory, which we have already noted, but the way that the project ignores the landscape and natural habitats, especially in the preliminary phases. The motorway has over the years been seen as a construction which is indifferent to the landscape it crosses: it crosses the landscape, changes it, hardly ever adapts to conditions worth protecting and is never seen as an opportunity to build a new quality landscape through integrated planning. This has taken place in a very delicate area. On one hand, the motorway crosses a region where open space has been reduced to only half the total space, with densely developed areas with only islands of open space, sometimes very small, where agriculture is no longer viewed as a beneficial activity and most land is abandoned and degraded. On the other hand the motorway crosses several rivers and waterways (the Ticino, the Olona, the Bozzente Lura and Seveso river systems, the Lambro, the Adda) flowing from north to south, of great value in terms of landscape and ecology (Magnaghi 1995).

Over the years only a little attention has finally been paid to these areas. First of all, many of the rivers were protected by creating regional and local parks with the support of the municipalities. Then citizens and the politicians and associations representing them came to be aware of the importance of protecting these green areas and, in many cases, redeveloping them and rethinking their agricultural function, their use and their role in the ecosystem.

\section{Remedial Projects: A Work Team for Research and Action}

\subsection{The Request Submitted to Our Research Group: A Parallel Project}

The context and the project described so far represent the scene in which, between 2007 and 2010, a research team composed of Politecnico di Milano researchers and freelance professionals coordinated by the authors of this chapter were appointed by the chairman of Autostrada Pedemontana Lombarda (APL spa) to help direct landscape aspects of the planning of the road system in the foothills of the Alps. The team began its work at an advanced stage in the process of design and 
construction of the motorway. In the transition from the preliminary project to the final project, restructuring of the company managing the project led to the emergence of a need for a new management policy which paid more attention to territorial and environmental aspects and the quality of the work. This took place for a number of reasons: the need to mediate with the opposition of local governments which resisted the project, and the desire to act in a way that would be useful, and therefore with a strategic orientation, a relatively small budget allocated for environmental compensation and the chairman's political intention of giving the project a form that acknowledged the importance of the environment to a greater extent. In this climate, the company's directors considered it too difficult to redesign a number of aspects of the project, particularly the complementary roads and a number of sections in the main route, to reduce fragmentation of open spaces and ensure a better relationship with the city on either side of the motorway, despite the work team's objections. Design work therefore focused on environmental and territorial compensation. Within this more limited scope, the work group was granted vast powers including direct, autonomous interaction with local governments and social parties in the area.

But just what is environmental compensation? The "Legge Obiettivo" and the resolution passed by CIPE, the body in the national Ministry of Economic Development that controls funding and implementation of major public works projects, set aside 96 million Euro for environmental and territorial compensation projects, that is, for all actions intended to make up for damage produced by the project that could not be mitigated directly. These included a series of actions analytically identified in the budget through an overall matrix assessing the physical properties of the construction and the resulting environmental impact and economic payment. Their content, on the other hand, remains entirely indeterminate. They may be reduced to the form of pure cash transfers to city governments, for use in any project - as has almost always been the case in Italy. Or they may be used for ecological and landscape purposes within a plan which is not fragmentary, and is capable of reorienting the expectations of local governments and triggering a widespread process of environmental redevelopment which goes beyond the resources invested in it.

\subsection{Environmental Compensation: The Character and Form of a Parallel Project}

The environment compensation project is therefore the result of common choice of this second definition of use of the compensation funds and partial inheritance of previous research work by the work team led by the authors of this essay.

The tools and vocabulary used in a classic practical reflective action are those of urban analysis and modern design, in the exploratory modes and in direct, 
inevitably risky confrontation of reality, both in its implicit forms (Dematteis 1995) and in its practical and critical forms (De Carlo 1964; Secchi 1996).

The overall policy guiding investment of Pedemontana Lombarda compensation funds is inspired by a general assumption and by two visions of the territory which were developed in previous projects.

The assumption is assignment of a key role to the remaining open spaces, in their various forms and uses, to the process of widespread urban redevelopment. The first of the two visions is recognition of a cross-cutting territorial scenario, between the Adda and the Ticino, complementary to the classic radial figure of Milan, capable of connecting natural resources and the character of local settlements with a view to achieving extensive urban redevelopment. This vision is entirely consistent with a plural, multicentric vision of the constructions in the urban region (Magnaghi 1995; Lanzani 2003; Macchi Cassia et al. 1994; Longo 2006) (Fig. 4).

The second vision is that of a potential Greenway cutting across the area, already developed in the "Dorsale Verde Nord Milano" project commissioned by the Province of Milan in 2007, which gives "territorial body" and visibility to the plan for a provincial ecological network. In this project, which is the principal matrix of the environmental compensation scheme, the functional ecological scheme has been translated into a prospective design and then a guide to the design resources present which are capable of integrating the plurality of projects and policies required to

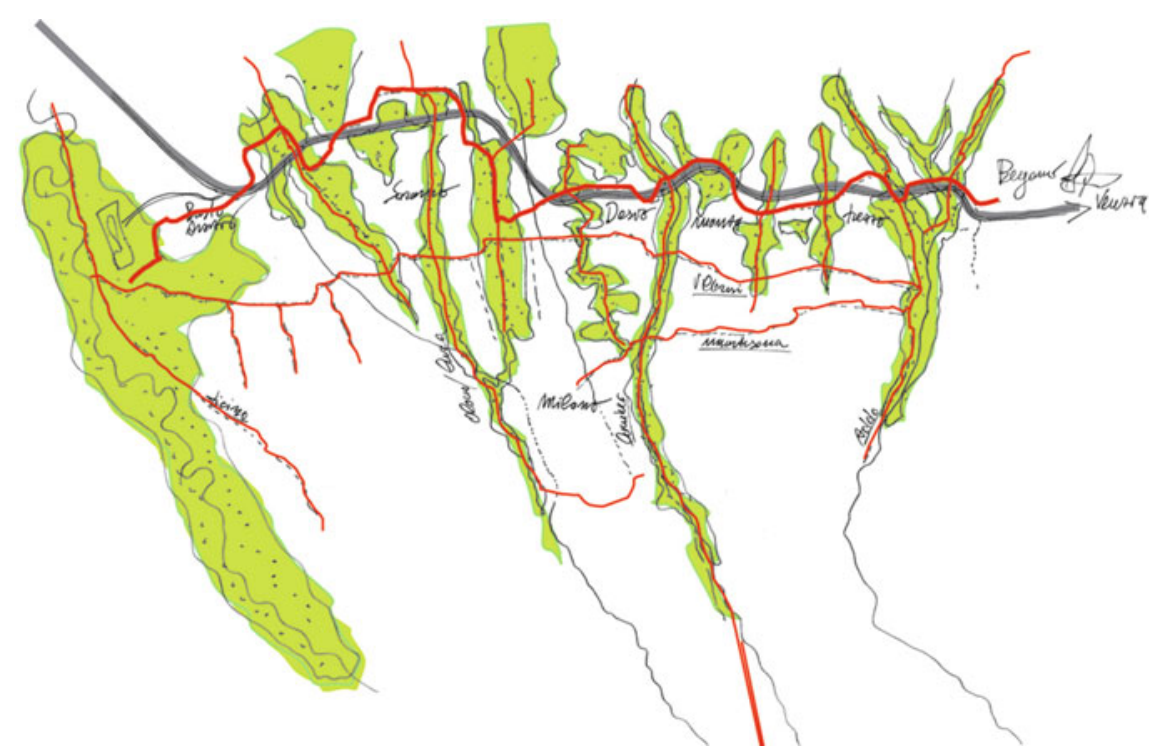

Fig. 4 Masterplan 2008. A general scheme of the vision for the Milan Urban Region. Slow infrastructure integrated with the main infrastructure frame, parks and rivers as natural background and green infrastructure. (Source Dastu Politecnico di Milano 2008) 
redesign the urban area at the foothills of the Alps (Lanzani et al. 2009). The design of the backbone, integrated with the first cross-cutting figure, represents the planning and geographic reference on which to locate the overall scheme for environmental compensation of the Autostrada Pedemontana Lombarda.

Consistently with these assumptions and this vision, the Masterplan that has guided the compensation project consists of a diagram revealing the presence of a complex system of open spaces which the planned motorway will cross, to be reinforced in view of their specific nature, interconnecting them with a new ecological and landscape infrastructure, a Greenway organising a sort of linear park running along its main axis (Longo 2009).

The proposed diagram is rather complex. On the one hand it defines the "rules" and "procedures" for interaction with various parties, while on the other it allows the results of this interaction to be implemented in concrete projects with a precise location in the area, in a continuous, nonlinear interweave of planning and design. The idea behind the project has been expressed and adapted on the basis of specific conditions of power and legitimacy in the role of the designers, stakeholders and clients. In adapting it, it has been modified to suit different scales in relation to the different forms the project takes (Fig. 5).

The design concepts were discussed with public and private clients with specific interests and visions which did not necessarily coincide with those of the work team, permitting verification and, in some cases, falsification of its assumptions and elements. Interdisciplinarity and curiosity - testing the limits between disciplinesand familiarity with the context - taking the local dimension as far as it would gostudying interaction with real processes of transformation of the territory were essential conditions for the development and future transferability of knowledge (Fig. 6).

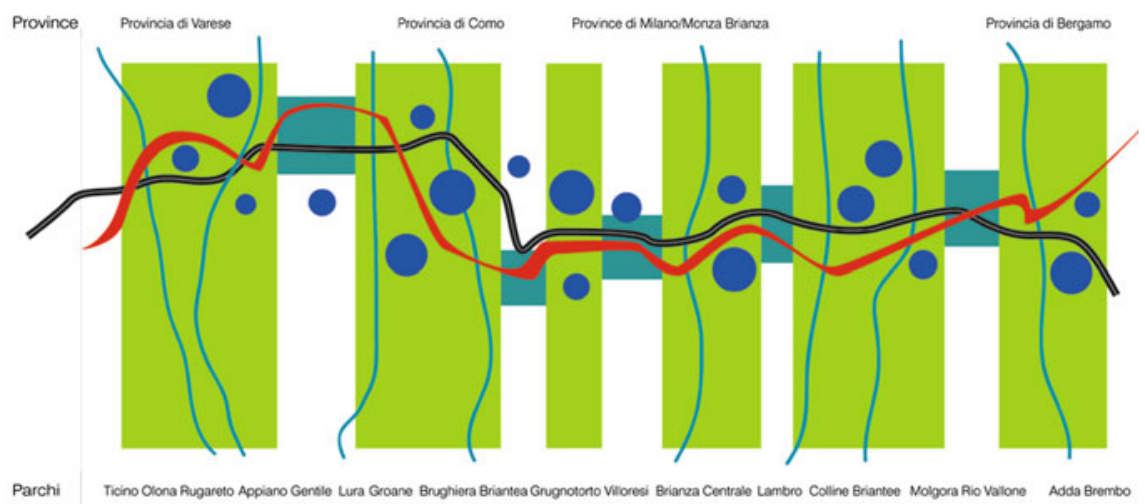

Fig. 5 Masterplan 2008. The diagram. (Source Dastu Politecnico di Milano 2008) 


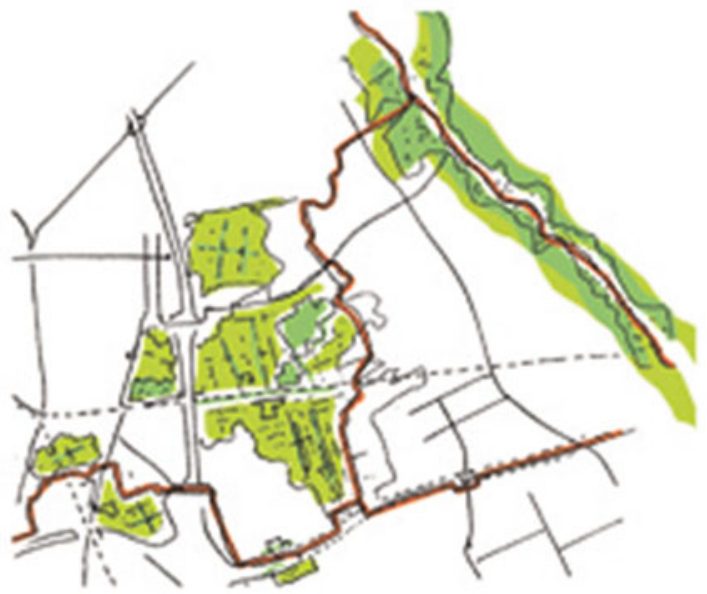

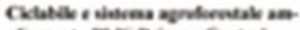

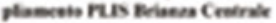

conirmor

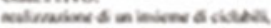

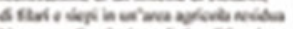

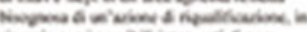

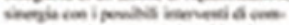

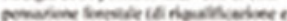

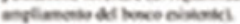

consen:

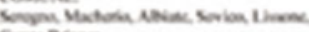
Conas Rave

coverncoviscest

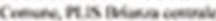

receros

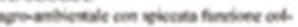

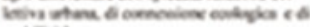
menolobs

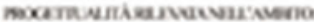
Cond Wod Net Mlow horicis

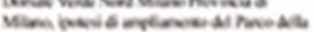

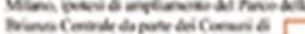
Matem dive Sobections $\square$

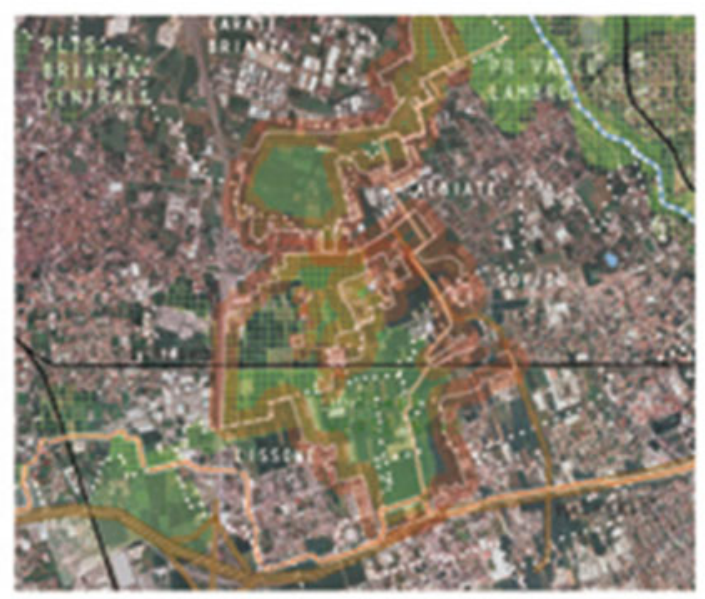

pascanow cin:

- enerdi

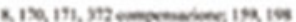

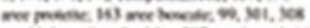

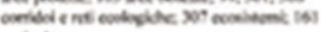
corvebus

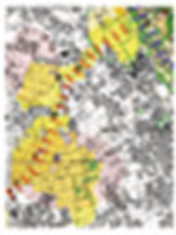

cusione

arn tcolosacue rep seave

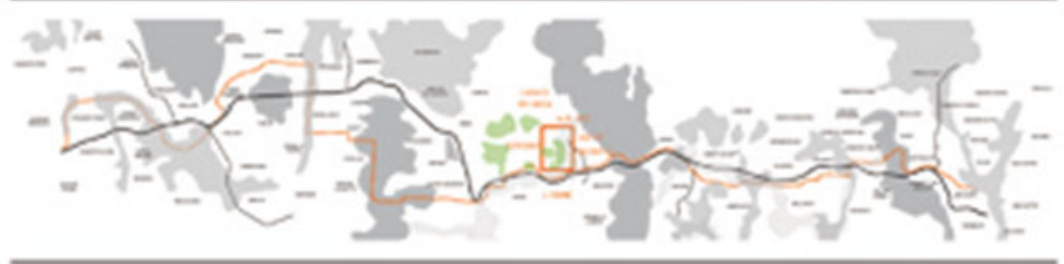

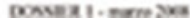

Fig. 6 Masterplan 2008. Interaction form for the local project "26". Each project has been discussed and outlined with local administration both in political and technical issues (Dastu Politecnico di Milano 2008) 


\section{Results and Direct Effects}

\subsection{Proposals for Implementation, Planning and Territorial Engineering}

The transition from the Masterplan to the subsequent phases in the final project was characterised by two stages. On one hand, it is possible to adapt the route of the Greenway, designed as a whole, to the different systems of open spaces, while the local projects developed in agreement with local governments may in turn be adapted to the Greenway. On the other hand, a number of choices in the route of the Greenway, and above all some of the content of the local projects, reflect the real balance of power among the various players involved and cease to be expressions of a technical intention, but become the temporary result of more complex political interaction: the local projects as negotiated "betray" the principle behind the project, which is deformed and sometimes weakened, but takes on a new concrete form in relation to the majority of experiences of large-scale urban planning and landscape design in our country.

Though it is defined as a parallel project which is relatively separate from the motorway project, the compensation work, at some limited points, can legitimately interact with the main project and the technical facilities (especially hydraulic facilities) connected with it.

The balance of power obviously ensures that the compensation project almost always has to adapt to the requirements of the motorway project. But it occasionally manages to have an impact on the main project, redesigning some of the service areas, modifying some sections of the route, and partially redrawing some of the intersections, with reformulation of some of the hydraulic solutions and above all some cases of more integrated design of greenery in the strip immediately adjacent to the infrastructure.

\subsection{Technical and Political Discontinuities, Expectations and Unforeseen Developments}

The balance that was established during review of the preliminary project and settled in the final project redrawn between 2008 and 2010 is broken at the stage of management of the executive project.

With the changes in the company and the management of the Pedemontana project, the company no longer acts as a substitute in a wider-ranging territorial redevelopment project. This is a role that is not new in Italy, as we have seen, but which is no longer of interest to the new management. Above all, it is a role that is not picked up on by the regional government of Lombardy, which ought to have been its principal promoter. The project thus finds itself orphaned of political tutorship and strategic technical guidance beyond the construction of the project. 
The procedures set forth in Italian legislation regarding tenders discourage continuity in planning and facilitate the advent of parties who inevitably have an interest in marginalising this complementary project in their work. For while continuity between the final project and the executive project is normally forbidden in Italy, the only body entrusted with checking the consistency of the project with general territorial and economic aspects is the central government, through the Inter-ministerial Committee for Economic Planning (CIPE), a body that is too far removed to be able to adequately check compliance with the very conditions it specified during approval of the project, and which does not play a role in planning. Thus, the general contractor is left alone, free to use his power as he wishes.

One of the most direct consequences of this, in the case at hand, is increasingly sectorial development of the Greenway project, which is treated as a second infrastructure project (a cycle path), rather than as an infrastructure for the landscape and environment capable of triggering environmental redevelopment projects going beyond the route itself. At the same time, local projects have mostly been abandoned to their fate and to the municipalities' absolute power, and are increasingly far removed from the original idea that integrated them.

What remains is still substantial: it is a rule introduced in the Masterplan which limits possible projects to a number of specific material projects: cycle and pedestrian paths, meadows, bushes, hedges, rows of trees. Though linked with "green" environmental projects, their link with a more complex landscape project is weakened. And now, at a stage in which the compensation projects still have not been implemented, even though the first section of the motorway has been built, while a number of municipalities are going back to the final project decisions others are giving them up in favour of new designs and set-ups, in a patchy overall situation.

\subsection{The Impact of the Recession}

In addition to all this, starting in the year 2010 the project as a whole encountered financial difficulty. The initial expectations of involvement around initial public investment of a majority of private capital have not been met. Almost all the resources available for completing the project are still public funds. They are sufficient to permit implementation of only one section of the project: the western portion, which, like the eastern portion, has always seemed to meet lower demand. What a few people initially reported now appears to be obvious to everyone: the entirely overestimated scale of demand for mobility not supported by third parties but proposed by public and private sector parties who already had an interest in seeing the project go through. It also appears clear that the economic recession is not merely a temporary trend and has further reduced mobility in the region.

The horizon appears uncertain at the outset of 2015. On one hand, it is unclear whether the company will have the resources required to complete compensation for the section of the motorway built. Work on the compensation project has not 
proceeded at the same time as construction of the motorway, or ahead of it, as stated in the masterplan and in the commitments publicly undertaken by the company's management. On the other hand, it is unclear if and when construction of the motorway will continue. An increasingly large number of players (the majority of the municipalities and a growing segment of the population) hope that it will be cancelled, while on the other hand the region, the nation and, above all, a number of important business lobbies continue to defend the project at any cost and contrary to all empirical evidence. This stand-off is preventing redefinition and rescaling of the continuation of the project and conception of a new integrated mobility project (limited to a number of sections with redefined carriageways) and ecological balancing and redevelopment of the landscape in the area (resuming and expanding on the environmental compensation project).

\section{Results and Indirect Effects}

\subsection{Going Beyond Compensation}

It is likely, though uncertain due to the scarcity of funds, that the unitary compensation project, the Greenway, will be completed, while local projects will be implemented here and there. A number of municipalities have already adopted them, while others have preferred to use the resources allocated to compensation for pretentious little city parks or, even worse, allocated them to projects unrelated to the damage to be compensated. The balance is therefore modest, if considered in terms of the engineering, architectural and landscape projects under way. After all, as we have noted, the practice of research into remedial actions implemented opted right away for processes and projects implemented on the sidelines by other parties. In this prospective, the picture is definitely more complex and open in terms of results.

\subsection{Development in Other Studies and Administrative Planning}

First of all, two documents and studies have followed up on this work: the compensation project has inspired further study and exploration of possible projects. The first document was prepared independently by the Region of Lombardy as a tool for in-depth study of its landscape plan. It consists of guidelines for infrastructure design (Regione Lombardia 2010). It picks up on the plan for infrastructure and compensation contained in the Masterplan for compensation for the Pedemontana project at some significant points, laying the foundations for 
wider-ranging discussion of some of its more general hypotheses, particularly in the public administration and certain public agencies.

The second document, on the other hand, is an action-study prepared by the same group of researchers led by the authors of this contribution for one of the three provinces the motorway runs through, the Province of Monza and Brianza (Lanzani et al. 2013). This project not only refines and fine tunes the vision of open spaces in the foothills of the Alps but lays down guidelines for possible redevelopment based on two distinct ways of working. The first model deals with the enclosed areas in the most urban part, where about two thirds of the total land is now built up, while a second model addresses the portion where open farmland still forms a continuous fabric dominating the landscape, where only about one third of the total land has been built on.

The Province, an institution in charge of territorial planning, is the right counterpart for development of reasoning regarding possible reorganisation of productive spaces in relation to construction of the motorway infrastructure. It is therefore possible to reason about different degrees of accessibility to their principal settlements and ways of fitting the project into the more general fabric of the urban area. The study is designed as an informal tool for coordination between the Province and the Region but also, though not complete, concerns the Province's general plan.

\subsection{Implications Within the Ordinary Spatial Planning}

A second indirect effect is the result of a return to these elements of the vision and the project in the ordinary spatial planning documents of the municipalities and provinces. Its greatest impact, supported, as we have seen, by continuation of the work, is on the Provincial Plan for Monza and Brianza. A complex system of instructions regarding strategic agricultural areas and the structure of the green network for recomposition of the landscape and the boundaries of protection of the landscape defends the territory against possible new urban development and sets forth a number of tools for redevelopment of the open spaces the motorway passes through.

The Masterplan project and local projects have had an impact on numerous municipal plans that have been prepared in the meantime. Here and there in the three provinces, local land use plans pick up on a number of wider-ranging plans contained in the masterplan, and sometimes include in their documents the most specific projects contained in the final plan, and sometimes both.

In this case, the compensation project becomes not so much a project to be implemented but inspiration for local discussion, political choices and technical actions developed through zoning laws, regulations and rules determining transformations. 


\subsection{The Project in Social Interaction and in the Phases of Policies}

If, however, we leave behind the world of ordinary administrative deeds, the most significant indirect effect of the project has perhaps been a proliferation of initiatives, both institutional and otherwise, promoted by committees, associations and networks of municipalities in favour of the construction of new territorial parks or federations and mergers of existing parks in the open spaces the motorway passes through.

These initiatives demonstrate an awareness of the importance of establishing new structural parks. During development of the masterplan, the parks boards in which groups of municipalities work together and collaborate, often on a voluntary basis, were the most active counterparts of the company Autostrada Pedemontana Lombarda and the work team. On these occasions the parks boards revealed their importance in terms not only of protection of the remaining open spaces but also, and above all, for rethinking these spaces as an environmental infrastructure of decisive importance for restoring the ecological balance, redeveloping the landscape, and ensuring the well-being of citizens and even the success of enterprises in the territory. A number of recent proposals for reorganisation of park geography pick up on the vision and structure of a number of aspects of the Pedemontana motorway compensation project, which in this case takes on a life of its own (independently of the motorway itself) as an idea included in a technical text and a plan that has ceased to have a direct impact on the motorway project for which it was conceived and which dialogues with and feeds different processes of transformation and governance. The text therefore becomes material contributing to the construction of on-going, open processes.

\subsection{Traces May (Surprisingly) Be Found in Other Projects}

Lastly, it is worth noting a number of material transformations of open spaces, a number of minor environmental projects that have been implemented by municipalities, parks boards or provinces, taking into account the planned arrival of the Greenway or of some form of environmental compensation. This sometimes takes the form of planning for connections which may remain on paper or require adaptation if construction of the motorway and/or the compensation project does not continue.

These works could then become fragments of an uncompleted project, or, less likely, provide the inspiration for a different future plan. Once again, this is happening on the basis of a logic which is far from the pyramidal, sequential development of modern architecture and engineering projects, but in a procedural, circular logic rooted in a different way of viewing the relationship between planning and the formation of architecture and landscape in history. 


\section{Conclusions: The Outcome of a Practical Process}

The conclusions of such a process can only be hypothetical and open. The goal of the experience described was explicitly operative, and went beyond the methods normally used to describe a research project. The authors' direct involvement obviously poses a limit in terms of distance in relation to a process that is still under way, but we believe that it also constitutes the specific focus of an increasingly necessary way of working, that of going beyond the limitations of laboratory research to get involved in processes and bring together fields of knowledge that are normally kept distant and separate. It is from this point of view that the acquisitions of this process of research and action seem to us to be worthy of brief description and discussion: as open notes for the development of further processes, rather than as a conclusive balance; as notes which do not outline a space for innovation but an experimental action of sedimentation of know-how and working methods whose value lies in their continuity.

\subsection{In the Absence of Institutions, We Must Accept Responsibility Going Beyond Technical Aspects}

The first acquisition concerns the way of interpreting the context, as well as noting its historical features. The Autostrada Pedemontana Lombarda affair appears consistent with the usual state of affairs in Italy, in which an organisation takes the place of institutional policies and in which the institutions in charge of territorial governance fail to fulfil their role even when they officially take back control of the process. This condition cannot be simply the subject of criticism, or be evaluated on the basis of its distance from more advanced European situations (a frequent temptation), but must underline the polytechnical, cultural and civil responsibility of the institutions in which such research and projects are developed, in the direction of necessary reform and overall improvement of existing conditions. It therefore reveals a broad political and cultural arena regarding the ways in which the principal opportunities for management of territory and infrastructures are handled and the interaction of places where know-how and responsibility are formed.

\subsection{In Search of Interrelations}

The second acquisition is that of the ways in which the project fits into its context, in search of conditions for reform: that is, by constructing the conditions required for dialogue between different fields of knowledge and the people who put them into practice, as a key technical goal. 
The paradox of management of complex processes which we face is that the various elements are dealt with separately, with the aim of achieving greater control, underestimating the additional expense and inconsistencies this generates, benefiting only the apparently efficient planning of linear processes. Once againand by no means to our surprise - we find ourselves involved in a process which has turned out to be self-referential and circular, which tests the ability to integrate geographical interpretation of the territory, reading of the large-scale formation of territories, large-scale planning, landscape design with an inherent focus on historical landscapes, the sedimentation of the work on which it is grafted, and landscape design. The language, methods and tools used in the project had to be adapted to these points of view in interaction with decision-makers, planners, associations and citizens.

\subsection{Constructing Demand, Redefining Problems: The Political Aspects of the Job}

The third acquisition pertains to the identity and specific position of the planner, who, in the scenario we have described, is at risk of becoming no more than a communicator, a mediator, or, in the most economically advantageous case, a managerial planner: in any case, a largely useless role in which it is unlikely he or she will remain neutral.

If there is a definite prerogative of architecture and urban planning projects in Europe and, specifically, in Italy, it is the need (rather than the desire) to establish a critical relationship with the territorial and civil context of territories and to propose possible future alternatives to the present condition from within certain defined and limited powers (De Carlo 1964; Secchi 1996; Gregotti 2014; Viganò 2010; Fabian 2013). On the other hand, quality of dialogue is achieved first of all through holding clear positions, also in order to make the various counterparts accept their responsibilities as a result. This requires real dialogue, which can be risky, if the risk is that of coming out of it with different positions, projects and points of view on things. The need to implement real processes in order to have an impact and produce innovation can from this point of view translate into dissident attitudes, with a limited range of power in the most difficult processes and dialogues: what Vaclav Havel called the space of "the power of the powerless" (Havel 1985). It is from this point of view that even the most complex and contradictory affairs, such as the one described in this essay, can offer an opportunity for a process of study and action which continues even after the key players have necessarily left the scene. 


\section{References}

Ambrosini, G. (2002). Strade e paesaggi. Celid, Torino: Letture e strumenti progettuali.

Angrilli, M. (2002). Reti verdi urbane. Roma: Palumbo.

Balducci, A., Fedeli, V., \& Pasqui, G. (Eds.). (2011). Strategic planning for contemporary urban regions. Farnham: Ashgate.

Bevilacqua, P. (2008). Miseria dello sviluppo. Roma-Bari: Laterza.

Boeri, S., Lanzani, A., Marini, E. (1993) Il territorio che cambia, Ambienti, Paesaggi e immagini della regione milanese. Milano: AIM, Abitare Segesta

Bonomi, A., \& Abruzzese, A. (2004). La città Infinita. Milano: Bruno Mondadori.

De Carlo, G. (1964). Questioni di Architettura e Urbanistica. Urbino: Argalia.

De Carlo, G. (Ed.). (1966). La pianificazione territoriale urbanistica nell'area milanese. Padova: Marsilio.

Dematteis, G. (1995). Progetto implicito: Il contributo della geografia umana nella scienza del territorio. Milano: Franco Angeli.

Fabian, L. (Ed.). (2013). New urban question. Ricerche sulla città contemporanea 2009-14. Roma: Aracne.

Fabian, L., \& Pellegrini, P. (2012). On Mobility 2 Riconcettualizzazioni della mobilità. Venezia: Marsilio.

Gasparrini, C. (2003). Passeggeri e viaggiatori. Bari: Meltemi.

Gregotti, V. (2014). 96 ragioni critiche del progetto. Milano: Rizzoli.

Havel, V. (1985). The power of the powerless: Citizens against the state in Central-Eastern Europe. London: Hutchinson e Co.

Ischia, U. (1999). Nuove immagini del territorio milanese. Territorio, 11, 7-108.

Körner, S., Holzapfel, H., \& Bellin-Harder, F. (Eds.). (2012). Landschaft und Verkehr. Kassel: Kassel University Press.

Lanzani, A. (1991). Il territorio al plurale. Milano: Franco Angeli.

Lanzani, A. (1996). Lombardia. In A. Clementi, G. Dematteis, \& P. C. Palermo (Eds.), Le forme del territorio italiano. Bari: Laterza.

Lanzani, A. (2003). I paesaggi italiani. Roma: Meltemi.

Lanzani, A., \& Longo, A. et al. (2009). Dorsale Verde Nord. Una guida alla scoperta degli spazi aperti del Ticino e dell'Adda. Maggioli, Sant'Arcangelo di Romagna

Lanzani, A. (2011). In cammino nel paesaggio. Roma: Carocci.

Lanzani, A., Alì, A., Gambino, D., Longo, A., Moro, A., Novak, C., Zanfi, F. (2013). Quando l'autostrada non basta. Infrastrutture, paesaggio e urbanistica nel territorio pedemontano lombardo. Quodlibet Studio, Macerata

Longo A. (2006). Parchi/infrastrutture/infrastrutture/parco. Simulazione di una mappa istituzionale. Territorio $39,45-147$

Longo, A. (2009). Un parco per la città infinita. Urbanistica, 139, 16-49.

Macchi Cassia, C., Orsini, M., Privileggio, N., \& Secchi, M. (Eds.). (1994). XMilano. Milano: Hoepli.

Magnaghi, A. (ed) (1995). Bonifica, riconversione e valorizzazione ambientale del bacino dei fiumi Lambro, Seveso, Olona. Linee orientative per un progetto integrato, Irer, Urbanistica Quaderni, Aprile

Moretti, A. (Ed.). (1996). Le strade. Un progetto a molte dimensioni. Milano: Franco Angeli.

Nucci, L. (2012). Reti verdi e disegno della città contemporanea. Roma: Gangemi.

Regione Lombardia (2010) Piano paesaggistico, Tracciati base paesisitici, Regione Lombardia. (http://www.territorio.regione.lombardia.it/shared/ccurl/269/348/3PTR_PPR_Lineeguida_ Tracciati.pdf)

Sapelli, G. (2005). Modernizzazione senza sviluppo. Il capitalismo secondo Pasolini. Milano: Bruno Mondadori.

Secchi, B. (1996). Un progetto per l'urbanistica. Torino: Einaudi. 
Secchi, B. (Ed.). (2010). On mobility. Infrastrutture per la mobilità e costruzione del territorio metropolitano. Venezia: Marsilio.

Secchi, B., \& Viganò, P. (2014). Porosità isotropia in Antifone e Zeto, 25, 26-132.

Shannon, K., \& Smets, M. (2010). The landscape of contemporary infrastrucure. Amsterdam: Nai Publishers.

Tiberghien, G., \& Desvigne, M. (2009). Intermediate natures, the landscape of Michel Desvigne. Basel: Birkhauser.

Viganò, P. (2010). I territori dell'urbanistica. Roma: Officina.

Waldheim, C. (Ed.). (2006). The landscape urbanism reader. New York: Princeton Architectural press. 


\title{
Plug\&Play Places: Subjective Standardization of Places in Multilocal Lifeworlds
}

\author{
Robert Nadler
}

\begin{abstract}
Plug\&Play' is a technological term describing the immediate usability of items in a system without having to configure them. Referring to this term, the present chapter introduces the heuristic concept of 'plug\&play places', which allows for an understanding of the meaning of places for multilocal people. Based on a set of 25 qualitative interviews with creative knowledge workers, this concept was developed in order to illustrate a specific feature of places within multilocal lifeworlds. This specific feature consists in the fact that multilocal persons configure a new place upon their first arrival, but on subsequent visits these places are immediately functional and usable within their multilocal lifeworlds. They standardize the places to be 'plug\&playable' in their lifeworlds. Comparing this finding to the existing body of literature on the standardization of space and places, it is argued that one has to distinguish between a subjective and an objective type of standardization of places, with the former not necessarily changing the physical space. Every multilocal person proceeds to an individual configuration of these places, in which only a limited quantity of objectively standardized elements are incorporated. In this sense, ideas of objective standardization of space have to be examined critically as mobile lifestyles do not automatically resort to objectively standardized places.
\end{abstract}

Keywords Plug\&play places - Multilocality - Creative industries - Mobility • Place attachment - Standardization of places

\footnotetext{
R. Nadler $(\bowtie)$

Leibniz Institute for Regional Geography, Leipzig, Germany

e-mail: R_Nadler@ifl-leipzig.de 


\section{Introduction}

Mobility becomes an ever more important aspect of our everyday lives (Urry 2000); geographical areas covered by our individual actions keep on expanding (Werlen 2000). Therefore the number of places relevant to our lives increases. The geographies of everyday live take on new forms, which are similar to archipelagos (Duchêne-Lacroix 2009). Mobile people have to make huge cognitive efforts in order to manage this multitude of places. Generally, places can be understood as objects of everyday life (Weichhart 1990). They can be differentiated from one another, and most people use this feature of places to differentiate between a 'here' and a 'there'. According to Weichhart (1990), places take on a denotative (physical) as well as a connotative (psychological) function for our orientation in space. Since the 1960s, psychologists, urban planners, and geographers have especially studied the denotative function of places. Lynch (1960) tried to facilitate the legibility of urban areas by analysing the perception of the built urban environment by residents and other 'city users' (cf. Martinotti 1996 for a discussion of different groups of city users). Building on Lynch's findings, Downs and Stea (1977) studied how one relates to a place and its expression in mental maps. Within the frame of Humanistic Geography, geographers also started to combine knowledge from social phenomenology and research on spatial perception (Buttimer 1976). Here, aspects of everyday life were stressed and places were looked at from an everyday perspective. As such, places act as anchor points for personal identities and they work as reference points for individual localization. Sociologists also point out that places can be determining factors for a person's attitudes, norms and values (Mühler and Opp 2006). Finally, places can also be considered as a set of conditions determining individual action (Petzold 2010).

No matter the definition, places and place relatedness are most probably being affected by the increasing demand for mobility in our post-modern societies. This hypothesis was a starting point for numerous multilocality studies. This field of research investigates the distribution of everyday lives over various places (Rolshoven 2006). Multilocality is described as a phenomenon midway between the following two extremes: first, daily commuting and, second, permanent migration (Weichhart 2009). Research topics both focus on the circulation between places as well as the multiple localization of individual lifeworlds. In particular this second aspect has been less researched. The wider field of mobility studies mainly scrutinizes movement and circulation, but often overlooks how place attachment is evolving through mobility.

Open questions comprise the following: What specific demands do multilocal people express regarding the characteristics of their places? How should places be designed in order to provide to multilocal people's needs? Which specific services and infrastructures do multilocal persons demand? This paper seeks to shed light on this scarcely studied issue. In particular, I will focus on the aspect of standardization of space and places using the exemplary cases of multilocal creative knowledge workers. I understand standardization of places as a means to ensure their 
'playability'. With the help of standardization, differences between places are reduced and orientation is less dependent on the specific features of a given place, and as such is made easier. An issue of interest is how multilocal people actually create such comparability between places and how do they appropriate their new places. Do they actually consume specific market-supplied services, or do they also develop their own practices of place standardization?

Therefore, I will use the subsequent section to introduce to the concept of 'plug\&play', which I deem helpful in order to understand 'standardization' in complex systems. This excursus is followed by a literature overview on the standardization of places. The fourth section will explain the specific character of creative knowledge work and its embeddedness in mobility. Then, Sect. 5 will deal with the methodology used during my fieldwork, while Sect. 6 will present its results. In Sect. 7, findings will be discussed and the concept of 'plug\&play places' will be introduced as a result of my analysis. The final section will indicate fields of interest for future research, interested in the spatiality of mobile lives.

\section{The Concept of 'Plug\&Play'}

Nearly all of us have used USB devices while working on our computers. USB stands for 'universal serial bus'; it is an example for the standardization of interfaces and software in the field of computer sciences. Such a type of standardization has been observed since the early 1990s and it is widely subsumed into the concept of 'plug\&play' (Kelsey and Kelsey 1995; Shanley 1995; Bigelow 1999). 'Plug\&play' devices are constructed in a way that they can immediately be 'played' without any major configuration effort after they were initially 'plugged' into a computer system. Plug\&play devices are compatible with as many systems as possible. The aspect of 'plug\&playability' consists of both the hardware (the physical design of a device's plug) and the software (the specific codes used to automatize communication between a device and a system). As such, computer users enjoy an enhanced utility of their peripheral devices, because they do not have to undertake a proper installation. Ideally, the device (e.g. a printer or an external hard disk drive) communicates through standardized protocols with any computer. The device and the computer recognize each other and exchange information about their resource requirements (e.g. in terms of processing power). Once an initial recognition between the device and the computer took place, the device is familiar to the system and it must not be recognized again upon future connections. This standardization and automation massively reduced efforts for computer users. Once 'plugged' into the system, a user can immediately 'play' a device upon further reconnections to the computer system.

Today, this technology is increasingly based upon wireless modes of connection. We can easily stream our photos from our last weekend trip to our TV screens using Bluetooth connections, or we are able to print out the flight ticket from our tablet PCs without having to plug a cable into the printer. In the future, plug\&play 
technology is expected to facilitate the integration of devices into larger networks instead of individual local computer systems (UPnP Implementers Corporation 2006). Yet, the principal of 'plug\&play' remains the same: It facilitates the usability of elements within a system through a standardization process.

This simplification of systemic integration is also appealing in a metaphoric way. In the field of business studies, the idea of 'plug\&play' was applied for the development of more efficient organizational structures and the design of more flexible production chains. Economist Veryard (2001), e.g., imagined companies as organizational systems - equal to a computer system - becoming more successful if they are capable of flexibly integrating and detaching business modules according to market demand. The idea of 'plug\&play' has however not yet been adopted by space-related studies in social sciences. Nevertheless, also social scientists observe phenomena, which resemble 'plug\&play' situations regarding people's own relation to space. I will show this in the subsequent section by introducing research findings that deal with the standardization of places.

\section{Standardization of Places in a Mobile Society}

Various spatial manifestations of the mobile society were recently portrayed in the media. One such phenomenon is the emergence of so-called coworking spaces (Schürmann 2013; Johns and Gratton 2013; Aguiton and Cardon 2007). Coworking spaces are shared office rooms that can flexibly be rented by office workers. The offered service goes beyond the mere provision of physical space, desks, or information and communication technology. Most coworking spaces also foster networking and exchange flows between their customers. Additionally, coworking spaces offer catering and specialized business services (e.g. web design, tax advice, business planning). Another phenomenon of standardization of places can be observed in the real estate sector. On 23 March 2014, journalist Nadine Oberhuber described in an article for German daily Frankfurter Allgemeine Zeitung Online that micro apartments become increasingly popular in central neighbourhoods of large European cities. These micro apartments seek to attract highly mobile professionals, whose workplace is located too far away to enable daily commuting. For these professionals, micro apartments offer a convenient full-serviced second home and as such a flexible alternative to relocation. Micro apartments are small, furnished and comparably cheap modes of accommodation. They include services like cleaning-up and contract processing with internet providers, or gas, electricity and water companies. A real estate developer, who was quoted in this article, spoke of 'plug\&play solutions' to dwelling. Also in this case, consumers can resort to standardized places in a temporarily flexible way and in different cities, and they will always know what service they are ought to expect.

Sociologist Ritzer $(1993,2010)$ described this standardization of consumption modes, which is neither place-specific nor much embedded in local cultures, as 'McDonaldization'. Drawing on the examples of business models such as IKEA 
furniture stores and McDonald's fast food restaurants, Ritzer described four central properties characterizing the standardization of places. First, these places are based on efficiency: Quantity is more important than the quality of the sold products and services. Customers should consume a lot and repeatedly. Second, calculability should be a main characteristic of the offered products and services in these places. The customers should know that they can afford a lot because of moderate prices. Third, price levels are stable and comparable between stores from different places, and the execution of sales and other services are standardized in a way that they are predictable regardless of the place. Fourth, business models comprise a rigid control of social interactions between sales people and customers. Salesmen are taught standard mechanisms and routines regarding the interaction with customers, and customers' behaviour in these stores is shaped through marketing strategies.

Dutch sociologist Duyvendak (2011) studied the standardization of places drawing on the example of global hotel chains offering identical services across the world irrespective of local cultures. His findings show four different types of highly mobile clients in these hotel chains, each representing a specific mode of place attachment. Duyvendak (2011: 12/15) introduces these four types with the help of a two dimensional matrix. Here, one dimension represents attitudes towards one's own mobile life (positive vs. negative), while the other consists of the types of places used within this mobile life (generic vs. particular places). This second dimension is interesting as it demonstrates the widely different features characterizing places used by mobile people. Duyvendak's notion of 'generic places' refers to the ones that are able to provide identical atmospheres all over the globe. Local culture is mainly ignored by generic places. Instead a global and standardized culture is being staged. For highly mobile people with positive attitudes towards mobility, these places can become a home, which is everywhere at hand. At the same time, these places hinder place attachment and settlement for those highly mobile persons with negative attitudes towards mobility. For the latter group of people, generic places do not provide a satisfying option for place attachment.

The lack of distinctiveness of standardized places was also a starting point for Augé's (1995) research on so-called 'non-places'. Augé argues that places are normally embedded in historical narratives and relational systems with social groups, which form the identity of a place. Yet, increasingly one can observe the emergence of places that become more relevant in our lives, but that are not framed by a specific history and/or relation to social groups. These places do not function as anchor points for feelings of belonging and attachment. This is why Augé calls them 'non-places'; they simply do not exist in our collective memory. According to Augé, the new places of a mobile society, e.g. airports, motorway service areas, and refurbished train stations epitomise such 'non-places'. We travel through these non-places, but seldom are they the destination of our trips. There is no organically grown and stable social life inherent to these places. They are characterized by pure uniformity, which facilitates circulation of individuals within them.

The emergence of standardized places can be understood as a reaction to the increasing mobility of our societies in an era of globalization (Urry 2000; Larsen et al. 2006). Flexibilized labour markets have generated new demands concerning 
labour mobility, and this in turn contributed to create new mobile lifestyles, affecting how and where we work, live and spend our leisure time. Market-based actors react to these new demands by offering solutions like coworking spaces, micro apartments or global hotel chains. As such, they are driving forces in the process of standardization of places.

\section{Creative Knowledge Workers as Consumers of Standardized Places?}

Looking at the demand side, creative knowledge workers are an interesting focus group [for a detailed definition see Nadler (2014, pp. 22-73)]. In the late 1990s, they were identified as a group of highly-skilled professionals who regard the new flexibility of labour markets as an opportunity for their individual career advancement (Lange 2007). Critical scholars interpret work in the creative and knowledge economy as post-modern slavery (e.g. Bröckling 2007), but more optimistic observers also view it as a release from the rigid organizational structures of industrial work (Friebe and Lobo 2006). Both perspectives underline that creativeknowledge work is taking place in a dynamic and still poorly regulated environment. Creative and knowledge economies developed rapidly in the wake of outsourcing processes and the re-organization of industrial production. Today, creative knowledge workers function as providers of highly specialized services for other sectors. Creative knowledge work is organized in compartmentalized structures, consisting in specialized and temporary project groups. Hence, many workers are freelancers or self-employed. The work itself mostly deals with a largely immaterial value creation, and large investments into production facilities or office space are not as necessary as in other economic sectors. Still, only a few large corporations control access to the market, provide relevant distribution channels and define legal structures (e.g. copyright, intellectual property) for the commercialization of products and services (Caves 2000). Consequently, creative and knowledge economies are characterized by power asymmetries, leaving freelance workers in a vulnerable position vis-à-vis their contractors (Bröckling 2007; Hesmondhalgh and Baker 2008; Gill and Pratt 2008).

Given the characteristics of such a labour market, mobility requirements of workers are high (Florida 2002; Favell 2008; Pethe et al. 2010; Martin-Brelot et al. 2010). The strong degree of specialization of individual workers and the projects' short lifetimes require spatial flexibility in order to sell their own expertise and thereby make a living. Given that many creative knowledge workers are self-employed, they are also self-reliant when it comes to the organization of their geographical mobility. This is unique compared to other labour market segments. Nowicka (2005), e.g., studied the transnational mobility of employees of the United Nations. She found that UN officials almost act like diplomats; when relocating to another country they do not have to organize their mobility by themselves. 
The employing organization assists with paper work and provides relocation services, and relocation costs are even covered by the employer. Equivalent services and financial resources are not available to most creative knowledge workers.

This self-dependence makes of creative knowledge workers an interesting focus group for mobility studies. They have a strong symbolic power [e.g. in defining values, norms, lifestyles; cf. Lange (2007)] and at the same time these workers are personally involved in the organization of their mobility. Given the strong competition in the creative knowledge market, it can be assumed that creative knowledge workers try - to a certain extent - to limit their costs and as such avoid market-based offers for mobility (cf. Sect. 3). Furthermore, I expect creative knowledge workers to develop individual practices when organizing the incorporation of different (work) places, and the mobility among them, into their own lifeworlds. The central questions are: How do creative knowledge workers organize their multilocality? How do they get attached to a multitude of places? Are they potential consumers of standardized places?

\section{Methodological Design}

In order to answer these questions, I draw on results from an empirical study conducted in the years 2010-2012. During fieldwork, a sample group of 25 creative knowledge workers were interviewed, applying a mix of biographical narration and problem-centred interview techniques (Hopf 1995). Interviewing was combined with the visual method of mental mapping (Ploch 1995; Scholz 2011). Both tools of data generation are well suited for investigation in the understudied fields of mobility studies (Scherke 2011). Sampling had to respect the following criteria: (1) a professional activity in one or more fields of creative or knowledge economies as well as (2) a transnational multilocality. Given that potential interviewees are not listed with these properties in official registers, I applied a snowball sampling method. This means I started sampling with two transnationally multilocal creative knowledge workers, whom I knew beforehand, and who then recommended future interview partners. Furthermore, I looked for interview partners in my private and professional networks and spread the word about my research in different events (such as conferences and exhibitions). When selecting interview partners, I sought to conserve a certain socio-economic heterogeneity regarding the characteristics of my sample.

The final sample was composed of 16 male and 9 female interviewees. Family status was heterogeneous: They represented singles, unmarried couples as well as married people. Some interviewees had partners from the same country, but others formed binational couples. Some of the respondents had small children in their households, others had adult children who already lived on their own. Further interviewees were childless. Nearly all interview partners are engaged in a variety of different professional and volunteering projects in different places and countries at the same time, and they regularly commute between these different countries. 
They also originated from a number of different countries. Many came from EU countries, some were also citizens of American and Central Asian countries. This implied that I had to conduct interviews in different languages [for a methodological discussion on problems related to multilingual fieldwork see Nadler (2014: 205207)].

At the beginning of the interviews, I asked respondents to draw a map including the places that were relevant to their own transnational lives. These mental maps helped to guide the narrative sections of the interviews; in some cases, these maps were also completed later during the interview. The interviews focused on relations between the interviewees and their places based upon their individual biographies and their current multilocality. Also, their perception of mobility, social networks and the professional field were discussed.

For an analysis of the interviews and the mental maps, I made use of approaches from Grounded Theory (Charmaz 2008; Clarke 2007), Qualitative Heuristics (Kleining and Witt 2000) as well as hermeneutics [in particular Geschichtenhermeneutik according to Vonderach (Vonderach 1997)]. In accordance with principles of Geschichtenhermeneutik, I reconstructed individual life stories of my interviewees. According to Vonderach (1997), only by looking at the aggregate of single biographical narratives, is one able to understand latent structures of sense and orientation in an individual's lifeworld. Subsequent cross-comparison of single cases was the basis for the development of categories and relations between categories, paving the way to the articulation of heuristic concepts.

\section{Empirical Results: Subjective Standardization of Places in Multilocal Lifeworlds}

This section will introduce empirical findings with a strong focus on the multilocal interviewees' practices of relating to places. The main aspects explored here are the techniques used in order to guide oneself within and to appropriate new places (Sect. 6.1), the professional multilocality and the incorporation of different workplaces (Sect. 6.2), as well as the private sphere of multilocality including dwelling practices (Sect. 6.3).

\subsection{Place Appropriation and Orientation}

Regular circulation between different places of residence and work in different countries generates continuous change among the individual geographies of my respondents' lifeworlds: New places are added to personal mental maps, while others lose relevance. Dealing with this continuous change is demanding in terms of 
place appropriation. The basic problem is that all places have their own proper way of functioning. The urban fabric looks different and orientation systems are designed differently. Local people have different mentalities from each other and local culture needs to be learnt. In order to become familiar with these new places, my interview partners develop routines of place appropriation.

Even individuals with lifestyles marked by a strong mobility do not automatically adapt to new places. Arriving to new places is often described as a 'temporary condition', which is characterized by a lack of knowledge of how things work and how my interview partners can best integrate into local networks. Christian - a young artist commuting between places in Germany and France-says that frequent relocation within France and later to Germany implied a huge cognitive effort:

Each time that you move, there's always a new difficulty. I don't think that one can say that you develop a habit of moving around. There is always a... every new place has its own constraints, one has to re-install one's own personality, one has to find footing again. You are always a different kind of person, because this depends on what others think of you. Uh, therefore, yes, I don't think... When I came to Germany, I didn't speak any German, and I couldn't be who I was elsewhere. And even if I moved around in France, when you arrive to a new location, the mentalities are different, the systems are different, people already know each other. You are always a stranger again. You always have to resettle. Therefore, the question of the stranger is that of the strangeness which comes along, to use Albert Camus, for instance. That's a question which I am highly interested in and which is part of my artistic work, mainly the poetry that I write.

Christian's quote shows that the development of new social relations is an important aspect of place appropriation. Place appropriation often works as a two stage process which transforms a new place from a foreign place (Fremdort) into a familiar one (Eigenort; cf. Stock 2009). In the first stage, immediately after arrival, my interview partners rather observe their social environment and they conceal their personality to a certain extent. They adapt by developing a form of 'humbleness'. This means that my interviewees do not expose their individual mentality, but embrace the position of an observer of local mentalities and they adapt to them. They do so in order to avoid offending locals. This technique enables a more rapid adaptation to local mentalities, values, and norms.

Only in the second stage, do they start building new social relations with locals and this in turn allows for the uncovering of their personality again. In this process, having a job in a new place is essential because it helps to build new networks starting from professional contacts, which then could lead to the development of further private social networks. Also, buying real estate can have a beneficial impact on the development of social networks as it increases social interaction levels (e.g. dealing with bureaucracy or neighbours). Finally, social relations predating relocation to a new place work as a catalyst for the creation of new social networks.

Another daily practice of place appropriation consists in discovering the physical environment. Many of my interview partners try to find modes of gradually exploring their local space, e.g. taking long walks in their new neighbourhoods. This includes methods such as 'losing oneself voluntarily'. Losing one's orientation in a new environment might force openness towards the new and unknown. 
One has to ask locals in the local language for directions; likelihood to meet people is thus high. Remaining open increases chances of intensive experiences of new places and getting to know new people; this in turn facilitates place appropriation.

The process of place appropriation - the passage from a foreign place to a familiar one-finishes once my interview partners feel that being in these places has become normal life. This is often the case when habits of everyday life start being developed. Birgit, who is working as an architect in one place and as a university professor in another, explains that she used to stay at the same hotel during her office days at the university. Her everyday routine there consists of long working hours and then eating out. By contrast, in her other place of residence, she lives in her own apartment, cooks with her partner and spends some free time with friends. Dirk lives and works both in Bulgaria and in Germany. He frequently cycles to his office in Germany, while he only walks to his office in Bulgaria. Emil is based in Germany and in Switzerland. In Germany, he loves to go to classical music concerts. In Switzerland, he never does so, but he often goes to theatre. My interview partners seek to develop place specific habits in their everyday life, in order to make sense of their individual multilocality. Such complementary routines in different places help people to become more aware of the benefits of multilocality. It is precisely when my interview partners become aware of this complementarity and the specific value of a new place, that this former foreign place becomes familiar to them and forms a component in the geography of their lifeworld. This implies to find a balance between the satisfaction of some needs and the renunciation of others. These multilocal creative knowledge workers adapt to local customs and culture, but they do not immerse themselves completely. They remain true to themselves by ignoring those elements of local culture that cannot be aligned on their personal attitudes. Striking a balance between remaining oneself and adapting to the environment is a condition to place appropriation.

Furthermore, in order for a place to take on an everyday life character, the ubiquitary availability of small gadgets and objects seems necessary. Emil stores swimming trunks in all his places because he loves swimming wherever he is. Oskar, living in Germany, Switzerland and Austria, keeps a pair of running shoes in each of his apartments. Aurélien has equipped his two ateliers in France and Germany with similar tools in order to be able to produce art work without having to carry his toolboxes around. Likewise, CDs, books, toiletry, or clothes are made available in each of these places. This reduces the amount of necessary luggage and thus facilitates travel, and it enhances the 'playability' of places upon returning.

Finally, it has to be mentioned that the passage from foreign places to familiar places can cause emotional stress. Often partners and other family members as well as close friends remain in 'the other' place, and my interview partners feel alone in their new place. In this situation, emotional stability is sought for through virtual and imaginary travel to more familiar places [cf. notions of 'virtual travel' and 'imaginative travel' in Larsen et al. (2006)]. At the same time, developing new social ties in new places can induce a reduction of social relations to previous familiar places, which then need to be re-intensified if these earlier places were to regain relevance for the individual's own lifeworld. 


\subsection{Multilocal Working}

My interview partners also employ different practices in order to manage their professional projects in different places. Surprisingly, these creative knowledge workers rarely rely upon services for multilocals provided by the market (e.g. coworking spaces). Federico - a historian and cultural mediator based in Germany, the Czech Republic, Slovenia and Italy_describes such a multilocal working world as follows:

Our coworking space is the library, you know. The libraries all have Internet now. They are very comfortable. Yeah, I think, it's like that. Because if I think of the Czech Republic, I always go to the library. If I am in Slovenia and Italy, I do the same. If I am in London, I always go... or I can go to the British Library.

Creative knowledge work mostly takes place within structures allowing flexible forms of organization. Creative knowledge workers need a table and a connection to the Internet. These services are provided by most libraries today. Libraries are supposed to provide infrastructure for learning and studying, and initially they were not conceptualized as substitutes for creative knowledge workers' office spaces. Yet, they offer the same services as marketed coworking spaces: desks, access to the Internet, often a small cafeteria and the possibility to exchange and discuss project ideas with other people. Same applies for airport lounges and train stations as well as cafés, which are used as working spaces by my interview partners, too. In the field of professional art, so-called residence programmes are established offering residential and working spaces for artists temporarily staying in different places. In the scientific world, travelling researchers have the possibility to make use of office spaces and research infrastructures (scientific libraries, archives, and databases) of local research centres. Furthermore, my interviewees also work in places made available by family members and friends.

As mentioned in Sect. 4, labour markets were flexibilized in the past decades. This favoured the development of short-term and part-time labour contracts as well as multiple job holding. Many of my interviewees hold positions in different organizations in various locations. Accordingly, they can make use of the different organization's infrastructures. When being self-employed in one place, they also seek to share their office space with other self-employed colleagues. In this regard, Pia-who works at a university in Germany and owns an architecture firm in Denmark - remarks that sharing an office space with a professional peer facilitates social integration into the (labour) market:

How we planned it is simply that we want to rent a larger office where we can sit together. Um, because we think that it is quite good to have some movement, and mainly because Ronald, the renovator, um has other competences than I have, and we already exchange advices with each other about our projects. And then we can directly sit together, and probably also develop projects together in Germany, by pooling what we both can offer, so to say. And this has... I can imagine that this works well on the personal level, if we share an office. 
My interview partners sought for loopholes in existing structures, in order to independently organize their multilocal working worlds while bypassing market-based infrastructures and services. Yet, this does not necessarily mean that they would completely refuse these offers, but they try to identify and favour the most cost-effective ways of organizing multilocal work. This includes a re-definition of places, which originally were not planned as workspaces for creative knowledge workers (e.g. train stations, airports, cafés). These spatial solutions are similar in that they respond to certain expectations in terms of utility and usability. They are accessible for free or at a low cost, and thus not provoke a drain on resources. In addition, these re-defined work places can be used flexibly upon arrival, what matches well with the unpredictable character of a creative knowledge worker's schedule. Finally, such work places are likely to generate encounters with other peers and locals, and as such, they provide entry points into local culture and networks.

\subsection{Multilocal Dwelling}

Besides the professional dimension, multilocal lifeworlds also entail a private sphere. Here, dwelling practices of the interviewed creative knowledge workers show some particularities that distinguish them from other highly mobile groups. In addition to the aforementioned solutions of settling in artist residences or at friends or family, there are further ways to organize economical multilocal dwelling. Like work spaces, dwellings have to be flexible and they should not cause a long-term drain on one's own resources. Within the frame of multilocality, creative knowledge workers irregularly pay visit to their places. Absence or presence are hardly foreseeable, as it depends on jobs and projects, which often arise spontaneously. This implies that not all places are equally important as residential places, but they must be available round the clock.

As a result, market-based offers such as rental apartments (including furniture) are not always the most appropriate form of dwelling. More often than not, it is the burden of maintaining one's own apartment, which keeps my interviewees from renting on the market. Isabel works as a translator and interpreter, and she was an exception in that she is still maintaining two rental apartments in Barcelona and Berlin. Yet, during our interview, she was also thinking about leaving one of her apartments. She illustrates her doubts by describing her routine when coming back to these apartments:

I first have to throw away or save all the plants, provided they are still alive. I always have forgotten some oranges or apples, and it smells somewhere. I forgot some food in the fridge, so it has rotten, and I always have to check everything. Or a handyman came by, and I had forgotten about the appointment. During my absence, the chimney sweeper came to the building, and I wasn't there. These things often happen. Uh, or the telephone broke, because lightning struck. This means I always have to check everything what has happened, and I have to clarify issues, and somehow these apartments need to be taken care of. 
Taking care of two different apartments is often too time-consuming for most of the interviewed persons. For them, it makes more sense to find more flexible and less demanding forms of dwelling. One such strategy consists of sharing an apartment - and being equally responsible for it. Sharing even extends to such practices, where creative knowledge workers share individual rooms within shared apartments with other multilocal workers, who are never present at the same time. Xaverio is a photographer who circulates between Milan, Berlin and Rome. He explains that he has rented an apartment and a studio in Milan, but in Rome and Berlin he shares rooms with an historian who also circulates between Berlin and Rome. They continuously exchange about their times of absence and presence in each of the places and they take turns at occupying the rooms. In Germany, Dirk shares an apartment with a friend who is multilocal too. This friend is working in another city and only returns during weekends. Additionally, Dirk has rented an own apartment with his girlfriend in Bulgaria.

Another way of flexibly organizing dwellings consists in re-interpreting hotels as flexible apartments. Correspondingly, Kate-who works as a supervisor for the dubbing of US American movies and who circulates between France, Spain, Germany, Italy, England and the USA - describes that she did not even have a registered place of residence for several years. She never spends more than five days in one place and she is not able to predict where she has to go afterwards. Therefore, she decided to resign from her rental apartment in Germany. Still she found a new way of organizing home within her mobile life by always booking the same rooms in the same hotels in the places to which she frequently returns. In these hotels, she leaves suitcases with her personal belongings, clothes, and toiletry. Upon booking, receptionists bring her suitcase with cleaned clothes to her room. Hence, she has several similarly equipped suitcases in various hotels across Europe and she actually lives in hotels. Similarly, Birgit says that she always returns to the same hotel while staying in one of her places, generally for three days per week (Sect. 6.1). She knows the staff members and they know her. She always takes the same room and she got so accustomed to dining in the hotel that it feels like being home. Furthermore, she appreciates not having to care about household chores.

Aurélien, who works as an artist, explains that he prefers staying at friends' places when he is in France. In return, he offers his French hosts to stay in his apartment in Germany whenever they need it:

It is about always having a free room for someone who needs to come spontaneously. [...] To work in Germany, for example. And like this establishing different places across Europe, where there is such a possibility too. And why not in a sense of uh... how to say that, also of professional assistance. You know, having this kind of relationship. That's what I am starting to do in Paris. I have some artist friends who will host me the time of an exhibition, because I will probably organise something in Paris, well, because someone also lets me use his apartment. Or there is a kind of exchange, of apartments which can be organised. This is also a completely new form of economy, which could be set up.

The advantages of such forms of dwelling consist in facilitating interaction with local people and providing access to local networks, which themselves can become important resources for creative knowledge work. Federico makes this explicit 
when speaking about the ways how he is accommodated during trips to the Czech Republic and Slovenia: He always seeks to stay with fellow local scientists. These encounters foster inspiring discussions and extend one's own contact list.

In general, my interview partners organize their accommodation in a cost-effective way. This also means that they avoid resorting to marketed services whenever this is possible. Furnished micro-apartments supplied by real estate agencies were not used by my interview partners. However, this avoidance is not only based upon financial motives. Rented apartments are also supposed to impede contact to local networks as my interviewees would feel secluded if living alone. Flexible forms of accommodation - such as organized by creative knowledge workers on their own - enable stronger interaction with the local people. Another argument in favour of flexible forms of accommodation is the more acceptable burden of household maintenance coming along with sharing compared to that of renting a second or even third apartment. Nonetheless, this is often combined with a main residence, which works as a base for individual multilocality and which is often one's own property or a traditional rented apartment (cf. Nadler and Montanari 2013).

\section{Discussion of Results}

\subsection{Plug\&Play Places}

The empirical results show that multilocal creative knowledge workers are self-reliant when it comes to organizing work and accommodation in multilocal contexts. They actively strive for attachment through practices of exploration and appropriation of places and by meeting local people. Through the continuous incorporation of new places in the frame of their professional activities, these creative knowledge workers develop a certain polyperspectivity. This polyperspectivity allows for an efficient comparison between places playing a role in their individual lifeworlds; one becomes conscious of each place's specific features (cf. Petzold 2010). Knowing about the utilities of places makes one aware of the value of one's own multilocality.

What analogies to the idea of 'plug\&play' become apparent here? First, multilocal lifeworlds can be understood as 'systems' too. These systems consist of individual components, which taken together form a coherent and functional structure for the conduct of one's own life. For each multilocal person, the specific composition of this system does condition individual courses of action and personal identity. Second, routinized practices of place appropriation can - in a metaphoric sense - be understood as a type of automatized initial configuration, just as when a device is being plugged into a computer system for the first time. When a new place is added to the geography of one's own lifeworld, multilocal creative knowledge workers compare current situations and contexts to experiences made in former 
environments. Through this comparison, multilocal creative knowledge workers evaluate the value added by the new place and they decide about the procedure of integration into one's own lifeworld. Similar to the plugging of a new device into a computer system, the opportunities for one to act are increased by adding a new place to the 'system' of one's own multilocal lifeworld. It was shown that these new places were then standardized in order to fit into one's own lifeworld through the above mentioned practices of constructing new social relations and through finding flexible forms of dwelling and working. As soon as a new place is 'plugged' into one's personal lifeworld, it is 'playable' again upon each return, as illustrated in Fig. 1. There is no need to re-configure the place according to one's own needs. Furthermore, the empirical results pointed out that the addition of new places to one's own lifeworld is a very subjective process. The specific patterns of places of one multilocal person are not equally 'playable' by any other multilocal person as they are always based on one's individual needs.

A third similarity to the 'plug\&play' concept consists in the management of resources. The computer system monitors resources needs (e.g. processing capacity) related to individual devices in the system. According to the availability of resources, each device receives a certain share of it, in order to optimize the system's efficiency. A similar distribution of resources takes place in multilocal lifeworlds. Resources like time, money, objects, and even emotional attachment or cognitive capacities are allocated to different countries and places in an appropriate-and subjectively perceived as coherent-way. This distribution supports the

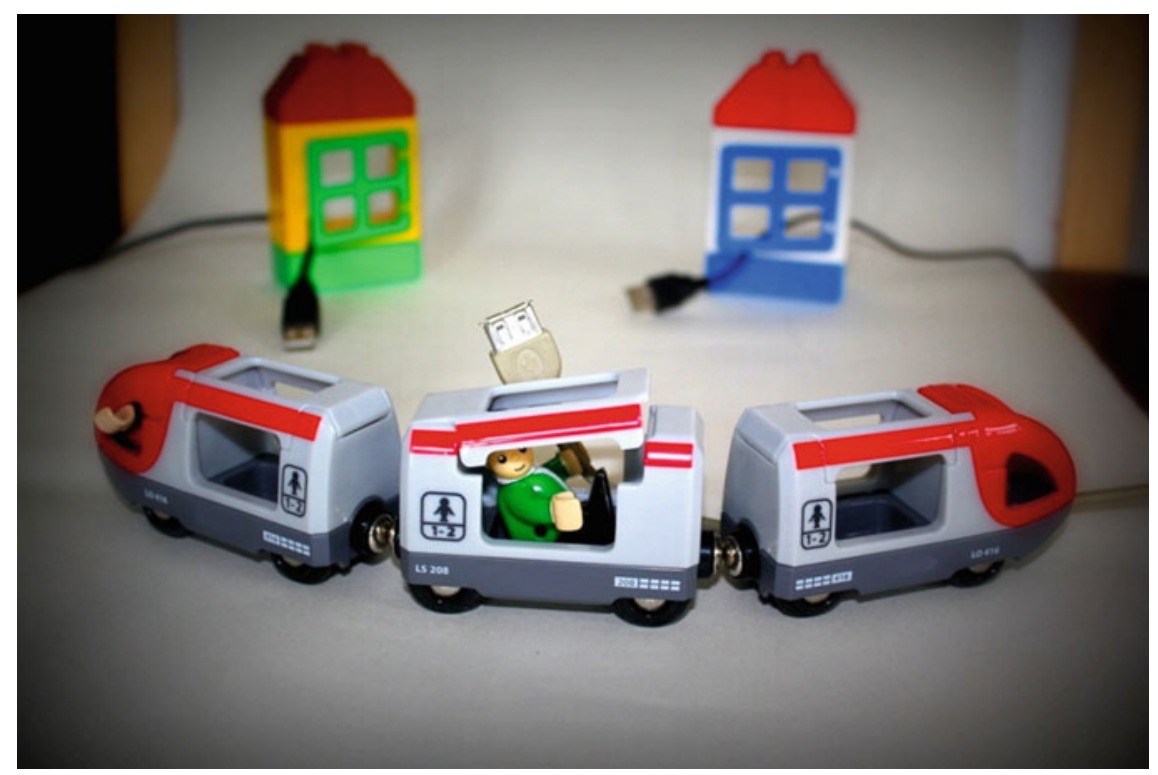

Fig. 1 Playful imagination of the plug\&play places (Source own picture) 
meaningfulness of multilocality. All places receive just as many resources as necessary in order to optimize the exploitation of place-specific characteristics.

Fourth, plug\&play devices are flexible as they do not consume any resources after they have been removed from the system. They unblock resources for other devices to use. Similarily, multilocal people organize the incorporation of places into multilocal lifeworlds in such a way that costs are minimized when multilocal people are physically absent. Flexible forms of accommodation and working require only little financial and organizational effort, and at the same time they are always available and 'playable' when multilocals need to 're-plug' to these places.

In this sense, I think that we can understand how multilocal creative knowledge workers relate to places as the social construction of 'plug\&play places'. Plug\&play places are coherently integrated into the systems of their multilocal lifeworlds. Upon each return, a plug\&play place is fully functional for the multilocal person. Social phenomenologists point to the fact that people design their individual lifeworld according to the criterion of coherence in order to be happy with their lives (cf. Buttimer 1976). This is exactly what happens when multilocal people turn places into 'plug\&play places' according to their own needs.

\subsection{Objective Versus Subjective Standardization of Place}

Regarding the reflections on the standardization of places as presented in Sect. 3, I will now suggest a differentiation between objective and subjective standardization of places, a distinction which is summarized in Table 1. Existing approaches to grasp the standardization of places refer to an 'objective' standardization. Ritzer's concept of McDonaldization, Duyvendak's reflections on generic places and

Table 1 Comparison of objective and subjective standardization of places

\begin{tabular}{l|l}
\hline $\begin{array}{l}\text { Objective standardization according to } \\
\text { the concept of 'generic places' }\end{array}$ & $\begin{array}{l}\text { Subjective standardization according to the } \\
\text { concept of 'plug\&play places' }\end{array}$ \\
\hline $\begin{array}{l}\text { Efficiency: quick and massive } \\
\text { consumption }\end{array}$ & $\begin{array}{l}\text { Efficiency: in terms of place appropriation; } \\
\text { practices of orientation; flexibility }\end{array}$ \\
\hline $\begin{array}{l}\text { Calculability: acquiring a lot for a modest } \\
\text { price }\end{array}$ & Calculability: costs and utility of multilocality \\
\hline $\begin{array}{l}\text { Predictability: standardized and simple } \\
\text { market transaction }\end{array}$ & Predictability: place-specific offers \\
\hline $\begin{array}{l}\text { Control: salesperson-client-Interaction } \\
\text { Actors: multinational corporations; } \\
\text { collective }\end{array}$ & $\begin{array}{l}\text { Control: relation between individual persons and } \\
\text { places; comparison and functional } \\
\text { complementarity; distribution of resources }\end{array}$ \\
\hline $\begin{array}{l}\text { Effect: transformation and creation of } \\
\text { new spatial structures }\end{array}$ & $\begin{array}{l}\text { Actors: multilocal person; individual } \\
\text { existing spatial structures }\end{array}$ \\
\hline
\end{tabular}

Source Own draft 
Augé's understanding of non-places all share the description of standardization based upon mass consumption. They imagine an anonymous mass of consumers, who purchase services and products offered in these standardized places. The example of global hotel chains as prototype of generic places illustrates McDonaldization in a metaphoric way. Based on efficiency, customers are quickly served and these standardized hotels seek to increase usage and their customer pool. Hotel guests are aware of the standardized value attached to the service they wish to purchase and it is predictable that this information is valid also in other world regions. Furthermore, the interaction between guests and the hotel staff is highly structured and standardized so that transaction processes take place efficiently and rapidly.

When comparing objective and subjective standardization, then one can see that the properties of the categories are different. As such, the 'plug\&play places' concept refers to a standardization of places as well. Yet, this standardization is rather subjective in character. It is about the standardization of only a few places from the perspective of an individual multilocal person. Plug\&play places refer to the incorporation of places into the complex and individual contexts of one's own life. Of course, this requires efficiency to some extent. Applying practices of orientation and place appropriation, multilocal people make use of their places as flexible components of their own multilocal lifeworlds. Once these places are standardized in such a subjective manner, their functions are foreseeable for multilocal individuals. A multilocal person can calculate what costs and benefits for self-fulfilment result from the incorporation of places. Furthermore, multilocals know exactly what to expect in each place in terms of working or dwelling opportunities as well as to what type of people and mentalities they will be facing. After this process of subjective standardization is completed, multilocals are aware of the complementarity of place-specific features, the requirements in terms of resources (e.g. time, money, attention, emotional attachment etc.) and the accordance with their own needs. They continuously reflect the relation to their places by comparing these places with each other. This in turn represents a mode of control over the geography of one's own lifeworld.

However, the standardization into plug\&play places is only functional for a single individual; it is not objective as retail stores like IKEA, global hotel chains or fast food caterers like McDonald's can be. This subjective standardization is based on the very individual needs of one multilocal person; it does not reflect an average pattern of needs of an anonymous group of customers. Subjective standardization is not managed by collective and corporate actors in the market, but by multilocal people themselves. While the objective standardization of places leads to changes in our physical environment, this is not necessarily the case with the subjective standardization of places. The manufacturing of 'plug\&playability' can just have a cognitive character. Sometimes it does not even materialize itself. Becoming aware of the benefits of multilocality - which is a rather cognitive process - , an individual is able to consider places as flexible and compatible constituents of one's lifeworld, but this process rarely involves a physical impact on the respective places themselves. 


\section{Conclusion}

I understand this conceptual idea of plug\&play places as a tool, which helps us to understand place attachment and the respective meaning of places in lifeworlds characterized by mobility and multiplicity of attachments. Places represent functional elements in the 'system of one's own lifeworld'. Considering places as 'plug\&play' devices allows for an understanding of standardization in the context of complex relational systems between human beings and their environments. Former approaches to conceptualize standardization of space and places remain insufficient, because they simply focus on objective and materialized phenomena. As a complement, I suggest the concept of 'plug\&play places' as a heuristic tool to depict phenomena of subjective standardization of place and place relatedness, which are not always physically observable. Both aspects of standardization of places will most probably become more important as societies continue to grow more mobile. As such, they both have their legitimation as a conceptual basis for future research in the field of mobility and multilocality studies.

Still, I admit that my remarks regarding the concept of 'plug\&play places' can only be considered as an early draft. My qualitative research followed an explorative approach, and the sample of the studied multilocal creative knowledge workers is specific in terms of their capability to act in a self-reliant way and accept mobile lifestyles. It is now important to elaborate on these early ideas and confront them to a more robust empirical study. Studies of other focus groups can complement the present findings, and larger samples need to be analysed. It would also be interesting to conduct a panel study in order to examine the changes of place relatedness over time. My own empirical results pointed to the fact that multilocal arrangements have a strongly temporary nature. Many interviewees signalled they considered multilocality as a passage to a more stable and monolocal life. Research could thus also question how stable subjective standardization actually is, when multilocals return to a more monolocal lifestyle.

\section{References}

Aguiton, C., \& Cardon, D. (2007). The strength of weak cooperation: An attempt to understand the meaning of Web 2.0. Communications \& Strategies Quarter 1, 65, 51-65.

Augé, M. (1995). Non-places: An introduction to an anthropology of supermodernity. London, New York: Verso.

Bigelow, S. J. (1999). The plug \& play book. New York: McGraw-Hill.

Bröckling, U. (2007). Das unternehmerische Selbst: Soziologie einer Subjektivierungsform. Frankfurt/Main: Suhrkamp.

Buttimer, A. (1976). Grasping the dynamism of lifeworld. Annals of the Association of American Geographers, 66(2), 277-292.

Cave, R. E. (2000). Creative industries: Contracts between art and commerce. Cambridge, London: Harvard University Press. 
Charmaz, K. (2008). Grounded theory as an emergent method. In S. N. Hesse-Biber \& P. Leavy (Eds.), Handbook of emergent methods (pp. 155-170). New York, London: The Guilford Press.

Clarke, A. E. (2007). Grounded theory: Critiques, debates, and situational analysis. In W. Outhwaite \& S. P. Turner (Eds.), The sage handbook of social science methodology (pp. 423442). Thousand Oaks: Sage.

Downs, R. M., \& Stea, D. (1977). Maps in minds: Reflections on cognitive mapping. New York: Harper \& Row.

Duchêne-Lacroix, C. (2009). Mit Abwesenheit umgehen. Kontinuität und Verankerung einer transnationalen Lebensführung jenseits territorialer Abgrenzungen. Informationen zur Raumentwicklung, 1/2.2009: 87-98.

Duyvendak, J. W. (2011). The politics of home: Belonging and Nostalgia in Western Europe and the United States. Basingstoke, New York: Palgrave Macmillan.

Favell, A. (2008). Eurostars and Eurocities: Free movement and mobility in an integrating Europe. Oxford: Wiley-Blackwell.

Florida, R. (2002). The rise of the creative class: And how it's transforming work, leisure, community \& everyday life. New York: Basic Books.

Friebe, H., \& Lobo, S. (2006). Wir nennen es Arbeit: Die digitale Boheme oder: Intelligentes Leben jenseits der Festanstellung. Munich: Wilhelm Heyne Verlag.

Gill, R., \& Pratt, A. (2008). In the social factory? Immaterial labour, precariousness and cultural work. Theory, Culture and Society, 25(7-8), 1-30. doi:10.1177/0263276408097794.

Hesmondhalgh, D., \& Baker, S. (2008). Creative work and emotional labour in the television industry. Theory, Culture and Society, 25(7-8), 97-118. doi:10.1177/0263276408097798.

Hopf, C. (1995). Qualitative interviews in der Sozialforschung. Ein Überblick. In U. Flick, E. von Kardorff, H. Keupp, L. von Rosenstiel, \& S. Wolff (Eds.), Handbuch Qualitative Sozialforschung: Grundlagen, Konzepte, Methoden und Anwendungen. Psychologie. Weinheim Union, Verlags: 177-182.

Johns, T., \& Gratton, L. (2013). The third wave of virtual work. Harvard Business Review, 2013, $1-9$.

Kelsey, J., \& Kelsey, J. (1995). Programming plug and play. Indianapolis: SAMS.

Kleining, G., \& Witt, H. (2000). The qualitative heuristic approach: A methodology for discovery in psychology and the social sciences. Rediscovering the method of introspection as an example. Forum: Qualitative Social Research (Forum qualitative Sozialforschung), 1(1), Art. 13. Avialable at: http://www.qualitative-research.net/index.php/fqs/article/download/1123/ 2496. Accessed 31 May 2015.

Lange, B. (2007). Die Räume der Kreativszenen: Culturepreneurs und ihre Orte in Berlin. Bielefeld: Transcript.

Larsen, J., Urry, J., \& Axhausen, K. (2006). Mobilities, networks, geographies. Aldershot: Ashgate.

Lynch, K. (1960). The image of the city. Cambridge: MIT Press.

Martin-Brelot, H., Grossetti, M., Eeckert, D., Gritsai, O., \& Kovács, Z. (2010). The spatial mobility of the 'creative class': A European perspective. International Journal of Urban and Regional Research, 34(4), 854-870. doi:10.1111/j.1468-2427.2010.00960.

Martinotti, G. (1996). Four populations: Human settlements and social morphology in contemporary Metropolis. European Review, 4(1), 3-23. doi:10.1017/S1062798700001708.

Mühler, K., \& Opp, K. D. (2006). Region-Nation-Europa: Die Dynamik regionaler und überregionaler Identifikation. Wiesbaden: VS Verlag für Sozialwissenschaften.

Nadler, R., \& Montanari, G. (2013). Der Wohnbegriff in der Multilokalitätsforschung Überlegungen anhand der Beispielgruppen Großeltern in Nachtrennungsfamilien und kreative WissensarbeiterInnen. In J. Scheiner, H. H. Blotevogel, S. Frank, C. Holz-Rau, \& N. Schuster (Eds.), Mobilitäten und Immobilitäten. Menschen - Ideen - Dinge - Kulturen - Kapital. Klartext Verlag, Essen: 417-430. 
Nadler, R. (2014). Plug\&play places: Lifeworlds of multilocal creative knowledge workers. Warsaw, Berlin: De Gruyter Open. Available at: http://www.degruyter.com/viewbooktoc/ product/447763. Accessed May 31, 2015.

Nowicka, M. (2005). Transnational professionals and their cosmopolitan universes. Munich: Campus.

Oberhuber, N. (2014). Mikroapartments: Vor zu viel Enge wird gewarnt. Frankfurter Allgemeine Zeitung Online, March 23, 2014. Available at: http://www.faz.net/aktuell/lebensstil/drinnendraussen/mikroapartments-vor-zu-viel-enge-wird-gewarnt-12859209.html. Accessed May 31, 2015.

Pethe, H., Hafner, S., \& Lawton, P. (2010). Transnational migrants in the creative knowledge industries: Amsterdam, Barcelona, Dublin and Munich. In S. Musterd \& A. Murie (Eds.), Making competitive cities (pp. 163-191). Oxford: Wiley-Blackwell.

Petzold, K. (2010). Wenn sich alles um den Locus dreht: Multilokalität, Multilokation, multilokales Wohnen, Inter- und Translokalität als Begriffe der Mehrfachverortung. In M. Hühn, D. Lerp, K. Petzold, \& M. Stock (Eds.), Transkulturalität, Transnationalität, Transstaatlichkeit, Translokalität (pp. 235-257). Theoretische und empirische Begriffsbestimmungen: LIT Verlag, Münster, Hamburg, London.

Ploch, B. (1995). Eignen sich Mental Maps zur Erforschung des Stadtraumes? Möglichkeiten der Methode. kea. Zeitschrift für Kulturwissenschaften, 8 (Stadtdschungel): 23-41.

Ritzer, G. (1993). The mcdonaldization of society: An investigation into the changing character of contemporary social life. Thousand Oaks: Pine Forge Press.

Ritzer, G. (Ed.). (2010). McDonaldization: The reader. Thousand Oaks: Pine Forge Press.

Rolshoven, J. (2006). Woanders daheim. Kulturwissenschaftliche Ansätze zur multilokalen Lebensweise in der Spätmoderne. Zeitschrift für Volkskunde, 102 (2006 II): 179-194.

Scherke, K. (2011). Transnationalität als Herausforderung für die soziologische Migrationsforschung. In G. Marinelli-König \& A. Preisinger (Eds.), Zwischenräume der Migration (pp. 79-90). Transcript, Bielefeld: Über die Entgrenzung von Kulturen und Identitäten.

Scholz, G. (2011). Der SaarLorLux-Raum zwischen Realität, Illusion und Vision: Wahrnehmung und aktionsräumliches Verhalten aus der Sicht von Bewohnern einer europäischen Grenzregion. Saarbrücken: Institut für Landeskunde im Saarland e.V.

Schürmann, M. (Ed.). (2013). Coworking Space. Springer Gabler, Wiesbaden: Geschäftsmodell für Entrepreneure und Wissensarbeiter.

Shanley, T. (1995). Plug and play system architecture. Colorado Springs: MindShare Inc.

Stock, M. (2009) Polytopisches Wohnen - ein phänomenologisch-prozessorientierter Zugang. Informationen zur Raumentwicklung, 1/2.2009: 107-116.

UPnP Implementers Corporation. (2006). UPnP ${ }^{\mathrm{TM}}$ technology - The simple, seamless home network. San Francisco. Available at: http://upnp.org/resources/whitepapers/UPnP\% 20Technology_The $\% 20$ Simple, $\% 20$ Seamless $\% 20$ Home $\% 20$ Network_whitepaper.pdf. Accessed May 31, 2015.

Urry, J. (2000). Sociology beyond societies - Mobilities for the twenty-first century. London, New York: Routledge.

Veryard, R. (2001). The component-based business: Plug and play. London, Berlin, Heidelberg: Springer.

Vonderach, G. (1997). Geschichtenhermeneutik. In R. Hitzler \& A. Honer (Eds.), Sozialwissenschaftliche Hermeneutik: Eine Einführung (pp. 165-189). Opladen: Leske + Budrich.

Weichhart, P. (1990). Raumbezogene Identität: Bausteine zu einer Theorie räumlich-sozialer Kognition und Identifikation. Stuttgart: Franz Steiner Verlag.

Weichhart, P. (2009). Multilokalität - Konzepte, Theoriebezüge und Forschungsfragen. Informationen zur Raumentwicklung, 1/2.2009: 1-14.

Werlen, B. (2000). Sozialgeographie: Eine Einführung. Bern, Stuttgart, Vienna: Haupt Verlag/UTB. 


\title{
Inhabiting Simultaneous Lives: Analysing Process of Reversibilization of Mobility Practices in Italy
}

\author{
Bruna Vendemmia
}

\begin{abstract}
This chapter aims to study some emerging mobility practices in Italy and the consequences they have had on the use and configuration of spaces. A growing number of people live their lives across a vast space consisting of work, family, and friendship networks, and are travelling longer distances, in shorter periods of time, than ever before. This paper addresses the hypothesis that those transformations are modifying the relationships between people and territory, allowing people to live simultaneous lives, and increasing relationships within multiple territories. I will use biographies of highly mobile people as a tool to describe this process. Describing and analysing their mobility behaviours allow to show how people try to "catch ubiquity and simultaneity" (Ascher in Cahiers internationaux de sociologie. PUF, Paris, p. 53, 2005) in their everyday lives, highlighting how far those practices have transformed the relation between people and territory and the spaces of mobility. The first results presented here consist on the identification of three territorial profiles based on the geography of personal relationships and revealing how this geography interacts with a general transformation of everyday urban rhythm in the construction of simultaneous lives.
\end{abstract}

Keywords Mobility practices - Mobile methods - Territorialisation - Mobilities • Urban rhythm

\section{Introduction}

A growing number of people live their lives across a stretched space consisting of work, family, and friendship networks, and are travelling longer distances, in shorter periods of time, than ever before. This phenomenon is widespread and reveals itself in many different ways; it includes kinetic nomadic elites travelling the

\footnotetext{
B. Vendemmia $(\bowtie)$

Politecnico di Milano, Milan, Italy

e-mail: bruna.vendemmia@gmail.com 
world on high speed/high cost transport, as well as people who are obliged to travel, for example, migrants. However, it also includes an increasing number of ordinary people travelling along more mundane paths in their everyday lives. Among those transformation it is also possible to observe what has been defined as a process of reversibilization of mobility practices (Kaufmann 2002, p. 24).

This chapter is part of a more general research that investigates this process and its consequences on the use and configuration of spaces, using direct observation of mobile people through semi-structured interviews, travel-along, and mapping. The interviewees are daily, or weekly, long distance commuters that are experiencing phenomena of double residences, relocations and long-distance relationships. They are all individuals with high motility ${ }^{1}$ (Kaufmann 2002, p. 37) characteristics who have chosen to be mobile in order to better match their personal expectations to their working conditions (type of contract, salary, and qualification). Due to these characteristics they offer an interesting viewpoint on changes in mobility behaviours as they have developed a scattered lifestyle in which different activities and relational networks such as job, leisure, family and personal relations, may be localised in different places; at the same time the regularity of their paths allows the construction of routines and stable, even though multiple, territorial relations. We can also refer to them as "mobility pioneers" because they "create specific arrangements of time and space to cope with the compulsion of mobility and to realise individual goals" (Kesselring and Vogl 2004, p. 5). Through the study of their mobility practices I will define different profiles of territorial relations. The maps will assist in representing these unstable, temporary and multi-scalar spaces that are the interviewees' everyday territory. The methodology of the research permitted the opportunity to explore these new dynamics in more details and using the actor's point of view.

After briefly introducing ongoing process of reversibilization of mobility practices, I will present the methodology of the research and the first results of the empirical analysis.

\section{Between Mobility and Moorings: Reversible Mobilities?}

Observing emerging practices of mobility Vincent Kaufmann has highlighted two parallel phenomena (Kaufmann 2002, p. 25). First there is the possibility to cook or eat traditional food when even hundreds of kilometres from home; to be in contact with loved ones when spatially distant; to listen to a song that reminds us of pleasant moments and places; to carry pictures and memories on our person in any given moment; all of these allow us to be in constant contact with our significant others.

\footnotetext{
${ }^{1}$ The concept of motility has been defined by Vincent Kaufmann. It is the "capacity of a person to be mobile, or more precisely, the way in which an individual appropriates what is possible in the domain of mobility and put this potential to use for his or her activities." (Kaufmann 2002, p. 37).
} 
Secondly, the availability of ICT and the increasing use of smartphones, tablets and faster means of transport, the transformation of societal and familiar structures (Elliott and Urry 2010, p. 48), the passage from the nuclear to the unclear family, with a radical transformation of family structure, as it has been clearly reported by Widmer (2006), the massive access of women to work, and the diffusion of new and more flexible job contracts ${ }^{2}$ (Colleoni and Zajczyk 2003, p. 40), are all factors that encourage people to make a choice in favour of more reversible forms of mobility. Under this process I include all those mobilities that, thanks to the accelerated speed potentiality, allow to "combine in everyday life places of activities that were, before, spatially impossible to assemble" (Vincent-Geslin and Ortar 2012, p. 40).

In order to undertake a deep analysis of the phenomenon I have sketched 11 biographies of mobile people. They can also be defined as "atypical commuters"; as matter of fact a commuter is a person who travels regularly for work, ${ }^{4}$ within his own life basin in a short temporality (Kaufmann 2011, p. 25). According to this definition the interviewees are commuters, though thanks to speed potentiality they have more spaces of actions, they multitask, and play different roles at the same time, definitely their time on the move cannot be considered related only to one life domain, as for example work, but involves more domains such as work, personal relation and interest and even familiar relation. To this regard, François Ascher has noted, "the hypermodern individual inhabits a time space with multiple dimensions, and sails between multiple places and times. Facing this growing variety of space-time dimensions, he chooses techniques that allow him to move as fast as possible in between different domains, trying to catch the ubiquity and the simultaneity that could help him to keep together this scattered life ${ }^{5 \%}$ (Ascher 2005, p. 53). For this reason I consider the interviewees as inhabiting simultaneous lives, spreading their roles, activities and relations across different territories and times.

\section{Methodology}

Despite their frequency those phenomena are really difficult to be catched using traditional mobile methods, thus many authors in the fields of urban studies and urban sociology (Urry 2000; Sheller and Urry 2006; Kaufmann 2002; Cresswell

\footnotetext{
${ }^{2}$ Colleoni and Zajczyk (2003) have observed that, "from the 70s there was an important growth of more flexible work contracts including free lance and part-time; in the area of Milan, $60 \%$ of new work contracts are part-time, fixed term or interim, including in large part women (Rapporto Milano Produttiva [C.C.I.A.A. di Milano 2001])" (Colleoni and Zajczyk 2003, p. 40). Original text in Italian translated by the author.

${ }^{3}$ Original text in French translated by the author.

${ }^{4}$ Commuter: a person who travels regularly, especially by automobile, bus, train, etc., between two points at some distance from each other, especially between a residence and a place of employment. In Collinsdictionary.com, http://www.collinsdictionary.com Accessed May 10, 2014.

${ }^{5}$ Original text in French, translated by the author.
} 
2006; Bourdin 2005) have underlined the need for an integrated approach to mobility and for more dynamic mobile methods of research. According to Buscher and Urry (2009), mobility research calls for more empirical methods that can involve different components and systems of mobility.

In order to answer to this call, I decided to adopt a qualitative approach based on semi-structured interviews, travel-along and mapping. I adopted this methodology, because it allows three considerable problems associated with the analysis of mobility and space to be overcome. The first problem is linked to the matter of the research. Mobility can be a very ambiguous subject depending on the point of view of the observer: "when geographers use the word mobility the goal is to evoke the idea of movement through space, unlike the traffic engineer, for whom mobility means transportation flows, or the sociologist, for whom mobility refers to a change in social position" (Kaufmann 2011, p. 23). Historically all of these different disciplines had completely different approaches to mobility (Tarrius 2000; Kaufmann 2002, 2011; Colleoni 2008), missing both the temporal dimension and the link between the spatial movement and the complex system of choices that determine them. Secondly, some interviews of mobility managers and an initial analysis of available data have highlighted the invisibility of these practices in traditional mobility analysis due to their small statistical importance; although recent research on the subject ${ }^{6}$ has highlighted the increasing relevance of these mobile practices for the study of everyday life and of the urban phenomenon. Thirdly, and lastly, due to the complexity of the phenomenon the use of a qualitative method of research can help to reveal its size and complexity.

Thanks to the use of tools such as interviews, ${ }^{7}$ travel along and maps, it has been possible to build biographies of mobile people.

\subsection{The Interviewees}

I have interviewed a group of 11 people $^{8}$ (Table 1), they are: Long Distance Commuters, shuttles and overnighter. Long distance commuters are people that commute at least $2 \mathrm{~h}$ a day ( $1 \mathrm{~h}$ to go to work and another one to return). Considering that the majority of the interviewees commute by high speed train, they can be considered both long time/long distance commuters as they cover a distance of $140 \mathrm{~km}$ every day. One of the interviewees, Alessia, when asked if she counted the distance in time or kilometres, answered: "Time. If I have to think of how many kilometres I do every day I'd be afraid: too many!'”. The case studies are illustrated

\footnotetext{
${ }^{6}$ I refer here to the research Job mobilities and family life that reports a sensitive growth of the phenomenon.

${ }^{7}$ All the interviews were conducted in Italian and translated by the author. The names mentioned in this chapter are false in order to preserve the privacy of the interviewees.

${ }^{8}$ I personally conducted the interviews and invited my interviewees to participate in a more detailed phase of the research including travel along and mapping of personal activities.
} 
Table 1 Case studies analyzed in the research containing all general information including: the date of the interview (Date), the type of mobility ( $L D C$ long distance commuter, $S$ shuttles, $O N$ over nighter), travel along (T.A.), job sector, year of birth, type of contract (Op. end. open ended, Fixed fixed term, F-L free lance, Per-pro per project)

\begin{tabular}{l|l|l|l|l|l|l|l}
\hline Name & Date & Mobility & T.A. & Job sec. & Year of birth & Cont. & Trans. \\
\hline Maurizio & Sept. 2013 & LDC & No & Constr. & 1979 & Op. end. & HS \\
\hline Ettore & Oct. 2013 & S & No & ICT & 1967 & Op. end. & Car \\
\hline Roberto & Oct. 2013 & S & No & ICT & 1974 & Op. end. & Car/HS \\
\hline Sandra & Jan. 2014 & S & Yes & Edu. & 1980 & Fixed & IC/HS \\
\hline Giorgio & Jan. 2014 & S & Yes & TV & 1971 & F-L & HS \\
\hline Beatrice & Oct. 2013 & S + ON & Yes & Fashion & 1972 & Op. end. & HS \\
\hline Valentina & Oct. 2013 & LDC & Yes & Design & 1966 & Op. end. & HS \\
\hline Alessia & Oct. 2013 & LDC & Yes & Com. & 1982 & Per-pro & HS \\
\hline Gennaro & Oct. 2013 & LDC & Yes & Com. & 1983 & Per-pro & HS \\
\hline Veronica & Jan. 2014 & S + ON & Yes & TV & 1976 & F-L & HS \\
\hline Lorenzo & Sept. 2013 & S & Yes & Edu. & 1971 & Fixed & HS \\
\hline
\end{tabular}

in Table 1. Furthermore, they all became highly mobile mainly due to work constraints: in order to get a paid job or to improve their career. They decided to be long distance commuters on a daily or weekly basis, or to temporarily relocate elsewhere, because they were principally forced to do so by unfavourable job conditions. As a matter of fact, they chose to inhabit environments "based on the opportunities made possible by speed potentials and the environment's receptiveness to their projects" (Kaufmann 2011).

\subsection{The Semi-structured Interview}

The semi-structured interview is composed of six different sections: 1, origins and places; 2, family life; 3, job; 4, job mobility; 5, personal characteristics; 6, socio-demographics. The structure of the interview is thus in order to highlight the complexity of mobility management, and to investigate the reasons of mobility and the relationships that allow the development of a highly mobile life-style. It has a special focus on the mobility generated by job conditions; nevertheless it covers different domains of life, with specific attention given to spatial consequences generated by mobility practices. The interviews were conducted telephonically.

While recognising the importance of the results provided by the telephonic interviews, and some of the strengths of this method such as the possibility to reach a larger number of people (mainly due to its less invasive approach), the construction of a detailed database, and the opportunity to compare the different results; it is also possible to highlight some limits: for example, the use of the telephone itself. The interview is very deep and detailed, but the telephone is an unfavourable means of 
communication with which to establish a sense of trust between the researcher and the interviewee. Furthermore, the very nature of the interview collided with the variety of the interviewees' everyday lives. During the travel along I tried to overcome these limits. In conclusion, it is possible to say that the completeness and depth of the questionnaire help to reveal the complexity and the richness of the subject.

\subsection{The Travel Along}

The travel along was a necessary complement to the semi-structured interview in order to have a better understanding of the phenomenon, and the opportunity to directly observe people in their travels in order to comprehend the process in a clearer way. During the travel along I travelled side by side with the interviewees on their most common trips. This method get inspiration by other methodologies of mobility research such as drive-alongs (Laurier 2010), being 'mobile-with' (Bissell 2009) and, more generally, the idea of a performed interview as elaborated by Latham (2003).

In the travel along I took notes and pictures of the interviewees, observed the objects they use while travelling; their strategies to feel comfortable in varying places such as the train station or the office; the people they meet along the trip, and the ones they keep in contact with when they are far away. Furthermore, I had the chance to elaborate on some of the topics encountered during the interview. During travel along I also ask the interviewees to fill in maps of the different cities that are part of their mobile life.

\subsection{The Mapping}

Two different types of maps have issued from this research. The first type is interactive. As said before, during travel along, I asked the interviewees to fill in the maps of their inhabited cities, taking note of the activities they carry out in a normal week and of the places they spend their time. The second type of map is elaborated by the author and is a synthesis of the information contained in the survey. While the first type of map highlights the complex relationship taking place between the interviewee and the territory, and which often reveals a functional and relational identification with multiple territories; the second type is more general and ranges from maps of life mobility, to understand the mobility biography of the interviewees and their competences, to maps of the different spaces inhabited in a given time (a day, a week or a month); this is in order to highlight the simultaneous coexistence of different territorial scales and multi-temporalities of actions.

More in detail regarding interactive maps, filling in the map helped people to place their activities and to deeply understand their way of being part of more territorial realities. After completing the map, one of the interviewees Beatrice affirms: "If you were to ask me where I live, I'd say Turin. Later, while I was putting 
my life on the map, I understood that all my activities are in Milan. There is another part of my life, which is the relationship with my partner: in Turin. So I can say that I live in Turin, because my loved one is there, but the rest, my personal interests: cinemas, theatres, exhibitions, are in Milan".

On the other side the maps of activities and places, help to understand the way in which the interviewees inhabit the territory. The maps have been built by considering the type and frequency of activities related to a place, while also recording activities undertaken while on the move. These maps show the distribution of different activities on a user-based territory. As it will be possible to see on the maps (cf. Sects. 6.1, 6.2, 6.3) in some cases the different activities are equally distributed on the map, in other cases it is possible to identify a preferential relationship with two hubs, in others only with one. Last synthetic maps of everyday mobility are an attempt to make more evident those different relations and highlight the relevance of the different places inhabited in the interviewees everyday life.

\section{The Main Characteristics of the Interviewees}

The interviewees have been selected according to the following characteristics:

- They all experience emerging mobility practices and they are, for example, Long Distance/Long Time commuters, Shuttles or Overnighters. It is a completely different dimension compared to a normal home-work schedule-says Gennaro to this regard;

- Their practices of mobility began mainly for reasons related to work, but have extended their influence over many different domains: in particular over personal and family life;

- Due to their mobility practices they all simultaneously occupy various and diverse life basins (this condition was verified in the course of the research thanks to the interviews, the mapping and the travel-along).

The interviewees are aged between 31 and 48 years old, 6 are men and 5 are women. ${ }^{9}$ When travelling by train, they travel by HSR (High Speed Railway). They work in: creative sectors (visual merchandiser, costume designer, designer), communication (press agent, reporter), ICT, and education; they are all highly qualified with bachelor, master or $\mathrm{PhD}$ degrees. From the economical point of view they are neither rich nor poor. They do not correspond to the description of highly mobile elite, travelling by plane all over the world in business class, nor do they travel by regional train (that are the slowest, least comfortable, and cheapest trains in the

\footnotetext{
${ }^{9}$ More in detail 9 of the 11 are in a couple, of these 3 are married and 6 are in a common law marriage, 4 have children ( 3 married and one in a common law marriage), while 5 are in couples without children. Four of the interviewees are Long Distance/Long Time commuters (LDC); 6 are double residents, one of whom is also an overnighter; the last one is relocated and an overnighter, and also in a long distance relationship.
} 
Italian railway system). Their mobility is both a sufferance and a choice, based upon a complex system of variables.

Looking at the interviewees, the proximity to family is, for example, one of the elements that most influences residential choices. A proximity to family allows children to grow up in a familiar context, and in many cases offers significant assistance in the management of family and personal duties. Another important factor of choice is represented by personal preferences. Seven of the interviewees affirm that one of the advantages of being mobile is that they can live in a more attractive city. An interesting insight is also related to the choice of neighbourhood: one of the interviewees declares: "my house is well connected by public transport, so it's not important if the central station is really close, but rather if I can easily reach it. If we (he and his partner e.n.) could find a house in a different neighbourhood that was equally well connected, then for me it would be the same", thus supporting the thesis that being well connected is more important than being very close from a geographical point of view (Amin and Thrift 2002, p. 37). ${ }^{10}$ Good public transport connections are an important matter also for dual residents.

In some other cases it has been possible to recognize circumstances that have encouraged the making of a choice: when one of the interviewees, Alessia, found her job in Milan she had a relationship in Turin, her partner was living and working there, and so she decided to be an LDC instead of relocating to Milan.

Undoubtedly income plays an important role in residential choice. For example, when shuttling in between different cities, while some highly mobile people can afford to rent two houses, others would prefer to relocate but cannot afford a monthly rent. As a consequence, they take advantage of friends' hospitality or stay in no-frills hotels.

Definitely, considering the reasons behind the decisions to be mobile, they are many and diverse, nevertheless it seems possible to specify some main characteristics: job insecurity, work commitments, chasing better working conditions while battling family constraints, struggling with the balance between professional aspirations and personal ties, or being in long-distance relationships.

\section{Are Mobilities Becoming More Reversible? Comparing Three Cases of Highly Mobility People}

In next paragraphs I will look, in particular, at three of the eleven interviewees. Those three cases make possible to focus on changes in mobility practices with particular attention to how mobilities support the construction of relationship with

\footnotetext{
${ }^{10}$ Regarding the connectivity of inhabited places it is possible to observe that almost all of the interviewees, that took part to this research, live in city centres, though this does not seem to be a discriminatory factor. Other research, such as that of Job Mobility and Family Lives, demonstrates that the diffusion of Long Distance commuting is a common phenomenon even for people that live in suburban areas.
} 
multiple territory, generating processes such as politopical dwelling (Stock 2006) and multiterritoriality (Haesbaert da Costa 2005), and transform everyday urban rhythm. The case are: Valentina, a 48 years old woman, married, long distance commuter, and the mother of a 7 years old boy; Beatrice, a 42 years old woman, in a common law marriage, and who is both a shuttle and an overnighter. Last, Gennaro, a 31 years old man who commutes every day; his partner is living in Germany. Thanks to the data and information collected in the research I have analysed their mobilities behaviours trying to understand the process of reversibilization of mobilities and how these last have influenced people life and consequently their use of space. Reversibilization of mobility has been considered in order to understand the impact of mobility on people lives. To this purpose I have considered four different dimensions of life: space-time, relational, existential and cultural dimensions.

Space-time dimension means to understand which mobilities strategies are assumed by an individual in order to reduce the impact of spatial distance and the quantity of time spent far from his own house basins. As matter of fact, for the interviewees being in a place means also to be far from another, being present or absent at the same time from the different domains of their life.

The relational dimension of reversibility was interpreted as the use of technology and systems of communication in order to reduce the impact of mobility on people's lives. It is clear that interviewees can be mobile not only because of the use of HST, but also because they can be always in contact with their beloved ones, while on the move.

The existential dimension, instead, measures the ability to build routines and reference points in order to reduce the impact of mobility on people's lives.

The cultural dimension of reversibility is, on one hand, related to the personal biography of mobility of the interviewees, highlighting if they have developed attitudes to be mobile (a kind of culture of being on the move); while on the other hand it measures how living in different places, and in general the habit of being mobile, may influence one's way of living and the approach to space.

This analysis helps to describe the ways mobile people build relationships with multiple territories that can be synthesized in the three following profiles.

\section{Three Profiles of Territorial Relations}

I have identified three different profiles of territorial relation (Fig. 1). Valentina has been considered as profile A: she inhabits an extended space, which includes all of the different places encountered in her everyday life: Turin where she lives with her family, Milan where she works and cultivate her passion for friends, arts, fashion and design and Pavia where her parents are living; Beatrice is profile B as she can clearly separate activities and places recognizing two main centres of life: Turin where she is lazy and completely dedicated to her relational life and Milan where she works and has a more active and vivid life; Gennaro instead recognizes one of 


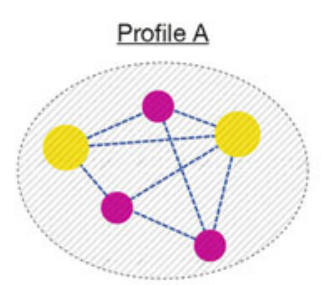

Main centers of interest

Secondary centers of interest
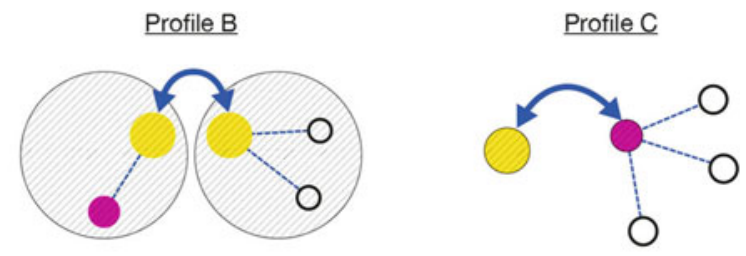

Other places of interest

Everyday territory of the interviewees

Fig. 1 Three profiles of territorial relations

the places as being the most important - the "home sweet home", and this is independent from the number of other places he inhabits in his everyday mobility. Thus I considered him as Profile C.

The profiles are not rigid categories. It was possible to find some characteristics crossing the boundaries of the different profiles, but broadly it was easy to delineate the main aspects. Another feature linked to methodological concerns needs to be clarified. This research is not a longitudinal one. It is a documentation of the conditions of the sample in the exact moment of the investigation. It may be that, on the basis of up-coming changes in their lives, the interviewees can cross the border between the different profiles or even stop being mobile.

\subsection{Profile A-Valentina, Inhabiting an Extended Territory}

Valentina was born in Pavia. She moved to Milan to study in 1985. She met her husband in 1994. After many years of a long-distance relationship they got married in 2006 and she moved to Turin to live with him. They have a child. She continues to work in Milan, and decided to be a Long Distance Commuter.

Valentina has good economical conditions and considers being mobile as an opportunity to enhance her professional career. Her space-time reversibility is good. She likes to travel, and considers it as a way to explore new places and meet people. She has good relational reversibility that she uses in order to keep in contact with family members and friends; She has low existential reversibility, as she is continuously exploring new places without necessarily building routines and defining reference points. As a consequence of her mobile life she developed the ability to find what she needs in different places. Furthermore, the fact that she is constantly on the move changes her way of interpreting and experiencing places. Her activities are spread over various places, at least the three places where she lives, works and visit family (Fig. 2). In Milan Valentina often meet her friends in the central station for breakfast in the morning or happy-hours in the afternoon before to go back in Turin, she also says "sometimes, if we (me and my friends e.n.) have time we like to 


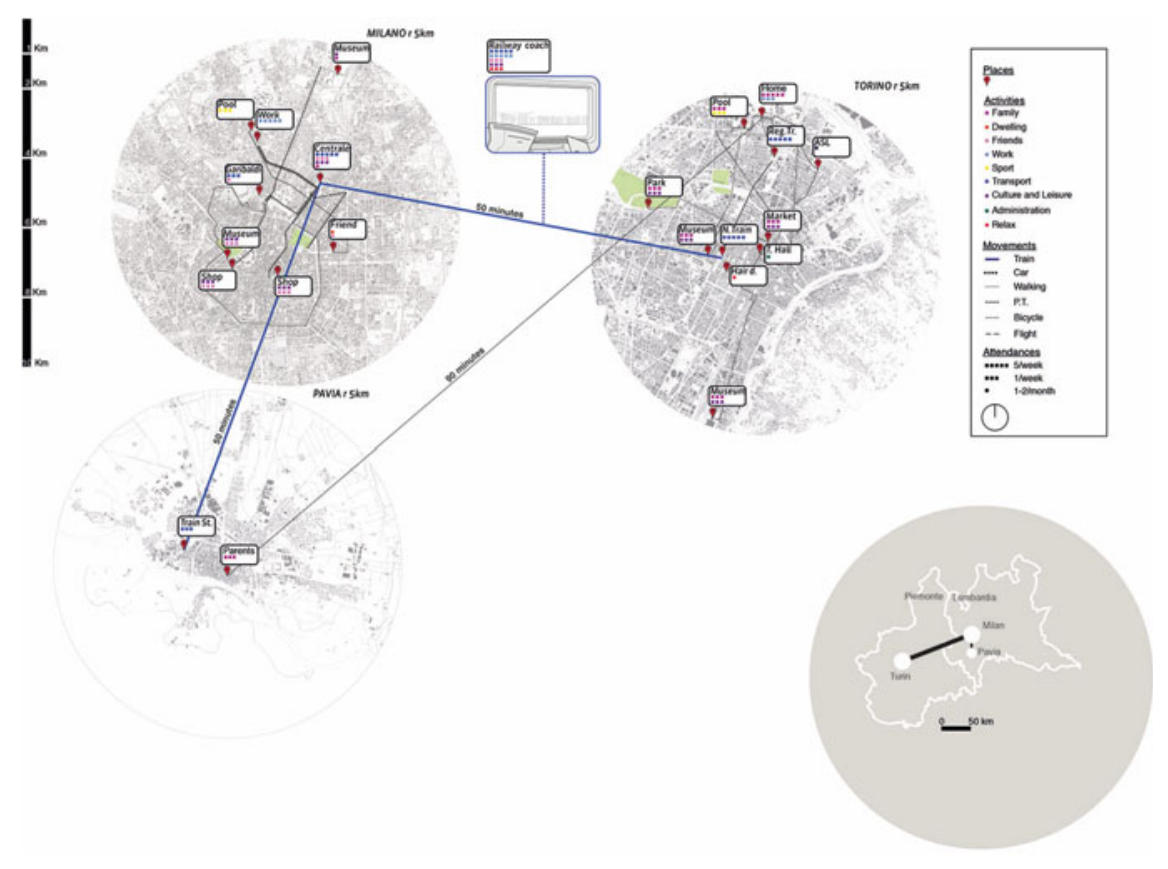

Fig. 2 Valentina's map of activities and places

go in nicer places. Maybe places we don't know, so that we can explore". Similarly, she is very explorative in Turin: "One of the thing that my husband loves of me is that I am like a tourist in Turin" she says. When asked to define the boundaries of her territory, she answered: "I don't feel boundaries and neither do I want to define them (...) I like this feeling of being in movement".

Thanks to her economical status which is also a consequence of her mobility, Valentina can travel in comfortable conditions. Because of smart phones, laptops and tablets she does many things on the move. When I have meet Valentina on the train she was working on her laptop. ${ }^{11}$ On the train she is constantly in contact with her husband and son, with her mother and sister and with her friends to organize her relational life in Milan. Her aptitude in taking advantage of different places is also applied on the move. In her cases, 'moving places' become places to stay while on mobility and are considered as the same as static places (Fig. 3).

Valentina has significantly transformed her relationship with territory as a consequence of her mobility practices. In her case it is not easy to define one place of residence, nor is it possible to say that she is nomadic or unattached to any place. It is more fitting to suggest that she inhabits a larger territory and that she uses

\footnotetext{
${ }^{11}$ Working on the train was a common task for most of the eleven interviewees.
} 


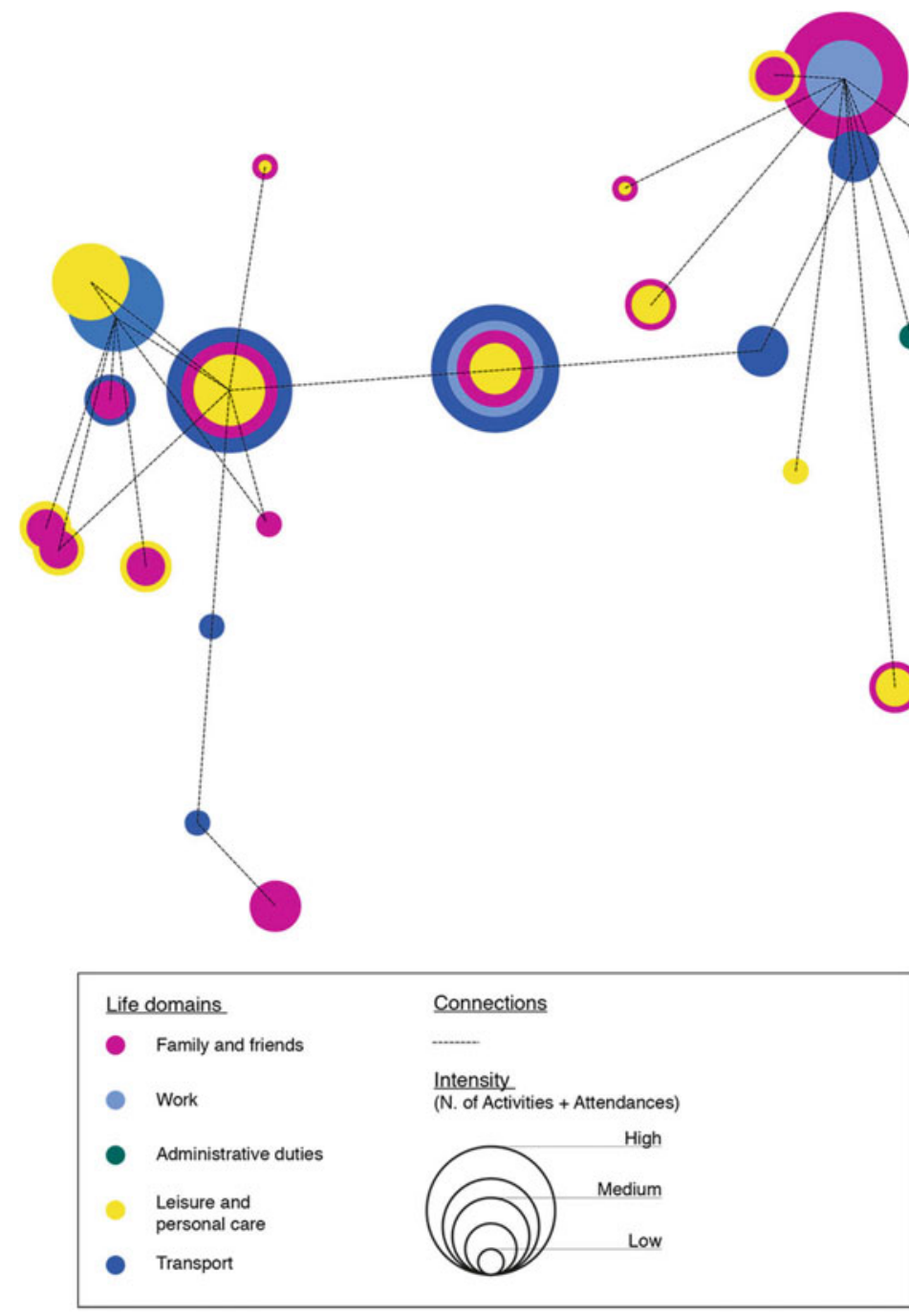

Fig. 3 Valentina's synthetic map of everyday mobility

different places according to different needs. Fast means of transport and mobile devices allow her to adapt to this new lifestyle. The space she inhabits can be considered a rhizome "it is a source of opportunities that are in a permanent state of reorganization" (Kaufmann 2012). ${ }^{12}$

\footnotetext{
${ }^{12}$ Source: http://fr.forumviesmobiles.org/ definition of Movement by Vincent Kaufmann.
} 


\subsection{Profile B-Beatrice, Recognizing Two Detached Centres of Life}

Beatrice has been living with her boyfriend in Turin since 2008 but works in Milan. She has been a long distance commuter for 4 years, traveling 5 days per week by train. She is also an overnighter and travels to Veneto and around Europe for her job. In 2012 Beatrice decided to rent a small apartment and to live in Milan from Monday to Friday, thus beginning a distance relationship. She currently shuttles between Turin and Milan, she has no child.

She cannot be considered to have a good relational reversibility, this is because to her being in Milan or in Turin represents two separated lives, she has different friends in the two places and to her is not easy to keep in contact with them when she is faraway. From an existential point of view Beatrice does not accept the fact of being mobile. Beatrice knows that her condition is permanent and she continuously builds reference points and routines in her life in order to avoid her condition of being mobile. She moved out of her parents' house twelve years ago, but she still keep her administrative residence there. Thus she has problem managing her health insurance, or bank issue. From a cultural point of view, living in different places has influenced her urban culture, but going back home is like going back to a different urban dimension. Talking about her life she refers mainly to two places that correspond to two main domains: working and family life. She mainly moves between Turin and Milan, although her parents live in Asti and the company she works for has its main office in Veneto. For her going to Asti is linked to her personal life and so she always departs from Turin, while going to Veneto or abroad for work reasons is part of her working life and so she always departs from Milan (Fig. 4).

She lives two parallel lives, and as matter of fact she declares this to be the case. Milan is the city for leisure while Turin is the city for her personal relationship (Fig. 5). Furthermore, she does not feel at ease while travelling and tries to reduce her travel time.

It is definitely possible to say that Beatrice inhabits a networked space made up of two main points, which are her main references.

\subsection{Profile C-Gennaro, No Place Like "Home"}

Gennaro has moved for study or work many times during his life. In 2010 he moved to Turin for personal reasons. His partner was working in Turin and they decided to settle there. Although Gennaro has been working as a press agent in Milan since 2009, he does not have many opportunities of finding an equivalent job in Turin. Gennaro decided to be a long distance commuter.

Gennaro is characterized by a high space-time, relational and cultural reversibility, but existential. Independently of if he travels between two, three or more cities (Fig. 6) and considers his condition permanent or temporary, he has chosen the place 


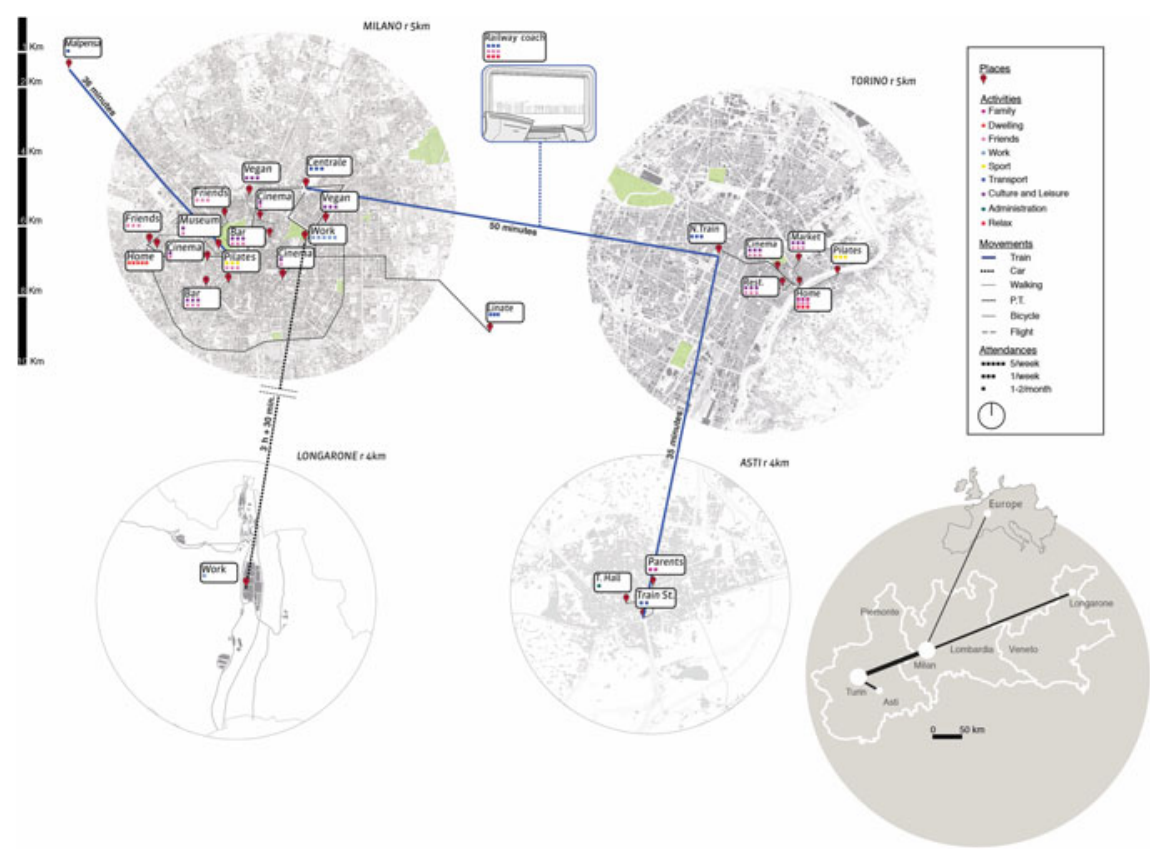

Fig. 4 Beatrice's map of activities and places

where he wants to live and defined it as "home". It doesn't matter if this is the place his families live, or where he comes from, it is the place he considers to be home. He is a frequent flyer to work and to visit his parents, furthermore, now that his partner is living in Germany, he goes twice a month to visit him, but he always tries to go back to Turin and to their home, because he affirms: "staying in Milan to some friends place, even if it can seems easier some times, is anyway occasional, then I prefer to come back to Turin, even late, to have all my stuff'.

$\mathrm{He}$ is at ease while travelling but he does not consider it to be fun. He is always connected to his partner and significant others thanks to the use of smart-phones. He loves to spend time in his main place of residence to go shopping and to meet friends. He prefers to move by bike or on foot while in the city. In the work place he is not very explorative and all his activities take place close to the office (Fig. 7). His satisfaction depends upon the organization of his trips. He prefers to travel by train because it is faster and because he can relax. Schedules and punctuality of public transport are very important matters for everyday organization, as well as the proximity and connectivity between home and station.

Gennaro tries to reduce to a minimum the impact of mobility on his personal life. He recognizes one place as a unique reference point, no matter how many other places impinge on his life through work, leisure, personal relationships or family, this place is clear and bounded, it is an areola space. Nevertheless, changing scale, an areola space can be linked to other spaces by a network and so changes from 

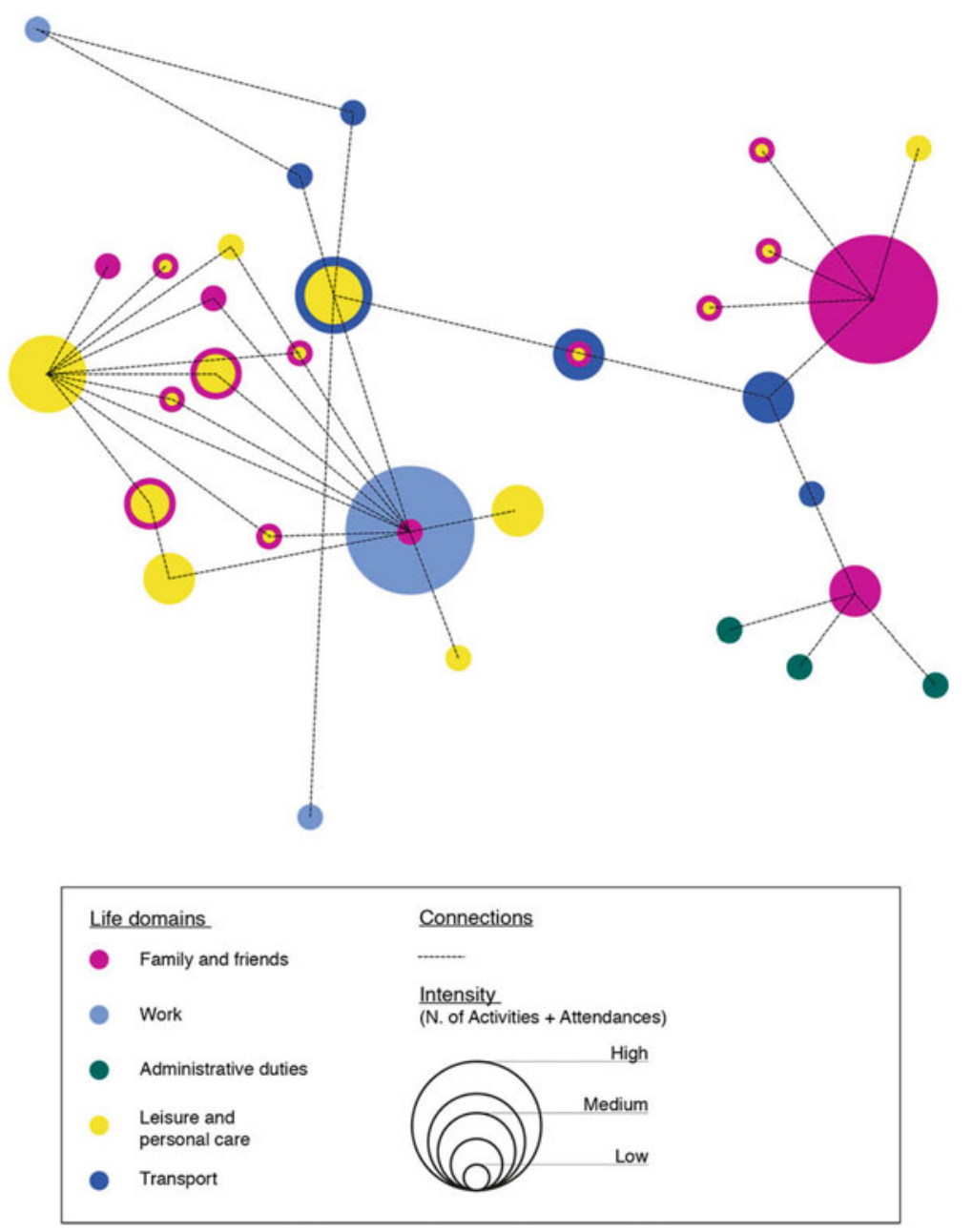

Fig. 5 Beatrice's synthetic map of everyday mobility

topographic to topological, being defined by its relation with other points of the network (Lévy 1994, p. 77).

\section{Mobility and (Im)Mobility and New Urban Schedule}

Looking at the biographies and maps of mobility of Valentina, Beatrice and Gennaro two other questions arose: the change in the schedule of the use of services and urban spaces; and the relationship between mobility and immobility. 


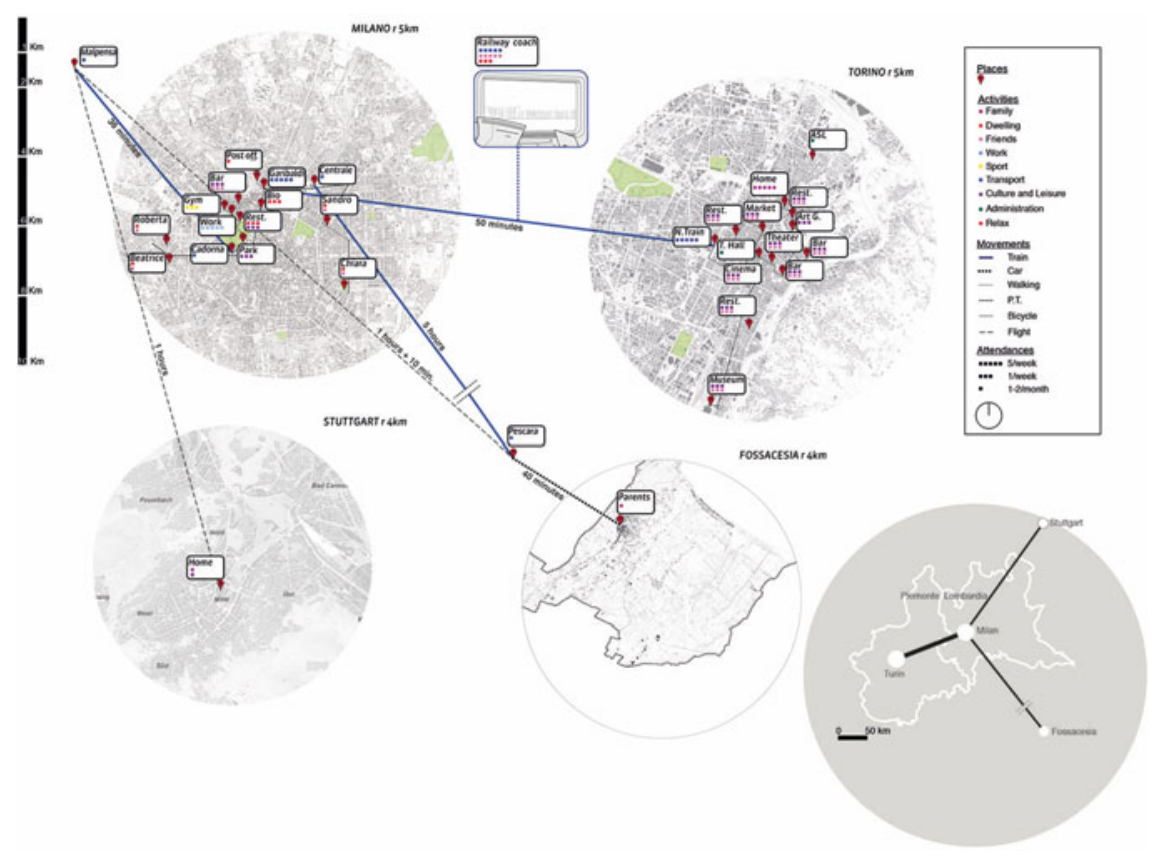

Fig. 6 Gennaro's map of activities and places

The description of shopping behaviours indicates the configuration of different urban rhythms and the de-synchronization of everyday activities. The de-synchronization of everyday activities has also been the subject of numerous studies in Italy, with particular regard to the access of women to work and the development of specific urban time policies. ${ }^{13}$ Currently all the interviewees are actuating new and different schedules. They all organise their lives in such a way as to spend as much time as possible with their families and children. In particular, even if Valentina is using her territory as a source of opportunity independent from the geographical localisation, she concentrates all the familiar activities during the week-end, while during the week days her husband is taking care of their son. On Saturday, Valentina swims with her son but her husband drops him off at school every day and goes to pick him up.

This last example shows a dynamic of mobile/immobile couple: for every mobile component, in a couple with children, as for example Valentina, there is always another component which is more immobile and is ready to deal with

\footnotetext{
${ }^{13}$ Urban time policies are public policies that intervene in the time schedules and time organization regulating human relationships at the urban level. In Italy they are implemented according to the national law 53/2000. In France, Germany and Holland, they are implemented by cities territories and companies (Mareggi 2013, p. 4). For more details about this subject: Bonfiglioli (1994), Henckel et al. (2013).
} 


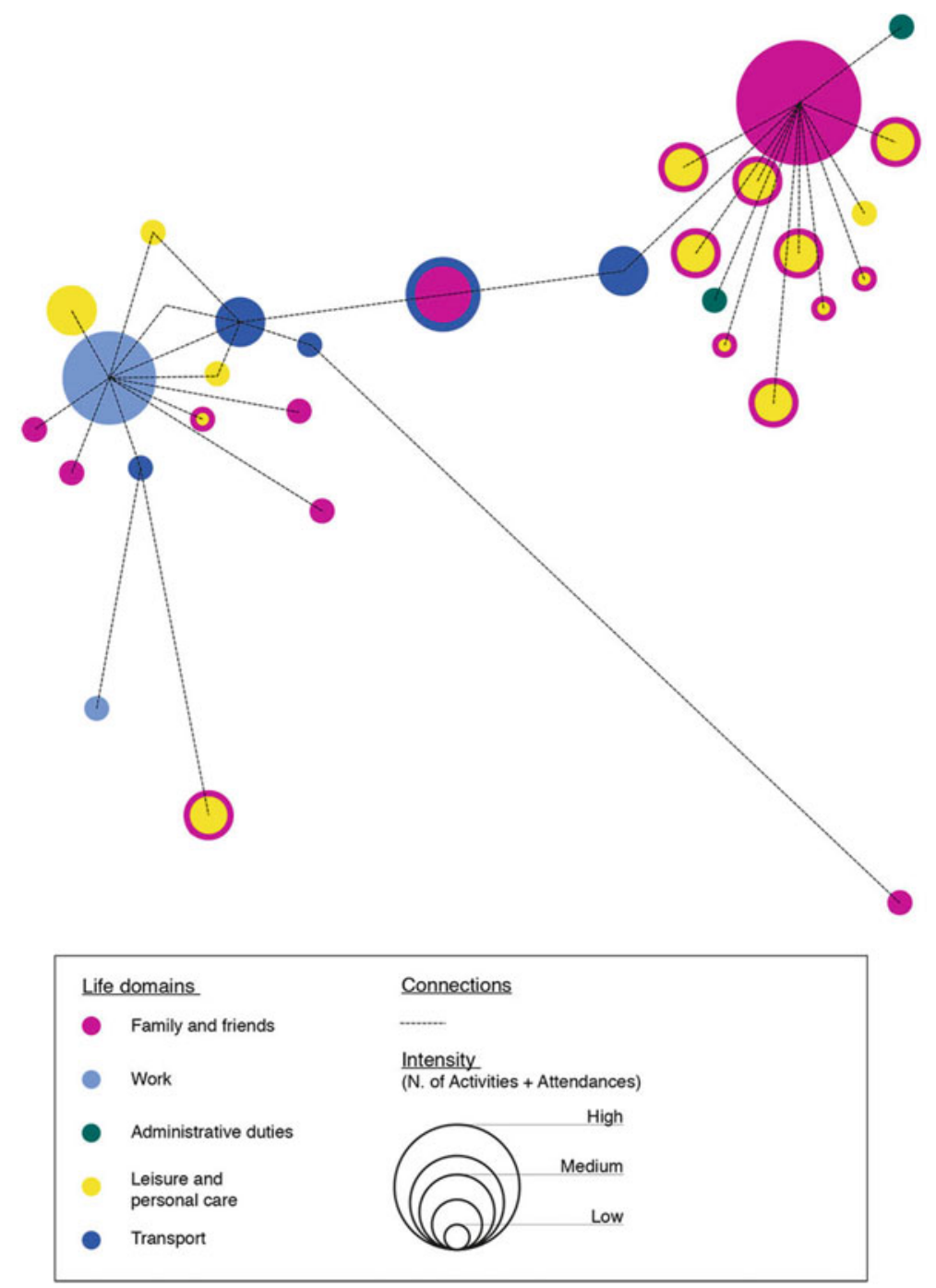

Fig. 7 Gennaro's synthetic map of everyday mobility

everyday duties. Nonetheless, a closer look reveals that Valentina has an open-ended contract, while her immobile counterparts runs a small business. And this is often the case: the mobile component of the couple is also the one that has more stable working condition and decide to be mobile in order to keep or improve them.

Also everyday rhythms of Valentina, Beatrice and Gennaro are clearly influenced by their mobility cycle. They consist of moments of high concentration that interchange with moments of relaxation, presence and absence respectively from 
the different spheres of activities and places. The rhythm of this presence and absence is determined by the dialog between the temporality of their travel and their work and family schedules. While shuttles, such as Beatrice, normally use the work place at night, everyday commuters, as Valentina or Gennaro, tend to do many activities during lunchtime. Furthermore, Valentina uses the morning before going to work and the late afternoon before returning home, either to meet friends in the central station, to swim, or have a walk. This articulation of personal life is leading gently to a reorganization of schedule activities such as home shopping or, more generally, the management of the house, causing additional changes in everyday rhythm.

Changes in shopping behaviours highlight the de-synchronization of everyday activities. Currently all the interviewees are actuating new and different schedules: they go shopping late at night, or during the week-end, or they benefit from their partner's availability. The way they organize their time is based on the time they spend near and far from their significant others, or from their work place. This clearly influences the cities in which they live by creating moments of high and low intensity of people and activities in different places and times. These are intensities that are difficult to highlight using traditional urban data. To this regard Beatrice's case seems to be emblematic: she is resident in Asti, officially rents an apartment in Turin but spends 5 days a week in Milan where she neither rents nor owns a house. Furthermore, considering that she does not commute every day, she is not even included in the official statistics of workers that enter Milan by train, even though she uses the city and its services everyday, 5 days/week.

In addition, different urban contexts call for different uses and rhythms, the same people can have a very intense use of a city while being very relaxed in another, according to the different offers, activities and life spheres that are associated to it.

\section{Conclusions}

In this chapter I have observed changes in mobility behaviours through three biographies of mobile people with particular reference to the way in which their mobile life style has consequences on the relationship with territory and on the configuration of urban rhythms.

The changes in mobility behaviours that have been defined at the beginning of the chapter as a process of reversibilization of mobilities has been used to define all those practices that allow different, even geographically dispersed, activities to be connected in everyday life. All the subjects that have been analysed in this research correspond to this characteristic.

Furthermore the research methods that start from the direct observation of people in order to describe the transformation of spaces due to changes in mobility behaviours allowed a more multiscalar and interdisciplinary approach to the experience of mobility supporting a description based on feelings and experiences of mobile 
people. The richness of details collected offers important insights of emerging mobility practices.

Presenting the story of the interviewees I have introduced some of the reasons why they have decided to be mobile, making it clear that even though they are a small group of pioneers of a new mobility style, they are not a mobility elite. Rather, in many cases they are mobile because they are obliged to be so by their work and by a complex system of personal and familiar relations and needs. After this more general consideration, I have introduced three biographies of mobility with particular reference to two main subjects of reflections: the change of the relationship between people and territory, and the transformation of urban rhythm.

Certainly changes in mobility behaviours have transformed the relation between people and territory. The three biographies of mobile people and their graphical transposition on the maps help to understand those changes and to outline three territorial profiles. At the same time I have considered how these different territorial relations also configure new urban rhythms, made up by the relation between presence and absence of people, the mobility and immobility and their different time schedules, configuring different intensity of use of spaces. These new rhythms also call for new urban schedules. Additionally, in order to fulfil their obligations in different domains of activities, interviewees push their personal limits and experiment with the possibilities offered by ICT and transport development. In this way they also modify everyday rhythms and configure new possibilities such as working from home, working on the train while travelling, or even organizing family needs while at the office via telephone or e-mail, thus creating a demand for more hybrid spaces. Thus, mobile people configure a city made up of the simultaneous presence of very different and extreme intensities of use (Viganò 2010, p. 31), where surfaces can shrink, and houses can be deserted during the week-end. At the same time spaces can be inhabited and services can be used in a very intense way. In this sense, urbanism is considered not only the discipline of material and permanent city design, but also as the coordination of these multiple urban rhythms made up of the alternation of different uses.

\section{References}

Amin, A., \& Thrift, N. (2002). Cities reimagining the Urban. Cambridge: Polity Press and Blackwell Publisher Ltd.

Ascher, F. (2005). La métaphore est un transport. Des idées sur le mouvement au mouvement des idées. Cahiers internationaux de sociologie (vol. 1(118), pp. 37-54). Paris: PUF.

Bissell, D. (2009). Conceptualizing differently-mobile passengers: Geographies of everyday encumbrance in the railway station. Social and Cultural Geography, 10, 173-195.

Bonfiglioli, S. (Ed.) (1994). Il Piano degli Orari. Antologia di Materiali per Progettare ed Attuare Politiche Pubbliche, Franco Angeli, Milano.

Bourdin, A. (2005). Les mobilités et le programme de la sociologie. Cahiers internationaux de sociologie (vol. 1(118), pp. 5-21). Paris: PUF.

Buscher, M., \& Urry, J. (2009). Mobile methods and the empirical. European Journal of Social Theory, 12(1), 99-116. 
Colleoni, M., \& Zajczyk, F. (2003). La mobilità nello spazio e nel tempo delle popolazioni urbane. Una lettura sociologica. Sociologia urbana e rurale., 72, 35-54.

Colleoni, M. (Ed.) (2008). La ricerca sociale sulla mobilità urbana. Metodo e risultati di indagine. Milano: Raffaello Cortina editore.

Cresswell, T. (2006). On the move: Mobility in the modern world. New-York: Routledge.

Elliott, A., \& Urry, J. (2010). Mobile lives. London: Routledge.

Haesbaert da Costa, R. (2005). De la Déterritorialisation à la Multiterritorialité. In S. Allemand, F. Ascher, \& J. Lévy (Eds.), Les Sens du Mouvement: Modernités et Mobilités (pp. 69-79). Paris: Belin.

Henckel, D., Thomaier, S., Könecke, B., Zedda, R., \& Stabilini, S. (Eds.) (2013). Space-time design of the public city, urban and landscape perspectives (Vol. 15). Dordrecht: Springer.

Kaufmann, V. (2002). Re-thinking mobility. Aldershot: Ashgate.

Kaufmann, V. (2011). Re-thinking the city. Lausanne: EPFL Press.

Kaufmann, V. (2012). Definition of movement. http://en.forumviesmobiles.org/marks/movement460. Accessed July 21, 2015.

Kesselring, S., \& Vogl, G. (2004). Mobility pioneers. Networks, scapes and flows between first and second modernity. Paper Presented at "Alternative mobilities Future" Conference in Lancaster, UK, January 9-11, 2004.

Latham, A. (2003). Research, performance, and doing human geography: Some reflections on the diary-photograph. Diary-Interview Method in Environment and Planning A 2003, 35, 1993 2017.

Laurier, E. (2010). Participant observation. In N. Clifford, S. French, \& G. Valentine (Eds.), Key methods in geography (pp. 116-130). London: Sage Publications.

Lévy, J. (1994). L'espace Légitime. Paris: Presses de la fondation nationale des sciences politiques.

Mareggi, M. (2013). Ritmi Urbani. Maggioli Editore, Santarcangelo di Romagna.

Sheller, M., \& Urry, J. (2006). The new mobilities paradigm. Environment and Planning A., 38, 207-226.

Stock, M. (2006). L'hypothèse de l'habiter poly-topique: pratiquer les lieux géographiques dans les sociétés à individus mobiles in EspacesTemps.net. http://www.espacestemps.net/en/articles/ lrsquohypothese-de-lrsquohabiter-poly-topique-pratiquer-les-lieux-geographiques-dans-lessocietes-a-individus-mobiles-en/\#. Accessed July 21, 2015.

Tarrius, A. (2000). Les nouveaux cosmopolitisme. Mobilités, Identités, Territoirés. Editions de l'aube, Monde en course, La Tour d'Aigues.

Viganò, P. (2010). Territorio dell'Urbanistica. Il Progetto come Produttore di Conoscenza. Roma: Officina edizioni.

Vincent-Geslin, S., \& Ortar, N. (2012). De la mobilitè au racines. In S. Vincent-Geslin \& V. Kaufmann (Eds.), Mobilité sans racine. Plus loin, plus vite... plus mobiles? (pp. 51-64). Paris: Descartes and Cie.

Widmer, E. D. (2006). Who are my family members? Bridging and binding social capital in family configurations. Journal of Personal and Social Relationships, 23(6), 979-998.

Urry, J. (2000). Sociology beyond societies. New York: Routledge. 
Part III

Mobilities, Inequalities and Conflicts 


\title{
Temporal Efficiency, Temporal Justice and Urban Mobility
}

\author{
Dietrich Henckel and Susanne Thomaier
}

\begin{abstract}
Urban areas are producers of the most productive and maybe efficient artefacts of humankind. They are characterised by different types of rhythms and temporal structures. The contribution analyses temporal (in)efficiencies in urban mobility and illustrates how these inefficiencies might be measured and made transparent. Exploring temporal inefficiencies and rhythms in transport and mobility offers hints at differences in mobility access and the distribution of space and time, that reach beyond pure questions of efficiency. Urban mobility involves important questions about equal and just mobility chances and options for all users of a city. Hence, temporal inefficiencies in urban mobility also raise questions about temporal inequalities and injustice and might call for redistributive action. To get to terms with temporal justice, the relations between transparency, equal access and individual temporal autonomy are disentangled. The right to one's own time is taken as a yardstick for an urban spacetime policy, which is also oriented to temporal justice. The concept of temporal justice is not yet established, but the authors are convinced, that temporal justice should get more attention in the development of a more time-related welfare policy.
\end{abstract}

Keywords Urban Rhythms - Temporal Justice - Temporal Efficiency • Accessibility • Time Policies • Infrastructure Quality • Diversity

\section{Introduction: Urban Rhythms, Urban Pace-Background and Research Questions}

Already in 1988 Michael Young claimed that the main work to decipher the time-prints of different cities and to compare them still has to be done (1988, p. 52). Since this statement, quite a lot of publications have been released using urban

D. Henckel $(\bowtie) \cdot S$. Thomaier

Institut für Stadt—und Regionalplanung, FG Stadt—und Regionalökonomie,

Technische Universität Berlin, Berlin, Germany

e-mail: d.henckel@isr.tu-berlin.de

S. Thomaier

e-mail: s.thomaier@isr.tu-berlin.de

(C) Springer International Publishing Switzerland 2016

P. Pucci and M. Colleoni (eds.), Understanding Mobilities

for Designing Contemporary Cities, Research for Development,

DOI 10.1007/978-3-319-22578-4_9 
rhythms as a key concept in their investigation, especially in recent years (e.g. Edensor 2010; Henckel 1995, 1996; Lefebvre 2004; Mareggi 2011; Mallet 2014; Mulicek et al. 2014; Neuhaus 2015). All these studies are based on the concept of urban rhythms - rhythm as the regular recurrence of the similar, not the same, thus comprising as well stability as change. However, they look at urban rhythms from various angles. Lefebvre in his small book (2004) develops a concept and method of rhythm analysis. Based on his concepts several authors look at different aspects of rhythms (rhythms of nature, rhythms of everyday life, rhythms of mobility, the multiple rhythms of the body) and their implications for space in a volume on the geographies of rhythm (see contributions in Edensor 2010). Henckel (1996) analyses the pace makers and different types of rhythms. Henckel (1996) analyses the pace makers and different types of rhythms, while Mareggi (2011), with special emphasis on three case studies in the Region of Milan, analyses the urban rhythms with the aim not only to describe but to contribute to the solution of so far unsolved problems. Mallet (2014) takes a critical perspective of the changing urban rhythms in the course of neoliberalisation. The unique temporality of specific urban areas due to different overlapping rhythms is analysed by Mulicek et al. (2014) using a chronotopic approach. They apply this approach to an empirical study of Brno. Neuhaus (2015) uses a set of different methods (e.g. interviews, mindmaps, geotracking of passengers and data from social networks) to trace the rhythmicity of mobile behaviour in the city and looks into the relation between urban rhythms and habitus of the cities. This increase in studies of urban rhythms is partly due to an increased sensibility to temporal aspects in urban studies generally and partly to new possibilities of analysis based on the availability of new data sets and new methods on the other (Henckel et al. 2013). However, in our view, urban rhythms are still a rather underdeveloped topic in urban studies. A major shortcoming is also that most of these studies concentrate either on a theoretical perspective or on case studies in individual cities. Comparative studies are practically not available.

Levine's (1999) geography of time is - as far as we know - the most advanced comparative study of cities in the US and worldwide regarding the speed of cities based on a few simple (and may be not any longer very appropriate) indicators (pedestrian speed in city centres, accuracy of clocks in public space, time for a standard service - selling a stamp). Therefore it analyses at least some aspects of urban rhythmicity or pace. A more recent study made another comparison between cities regarding pedestrian speed in inner cities (Wiseman 2007). A couple of theories were developed, why people in cities walk faster (Jaffe 2012) and showed an increase in speed over the years. Another bit of comparative indicators of urban rhythms was the analysis of sleeping times of users of smart bands (Jawbone 2014), showing quite interesting differences between cities. In this vein an analysis of the duration of the daily chores (however defined) between different cities would be a worthwhile endeavour, indicating the time stress different cities are producing. As daily urban out of home chores could be seen commuting, necessary shopping, necessary use of public and private services, eating out for work, banking, connecting different duties (chains of ways). We suppose that the duration of these chores differ significantly between cities on the one hand and between social groups 
and locations within cities on the other. A study in that line was published for London (Jarvis 2005).

The duration of daily chores in comparison could be one indicator of the efficiency of the temporal organisation of the city, of the synchrony of public rhythms, the possibility to synchronise private and public rhythms and to organise one's own chores in an efficient way, co-ordinating different tasks. This would give clues regarding the temporal efficiency of cities. In some respect one could interpret the study by Goodin et al. (2008) as a case in point, but in their analysis of discretionary time the authors only compare the impact of social systems and different institutional arrangements for countries and social groups within countries with no spatial focus whatsoever.

The notion of temporal efficiency relates the described changes to the economic problem of time becoming a scarcer and more valuable resource under conditions of acceleration. Of course it is a rather limited and narrow approach to deal with the temporal aspects of a city (which is in line with an economistic view) and with only a limited perspective of time. Yet we are convinced that even this narrow perspective could provide valuable insight into the functioning of cities and consequently enrich planning or help to improve actual situations.

The daily chores or measures like walkability or the Hägerstrand (1970) timespace hint at the implicit economic problem: the relative scarcity of time in relation to desired or required options of activities. The amount of time used for different activities could be reduced by e.g.

- facilitating and speeding up access to services and functions,

- synchronising and coordinating activities,

- substituting co-presence by telecommunication,

- rearranging the spatial structure.

The changing economy is one of the central pacemakers also for the changing temporal structures of society and especially the cities, influencing the compatibility of rhythms, whether urban rhythms result in a symphony or a cacophony, producing either compatibility or disruptions. This implies a relevant impact on temporal efficiency and justice. Cities as well as individuals and organizations have to develop strategies to adapt to new rhythms - especially for mobility services because of their decisive role for urban development. Besides, (travel) time and accessibility to services are decisive factors for competitiveness and are important themes in mobility strategies and concepts. Therefore the remainder of the article will elaborate on temporal (in)efficiencies and (in)justice in urban mobility.

Within a limited framework of temporal efficiency (see next paragraph) in urban contexts, we try to collect - since systematic data are not available - at least sketchy and eclectic empirical evidence for the relevance of temporal inefficiency (or efficiency) in urban mobility for different cities and its impact on temporal justice. In describing examples of temporal inefficiency we also look at methods and instruments which reveal differences and disparities in the spatio temporal distribution and which are-implicitly or explicitly - meant to enhance temporal efficiency and at best improving also temporal justice. 
We pose the question whether differences, diversity and selectivity are indicators of inequality and could be interpreted as injustice and if so how temporal justice could be enhanced. In the end we look at the new concept of the right to one's own time as a base to come to terms with temporal justice. Due to the lack of empirical data the article is more of a thought provoking exercise than a rigorous empirical study.

\section{Temporal Efficiency and Temporal Justice}

Because we deal with the temporal organisation of the city, with special emphasis on urban mobility, we base our discussion - as indicated - on a restricted concept of time: Time as chronographic, measurable time and a scarce resource. If time is conceptualised as a scarce resource it should be dealt with economically, i.e. in terms of economic efficiency. Temporal efficiency, as an economic concept, is looking either at the provision of a maximum of options in a given time or at minimising the required time for a given range of options. The range of potential options depends on the spatial organisation, the institutional framework, and other (locally) specific conditions. Depending on these different conditions (different) efficient outcomes are possible. Within these conditions moreover it is crucial how the individual finally decides and how he or she uses the given options, irrespective if the provider offers possible efficient solutions. The framework might enhance efficiency, give incentives for efficiency, but it is subject to individual decisions. To look solely at efficiency does not provide solutions for problems of social selectivity, the distribution of chances etc. within different frameworks. Therefore the decisions on the framework, the institutions are political decisions with far reaching implications for temporal distribution.

Looking at the institutional framework brings also the distributive aspects of temporal efficiency into perspective, because the chance to economise on time might be different for different social groups depending on their socio-economic status or their spatial distribution. This leads to the question of differences and diversity in the use of time, in the opportunities to use one's time in a self-determined autonomous way, and in the access to services. Hence, it is about options rather than actual decisions, because it might well be to decide against the options to economise on time due to personal preferences. Looking at the given options for individuals and groups reveals differences. The key question is, whether these differences are based on voluntary decisions on the use of one's own time or if they indicate disparities in the distribution of options and a polarisation of temporal opportunities.

Even then it is not clear, whether the differences are problematic, and are an indicator of (uncompensated) inequalities. But if these differences are valuated as unfair and unjust, they might call for public redistributive action, i.e. political intervention. That means that a politically highly contested field is entered. 
Therefore we want to stress that even if temporal efficiency and temporal justice are different concepts, yet they are closely interrelated. Temporal efficiency is an inherently economic concept, whereas temporal justice is a sub concept of social justice and equity.

In recent years justice in different respects is coming on the agenda for the valuation of urban life. The notion of justice is getting more and more recognition in different parts of urban studies - temporal justice being the latest and in our view least developed one. Urban studies are discussing a variety of different justices. Examples of the last decades are:

- The right to the city (Lefebvre 1968; Harvey 2008)

- The just city (Fainstein 2009, 2010; Marcuse et al. 2011)

- Environmental justice (e.g. Preisendörfer 2014)

- Food justice (Gottlieb and Anupama 2010)

- Temporal justice (Goodin et al. 2008; Goodin 2010)

Also in mobility studies, justice and equality play an increasing role, since access to transport modes and mobility services on the one hand differ among social and ethnical groups, elderly and young, healthy or disabled persons. On the other hand, mobility options vary also spatially. Justice and especially social justice is a highly contested field of research and political action. And the situation is getting more complex with new aspects coming on the agenda. The closest debate is the one on environmental justice - which developed in the US, gained momentum in the UK and is now being established also in Germany (Preisendörfer 2014; Senatsverwaltung 2014). The point here is, that negative environmental impacts are spatially unevenly distributed and cumulate in areas where underprivileged social groups are overrepresented, aggravating the uneven distribution of disadvantages. Taking the ample varieties of environmental states and even more so the ample varieties of temporalities into account it becomes obvious that we are discussing a variety of social justices.

A starting point is to conceive temporal justice as a relational and a relative concept:

- Relational means that the interrelations between social structures (e.g. institutions in the sense of organisations or rules), the material framework (e.g. urban structures, scope of infrastructures), the perception of temporalities, and the behaviour of different actors in specific spatial contexts play a major role. The variety of relations and conditions indicate that the constellations will be very different and very dynamic.

- Temporal justice is a relative concept because the provision of access and options depends on the cultural and economic context of the relevant city. Temporal justice could - like poverty or wealth — only be measured in relation to the context, i.e. it changes between locations and historical periods. Temporal justice is a relative state for a specific period in time, in a specific context, under specific conditions. 
Even taking these qualifications into account temporal justice is far from being well defined. We relate our contribution to justice in the sense of distributional justice and to equal access to transport, (public) services, and open spaces. Therefore the concepts are applicable to many aspects of urban spatio-temporal planning and the provision of public and private services. In the rest of the paper we will mostly concentrate on mobility related aspects (e.g. planning, access to and provision of services), because mobility is one of the key features of urban structure rising questions about temporal efficiency and temporal justice.

\section{Temporal (In)Efficiencies in Urban Mobility}

In comparison to other types of settlements, cities are in many ways more efficient (Glaeser 2011). Cities could be interpreted as artefacts to economise on space and time (Henckel 2007). Therefore the efficiency of cities also applies to temporal efficiency, since implicitly a lot of organisational, technical and other strategies are implemented to enhance temporal efficiency. However, in the following section we draw on sketchy evidence of different types of temporal inefficiencies in urban mobility. Examples of what could be seen as temporal inefficiencies are widely diffused in urban contexts. We structure the evidence according to the following aspects:

- Infrastructure networks

- Spatial structure

- Service quality

- Intermodality

- Information, orientation and image

\subsection{Design of the Infrastructure Network}

It seems difficult to measure the overall (in)efficient layout or organisation of an entire transport network. But in an extended agglomeration a transport system which is only structured around and through the city centre, lacking rings, tangential and peripheral relations will inevitably produce time consuming transport relations. Paris is an interesting case in this respect because of its centralised structure. To overcome this temporally inefficient centralised structure Paris is investing massively in ring lines. Likewise a transport system relying only on one mode is probably less efficient. But this also indicates potential conflicts between different modes, because there are several types of trade-offs. Not only in public transportation the design of the network influences travel times, also the design of the street space and how it is distributed to different traffic modes involves temporal aspects. The limitation of street space requires political decisions about how much 
space is given to different transport modes. In Copenhagen for example, space for cars was consequently reduced and "redistributed" to bicycle infrastructure. Hence, time efficiencies for individual motorized transport and cycling changed respectively. Further, time inefficiencies within the existing street or bicycle network are created by gaps in the net due to restrictions like one-way streets and related detours. In many places, bicycle contraflows in one-way streets are allowed to reduce travel times for cyclists.

\subsection{Spatial Structure and Consumer Discontent with Commuting}

The structure of agglomerations changed in the last decades by the suburbanisation, which meant that ever more people were living in the periphery of cities, which was heavily subsidised by tax allowances and deductions (Litman 2014). Moreover the increasing labour force participation of women and job flexibility further increased the number of people who have to commute. Commuting is rather time consuming. A study by Stutzer and Frey (2004) shows that with increasing time of commuting the index of life satisfaction is decreasing. The authors interpret this as a commuting paradox, because "according to economics, the burden of commuting is chosen when compensated either on the labour or on the housing market so that individuals' utility is equalized. However in a direct test of this strong notion of equilibrium, we find that people with longer commuting time report systematically lower subjective well-being" (p. 1). I.e. they incur losses. Besides the explanations the authors offer this might be interpreted as a discontent with the necessity to commute longer distances/longer times (on average) and therefore an inefficient allocation of time due to a maybe not so deliberate choice of residential location and/or the provision of services in public transport or individual traffic modes, especially the access to transport and its (temporal) service quality.

If one takes this result seriously one could expect, that it makes a case for shorter distances, therefore higher residential densities and an enhanced mix of urban functions and/or an improvement of the access to and the provision of (public) transport. This is due to the fact that the temporal distance depends heavily on the access to public and private transport. Access in this regard involves different aspects: especially the distance to the entry point of the transport mode, but also the quality of the service (see below).

\subsection{Service Quality}

The quality of mobility relates to quite a range of different aspects, which we will describe in turn. Not all of the aspects are equally relevant to all modes of urban 
transport. Some of them apply only to public transport (such as frequency, temporal extension, punctuality). The temporal organisation of public transport decides on the access people can have from different locations within the city and the agglomeration. The frequency and temporal extension of the services are relevant aspects here. Since public transport is especially costly there are remarkable differences in the coverage. The effects are a spatial and social selective imposition of different time costs. These problems are typically aggravated for night time traffic. Other quality aspects, such as information and signage etc. also influence time (in)efficiencies of cycling, walking or car driving.

Frequency of service is normally organised according to expected demand and the related costs. Therefore frequencies of public transport modes differ remarkably temporally (between different times of the day or the night) and spatially. Times for waiting for the service and eventual connections (and their reliability) are critical indicators for the efficiency of a system.

Especially in times of extending activities into the night and the weekend the temporal extension and the organisation of the night time transport network is of great importance for access and (implicit) decisions for or against specific transport modes. This in turn implies a (re)distribution of spatial and/or social selectivities during certain times. A systematic analysis of the night time public transport network would probably reveal huge differences between cities, even if one takes the different types of night time activities in the respective cities into account.

Even cities with the fame of being 24/7 cities like London or Paris have - at least for the tube - a rather limited schedule and are introducing night time service only recently and only for weekends.

Of course speed or velocity are key aspects for economising on time. But even here different concepts have to be kept in mind, which could be exemplified in the contrast of - indeed not urban-organisational structure of the rail systems in Switzerland and France. Switzerland as a rather decentralized country organises stations as markets for connections and changes, thus optimising the overall velocity within the whole net. France in contrast, as a centralised country with special regard to the capital is optimising the velocity on different lines (Stohler 1994). For this reason France has the fastest trains in Europe.

The Copenhagen Bicycle Strategy (The City of Copenhagen 2011) points out that "Travel time isn't just about speeding through the streets, it's also about being able to choose your own tempo and direct routes. Too many brief stops, detours and stretches where overtaking is impossible make travel times much longer" (p. 20). Hence it is not only gaps in the infrastructural bicycle network but also an inadequate quality of the net that hampers fast cycling in the city.

Moreover punctuality and reliability are other key features of the functioning of many public transport systems, especially if one has to change between lines or modes. Many providers of transport use punctuality as a marketing instrument (be it Ryan Air for flights, the London Underground for public transport, an interesting example is the withdrawal of punctuality indications for the Deutsche Bahn in recent years, because punctuality aims were not met). If a transport system is not 
able to provide on time service, which make also the change between lines and transport modes reliable time losses are inevitable.

The design of pedestrian or bicycle routes has a great influence on the necessary time spent. Spatial barriers like big roads or missing (barrier-free) crossings may cause detours for pedestrians or waiting times at unfavourably organised traffic lights. The layout of transport stations (information, barriers for handicapped) causes an uneven distribution of favourable access or temporal delays.

Quеиеs are pervasive in urban life and could be interpreted as an indicator of inefficiency. In microeconomics queues are seen as one device to allocate scarce goods according to the willingness to spend time instead of other modes of allocation-e.g. prices (willingness to pay). Traffic jams and congestion especially on inner city roads or within the agglomeration could be interpreted as a special type of queues. Meanwhile there are quite a few studies trying to measure the loss of time in jams in economic terms (e.g. Oxford Economic Forecasting 2005): "Transport within congested urban areas will inevitably be less rapid than elsewhere. This slower speed of transport has a cost in itself, but one that is outweighed by the benefits of urbanisation. Our approach is to focus on the cost of transport delays over-and - above those that are already allowed for in the normal operation of the transport network (i.e. the cost of additional transport delays when timetables are not met or road traffic travels at slower speeds because of congestion)" (p. IV). The special emphasis lies therefore on types of temporal inefficiency which can be reduced by appropriate means, which is a relevant argument for reducing transport delays. The costs of such improvements (investment, organisation etc.) have to be balanced "against the benefits from a reduction in delays to establish an economic optimum level of delay. This optimal point is unlikely to be zero as the costs of eliminating all delays would almost certainly be larger than the benefits achieved." (ibidem) Despite massive investments to improve the transport infrastructure organisational measures are taken. For London (and other cities) congestion charges are one method to enhance velocity, throughput, and give incentive to substitute the private car for the faster public transport etc. But the distributional effects are far from obvious. They have been criticised for being distributionally regressive and unfair because only the wealthy could afford the charge and having quicker road service. Especially on toll roads (or borders) pre-booking is also a means to reduce queues and waiting time, thus enhancing temporal efficiency.

The service quality in its different dimensions might be massively influenced by economic pressures in other fields. Examples are the (planned or executed) privatisation of public transport. Due to higher profitability pressures the maintenance intervals were extended (e.g. for the tracks of British Rail or for the coaches of the Berlin S-Bahn). The resulting technical problems lead to accidents and a close to breakdown of relevant parts of the service in the case of the Berlin S-Bahn. That means that economic pressures put on service providers may have implicit temporal components which in the end influence the temporal efficiency in the city. The hoped for enhancement of financial efficiency resulted in huge temporal losses by the clients - with unknown distributional effects. The externalisation of costs by the public transport provider resulted in a huge increase in temporal inefficiency 
(in the end in an economic inefficiency, too, even in private terms, because of the loss of clients and compensations costs).

\subsection{Intermodality}

Another point in case is intermodality or multimodality, when different transport modes and networks are combined to get from A to B or within a certain period of time (Beutler 2004; Deffner et al. 2014). The necessary time for changing modes and nets is influenced by a variety of factors and depends on the types of modes that are used and combined. Besides accessibility and synchronisation of schedules, an easy understanding of the transfer is essential. The use and combination of different modes needs to be self-explaining. There are a lot of examples available, where intermodal behaviour leads to time losses due to bad spatial design of stations and/or nets, insufficient information and orientation, non-synchronised schedules or differing payment schemes of transport systems-especially if the services are provided by different companies.

Also the "patti della mobilità" (mobility pacts) as part of the Italian urban time policy are a case in point here. They were often meant not only to harmonise supply and demand, but to establish and optimise the intermodality at locations where different (public) transport modes (offered by different authorities) meet.

\subsection{Information, Orientation and Image}

Another relevant point here is the specific temporalities of public (and private) services. Very often the decisions taken on the temporality are implicit and therefore not transparent, i.e. information is lacking. A relevant example is the arrival times of emergency cars in Berlin. After the call of the emergency the car should arrive within $8 \mathrm{~min}$ for $75 \%$ of the cases for some areas of the city and for at least $50 \%$ of all cases for the other areas. Only slightly exaggerated this temporal zoning is a decision on survival opportunities, which are highly spatially and socially selective.

Other aspect of information is the availability of information of the functioning of the network, on delays, on arrival and parting times - devices that are ever more available at electronic boards at stations or by real-time apps-with its own social selectivities.

Bad signage could also be interpreted as a cause of temporal inefficiency because - especially for strangers - connections in station, directions etc. are not known and sometimes not easy to find and therefore producing detours and temporal losses. Many cities invested heavily in recent years in new signage systems, for pedestrians [in public transport, in public space (Wilke 2013)] or for users of streets (even indicating temporal distances instead of physical distances in road 
signage). Even the availability of navigation systems in cars and apps could be interpreted as strategies to enhance individual temporal efficiency and therefore also aggregated efficiency. Signage systems for congestion and free parking lots are also examples to reduce temporal inefficiency.

Even the image (and its change) could influence the provision of public transport -e.g. due to the perception of insecurity of night time public transport might lead to reduced demand and finally less supply - excluding parts of the city or parts of the population entirely from night time connections. The very limited provision of night time public transport in Milan could serve as an example in this respect. The online tool for public transport connections in Milan even recommends walking because of the cessation of many relations during the night.

The results of all these examples are losses of time or opportunities of various types (e.g. travel times, waiting times, looking for substitutes) and/or financial resources. We are aware of the fact that travel time does not necessarily need to be wasted time, rather it can also be perceived as productive activity time (even more with ICT). Hence, also the individual understanding of the economic value of travel time changes (Lyons and Urry 2005).

\section{Transparency: Measuring Differences and Inequalities in Access and Performance}

To get an idea whether differences are problematic, indicate inequalities and polarisations which pose questions of injustice and call for action, it is necessary to make the differences transparent and to measure them in the first place. Since we emphasise the mobility aspects we look at access to mobility, mobility times and the options available. Of course access and mobility can be valuated on different scales: Worldwide, within Europe, within a region, within a city. For this paper we concentrate on the latter.

Relevant questions are: Are there spatial and/or social differences in the temporal access to (public) transport or other mobility options? Do they vary over the course of the day, the night, and the week? Who gains from temporal efficiency who suffers from temporal inefficiencies? Is the distribution of the effect of malfunctioning evenly distributed (by socio-economic criteria, spatially) or distributed at random? Are there groups that bear a more than average temporal burden or have systematically less access to substitutes?

We won't be able to answer all the questions but only to give some first evidence. Since data bases with respect to time and time budgets are hard to find one has to look for substitutes which might give at least some indications of measurements of access/performance and to (re)interpret these data also as 
measurements of differences and inequality. In recent years quite few new tools have been developed which might provide preliminary insights. ${ }^{1}$

The "Syndicat des transports d'Île-de-France" (STIF) provided already in 2004 (e.g. http://www.stif.org/IMG/pdf/isochrone_CRETEIL_dec06.pdf) isochrones for the public transport system, showing the very divergent accessibility of different areas of the city depending of the location and the entry point to the system. This is only a first indication of the huge spatial differences in access and access times and travel times to desired locations in the Paris region.

Mapnificent (http://www.mapnificent.net/) could be interpreted as a similar system showing the areas which can be reached with public transport in a given time, describing the accessibility of places. It is available for many cities in the US and worldwide (26 in Europe - among them London, Paris and Berlin), depending on the accessibility of the timetable data or their provision by the transport authorities. Meanwhile quite a few similar systems have been developed or are being developed.

One of the most advanced ones it "Walkable Cities" (https://www.walkscore. $\mathrm{com} /$ ), a website by a private enterprise. The providers write: "We believe that walkable neighborhoods with access to public transit, better commutes, and proximity to the people and places you love are the key to a happier, healthier and more sustainable lifestyle." The data products of the web site comprise: Walk score for location walkability scoring, the pedestrian friendliness, the transit score for public transit coverage of an area, the bikability score, points of interest, travel time analysis, mapping of food deserts, park deserts, or play deserts, car and bike share datasets. It is obvious that this information - also not meant as a dedicated temporal orientation - are of course at least implicitly an evaluation tool on temporal accessibility and its spatial differences between different locations within one city and between different cities. Even if walkscore was criticised for the limits of its accuracy and relevancy in methodology and results being not detailed enough regarding qualitative aspects (e.g. sidewalks, necessity to cross roads, security of the neighbourhood, type of stores) it is a rather valuable source already and it has been improved and extended during the recent years. A systematic temporal analysis and interpretation could serve for answering at least some of the posed questions. The interpretation in real estate terms makes also clear the economic relevance of different temporal distances.

Somewhat similar tools are also available by public bodies for their respective city. Transport for London (2010a, b) is a good example with two tools measuring access in London: PTALs-Public Transport Accessibility Levels and ATOSAccess to Opportunities and Services. PTALs are giving information on access to public transport - including walking time, reliability of service, number of transport services available, average waiting time, whereas ATOS is reflecting not only

\footnotetext{
${ }^{1}$ We do not elaborate on tools using mobile phone data or data from social media which are recently used more intensively for researching on urban rhythms (e.g. Manfredini et al. 2011; Kitchin et al. 2015; Neuhaus 2015).
} 
access to transport but also to jobs, educational establishments, health services, food shopping/town centres and open spaces. Taking account of "user choice".

Unsurprisingly, PTAL scores, reflecting access to public transport, relate to basic urban density and are typically higher towards central London. However, they also clearly reflect the pattern of strategic town centres throughout both Inner and Outer London. ATOS scores show a similar overall pattern, although higher scores are more evenly distributed through (particularly) Inner London. This pattern reflects a higher level of public transport provision, and also a concentration of services in inner and central areas (Transport for London 2010a, b).

A rough comparative analysis between Berlin and Milan of the night time coverage of the cities' territory with public transport shows that Milan has a very restricted coverage. The structure of the Milan night time network makes major parts of the city hardly accessible by public transport during the night. One would expect that the night time access to the city, to jobs, entertainment etc. is much more unevenly distributed in Milan, that the temporal burdens in Milan are much higher and socially much more selective.

This sketchy description of some analyses of the spatial distribution of temporal efficiencies or inefficiencies shows how limited the available information is on the one hand. On the other hand it stresses the importance and relevance of the topicdemonstrating the huge spatial (and social) differences within cities and between cities, and the redistributive effects of measures to enhance efficiency.

\section{The Nexus of Diversity, Inequality and Injustice}

Access to modes of transport and services etc. is not at all evenly distributed. Cities as places and "rhythm producers" (Henckel 1996) are of utmost diversity which makes them such interesting, productive and innovative places (Glaeser 2011). Therefore the differences between diversity, inequality and injustice have to be disentangled.

Temporal diversity as such cannot be seen as problematic because of the inherent social and cultural embeddedness of time concepts and time use. On the contrary (possible) diversity is a value in itself. To regard diversity and differences as unproblematic skip is a common (institutional) framework for all citizens seems necessary, comprising at least

- transparency,

- equal access,

- individual autonomy in the decision on time.

The notion of transparency comprises the availability of information on type, availability, conditions etc. of access to all kinds of (mobility) services in the first place. But to get an idea of potential injustice also on the normative assumptions for decision making and the organisation of say public transport have to be discussed openly. This also means that the monitoring and discussion of changes on spatial 
and social (re)distribution of times have to be extended. The call for transparency and the provision of information is far from being a trivial condition, because lots of data which would have to be made public are not collected and/or processed at all, or are not made public (not even for research) because of privacy or security reasons. Even if the amount of information available is continuously improving over time - especially due to the diffusion of smart phones and the supply of apps provided by public authorities or commercially - we would still claim that quite a lack of transparency will remain. But information is a prerequisite to the calculability of a necessary temporal "input".

Equal access means that there are no discriminatory practices (which in itself is not trivial, since even different prices for different modes of transport or different times of day, or tolls for directing traffic demand - congestion charges - could be valuated as discriminatory). Often equal access is seen more easily by its opposite, the unequal access due to different kinds of exclusionary and discriminatory practices like the ones Graham and Marvin (2001) are describing as aspects of splintering urbanism, like prime (networks) spaces, bypasses, technical sorting and exclusion (Graham 2004). There are quite a few selectivities in potential efficiency but also in the opportunities to buy extra speed (e.g. prime network spaces, express trains, motorcycle taxis).

Individual autonomy means that there should be no need, no coercion by the institutional or material framework to decide in a specific way. The basic condition must be that the decision is a voluntary and not a forced one.

"Where you live is what you get" nicely reflects diversity and inequality issues in access. Therefore the potential options depend on:

- spatial structures (the morphology of the city, the densities, functional diversity, the distribution of infrastructures and services),

- the structure and capacity of the net and its connectivity,

- regulations, e.g. the governance of provision of services (public vs. private), economic incentives (taxes, user charges etc.), temporal structure of availability (e.g. night vs. day),

- path dependencies,

- temporal patterns, i.e. the individual organisation of personal time tables (Dollase et al. 2000).

The provision and regulation of access is therefore prone to many types of direct or indirect-(time) political interventions. Equality of access therefore could be defined as the equal availability of services for everyone as an option. Since it falls into the autonomy to take the option or not individual preferences play a major role in the production of diversity. However, the degree of autonomy or coercion is often hard to evaluate.

Whether heterogeneity/diversity causes problematic inequalities is depending on explicit or implicit compensations (e.g. higher centrality against worse environmental conditions, less developed connections against lower property prices). A good example with respect to environmental justice is the fact that in Berlin the environmental quality is on average worst for the lower status groups, but also for 
some of the highest, like in Berlin-Mitte (Senatsverwaltung 2014 for data). Obviously there are trade-offs between different aspects of quality. It seems that inhabitants according to their preferences are willing to pay more for factors such as centrality, walkability or functional integration while compromising with environmental quality.

In our view framework conditions which make temporal efficiency possible can be seen as one criterion of the quality of life, providing the option to avoid "unnecessary" time losses. Temporal efficiency as an option means, that a city should provide the prerequisites for individually defined efficient time use. That makes the evaluation of measured behaviour in terms of efficiency and justice extremely difficult, but the evaluation of the structural framework, the incentives and disincentives, the provided options could be evaluated in this sense. We would like to recall the example of the emergency call as an emblematic example. Therefore observed differences to be regarded as unjust and calling for corrective action must be ascribed to objective conditions and not to individual discretionary behaviour.

Looking at the objective conditions comparisons between cities or different parts of cities and reflecting them against the economic and social capital become feasible. Comparisons between different spaces on different scales would inform about

- Different welfare conditions - with respect to possible temporal efficiency and its even or uneven distribution-between cities in different countries,

- Differences between cities within one country highlighting questions of unequal distributions which might be problematic within the ideals of the country,

- Differences within a city between different quarters, the most obvious case for redistributive action.

We only touched upon the relations between temporal efficiency, diversity, disparities and injustice.

Which diversity/inequality/selectivity is acceptable or even desirable, which ones are problematic, which equality must be attained to be deemed as just has to be further developed. Further enquiry has to deepen the understanding of the relations between these different concepts.

\subsection{The Right of One's Own Time as a Yardstick}

If it is correct, that time is getting more importance in public policy and could be seen as a second tier in the policy of the welfare state one has to look at baselines or yardsticks for evaluation. A broad statement poses the right to time as a fundamental right of citizens (Council of Europe 2010). In this line citizens should not be excluded from the practice of certain activities, nor be deprived of urban services (Mallet 2014, p. 15). A more extended concept was proposed by Mückenberger (2004) as the right to the right to one's own time. According to him the basic conditions are: 
- The individual or collective use of time is not heteronomous, it is the individual right to decide on the use of time, heteronomous decision which are of course necessary in a complex society have to be restricted and at least qualified by law.

- The individual time must not be systematically devaluated by discrimination, denial of access etc.

- Time use must not be subject to discrimination, excluding certain groups (spatially, temporally) systematically from access.

- Individuals and groups should have the positive option of their own choice of cultural values regarding their use of time.

- There must be a scope of collective times of families, religious groups etc.).

Regarding the relations between the right of one's own time and temporal efficiency and justice one could argue that the option of temporal efficiency is one part of the right of one's own time. But one has to bear in mind, that efficiency is always only relative according to the social, legal and economic conditions, therefore temporal efficiency looks different under different conditions.

Decision on one's own time could be seen as an extension of the human rights and as a baseline for temporal justice - as an ideal, worth fighting for. Then we have to accept that time has to become a systematic topic in all fields of politicsand of course in spatial planning. This is only going to take place if the temporal perspective is institutionalised and equipped with power and resources. The analogy of environmental policy is instructive here (Henckel and Thomaier 2013). Only after the Chernobyl catastrophe the environmental policy was institutionalised in its own right, which until then had been only seen as a transversal topic to be dealt with in each organisation.

There are already some preliminary institutionalisations of time policies-like the Italian case with the Legge Turco (2000) which gives the local authorities the right and the necessity to deal with the local times. But we would call it a weak institutionalisation because despite of this legal base temporal policies let alone spatio-temporal ones are still not very well established and important in Italian cities. Despite the law, which makes urban time policies legally binding, the local entities for time planning are hardly accessible e.g. on the websites of the local authorities (Bayer 2014). Institutionalisation of temporal policies is therefore neither a guarantee for temporal efficiency nor temporal justice unless it is getting stronger and more powerful.

A lot of open questions remain regarding urban temporal and spatio-temporal policies in general and the relations between the different concepts in this article specifically, e.g.:

- Who could or should be in charge of temporal policy and especially a policy for temporal efficiency and justice?

- How could the mostly implicit temporal aspects of the actions of many providers of transport and services and their impacts made explicit?

- How could a coherent picture and appraisal of temporal issues, their impacts on efficiency and justice be produced? 
Fig. 1 Structure of an integrated spatio-temporal policy. Own design

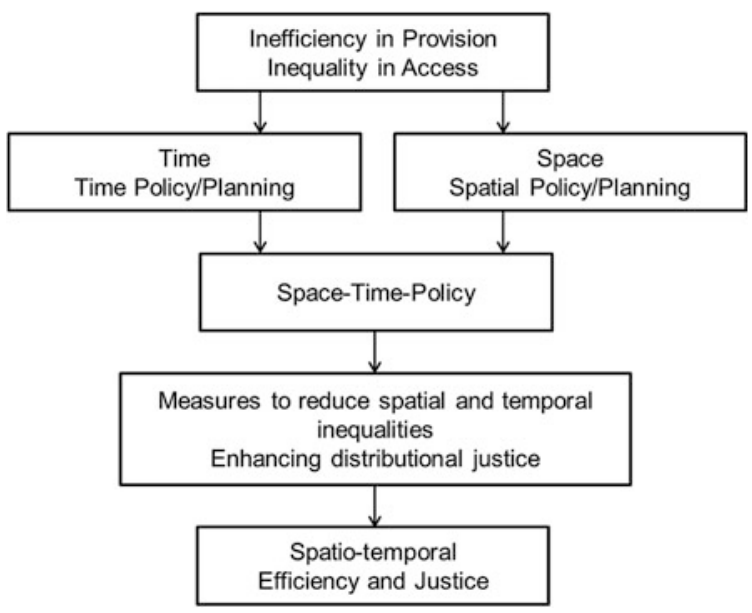

- How could the obstacles for an integrated policy like spatio-temporal policies be removed?

- How could the temporal perspective of traditional actors strengthened or mainstreamed?

A rather generic concept of a policy which takes inefficiency and inequality as a starting point would look at the potentials of temporal and spatial planning for integration and to develop measures to reduce spatial and temporal inequalities to enhance spatio-temporal efficiency and justice (Fig. 1). We are well aware of the fact that the road to establish such a kind of policy, even if one looks only at specific areas, like mobility, is still very long.

\section{Final Remarks}

Time as a central category and a topic is getting more and more recognition in urban studies. After a long time of spatially dominated analyses temporal and spatio-temporal analyses become ever more relevant in many fields of urban inquiry. This is i.e. due to major changes in the temporal structure of society, the social changes and the more pronounced recognition of time as a relevant category of the welfare state and its advancement. Regarding time as a part of the welfare state implies that urban studies do not only look analytically but also with a normative impetus on temporal issues. Our text looking at temporal justice (and efficiency) is meant as a preliminary step to a more in depth reflection and debate on these concepts. We are well aware that temporal efficiency and justice are-like poverty-relative and relational concepts. But we are convinced of the relevance of the topic and that the concepts are worth further inquiry. But there remain still many open questions, e.g. 
- Does looking at temporal efficiency proliferate a simplistic economisation of time? Does is lead to further commodification of time?

- What are the contradictions between efficiency concepts on different levels?

- Does potential temporal efficiency really contribute to the quality of life-as we suggest?

- Is potential temporal efficiency not only an important but also a necessary condition of temporal justice?

- How could the relations between efficiency and redundancy, between efficiency, temporal distribution and justice be operationalised for empirical inquiry and testing?

- Could $a$ temporal justice be described or is it necessary to think of a plurality of justices, because of the diversity of value systems, the lack of common concepts, the lack of clarity, the lack of data for empirical inquiry? ("But the recognition of the diversity of social rhythms also comes with that of the different temporal territories, reinforcing the idea that spatial justice can only happen when the heterogeneity of space is taken into consideration." (Mallet 2014, p. 16)

The necessity to take also temporal issues seriously in to account and open the analysis and debate on temporal efficiency and justice does not make things easier. We will end up with a variety of aspects of different justices. Despite the impossibilities to get clear cut answers we will have to make the debate and the decisions transparent. These issues are of utmost importance in mobility research, because mobility and transport in urban areas are most relevant pace makers for urban rhythms. Urban mobility and the related rhythms or efficiencies are not only decisive factors for the functioning of a city, they also influence the well-being and living quality of a city tremendously. Urban mobility involves important questions about equal and just mobility chances and options for all users of a city. Time is an important factor in this context: the analysis of temporal inefficiencies and rhythms in transport and mobility can offer hints at (in)equalities in mobility access and the distribution of space, that reach beyond the pure question of efficiency.

Acknowledgments We would like to thank our colleagues from the ARL working group on "Temporal Justice in the City", several groups of students at our department, colleagues in the international community of researchers on urban times for valuable discussions on the topic.

\section{References}

Bayer, R. (2014). Zeitpolitik in Italien. Berlin: Studienarbeit TU Berlin.

Beutler, F. (2004). Intermodalität, Multimodalität und Urbanibility - Vision für einen nachhaltigen Stadtverkehr. Discussion Paper SP III 2004-107. Wissenschaftszentrum Berlin für Sozialforschung.

City of Copenhagen. (2011). Good, better, best. The city of Copenhagen's bicycle strategy 2011-2025. Copenhagen: City of Copenhagen.

Council of Europe-The Congress of Local and Regional Authorities (2010). Social time, leisure time: Which local time planning policy? Recommendation 295 and Resolution 313 (19th session October 26-28, 2010). 
Deffner, J., Hefter, T., Götz, K. (2014). Multioptionalität auf dem Vormarsch? Veränderte Mobilitätswünsche und technische Innovationen als neue Potenziale für einen multimodalen Öffentlichen Verkehr. In: O. Schwedes (Hrsg.), Öffentliche Mobilität. Wiesbaden: Springer.

Dollase, R., Hammerich, K., \& Tokarski, W. (Eds.). (2000). Temporale Muster: Die ideale Reihenfolge der Tätigkeiten. Opladen: Leske und Budrich.

Edensor, T. (Ed.). (2010). Geographies of rhythm. Nature, place, mobilities and bodies. London: Ashgate.

Fainstein, S. (2009). Planning and the just city. In P. Marcuse, J. Connolly, J. Novy, et al. (Eds.), Seraching for the just city: Debates in urban theory and practice (pp. 19-40). London: Routledge.

Fainstein, S. (2010). The just city. Cornell: Cornell University Press.

Glaeser, E. (2011). Triumph of the City. How our greatest invention makes us richer, smarter, greener, healthier, and happier. London: Penguin.

Goodin, R. E. (2010). Temporal justice. Journal of Social Policy, 39, 1-16. doi:10.1017/ S0047279409990225.

Goodin, R. E., Rice, J. M., Parpo, A., \& Eriksson, L. (2008). Discretionary time. A new measure of freedom. New York: Cambridge University Press.

Gottlieb, R., \& Anupama, J. (2010). Food justice. Cambridge, MA: The MITPress.

Graham, S. (2004). Software sorted geographies. http://www.intelligentagent.com/CNM200/ Graham_software_geography.pdf. Accessed January 17, 2011.

Graham, S., Simon, M. (2001). Splintering urbanism. Network infrastructures, technological mobilities and the urban condition. New York: Routledge.

Hägerstrand, T. (1970). What about people in regional science? Papers of the Regional Science Association, 24, 7-21.

Harvey, D. (2008). The right to the city. New Left Review, 53, 23-40.

Henckel, D. (1995). Rhythmen der Stadt. In M. Held \& A. Geißler (Hrsg.), Von Rhythmen und Eigenzeiten. Perspektiven einer Ökologie der Zeit (pp. 157-167). Stuttgart: Hirzel.

Henckel, D. (1996). Cityrhythms. Cybergeo: European Journal of Geography. url: http:// cybergeo.revues.org/284. doi: 10.4000/cybergeo.284.

Henckel, D. (2007). Building high and running fast. In: D. Henckel, B. Herkommer, \& E. Pahl-Weber (Eds.), Time space places (pp. 59-74). Frankfurt/M.: Peter Lang.

Henckel, D., Könecke, B., Thomaier, S. (2013). Further research and policy perspectives. In: D. Henckel, et al. (Eds.), Space time design of the public city (pp. 301-309). Dordrecht: Springer.

Henckel, D., Thomaier, S. (2013). Efficiency, temporal justice, and the rhythm of cities. In: D. Henckel, et al. (Eds.), Space time design of the public city (pp. 99-118). Dordrecht: Springer.

Jaffe, E. (2012). Why people in cities walk fast. From the Atlantic Citylab. http://www.citylab. com/work/2012/03/why-people-cities-walk-fast/1550/. Accessed April 20, 2015.

Jarvis, H. (2005). Moving to London Time. Household co-ordination and the infrastructure of everyday life. Time and Society, 14(1), 133-154.

Jawbone (2014). The Jawbone Blog. In the city that we love. https://jawbone.com/blog/jawboneup-data-by-city/Zugriff. Accessed March 21, 2015.

Kitchin, R., Lauriault, T. P., McArdle, G. (2015). Knowing and governing cities through urban indicators, city benchmarking and real-time dashboards. Regional Studies, Regional Science, 1, 6-28. doi: 10.1080/21681376.2014.983149.

Lefebvre, H. (1968). Le droit à la ville. Paris: Éditions Anthropos.

Lefebvre, H. (2004). Rhythmanalysis. Space, time and everyday life. New York: Continuum.

Legge, T. (2000). Legge 8 novembre 2000, n. 328: Legge quadro per la realizzazione del sistema integrato di interventi e servizi sociali. http://www.parlamento.it/parlam/leggi/003281.htm. Accessed March 12, 2015.

Levine, R. (1999). Eine Landkarte der Zeit. München. Zürich: Piper.

Litman, T. (2014). Analysis of policies that unintentionally encourage and subsidize urban sprawl. Victoria Transport Policy Institute, Supporting paper commissioned by LSE Cities at the 
London School of Economics and Political Science, on behalf of the Global Commission on the Economy and Climate. www.newclimateeconomy.net for the New Climate Economy Cities Program.

Lyons, G., \& Urry, J. (2005). Travel time use in the information age. Transportation Research Part A, 39, 257-276.

Mallet, S. (2014). The urban rhythms of neoliberalization. Iustice Spatiale, Spatial Justice, 6, 1-19. http://www.jssj.org.

Manfredini, F., Pucci, P., \& Mückenberger, U. (2011). Local time policies in Europe. Time \& Society, 20, 241-273.

Mapnificent. (n.d.). www.mapnificent.net. Accessed March 11, 2015.

Marcuse, P., Connolly, J., \& Novy, J. (Eds.). (2011). Searching for the just city: Debates in urban theory and practice (Questioning Cities). New York: Routledge.

Mareggi, M. (2011). Ritmi urbani. Santarcangelo di Romagna: Maggioli.

Mückenberger, U. (2004). Metronome des Alltags. Berlin: Edition Sigma.

Mulicek, O., Osman, R., Seidenglanz, D. (2014). Urban rhythms: A chronotopic approach to urban timespace. Time and Society, 1-22.

Neuhaus, F. (2015). Emergent spatio-temporal dimensions of the city. Habitus and urban rhythms. Dordrecht: Springer.

Oxford Economic Forecasting (2005). Time is money. The economic effects of transport delays in Central London. London (Greater London Authority). http://www.london.gov.uk/mayor/ economic_unit/docs/time_is_money.pdf. Accessed March 12, 2015.

Preisendörfer, P. (2014). Umweltgerechtigkeit. Von sozial-räumlicher Ungleichheit hin zu postulierter Ungerechtigkeit lokaler Umweltbelastungen. Soziale Welt, 65, 23-45.

Senatsverwaltung für Stadtentwicklung und Umwelt (Hrsg.) (2014). Handlungsfeld Umweltgerechtigkeit. Berlin: Basisbericht Entwurf.

STIF (Syndicat des Transports Île de France) (n.d.). http://www.stif.org/IMG/pdf/isochrone_ CRETEIL_dec06.pdf. Accessed March 11, 2015.

Stohler, W. (1994). Zeitdistanzen statt Raumdistanzen. Flächendeckende Angebotskonzepte für Bus und Bahn. In: Vereinigung für Stadt-, Regional- und Landesplanung (SRL) (Hrsg.): Um die Wette leben - Geschwindigkeit, Raum und Zeit. Bochum.

Stutzer, A., Frey, B. S. (2004). Stress doesn't pay: The commuting paradox. Bonn (IZA discussion paper 1278).

Transport for London (2010a). Measuring public transport accessibility levels. PTALs. Summary, London.

Transport for London (2010b). Travel in London. Report 3, London.

Walkscore (n.d.). https://www.walkscore.com/. Accessed March 11, 2015.

Wilke, H. (2013). Raum ist Zeit Zeitentfernungskarten als Orientierungssystem im städtischen Fußverkehr. Berlin (Institut für Stadt- und Regionalplanung). https://opus4.kobv.de/opus4tuberlin/solrsearch/index/search/searchtype/advanced/start//rows/10/sortfield/score/sortorder/ desc/author/Henry+Wilke/authormodifier/contains_all/title/raum+ist+zeit/titlemodifier/ contains_all. Accessed April 10, 2015.

Wiseman, R. (2007). Pace of life. http://www.richardwiseman.com/quirkology/pace_home.htm.

Young, M. (1988). The Metronomic Society. Natural rhythms and human timetables. Cambridge: Harvard University Press. 


\title{
Transport Disadvantage, Car Dependence and Urban Form
}

\author{
Giulio Mattioli and Matteo Colleoni
}

\begin{abstract}
In a more mobile world, the ability to cover greater distances and access to motorised means of transport are increasingly important for access to services and opportunities and, as a result, for social status and inclusion. In this chapter, we put forward an integrated conceptualisation of transport disadvantage, based on an extensive literature review and on insights from our own research. Given the dominance and the structuring power of car-based mobility in developed societies, we sketch a typology of different forms of car-related transport disadvantage, which allows us to show how access problems vary considerably in relation to car ownership and use. Given the important relationships between transport disadvantage, urban structure and the built environment, we then illustrate the spatial dimension of all forms of car-related transport disadvantage and demonstrate the role of urban socio-spatial configurations (i.e. patterns in the distribution of different social groups within metropolitan areas) in compounding or alleviating these issues. In the concluding section, we briefly review the policy options to tackle transport disadvantage, providing concrete examples of the measures proposed and implemented in a number countries.
\end{abstract}

Keywords Transport disadvantage - Social exclusion - Car dependence • Urban form - Accessibility - Transport policy

\footnotetext{
G. Mattioli (衤)

University of Leeds, Leeds, UK

e-mail: g.mattioli@leeds.ac.uk; giulio.mattioli@gmail.com

M. Colleoni

University of Milan Bicocca, Milan, Italy

e-mail: matteo.colleoni@unimib.it 


\section{Introduction}

There are several goods and bads arising from transport and mobility, and both are distributed unequally across society, with implications for justice (Lucas and Jones 2012; Mullen et al. 2014). Negative externalities and conflicts related to transport have drawn much policy and research attention, and some of them are considered elsewhere in this volume (see chapter "Resident and Non-resident Populations: Types of Conflicts"). This chapter focuses on what is arguably the main good of transport: access to services, opportunities and social networks.

In recent decades, levels of mobility, motorisation and car dependence have increased steadily. In a more mobile world, the ability to cover greater distances and access to motorised means of transport, such as the car, is increasingly important for social status and inclusion (Knowles 2006). This is the context behind the rise of the transport and social exclusion agenda (Lucas 2012). The definition of 'mobility-related social exclusion' proposed by Kenyon et al. (2002) is useful to define a field of study:

the process by which people are prevented from participating in the economic, political and social life of the community because of reduced accessibility to opportunities, services and social networks, due in whole or in part to insufficient mobility in a society and environment built around the assumption of high mobility (pp. 210-211)

In other words, transport-related problems can effectively hinder access to things as essential as employment and education opportunities, health care, cheap and healthy food, support networks, etc. In turn, lack of access to such services and opportunities can result in social exclusion, i.e. reduced participation in society. ${ }^{1}$

A wide and sometimes confusing variety of terms is found in the literatureincluding e.g. transport/mobility (related/based) (and) (social) exclusion/inclusion, transport disadvantage, socio-spatial exclusion, accessibility poverty and transport/mobility poverty - all of which are used to refer broadly to inequalities in transport and access. This is unhelpful and, as Lucas and Markovich (2011, p. 233) note, "there is a need to establish a "lexicon of definitions" to ensure a greater degree of clarity and consistency within and between the academic and policy literature". We argue that there is also a need to make connections between transport and social exclusion research and wider debates about increasing car ownership and use and the impact of urban form and the built environment on travel behaviour (Mattioli 2013a, b, 2014a).

In this chapter, we address these limitations by putting forward (in the next section) an integrated conceptualisation of transport disadvantage, based on an extensive review of the literature. Then we then sketch a typology of different forms of car-related transport disadvantage, which allows us to show how access problems vary considerably in relation to car ownership and use (Sect. 3), and to bring to light the spatial dimension of transport disadvantage (Sect. 4). In Sect. 5, we briefly review the policy options to address these issues.

\footnotetext{
${ }^{1}$ Debates around the precise definition of social exclusion are reviewed in Levitas (2006).
} 


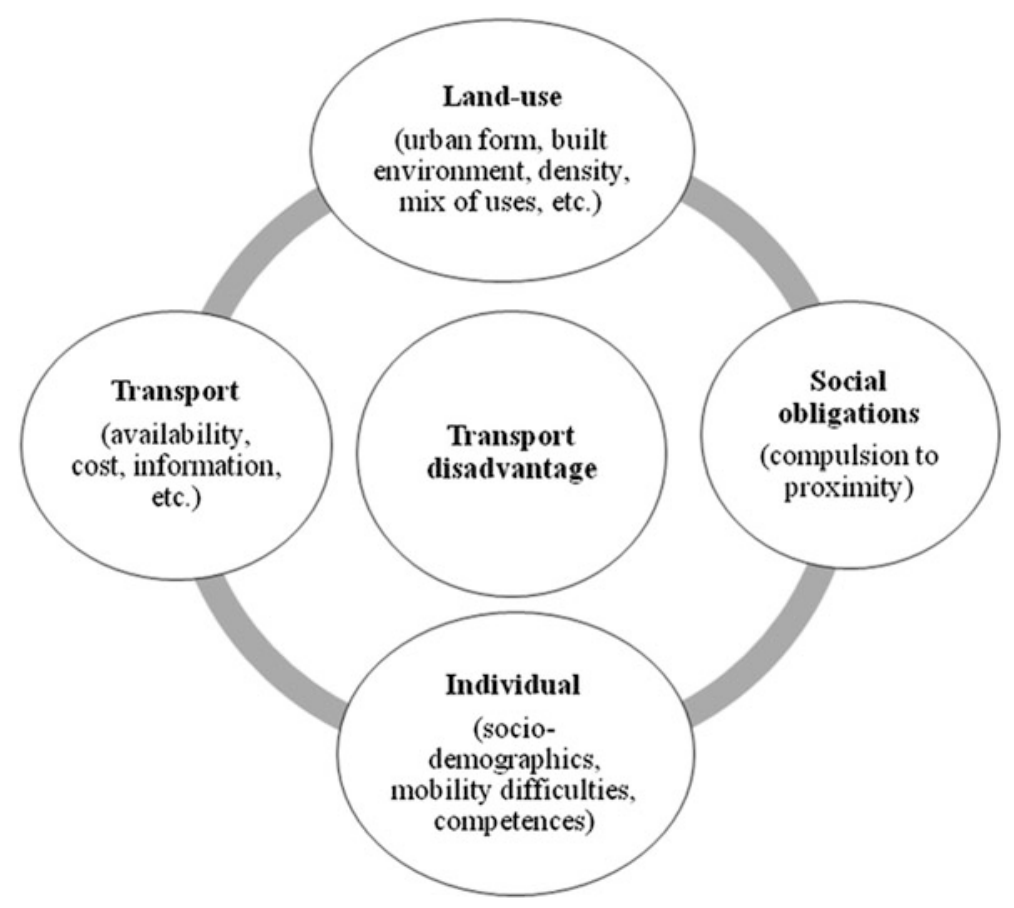

Fig. 1 Factors affecting transport disadvantage. Source Adapted and integrated from Lucas (2004), Currie (2011), Cass et al. (2005)

\section{Transport Disadvantage and Social Exclusion}

Figure 1 depicts transport disadvantage as emerging from the interaction of four sets of factors. For ease of exposition, we discuss three of them first and social obligations later. First, individual and household attributes can make access to desired services and opportunities problematic. Indeed, recurring characters in transport and social exclusion research are: low-income households, older people, women, ethnic minorities and immigrants, young people, the disabled and the unemployed. ${ }^{2}$ Similarly, transport-related factors such as poor public transport services or high transport costs clearly have an important impact on limiting access. Finally, factors related to land use, such as population density and mix of uses, are crucial as they influence the distance to the activity locations that people need to travel to.

It is important to stress that transport disadvantage should always be considered as the result of an interaction between different factors, and can seldom be attributed to just one of them. For instance, while disability can be seen as a personal attribute,

\footnotetext{
${ }^{2}$ Significantly, these are also the social groups generally considered more at risk of social exclusion more broadly, as well as the most likely not to own cars (Mattioli 2014a).
} 
the difficulties that disabled people experience in using public transport are also the results of shortcomings of public transport infrastructure in accommodating them. Teenagers are often considered at risk of transport disadvantage, because they cannot drive cars; however, this is likely to result in accessibility problems only in areas where desired activities are difficult to reach by other transport means (such as low-density suburban areas).

In this context, another factor of interest has to do with the skills and competences of individuals. The key insight here is that even when transport linkages exist, individuals might not be aware of them, lack the skills required to use them, etc. French scholars have been perhaps the most active in exploring the socio-cognitive dimensions of transport disadvantage (Allemand 2008; Le Breton 2004a), often with reference to the motility framework put forward by Kaufmann et al. (2004). British research has shown that limited travel horizons, reluctance to travel and reduced expectations can result in transport disadvantage even in contexts where suitable transport infrastructure is available (Lucas 2004; SEU 2003).

While social policy (Lucas 2004) and planning (Currie 2011) approaches to transport disadvantage tend to emphasise the role of individual, transport and land-use factors, the sociological perspective of Cass et al. (2005) highlights the crucial role of social obligations. Since co-presence is a requirement for a wide range of human interactions, it is this 'compulsion to proximity' (Boden and Molotch 1994) that explains most passenger travel (Urry 2002). This has important implications for conceptualising transport disadvantage.

First, Cass and colleagues encourage a broader understanding of accessibility needs: people do not need to access just public and formal services (e.g. shops and hospitals), but also social networks, which can be crucial for social inclusion.

Second, as social obligations vary among people, different individuals and social groups need to access different services, opportunities and social networks. As a result, people for whom meeting these obligations requires a greater amount of travel, either because of the sheer number of obligations or because of more distant destinations, are more at risk of transport disadvantage (all other factors being equal). Indeed, British data show that, once car ownership is controlled for, higher-income households are more likely to report travel difficulties for all travel purposes except 'travelling to the doctors/hospital' (Mattioli 2014b), presumably because of more dispersed social networks and activity locations. This is consistent with the growing number of studies showing that richer and more mobile groups are equally or even more likely to report accessibility problems than the rest of the population (Colleoni 2013; Currie and Delbosc 2010; Unbehaun and Uhlmann 2013), notably when time poverty is taken into account (see Sect. 3.3).

Finally, obligations to proximity, being socially constructed, are subject to change over time and this might result from increasing mobility at the societal level. For example, older people today engage in a wider range of leisure activities than a few decades ago: while difficulties in accessing these activities might not have been a problem then, they probably have an impact on social exclusion now. As Cass et al. (2005, p. 553) argue, "the relation between social exclusion, mobility and access (is) a dynamic one, and one that plays at the level of society as a whole". 
While most literature in this field focuses on the relationship between transport disadvantage and social exclusion, recent research has expanded the range of theoretical constructs taken into consideration. Based on large survey data and structural equation modelling techniques, Currie (2011) and his research team have investigated the causal relationships between transport disadvantage, social exclusion, social capital and well-being in Victoria, Australia. The results suggest that transport disadvantage has both a small direct effect and an indirect effect (via social exclusion) on well-being, and that the effect is stronger in peripheral areas. Related research has highlighted the role of social capital (defined as individual access to social networks) in mediating between transport disadvantage and social exclusion (Stanley et al. 2010).

The complex web of relationships between transport disadvantage and related constructs is depicted in Fig. 2, showing a further complicating factor: the mutual causal relationships between lack of access, on one hand, and social capital and social exclusion, on the other. Indeed, people may lack access to transport and services because of limited social networks and/or pre-existent social exclusion (e.g. unemployment), as much as the other way around. Empirically, this makes it extremely challenging to measure the impacts of transport disadvantage in a robust way.

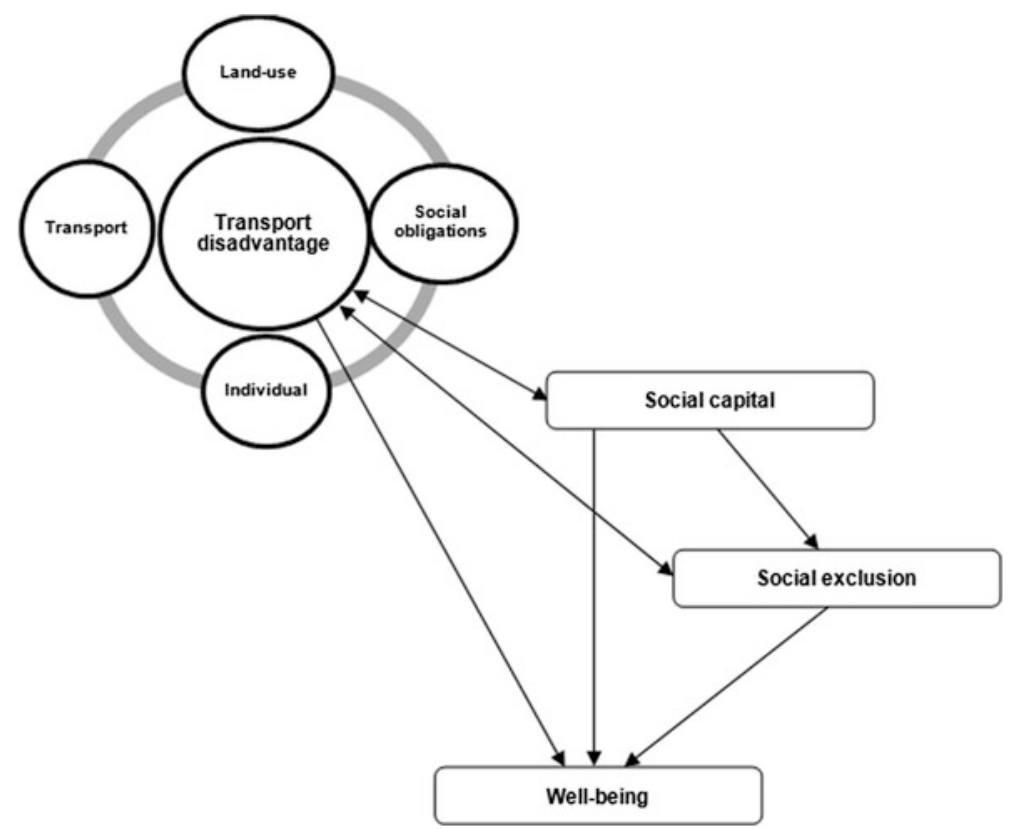

Fig. 2 Relationships between transport disadvantage and related constructs. Source Adapted and integrated from Currie (2011), Stanley and Stanley (2007) 


\section{Transport Disadvantage and the Car: A Typology}

In most developed countries the car is the dominant mode of transport. In the EU-28 in 2014, it accounted for between 65 and $91 \%$ (depending on the country) of passenger kilometres by powered transport (European Commission 2014). The structuring power of car-based mobility has led researchers across disciplinary boundaries to talk of automobile dependence (Newman and Kenworthy 1999) and of a system of automobility (Urry 2004). It therefore makes a lot of sense to distinguish different forms of transport disadvantage depending on specific patters of car ownership and use (including of course non-ownership and use). This allows us to go beyond a generic discussion of transport disadvantage in which essentially different exclusionary processes are confounded and conflated.

Based on a literature review and insights from our own research, we argue that four main forms of car-related transport disadvantage can be distinguished: car deprivation, car-related economic stress, oil vulnerability and car-related time poverty.

\subsection{Car Deprivation}

We define car deprivation as the lack of access to services, opportunities and social networks that can arise from not having access to a car. To be clear, this does not mean that the lack of a car always corresponds to transport disadvantage, nor that having access to a vehicle is an absolute defence against it. However, most transport and social exclusion research suggests that, in certain contexts and for certain categories of people, lack of car availability is a crucial determinant of transport disadvantage. Indeed, car deprivation is the most investigated form of disadvantage in this field, with the first studies dating back from the 1970s (Paaswell and Recker 1976). In the US - arguably the world's most car dependent society-much research has investigated the role of the car in the welfare to work transition, generally concluding that it is an essential precondition to securing employment (Blumenberg and Manville 2004). In such a context, lack of access to a car is virtually equivalent to car deprivation. Broadly speaking, however, car deprivation should be considered as an emergent property of interaction between four factors:

- individual characteristics, such as certain mobility difficulties, can make the car virtually the only viable means of transport. When this happens, however, the shortcomings of alternative modes (such as public transport) in accommodating impaired passengers should be considered as a contributing factor

- transport-related factors, such as the lack of public transport in the area, are obviously crucial in making lack of access to a car equivalent to transport disadvantage. Even in this case, however, other factors (such as the absence of services at walking or cycling distance in the area) should be considered as a contributing factor 
- land-use patterns are crucial: low-density built environment increases the distance to destinations, and thus makes the car more of a necessity for access to essential services, opportunities and networks (see Sect. 4). However, even here the lack of competitive modal alternatives may be seen as a contributing factor

- finally, the nature of individual obligations to proximity may contribute crucially to turn lack of car access into disadvantage. For instance, women tend to trip-chain more than men, due to multiple responsibilities, and this can exacerbate car deprivation, even though other factors such as the spatial separation of women's activities contribute as well

Moreover, car deprivation can arise directly from the fact that accessing certain services, opportunities or networks without a car is difficult, and this discourages participation. However, it can also arise indirectly from a process whereby e.g. access to employment with alternative modes is possible, but so time-consuming that little time is left for other activities that are essential for social inclusion (such as visiting friends and relatives at their home), thus resulting in time poverty (Farber and Páez 2011). This highlights the importance of the temporal dimension of accessibility (see chapter "Temporal Efficiency, Temporal Justice and Urban Mobility").

\subsection{Car-Related Economic Stress and Oil Vulnerability}

While car deprivation has attracted most of the attention, there is increasing recognition that there are forms of transport disadvantage arising from car ownership and use as well. In the literature, several terms are used to indicate the financial stress associated with owning and operating cars and its negative consequences, including forced car ownership (Currie and Delbosc 2011), transport poverty (Gleeson and Randolph 2002), commuter fuel poverty (Lovelace and Philips 2014) and, in France, precarité/vulnerabilité énérgetique des transports (Jouffe and Massot 2013). In this chapter, we put forward the term car-related economic stress (CRES) as it is more neutral and does not suggest that affected households lack agency (as in forced car ownership), nor a spurious analogy with issues of affordability in the domestic energy domain, which are arguably conceptually different. ${ }^{3}$

The reason why CRES is a form of transport disadvantage is that excessive expenses for car ownership and use (notably for commuting) can lead households to cut spending in other essential areas (including other travel purposes), with knock-on effects on social inclusion and well-being (Jouffe and Massot 2013; Taylor et al. 2009). Alternatively, households may choose to allocate enough money to other activities (considered essential), and reduce travel spending accordingly: this in turn

\footnotetext{
${ }^{3}$ There is value, however, in explicitly considering the similarities and interrelationships between questions of affordability in the transport and domestic energy sectors (see Mattioli 2015).
} 
can restrict their activity spaces and the opportunities to participate in mainstream social life. In most cases, these negative effects will cumulate.

It is important to stress that (low-income) households are not forced into car ownership and economic stress: in fact, research suggests that often households choose to locate in car-dependent areas, where car ownership is essential, because of other benefits, notably lower housing costs (e.g. Currie and Delbosc 2011; Polacchini and Orfeuil 1999). This suggests that CRES should not be studied in isolation but in conjunction with the cost of housing - and daily travel in relation with residential mobility.

The notion of oil vulnerability refers to people who are not necessarily experiencing CRES now, but are likely to do so in the future in the event of increasing fuel prices (Dodson and Sipe 2007; Lovelace and Philips 2014; Rendall et al. 2014). Obviously, households currently in economic stress are even more at risk of social exclusion in the event of a sudden spike in oil prices. On the other hand, such price hikes result in more than a mere increase in the number of people affected by CRES. As we have argued, households experiencing car-related economic stress in a context of relatively stable motoring costs should be considered as having at least some agency. By contrast, fuel price rises change the structural constraints that they face: for instance, a household might have chosen residential location so as to achieve a good overall balance between housing, transport and other expenses. Large price changes can alter this fine balance, as households struggle to cope with an unanticipated situation. Research suggests that households' coping strategies towards motoring cost increases include reducing activity participation and cutting other areas of expenditure, both of which can result in social exclusion (Currie 2011; BBSR 2009). In extreme cases, they result in major life changes such as residential relocation (Motte-Baumvol et al. 2010) or mortgage defaults (Sexton et al. 2012).

While research on oil vulnerability and CRES has focused first and foremost on identifying geographical areas of low resilience (see Sect. 3.1), studies from France suggest that, after controlling for income and type of area, households including children and employed adults are more likely to spend a high proportion of their income on car travel, as a result of long commuting distances (Nicolas et al. 2012). This shows that the social profile of households affected by these types of transport disadvantage is radically different from that of the car deprived, demonstrating the value of distinguishing between them.

\subsection{Car-Related Time Poverty}

Besides economic stress (actual or potential), there is arguably a second type of car-ownership-related disadvantage, arising from the temporal burden of car dependent activity patterns. We define car-related time poverty as the form of transport disadvantage associated with the lack of time deriving from spending an excessive amount of time for car travel, which in turn can result in social exclusion. 
A typical example is how a long-distance car commuter may give up participating in leisure or social activities because of the priority accorded to travelling to and from work.

The empirical evidence to illustrate this point is provided by a study on Canadian metropolitan areas (Farber and Páez 2011) showing that between 1992 and 2005, the increase in urban sprawl, car dependence and traffic congestion has been associated with a growth in travel durations for mandatory activities (e.g. work, shopping and childcare). At the same time, participation in discretionary out-of-home activities (such as visiting social contacts and volunteering activities) has declined in favour of participation in in-home activities and time spent alone. The hypothesis here is that "mandatory trip durations have grown at the expense of participation in other types of activities" (p. 788). In a separate study, the same authors (Farber and Páez 2009) show that in Portland (US) individuals relying on cars for the totality of their travel were more likely to travel more and to participate in in-home amusements, but less likely to participate in visiting and out-of-home amusement activities than multimodal individuals, even after controlling for residential location and socio-demographics.

This is consistent with findings from Australia (Currie and Delbosc 2010), showing that the transport disadvantage associated with time poverty reduces well-being and is more common among employed, more mobile and higher-income sectors of the population. Arguably, it is the different social obligations of the middle classes (which tend to travel longer distances to more specialised jobs) that explain the greater incidence of car-related time poverty amongst this group (Cass et al. 2005). This is consistent with the original notion of time poverty, which highlights how people can be "work rich but time poor" in contemporary societies (Sullivan and Gershuny 2004). Yet these groups have so far been overlooked by transport and social exclusion research, with its predominant focus on carless, low-mobility and otherwise disadvantaged social groups.

\section{The Spatial Dimension of Transport Disadvantage}

\subsection{Urban Form and the Built Environment}

The relationship between urban form, the built environment and travel behaviour is one of the most thoroughly researched in urban planning (Ewing and Cervero 2010). In this context, the notion of car dependence is used to indicate the degree to which the car is the only practicable option for passenger travel in a given local $\operatorname{area}^{4}$ (Newman and Kenworthy 1999). This depends on the availability and the performance of alternative transport modes, which in turn are greatly influenced by

\footnotetext{
${ }^{4}$ Beyond its original understanding, the notion of car dependence is used in a variety of different ways in transport research (Mattioli et al. forthcoming).
} 
built environment characteristics such as density, diversity (Ewing and Cervero 2010) and, notably in Europe, distance from urban centres (Næss 2006). Overall, the research consensus is that the car is more of a necessary good in low-density suburban and rural areas than in compact city-cores, a conclusion supported by empirical studies relying on a diversity of methods, ranging from econometrics (Dargay 2002) to geographical analysis (Siedentop et al. 2013) and focus groups (Smith et al. 2012).

As a result of the geographical patterning of car dependence, the intensity of the four forms of car-related transport disadvantage varies systematically between different types of area. To illustrate this, in Table 1 we assume the existence of only two types of area, defined by population density and location within the metropolitan area: a high-density city-core and a low-density outer suburban area. These should be considered as extremes on a continuum of car dependence, with most areas located somewhere between the two. Another assumption is that employment opportunities and services are rather concentrated in and around the city core, as it is generally the case in European cities (Kesteloot 2005).

With regard to car deprivation, it follows almost necessarily from what argued above that this form of disadvantage is most pronounced in very car dependent areas. However, the proportion of the population that lacks access to a car is positively associated with density and urbanity. As a result, while the intensity of car deprivation is strongest in low-density outer suburban areas, the number of people affected by it is actually at its lowest. The opposite happens in compact city cores, with low intensity disadvantage affecting a greater number of people.

Mattioli's study of households without cars in Germany and Great Britain (2013b, 2014a) shows that the gap between motorised and non-motorised households in terms of actual travel behaviour (number of trips, travel distance and time) and accessibility to basic services and opportunities increases as density and urbanity decrease. While this demonstrates the relationship between car dependence

Table 1 Incidence and intensity of four forms of car-related transport disadvantage across different types of area in European cities

\begin{tabular}{l|l|l}
\hline & $\begin{array}{l}\text { High-density city } \\
\text { core }\end{array}$ & $\begin{array}{l}\text { Low-density outer } \\
\text { suburban area }\end{array}$ \\
\hline Car deprivation & $\begin{array}{l}\text { More people } \\
\text { affected } \\
\text { Minimum } \\
\text { intensity }\end{array}$ & $\begin{array}{l}\text { Less people affected } \\
\text { Maximum intensity }\end{array}$ \\
\hline $\begin{array}{l}\text { Car-related economic stress and oil } \\
\text { vulnerability }\end{array}$ & $\begin{array}{l}\text { Less people } \\
\text { affected } \\
\text { Minimum } \\
\text { intensity }\end{array}$ & $\begin{array}{l}\text { More people affected } \\
\text { Maximum intensity }\end{array}$ \\
\hline Car-related time poverty & $\begin{array}{l}\text { Less people } \\
\text { affected } \\
\text { Minimum } \\
\text { intensity }\end{array}$ & $\begin{array}{l}\text { More people affected } \\
\text { Maximum intensity }\end{array}$ \\
\hline
\end{tabular}


and car deprivation, it is also partly (but not entirely) the by-product of the different socio-demographic composition of the carless group. Indeed, where population density is lower the group of non-motorised households is not only smaller, but also much more concentrated among marginal social groups (e.g. older, female-headed and single-person households). Conversely in dense urban areas it is not only larger, but also more socially diverse, including e.g. a relevant proportion of working households and families with small children. Since the marginal social groups mentioned above tend to travel less and are more likely to have mobility difficulties (e.g. for age reasons), this magnifies the mobility and accessibility gap of carless households in car dependent areas.

Another significant finding from the study is that both in Germany and the UK carless individuals in compact cities report high values of travel time, often higher than their motorised counterparts. This is particularly true for students and the employed, who appear to travel little for reasons other than work or education. This suggests that, while the overall intensity of car deprivation is lower in compact city centres, the issue of time poverty for non-car owners is, perhaps counter-intuitively, more widespread in the least car-dependent areas.

With regard to car-related economic stress and oil vulnerability, a substantial body of research from countries as diverse as Australia (Dodson and Sipe 2007), New Zealand (Rendall et al. 2014), France (Nicolas et al. 2012), Germany (BBSR 2009) and the UK (Lovelace and Philips 2014) shows that they are more pronounced in suburban and rural areas. This results from longer travel distances and less opportunities to shift to other transport modes (greater intensity) and from higher car ownership rates, notably among low-income households (greater incidence). Car dependent areas with high concentrations of low income households are obviously particularly vulnerable (Dodson and Sipe 2007).

In this context, the role of housing costs is crucial. Households are attracted to peripheral, car dependent locations by lower housing prices, which should offset the corresponding increase in transport costs (Polacchini and Orfeuil 1999). Yet, households may still end up experiencing economic stress, as they tend to underestimate the increase in transport costs associated with the relocation (Currie and Delbosc 2011; Münter 2013), and may struggle to cope with further, externally induced increases in motoring costs. The low resilience of car dependent suburbs to increasing fuel prices is therefore a great concern for urban planners. On the longer term, however, sustained higher fuel prices can change household location preferences, contributing to a trend towards re-urbanisation (BBSR 2009; Motte-Baumvol et al. 2010).

Almost by definition, the residents of low-density suburban areas are the most affected by car-related time poverty (see Sect. 3.3). Indeed, this form of transport disadvantage is the product of the time required for car commuting and that required for access to leisure activities. While commuting time can also be high for inner-city residents (as they generally cover shorter distances, but in more congested conditions), the accessibility of leisure activities is typically much better there. Overall then, they are both less likely to experience car-related time poverty and, when they do, it is less intense. As argued above, travel-related time poverty is 
a concern in urban areas as well, but it tends to affect carless, rather than car-reliant individuals.

Overall, as shown in Table 1, the intensity of all forms of car-related transport disadvantage increases with car dependence. In terms of incidence, however, in more car dependent areas there is a shift from the disadvantage arising from lack of car access to that related to the financial and temporal burdens of vehicle ownership and use. In other words, despite very high rates of access to cars in these areas, transport disadvantage still exists, albeit under different (more energy-intensive and less resilient) disguises.

\subsection{Urban Socio-Spatial Configurations}

In Table 1 we have implicitly assumed that there are no systematic social differences (in terms of income, social status, etc.) between residents in the two types of area. However, urban socio-spatial configurations (Kesteloot 2005), i.e. patterns in the distribution of different social groups within metropolitan areas, can either compound or mitigate the spatial patterning of the different forms of car-related transport disadvantage.

For ease of exposition, in Fig. 3, we assume the existence of only two configurations and only two social groups. To adopt the terminology used by Kesteloot (2005), city-type A is the dramatic city, where employment, services and lower classes are concentrated in the urban core, while middle and upper classes live in the suburbs (European examples are certain British and Belgian cities). City-type B is a topologic city with a concentric socio-spatial structure, i.e. middle and upper classes live in the urban core, while the poor are concentrated in the suburbs (European examples are Milan and Stockholm).

In city-type B the gradient of car deprivation across areas is steeper, as disadvantage is even worse in low density suburban areas, where many low-income households are not able to afford a car, despite it being virtually a necessity. At the same time, car deprivation is residual in the urban core, where alternatives to car use are better and the ability to afford cars is greater. By contrast in city-type A the

CITY-TYPE A

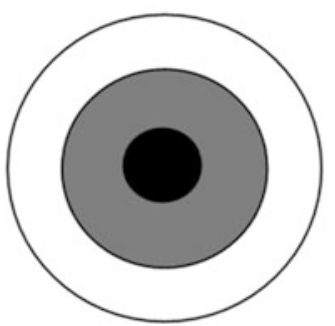

CITY-TYPE B

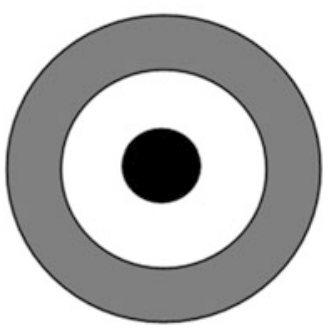

Fig. 3 Ideal-typical urban socio-spatial configurations for European cities. Source Adapted from Kesteloot (2005) 
consequences of low car ownership among the city-centre poor are mitigated by better accessibility, and richer suburban residents are able to afford vehicle ownership in car dependent areas. ${ }^{5}$

The same applies to car-related economic stress and oil vulnerability. Dodson and Sipe (2007) have highlighted how the typical urban socio-spatial configuration of Australian cities (city-type B) compounds oil vulnerability, as "low socioeconomic status and car dependence are strongly co-located" (p. 57) in sprawling outer suburban areas with cheap housing. By contrast, in type-A metropolitan areas, relatively well-off suburbanites should find it easier to meet higher motoring costs.

Overall, it appears that urban socio-spatial configuration A mitigates three out of four forms of car-related transport disadvantage, as the poor are concentrated in the least vulnerable areas. The exception is car-related time poverty, which affects essentially working middle classes with long commuting distances in suburban areas, more common in city-type A. The problem is probably less pronounced where these groups are concentrated in compact city cores (city-type B).

Based on the framework sketched in this section, we argue that future research efforts on transport and social exclusion should take more into account the impact of urban socio-spatial configurations, which are often very country-, region- or even city-specific.

\section{Policies}

Changing Transport Decision Making According to Martens (2006), established tools of transport decision-making such as transport modelling and cost-benefit analysis (CBA) inherently work to the advantage of higher-income, motorised population groups. In order to counter this bias, it has been proposed to adapt transport decision making to take into account its social consequences (Lucas and Jones 2012). In the work of Currie (2011, see Sect. 2), the whole point of measuring the impact of transport on well-being is to feed these metrics into existing transport-decision making tools such as CBA. This, in turn, allows researchers to demonstrate the economic value of targeted 'social transit' improvements aimed at tackling transport-related social exclusion.

However, transport disadvantage arises not only from biased planning tools, but also from existing institutional arrangements. In the UK, recognition that historically "no single public body has had overall responsibility for accessibility" (SEU 2003, p. 39) has inspired a new framework of Accessibility Planning, whose goal is to "ensure that there is a clear responsibility and accountability for identifying

\footnotetext{
${ }^{5}$ However, this conclusion crucially depends on the assumption that workplaces and services are strongly concentrated in inner cities. Where this does not apply, as in American cities, the inner city poor suffer from a spatial mismatch between housing and job opportunities, as well as from an automobile mismatch, whereby they are unable to afford the cars required to access them (Taylor and Ong 1995).
} 
accessibility problems and deciding how to tackle them" (p. 28). While the merits of Accessibility Planning are debated in the UK (Curl et al. 2011), its influence worldwide cannot be understated.

Finally, the expectation that allowing the general public, and notably disadvantaged groups, to participate in transport decision-making would improve its outcomes in terms of social equity has motivated initiatives to ensure public participation e.g. in the US and the UK (Lucas 2004).

Changing Land-Use and Urban Planning Given the importance of the built environment and urban form for transport disadvantage, it is not surprising that compact, mixed-use and public transport oriented development has been advocated to reduce car dependence and the need to travel more broadly. This would help alleviate all forms of car-related transport disadvantage described in this chapter.

Despite its attractiveness, this is an inherently long term strategy, and one with wide-ranging institutional and organisational implications, as it requires greater coordination between transport, land-use policies and the location decisions of public services and private actors (Gallez and Kaufmann 2010; Lucas 2004; Newman and Kenworthy 1999). Also, it may not adequately address forms of transport disadvantage that are scattered rather than clustered in space (Hine and Grieco 2003), as those that arise primarily from individual or households characteristics (e.g. old age, disability, etc.).

Influencing Residential Location Choices As illustrated above, car-related economic stress and oil vulnerability result in part from the limited rationality of the individuals making residential choices, who are often attracted to car dependent areas because of low housing costs, but underestimate the corresponding increase in transport costs. In order to tackle this problem, online calculators have been developed in countries such as France, Germany and Austria. ${ }^{6}$ These allow households to estimate total housing and transport expenses for possible relocation destinations within a region. The aim is to steer residential location choices towards the core of metropolitan areas, for both social and environmental reasons.

In North America, the development of housing and transport affordability indexes has similar goals (Litman 2015). Location efficient mortgages, which take into account the better repayment capacity of those buying properties in accessible areas with lower transport costs, have also been implemented in the US, although they have encountered only limited success (Chatman and Voorhoeve 2010).

Improving Modal Alternatives Since all forms of car-related transport disadvantage arise from the increasing need to own and use cars, an obvious solution is to ensure that alternative modes of transport provide adequate access to services and opportunities. Improvements to walking and cycling conditions can help tackling transport disadvantage, as they reduce the need for motorised travel and enhance the viability of the cheapest modes of transport. However, these can be effective only if

\footnotetext{
${ }^{6}$ See e.g. http://womo.mvv-muenchen.de/, http://womo-rechner.hamburg.de/, www.e-mob.fr, http://www.mobilitaetsausweis.at/.
} 
distances between activity locations are not too great. In most contexts, improvements to public transport will also be necessary.

Based on findings from the UK, Lucas et al. (2008) demonstrate that providing new public transport in deprived areas results in more travel, better access to work, costs savings, more social capital and expanded travel horizons for residents, bringing to light the existence of suppressed travel demand.

However, scholars of transport and social exclusion often point out that most investments in public transport do not actually improve the situation of the transport disadvantaged. There is indeed a latent tension between patronage goals, i.e. improvements to mainstream public transport services aimed at encouraging modal shift away from cars, and coverage goals, i.e. ensuring the satisfaction of the access needs of the most disadvantaged (Walker 2008). Achieving the latter arguably requires the complementary provision of services that are flexible (demand responsive, door-to-door service) and targeted at specific groups (e.g. the disabled) and/or specific access needs (e.g. access to employment) (Lucas 2004).

Finally, it is common practice to offer discounted or free fares to groups deemed to be disadvantaged or essentially reliant on public transport such as pensioners, students, jobseekers, low-income workers and the disabled. This can be seen as recognition of the essential role of public transport in ensuring social inclusion.

Promoting Car Ownership and Use Given high and increasing levels of car dependence, in many areas alternative transport modes are not sufficient to provide access to essential services and opportunities. Therefore, it is sometimes argued that promoting car ownership and use should be considered as a policy option to tackle transport disadvantage (Lucas 2004).

Auto programs including short-term car loans, financial aids for vehicle purchase, driving lessons and maintenance, mostly focused on work-related travel needs have been implemented at the local level in countries such as France, the UK and the US (Fol et al. 2007; Le Breton 2004b; Lucas 2004; SEU 2003). However, they have not been scaled up, for reasons including excessive cost, the risk of undermining public transport and the fundamental conflict with environmental objectives (Fol et al. 2007). Moreover, to adopt the terminology proposed in this chapter, programmes to increase car ownership among the poor would just shift them from one form of transport disadvantage (car deprivation) to another (car-related economic stress).

Virtual Mobility With the rapid development of Information and Communication Technologies (ICTs), it is increasingly possible to access online services as an alternative to physical travel (e.g. online banking). These can improve the condition of those who experience limitations to travel, suggesting the "possibility of promoting inclusion through virtual mobility" (Kenyon et al. 2002). However, access to ICTs is far from universal, and the digital divide excludes some of the very same groups that are more exposed to (physical) transport disadvantage, e.g. older people and rural communities with poor broadband coverage (Velaga et al. 2012). 
Education and Training Given the importance of individual competences, skills and travel horizons (see Sect. 2), policy measures have been developed to address the socio-cognitive dimension of transport disadvantage. These have mostly taken the form of education and training initiatives. In the UK, the Social Exclusion Unit (2003) has listed "helping people know and understand the travel options available to them", notably through "travel and advice, personal travel plans and better travel information" (p. 6) among the five key measures to improve accessibility. In France, local training programmes have addressed travel difficulties with regard to e.g. sense of direction, moped driving skills, driving licence acquisition and the basic competences (e.g. map- and timetable-reading skills, etc.) required to travel by public transport (Allemand 2008; Le Breton 2004b).

\section{Conclusion}

In this chapter, we have focused on how increasing levels of mobility have resulted in a situation where access to powered means of transport is often crucial for access to services and opportunities and, as a result, for social participation. In this context, the role of the car is fundamental, as most forms of transport disadvantage can be related in one way or another to the negative consequences of car dependent mobility patterns. These in turn are strongly related to the rise of car-oriented development and to changes in the form of metropolitan areas. The typology of forms of car-related transport disadvantage that we put forward in this chapter makes it possible to bring to light the multifaceted nature and the spatial dimension of transport disadvantage, as well as the crucial role of urban socio-spatial configurations. In doing this, we have put forward a number of propositions that are based on existing research, but should also be taken as hypothesis to be tested in future research at the intersection between transport and urban studies.

From a policy perspective, our short review of policy measures to tackle transport disadvantage suggests that while policy options exist, all of them have limitations. Notably, reconciling short- and long-term perspectives and environmental and social goals in transport policy (Mattioli 2013a, b; 2014b) is likely to be particularly challenging.

\section{References}

Allemand, S. (2008). Apprendre la mobilité. Les ateliers mobilité: une expérience originale. Paris: Le Cavalier Bleu.

BBSR. (2009). Chancen und Risiken steigender Verkehrskosten für die Stadt- und Siedlungsentwicklung unter Beachtung der Aspekte der postfossilen Mobilität. BBSR-Online-Publikation 06/2009. 
Blumenberg, E., \& Manville, M. (2004). Beyond the spatial mismatch: Welfare recipients and transport policy. Journal of Planning Literature, 19, 182-205. doi:10.1177/ 0885412204269103.

Boden, D., \& Molotch, H. (1994). The compulsion to proximity. In R. Friedland \& D. Boden (Eds.), Nowhere. Space, time and modernity. Berkeley: University of California Press.

Cass, N., Shove, E., \& Urry, J. (2005). Social exclusion, mobility and access. The Sociological Review, 53(3), 539-555. doi:10.1111/j.1467.

Chatman, D., \& Voorhoeve, N. (2010). The transportation-credit mortgage: A post-mortem. Housing Policy Debate, 20(3), 355-382. doi:10.1080/10511481003788786.

Colleoni, M. (2013). Mobility, accessibility and social equity: A comparative and interdisciplinary empirical study in the metropolitan areas of Milan, Bologna and Turin. In D. Henckel, S. Thomaier, B. Könecke, R. Zedda, \& S. Stabilini (Eds.), Space-time design of the public city (pp. 137-156). Berlin: Springer.

Curl, A., Nelson, J. D., \& Anable, J. (2011). Does accessibility planning address what matters? A review of current practice and practitioner perspectives. Research in Transportation Business \& Management, 2, 3-11. doi:10.1016/j.rtbm.2011.07.001.

Currie, G. (Ed.). (2011). New perspectives and methods in transport and social exclusion research. Emerald: Bingley.

Currie, G., \& Delbosc, A. (2010). Modelling the social and psychological impacts of transport disadvantage. Transportation, 37(6), 953-966. doi:10.1007/s11116-010-9280-2.

Currie, G., \& Delbosc, A. (2011). Mobility vs. affordability as motivations for car-ownership choice in urban fringe, low-income Australia. In K. Lucas, E. Blumenberg, \& R. Weinberger (Eds.), Auto motives. Understanding car use behaviours (pp. 193-208). Bingley: Emerald.

Dargay, J. M. (2002). Determinants of car ownership in rural and urban areas: A pseudo-panel analysis. Transportation Research Part E, 38, 351-366. doi:10.1016/S1366-5545(01)00019-9.

Dodson, J., \& Sipe, N. (2007). Oil vulnerability in the Australian city: Assessing socioeconomic risks from higher urban fuel prices. Urban Studies, 44(1), 37-62. doi:10.1080/ 00420980601023810.

European Commission. (2014). EU Transport in figures. Statistical pocketbook 2014. Luxembourg: Publications Office of the European Union.

Ewing, R., \& Cervero, R. (2010). Travel and the built environment. A meta-analysis. Journal of the American Planning Association, 76(3), 265-294. doi:10.1080/01944361003766766.

Farber, S., \& Páez, A. (2009). My car, my friends, and me: a preliminary analysis of automobility and social activity participation. Journal of Transport Geography, 17(3), 216-225. doi:10. 1016/j.jtrangeo.2008.07.008.

Farber, S., \& Páez, A. (2011). Running to stay in place: The time-use implications of automobile oriented land-use and travel. Journal of Transport Geography, 19(4), 782-793. doi:10.1016/j. jtrangeo.2010.09.008.

Fol, S., Dupuy, G., \& Coutard, O. (2007). Transport policy and the car divide in the UK, the US and France: Beyond the environmental debate. International Journal of Urban and Regional Research, 31(4), 802-818. doi:10.1111/j.1468-2427.2007.00755.

Gallez, C., \& Kaufmann, V. (Eds.). (2010). Mythes et pratiques de la coordination urbanisme-transport. Regards croisés sur quatres agglomérations suisses et françaises. INRETS.

Gleeson, B., \& Randolph, B. (2002). Social disadvantage and planning in the Sidney context. Urban Policy and Research, 20, 101-107. doi:10.1080/08111140220131636.

Hine, J., \& Grieco, M. (2003). Scatters and clusters in time and space: Implications for delivering integrated and inclusive transport. Transport Policy, 10, 299-306. doi:10.1016/S0967-070X (03)00055-6.

Jouffe, Y., Massot, \& M. H. (2013). Vulnérabilités sociales dans la transition énergétique au croisement de l'habitat et de la mobilité quotidienne. 1er Congrès Interdisciplinaire du Development Durable. Available at: https://hal.archives-ouvertes.fr/hal-00852513. Accessed in July 17, 2015. 
Kaufmann, V., Bergman, M. M., \& Joye, D. (2004). Motility: Mobility as capital. International Journal of Urban and Regional Research, 28(4), 745-756. doi:10.1111/j.0309-1317.2004. 00549 .

Kenyon, S., Lyons, G., \& Rafferty, J. (2002). Transport and social exclusion: Investigating the possibility of promoting inclusion through virtual mobility. Journal of Transport Geography, 10(3), 207-219. doi:10.1016/S0966-6923(02)00012-1.

Kesteloot, C. (2005). Urban socio-spatial configurations and the future of European cities. In Y. Kazepov (Ed.), Cities of Europe. Changing contexts, local arrangements, and the challenge to urban cohesion (pp. 123-148). Oxford: Blackwell.

Knowles, R. D. (2006). Transport shaping space: Differential collapse in time-space. Journal of Transport Geography, 14(6), 407-425. doi:10.1016/j.jtrangeo.2006.07.001.

Le Breton, E. (2004a). Exclusion et immobilité: la figure de l'insulaire. In J.-P. Orfeuil (Ed.), Transports, pauvretés, exclusions. Pouvoir bouger pour s'en sortir. Paris: Editions de l'aube.

Le Breton, E. (2004b). Nouveaux problèmes de mobilité, nouveaux acteurs? L'aide à la mobilité dans le secteur de l'insertion sociale et professionelle. In J. P. Orfeuil (Ed.), Transports, pauvretés, exclusions. Paris: Pouvoir bouger pour s'en sortir. Editions de l'aube.

Levitas, R. (2006). The concept and measurement of social exclusion. In C. Pantazis, C. Gordon, $\&$ R. Levitas (Eds.), Poverty and social exclusion in Britain. Bristol: The Policy Press.

Litman, T. (2015). Affordable-accessible housing in a dynamic city. Why and how to increase affordable housing in accessible neighborhoods. Victoria Transport Policy Institute: Victoria.

Lovelace, R., \& Philips, I. (2014). The 'oil vulnerability' of commuter patterns: A case study from Yorkshire and the Humber, UK. Geoforu, 51, 169-182. doi:10.1016/j.geoforum.2013.11.005.

Lucas, K. (Ed.) (2004). Running on empty. Transport, social exclusion and environmental justice. Bristol: The Policy Press.

Lucas, K. (2012). Transport and social exclusion: Where are we now? Transport Policy, 20, 105113. doi:10.1016/j.tranpol.2012.01.013.

Lucas, K., \& Jones, P. (2012). Social impacts and equity issues in transport: An introduction. Journal of Transport Geography, 21, 1-3. doi:10.1016/j.jtrangeo.2012.01.032.

Lucas, K., \& Markovich, J. (2011). International perspectives. In G. Currie (Ed.), New perspectives and methods in transport and social exclusion research (pp. 223-239). Emerald: Bingley.

Lucas, K., Tyler, S., \& Christodoulou, G. (2008). The value of new transport in deprived areas. York: Joseph Rowntree Foundation.

Martens, K. (2006). Basing transport planning on principles of social justice. Berkley Planning Journal, 19(1), 1-17. doi:10.1007/s11116-012-9388-7.

Mattioli, G. (2013a). Car dependence, sustainability and the transport policy stalemate: The potential trade-offs between intra- and inter-generational equity. The International Journal of Sustainability Policy and Practic, 8(1), 45-57.

Mattioli, G. (2013b). Where sustainable transport and social exclusion meet. Households without cars and car dependence in Germany and Great Britain (PhD thesis). Università degli Studi di Milano-Bicocca.

Mattioli, G. (2014a). Where sustainable transport and social exclusion meet: Households without cars and car dependence in Great Britain. Journal of Environmental Policy \& Planning, 16(3), 379-400. doi:10.1080/1523908X.2013.858592.

Mattioli, G. (2014b). 'How the transport system ought to be': Revisiting transport \& social exclusion research in light of energy justice concerns. Paper presented at the RGS Annual Conference 2014, London, August 26-29, 2014.

Mattioli, G. (2015). Energy-related economic stress at the interface between transport, housing and fuel poverty: A multinational study. 2nd International Days of Sociology of Energy, 254257. Available at http://eprints.whiterose.ac.uk/87866/. Accessed in September 8, 2015.

Mattioli, G., Anable, J., Vrotsou, K. (forthcoming). Car dependent practices: Findings from a sequence pattern mining study of UK time use data. Transportation Research Part A.

Motte-Baumvol, B., Massot, M. H., \& Byrd, A. M. (2010). Escaping car dependence in the outer suburbs of Paris. Urban studies, 47(3), 604-619. doi:10.1177/0042098009349773. 
Mullen, C., Tight, M., Whiteing, A., \& Jopson, A. (2014). Knowing their place on the roads: What would equality mean for walking and cycling? Transportation Research Part A, 61, 238-248. doi:10.1016/j.tra.2014.01.009.

Münter, A. (2013). Informations- und Wahrnehmungslücken von Stadt-Umland-Wanderern bei der Wohnstandortwahl. In j. Scheiner, H. H. Blotevogel, S. Frank, C. Holz-Rau, \& N. Schuster (Eds.), Mobilitäten und Immobilitäten. Menschen - Ideen - Dinge - Kulturen - Kapital (pp. 263-275). Essen: Klartext.

Næss, P. (2006). Urban structure matters. Residential location, car dependence and travel behaviour. New York: Routledge.

Newman, P., \& Kenworthy, J. (1999). Sustainability and cities. Overcoming automobile dependence. Washington, DC: Island Press.

Nicolas, J. P., Vanco, F., \& Verry, D. (2012). Mobilité quotidienne et vulnerabilité des menages. Revue d'Economie Regionale \& Urbaine, 1, 19-44. doi:10.3917/reru.121.0019.

Paaswell, R. E., \& Recker, W. W. (1976). Problems of the carless. Report prepared for the U.S.. Washington, DC: Department of Transportation.

Polacchini, A., \& Orfeuil, J. P. (1999). Les dépenses des ménages franciliens pour le logement et les transports. Recherche Transports Sécurité, 63, 31-46.

Rendall, S., Page, S., \& Krumdieck, S. (2014). Voila! A new measure of oil vulnerability for cities. Paper presented at the 1st International e-Conference on Energies, March 14-31, 2014.

SEU. (2003). Making the connections: Final report on transport and social exclusion. London: Office of the Deputy Prime Minister.

Sexton, S., Wu, J., \& David, Z. (2012). How high gas prices triggered the housing crisis: Theory and empirical evidence. University of California, Center for Energy and Environmental Economics Working Paper Series. Berkeley.

Siedentop, S., Roos, S., \& Fina, S. (2013). Ist die „Autoabhängigkeit“ von Bewohnern städtischer und ländlicher Siedlungsgebiete messbar? Entwicklung und Anwendung eines Indikatorenkonzepts in der Region Stuttgart. Raumforschung und Raumordnung, 71, 329341. doi:10.1007/s13147-013-0240-0.

Smith, N., Hirsch, D., \& Davis, A. (2012). Accessibility and capability: The minimum transport needs and costs of rural households. Journal of Transport Geography, 21, 93-101.

Stanley, J., \& Stanley, J. (2007). Public transport and social exclusion: An operator's perspective. In G. Currie, J. Stanley, \& J. Stanley (Eds.), No way to go. Transport and social disadvantage in Australian communities (pp. 14.1-14.11). Clayton: Monash University Press.

Stanley, J., Stanley, J., Vella-Brodrick, D. A., \& Currie, G. (2010). The place of transport in facilitating social inclusion via the mediating influence of social capital. Research in Transportation Economics, 29, 280-286. doi:10.1016/j.retrec.2010.07.035.

Sullivan, O., \& Gershuny, J. (2004). Inconspicuous consumption. Work-rich, time-poor in the liberal market economy. Journal of Consumer Culture, 4(1), 79-100. doi:10.1177/ 1469540504040905.

Taylor, J., Barnard, M., Neil, H., \& Creegan, C. (2009). The travel choices and needs of low income households: The role of the car. The National Centre for Social Research.

Taylor, B. D., \& Ong, P. D. (1995). Spatial mismatch or automobile mismatch? An examination of rase, residence and commuting in US metropolitan areas. Urban Studies, 32(9), 1453-1473. doi: $10.1080 / 00420989550012348$.

Unbehaun, W., \& Uhlmann, T. (2013). Chancengerechtigkeit im Mobilitätsalltag - eine messbare Größe? In J. Scheiner, H. H. Blotevogel, S. Frank, C. Holz-Rau, \& N. Schuster (Eds.), Mobilitäten und Immobilitäten: Menschen - Ideen - Dinge - Kulturen - Kapita (pp. 181-194). Essen: Klartext.

Urry, J. (2002). Mobility and proximity. Sociology, 36(2), 255-274. doi:10.1177/ 0038038502036002002.

Urry, J. (2004). The 'system' of automobility. Theory, Culture \& Society, 21(4-5), 25-39. doi:10. $1177 / 0263276404046059$. 
Velaga, N. R., Beecroft, M., Nelson, J. D., Corsar, D., \& Edwards, P. (2012). Transport poverty meets the digital divide: Accessibility and connectivity in rural communities. Journal of Transport Geography, 21, 102-112. doi:10.1016/j.jtrangeo.2011.12.005.

Walker, J. (2008). Purpose-driven public transport: Creating a clear conversation about public transport goals. Journal of Transport Geography, 16(6), 436-442. doi:10.1016/j.jtrangeo. 2008.06.005. 


\title{
Resident and Non-resident Populations: Types of Conflicts
}

\author{
Giampaolo Nuvolati
}

\begin{abstract}
Contemporary urban areas are characterized by the growing number of resident and non-resident people living, working, and consuming in cities. According to the analysis of Martinotti (1993), we have four types of metropolitan populations: inhabitants, commuters, city users (mainly tourists), and businessmen. These populations come and stay in the city in different moments during the day or in different seasons, for different reasons and purposes, generating different types of real or potential conflicts. In particular, it is possible to focus on six types of possible conflicts: from a spatial point of view, in terms of conflicts concerning occupation and mobility in the space; from a more general point of view, in terms of economic, cultural, fiscal, and political conflicts. Of course, non-resident populations constitute very important resources also for improving the living conditions of resident populations, and vice versa. However, scholars and planners should also recognize that contemporary cities have to tackle many problems related to the high concentration and flow of people in urban areas, where new worrisome phenomena of social polarization and political disenfranchisement are emerging that require innovative types of public policies.
\end{abstract}

Keywords Urban mobility - Urban conflicts - Resident populations • Commuters - City users $\cdot$ Tourists

\section{Urban Transformation}

Urban sprawl is one of the most evident processes in many regions of the world. Every year in Italy more than one million people change their residence, and the main path is from the core of the metropolitan area or the core of the province

G. Nuvolati ( $\square)$

Università degli Studi di Milano Bicocca, Milan, Italy

e-mail: giampaolo.nuvolati@unimib.it

(C) Springer International Publishing Switzerland 2016 
Table 1 Intra-provincial residential mobility from 2002 until 2010

\begin{tabular}{l|l}
\hline Cities & $\begin{array}{l}\text { Incoming minus outgoing individuals from the } \\
\text { Italian metropolitan capoluoghi di provincia }\end{array}$ \\
\hline Turin & $-43,261$ \\
\hline Milan & $-67,780$ \\
\hline Genoa & -6455 \\
\hline Bologna & $-25,479$ \\
\hline Florence & $-15,335$ \\
\hline Rome & $-76,657$ \\
\hline Naples & $-28,272$ \\
\hline Bari & $-10,828$ \\
\hline Palermo & $-23,371$ \\
\hline Catania & $-11,791$ \\
\hline Total & $-309,229$
\end{tabular}

Source Elaboration on Istat, Movimento anagrafico della popolazione residente, 2002-2010

toward communes located in the surrounding of the main city. In particular, in Italy all of the 10 metropolitan areas are strongly affected by this trend. The balance between incoming and outgoing residents is negative everywhere. From 2002 till 2010, Rome lost more than 76,000 individuals in favor of its province, Milan almost 68,000, Turin more than 43,000 (Table 1). The situation is similar also in medium size cities, the so called capoluoghi di provincia. The total negative balance (including metropolitan cities) is 518,487 (Table 2). The main reasons of the exodus from the cities mainly concern cost of living, housing opportunities, transport facilities, the quality of life that families consider more appropriate to their expectations in the external areas than in the central commune (Nuvolati 2006). Of course, such a phenomenon does not mean that cities are disappearing; on the contrary, cities are confirming their supremacy. What is changing are the functions of the cities. They have become places where people go to work, consume, visit but less so to live. The amount of commuters (workers and students) traveling every day from the hinterlands or the satellite cities toward the core of the metropolitan area is huge and growing in many urban areas. This finding contradicts Alvin Toffler's (1980) prediction concerning a diminishing of commuting travel toward the downtown due to widespread and successful technology allowing people to work at home in their electronic cottages. These phenomena are not happening at the moment and the death of the traditional cities is a long way away. In particular technology does not hinder but rather facilitate mobility. 
Table 2 Intra-provincial residential mobility

\begin{tabular}{l|l}
\hline Year & $\begin{array}{l}\text { Incoming minus outgoing individuals from all the } \\
\text { Italian capoluoghi di provincia from 2002 till 2010 }\end{array}$ \\
\hline 2002 & $-46,205$ \\
\hline 2003 & $-56,822$ \\
\hline 2004 & $-64,375$ \\
\hline 2005 & $-69,666$ \\
\hline 2006 & $-70,253$ \\
\hline 2007 & $-67,406$ \\
\hline 2008 & $-65,141$ \\
\hline 2009 & $-39,876$ \\
\hline 2010 & $-38,743$ \\
\hline Total & $-518,487$ \\
\hline
\end{tabular} $\begin{aligned} & \text { Source Elaboration on Istat, Movimento anagrafico della } \\
& \text { popolazione residente, 2002-2010 }\end{aligned}$

\section{Types of Populations}

Cities are not only a magnet for commuters. Different types of populations like city users, tourists, businessmen, use and consume cities in which they do not live. ${ }^{1}$ Each of these populations will display specific characteristics in terms of relationships that are more or less instrumental or affective with the city, different types of cultural and economic resources, different types of habits. Each population presents a prevalent type of relation with the city. Many inhabitants may display a sense of belonging, attachment, and identity with the city where they live. On the contrary, many commuters and city users make an instrumental use of the city, linked to their work or visiting activities. However, once more, it is quite difficult to distinguish with exact precision different feelings and performances according to the variety of populations. If we compare commuters and inhabitants, we discover that their behaviors in consuming and using services are overlapping, and therefore becoming more and more analogous. Populations show some similarities due to the process of globalization, the standardization of services, and the diffusion of information technologies. This finding is particularly true in relation to the use of a large set of services during lunch breaks (Boffi and Nuvolati 2002). Of course, the result is less evident for non-replaceable services like registry offices or health services and more pronounced for replaceable ones like post offices and shops. Nevertheless, the profiles of these two populations are converging, making it more difficult to distinguish between the practices and life styles of residents and

\footnotetext{
${ }^{1}$ Starting from the beginning of this century, many general studies and much local research have been conducted in Italy on this topic due to the growing presence of tourists and commuters in many cities and the lack of appropriate public transports (Mela et al. 2000; Casarin 2002; Nuvolati 2002; Cristaldi 2003; Tornaghi 2004; Bernareggi 2007; Cecchini and Cannaos 2007; Nuvolati 2007; Balducci et al. 2008; Censis 2008; Colleoni 2008; Pasqui 2008).
} 
non-residents. In general, data show that transients are becoming part of new enlarged and adaptable communities also based on an increasing number of in and out population flows. According to the Optimal Urban Size Theory (Cicerchia 1996, 1999), the quality of life of a city increases with the size of the city itself. The concentration of populations means more services, more work opportunities and cultural events, but after a threshold the social, economic and environmental costs become greater than the benefits. If we daily add to the resident population an excessive number of non-residents the equilibrium of the city could be compromised.

The attractiveness of cities is particularly true for cities having a specific degree of glamor, cultural and environmental attractiveness, infrastructure, and opportunities. According to 2009 estimates nearly $25 \%$ of the daily population present in the main Italian cities is non-resident: commuters, tourists, students, illegal immigrants, ${ }^{2}$ businessmen, and city users. In the most touristy cities, like Venice and Florence, the percentage is higher than $40 \%$. Milan also presents a quite pronounced percentage due to the concentration in this city of many economic activities, meanwhile the percentage of Rome is quite low: $21.7 \%$, of course not because of the low number of visitors (Rome has the highest additional population) but because of the high number of residents (Table 3). Other types of temporary populations can be found in a city like seasonal workers, soldiers, homeless people, protesters, and so on. These interstitial populations are not as large as the previous ones; however, they are part of the urban landscape, present specific needs, expectations and behaviors. Of course each individual is ascribable to more than one category. For example, people could be commuters in the morning when they go to work downtown, inhabitants of their cities where they return back in the evening, or tourists during the week end. This assumption makes it very difficult to discern clear conflicts, as well as to identify comprehensible interests and representation agencies. In other words, modern cleavages are no longer pure and interpretable as they were in the past. They are continually changing; presenting a high turn-over of the people involved, and crosscutting features from a socio-economic point of view, although they concur in generating new forms of social exclusion. Moreover, from a methodological point of view, to count and statistically analyze resident and non-resident populations is quite difficult, especially when visitors do not "sleep" in the cities, but just pass through or window shop. Only a slice (the official one) of the non-residents can be calculated.

\footnotetext{
${ }^{2}$ In our analysis regular immigrants are conceived as inhabitants (if residents) or commuters or other already considered categories (if non-residents).
} 
Table 3 Estimate of non-resident population (commuters, tourists, students, illegal immigrants, businessmen, city users) in the main Italian cities

\begin{tabular}{l|c|l|l|l}
\hline $\begin{array}{l}\text { Italian } \\
\text { metropolitan } \\
\text { cities }\end{array}$ & $\begin{array}{l}\text { Resident } \\
\text { population, } \\
\text { 2009 (Istat) }\end{array}$ & $\begin{array}{l}\text { Additional population } \\
\text { considering incoming } \\
\text { and outgoing, 2009 } \\
\text { (estimation) }\end{array}$ & $\begin{array}{l}\text { Daily present } \\
\text { population, 2009 } \\
\text { (estimation) }\end{array}$ & $\begin{array}{l}\text { Percentage of } \\
\text { non-resident } \\
\text { population on } \\
\text { daily present } \\
\text { population, 2009 } \\
\text { (estimation) }\end{array}$ \\
\hline Turin & 908,825 & 199,406 & $1,108,231$ & 25.4 \\
\hline Milan & $1,295,705$ & 497,133 & $1,792,838$ & 33.9 \\
\hline Venice & 270,098 & 155,479 & 425,577 & 45.7 \\
\hline Genoa & 611,171 & 84,500 & 695,671 & 14.6 \\
\hline Bologna & 374,944 & 96,524 & 471,468 & 29.2 \\
\hline Florence & 365,659 & 171,466 & 537,125 & 40.6 \\
\hline Rome & $2,724,347$ & 601,282 & $3,325,629$ & 21.7 \\
\hline Naples & 963,661 & 229,581 & $1,193,242$ & 23.1 \\
\hline Bari & 320,677 & 86,043 & 406,720 & 25.0 \\
\hline Palermo & 659,433 & 92,141 & 751,574 & 14.4 \\
\hline Catania & 296,469 & 88,847 & 385,316 & 26.6 \\
\hline Total & $8,790,989$ & $2,302,401$ & $11,093,390$ & 25.7 \\
\hline Source Nuv & $2011)$ & & \\
\hline
\end{tabular}

Source Nuvolati (2011)

\section{Criteria for Subdividing the City}

Traditionally, cities can be segmented according to a set of functions (residential, productive, commercial, special) or to the characteristics of the residential populations. A zoning approach has been adopted by many local authorities, planners, and urban sociologists in order to study and design cities. One of the main aims of the School of Chicago in the ' 20 was to analyze the distribution of the population (by social class and ethnicity) in different sectors of the city. In the famous map of Burgess (1925) also the area where commuters live is considered, but what was missing was the distribution of the commuters during the day. Nowadays it is urgent for urban researchers to focus on the neighborhoods as place changing during the day according to the different composition of the present population. Rhythms of the city are the coordinates through which inhabitants and visitors frame and order their urban experience. Many authors (Lynch 1976; Goodchild and Janelle 1984) have already characterized cities according to the cycles of daily uses. In combining spatial and temporal variables, they were able to categorize urban sub-areas and therefore to contribute to the study of the quality of life in these neighborhoods.

In particular, Lynch subdivided Boston in different areas according to the concentration or dispersion of the population during the day and the night. He discovered districts with a constant presence of population defined as incessant areas; 
Table 4 Presence of resident and non-resident populations in different daily time

\begin{tabular}{l|l|l|l}
\hline Period during the day & $\begin{array}{l}\text { Presence of } \\
\text { resident } \\
\text { population }\end{array}$ & $\begin{array}{l}\text { Presence of } \\
\text { non-resident } \\
\text { population }\end{array}$ & $\begin{array}{l}\text { Identity } \\
\text { number }\end{array}$ \\
\hline Morning 6:00 a.m.-2:00 p.m. & Yes & Yes & 1 \\
\hline & Yes & No & 2 \\
\hline & No & Yes & 3 \\
\hline & No & No & 4 \\
\hline Afternoon 2:00 p.m.-10:00 p.m. & Yes & Yes & 5 \\
\hline & Yes & No & 6 \\
\hline & No & Yes & 7 \\
\hline Night 10:00 p.m.-6:00 a.m. & No & No & 8 \\
\hline & Yes & Yes & 9 \\
\hline & Yes & No & 10 \\
\hline & No & Yes & 11 \\
\hline & No & No & 12 \\
\hline
\end{tabular}

Source Elaboration on Nuvolati (2007)

districts with a sort of night evacuation by the population defined as empty at night; districts, on the contrary, with an invasion of population during the night are called active especially at night; and, finally, other districts with a constant but heterogeneous presence named shifting from day to night.

Actually people mobility is one of the main issues to look at in order to study (thanks to specific instruments like GPS, cellular phones, time-space diaries, etc.) the concentration and distribution of the population in different places, at different times and with different motivations.

The next table shows a grid which may be adopted in order to label each urban district according to the different combination of resident and non-resident populations at different times during the day. In particular, district can be labeled according to the sequence of three identity numbers. For example, the sequence 15-9 indicates a district always populated by resident and non-resident populations and therefore one that could be labeled as an "intense and open district"; the sequence 2-6-10 reveals an exclusive presence of residents and therefore indicates a situation of "closing district" (it could be a ghetto or a gate community), 4-8-11 refer to a "night district" (maybe for leisure) being populated only by non-residents in the night; 4-8-10 to a "dormitory district", and so on (Table 4). Although it would be quite difficult to make quantitative estimations of the resident and non-resident populations for each urban district, pilots and qualitative analysis could be very useful for approaching this issue and therefore to be utilized by those for providing services and preventing conflicts. 


\section{Conflicts and Solutions}

Many cities compete in order to improve their attractiveness and the number of visitors. Local public actors as well as private companies in the city invest time and resources with the aim to seduce other qualified workers, companies, and tourists. Quite often, local development is strictly connected to the capacity of the city to open itself to exogenous components, that is, to build up networks with other urban units. Although cities try to defend their identity and traditions they are also strongly oriented to transform their history and culture into a product to sell. City marketing is one of the most diffused strategies with the aim to promote cities and lure "buyers." Of course, the concentration and interaction of resident and non-resident populations does not generate only positive aspects, especially for the poorest segments of the local communities. As a matter of fact, the morphology of the city, the limited amount of infrastructures, and the problematic accessibility of the services generate conflicts in the short as well as in the long-run between populations with different personal resources and interests.

Six types of conflicts between residents and non-residents, more or less explicit, can be depicted.

The first regards the struggle for the occupation of space. Actually, the tertiarization processes of some central quarters promoted by multinational enterprises and the invasion of the same or other prestigious neighborhoods by the so-called international iper-bourgeoisie (Marceau 1989; Castells 1996; Duclos 1999; Martinotti 1999) are generating in many cities a process of gentrification of some areas and the consequent marginalization of the expelled residents. The effects of the disenfranchisement of the local community are linked to the phenomena of space occupation. Public policies oriented to the upgrading of central neighborhoods and to the safeguarding of the old function and population of selected areas constitute quite diffused forms of reaction. For example, several European UDPs (Urban Development Programs), like Urban I and II (Mingione and Nuvolati 2003), are heading in this direction as they aim to revitalize the central historic neighborhoods of cities without driving away low income families.

The second conflict is related to the concept of accessibility in terms of traffic congestion and pollution in the use of available resources and services. To contend with negative situations, local communities and governments have often implemented two different actions: the hard ones in terms of the improvement and betterment of infrastructures, and the soft ones in terms of the development of time policies. Time policies are very useful instruments aimed at improving living standards in the local community with the specific objective of integrating the individual needs of the resident and non-resident populations, with the time schedule of public and private services. Several administrative practices of time policy implementation have been built up over the last decade in many European cities, Italian in particular (Mareggi 2002, 2013). But, in order to solve problems linked to the increasing mobility of people, innovative procedures for accessing services have been defined also considering technological devices and individual competence. 
Information and Communication Technologies (ICT) are now so widespread that they affect every aspect of our everyday life. Working, shopping, traveling, banking, receiving services from our local council, and going to the hospital or to the cinema are all activities that involve contact with ICT to a greater or lesser extent (Craglia et al. 1999).

The third point regards the cultural conflict, mainly between residents and transients, and is, above all, connected to the safeguarding of local identity and culture in reaction to the standardization of life styles and the dis-embedding of the human relationships (Giddens 1990) more or less explicitly formed by predominant global models. In the 1990s, in the context of postmodernism in architecture, several practices aimed at preserving the urban scene had been promoted. This school stresses and encourages fragmentation, urban mosaics, and the colorfulness of cultural difference as aspects that improve the urban quality of life (Harvey 1989; Leontidou 1993; Ellin 1996). But cultural conflicts also concern a set of questions linked to the process of immigrant integration. Many European cities are nowadays characterized by new and widespread phenomena of migration, especially from African and Eastern countries which produce several problems in terms of social and cultural inclusion and cohesion.

Another conflict is more socio-economic and concerns the growing polarization of the population in modern global cities (Sassen 1991) where the presence of low-wage workers, especially in the service sector (restaurants and bars, commerce, leisure) is functional to the permanence and livelihood of the local upper class but also to the already mentioned international iper-bourgeoisie. New stratification cannot be analyzed and interpreted only at the level of the local community. As a matter of fact, the origin of the polarization is often exogenous to the community. Strategies to avoid large disparities and social exclusion regard the improvement of the local economy and the welfare system, the development of vocational training activities and new forms of social participation for the more disadvantaged groups, immigrants included.

The fifth type of conflict is a fiscal one, the so called spillover problem, and it is related to the taxes paid by the inhabitants to the local municipality in order to create or maintain a set of services used also by the transient populations. Many solutions have been adopted in order to balance the fiscal contribution. In some cities - like London or Venice - special fees for visitors entering the city by car or using public transports are foreseen.

The last conflict is a political one. Non-resident actors (visitors, firms, and associations) consider themselves as part of the local community or important sources for local development, and expect and many times succeed in participating in the public debate regarding the city, in supporting local players in the electoral competition, and, more in general, in influencing political life. Therefore, they could generate a process of disenfranchisement of the local population, especially of the weakest and less organized segments. The solution to such a problem is the reinforcement of the local communities, their involvement in the local arenas and in the decision processes (Table 5). 
Table 5 Conflicts between resident and non-resident populations

\begin{tabular}{|c|c|c|c|}
\hline Conflicts & $\begin{array}{l}\text { Objects of the } \\
\text { conflicts }\end{array}$ & Problems & Reactions \\
\hline Spatial & $\begin{array}{l}\text { Conflicts related to } \\
\text { the occupation of } \\
\text { the space }\end{array}$ & $\begin{array}{l}\text { Tertiarization, } \\
\text { gentrification, } \\
\text { disenfranchisement }\end{array}$ & $\begin{array}{l}\text { Re-qualification of } \\
\text { poor neighborhoods }\end{array}$ \\
\hline Accessibility & $\begin{array}{l}\text { Conflicts related to } \\
\text { physical } \\
\text { accessibility of the } \\
\text { services }\end{array}$ & $\begin{array}{l}\text { Density, traffic, } \\
\text { pollution }\end{array}$ & $\begin{array}{l}\text { Improvements of the } \\
\text { infrastructures system, } \\
\text { time policies }\end{array}$ \\
\hline Cultural & $\begin{array}{l}\text { Conflicts related to } \\
\text { the predominance of } \\
\text { external cultural } \\
\text { models }\end{array}$ & $\begin{array}{l}\text { Standardization, } \\
\text { dis-embedding }\end{array}$ & $\begin{array}{l}\text { Safeguard of the local } \\
\text { culture }\end{array}$ \\
\hline Socio-economic & $\begin{array}{l}\text { Conflicts related to } \\
\text { the increasing } \\
\text { inequalities }\end{array}$ & Social polarization & $\begin{array}{l}\text { Development of local } \\
\text { economy and welfare }\end{array}$ \\
\hline Fiscal & $\begin{array}{l}\text { Conflicts related to } \\
\text { taxation for } \\
\text { financing services }\end{array}$ & $\begin{array}{l}\text { High taxation for the } \\
\text { non-user resident } \\
\text { population, high cost } \\
\text { of living }\end{array}$ & $\begin{array}{l}\text { New forms of direct } \\
\text { and indirect taxation } \\
\text { for the non-resident } \\
\text { populations }\end{array}$ \\
\hline Political & $\begin{array}{l}\text { Conflicts related to } \\
\text { political rights }\end{array}$ & $\begin{array}{l}\text { Local population } \\
\text { disenfranchisement }\end{array}$ & $\begin{array}{l}\text { New forms of political } \\
\text { participation }\end{array}$ \\
\hline
\end{tabular}

Source Elaboration on Nuvolati (2003)

The conflicts here drafted and their combinations change among cities, neighborhoods and through time. Of course, many aspects are very controversial. Residents and non-residents are not always in conflict and many positive effects are produced by the concentration of populations in the city in terms of economic, social, and cultural progress for residents also. Quite often local economies, especially in tourist and business cities or neighborhoods, are exclusively based on the presence of visitors. Sometimes inhabitants are the weak actors of the play, sometimes they coincide with the strong side, especially if we include immigrants in the transient populations. In this chapter, the typology of populations has been simplified. Legal immigrants, whether they live in the city or travel to the city for a variety of reasons have been included within the categories of inhabitants, commuters or city users, even if they probably correspond to the more fragile segments of these populations. Only illegal immigrants have been considered as a transient, non-resident population.

Focusing on the conflicts between residents and non-residents does not mean forgetting the more classical struggles between social classes, or between autochthonous and allochthonous groups. On the contrary, one of the main aims of urban research is to find linkages between old and new conflicts in order to shed light on the growing process of socio-economic polarization in cities due to population spatial mobility. As a matter of fact, the conveyance in cities of tourists and business, on the one hand, and the presence of poor groups (immigrant and local 
populations), on the other, generate alliances between rich and powerful individuals, resident and non-resident, reinforcing disparities, and making the weakest people weaker because of the diminishing of the sense of belonging to community. A reaction to these trends is the re-construction of an urban community, able to deal with or, even, to fight the incessant phenomena of globalization.

Starting from the classical dichotomy proposed by Tönnies, Gemeinschaft versus Gesellschaft (1887), the debate about community formation is crucial in sociological theory. In particular, the discussion concerning communities in rural and urban context was very strong in the ' 50 and ' 60 when Gans and Lewis in contrast to Wirth e Redfield, observed that many urban communities (mainly at the level of the neighborhood) were even more strong and cohesive than rural villages. This dispute regarded one the main questions dealt with in the history of the urban sociology (Saunders 1981). In some way contrasting the idea of the urban villages, Webber in his famous article "Order in Diversity: Community without Propinquity" (1963) introduced the idea that places were losing relevance in generating communities. Also the concepts of non-place urban realm (Webber 1968) and non-lieux (Augé 1992) strongly contributed to reformulate the idea of community. Patterns of opposition and integration between resident and non-resident populations are crucial analytical coordinates to look at in order to define new types of communities.

All these issues are very important and preliminary to all the debate regarding the invasion of technological communication devices and the proliferation of virtual communities as non-rooted communities. Nowadays some new phenomena, like social street, and hybrid communities demonstrate that ICT should be considered as a first and crucial step not to undermine but, on the contrary, to reinforce and maintain strongly embedded relationships. Such findings depict a quite complex picture we have to deal with in order to understand the evolution of the modern communities. In particular, a specific question remains nowadays still unanswered: are places simply the physical recipients of new relationships based on different interests expressed from different populations (many of them non-residents), or are they the origin of communities based on propinquity and a common rooted identity?

\section{Conclusions}

In general, given that modern societies, and in particular urban contexts, are strongly influenced by the mobility and conflicts of different types of populations, the concept of community also needs to be revisited. Is community exclusively based on territorial, historical, and cultural issues linked to a specific place? Is community only formed by its stable inhabitants? Or is community the result of a combination of several populations using the same services, even if at different points in time during the day and coming from different places? As far as we increasingly distribute our time and activities in different contexts are we still part of only one community or more than one? It is not easy to answer these questions, but 
two aspects seem to be quite clear. First, the quality of life in the community has to be conceptualized considering not only the availability of resources and services, but also reflecting on the real accessibility and usability of such resources and services, in terms of time, knowledge, and competence achieved by the individuals in dealing with urban congestion and complexity (Nuvolati 2009). According to Sen (1993) an approach based on the functionings and capabilities of the individuals in accessing and using the resources seems to be more appropriate than one simply grounded on the availability of commodities and services in the city. Second, in order to study the living conditions in a community, we cannot avoid analyzing the stock of human resources and services available not only in relation to residents but also to potential external users. Having these points in mind it is nowadays worthwhile to ask ourselves if the copresence of resident and non-resident populations generate constraints or favor a fluid use of the urban services.

From a more methodological point of view, it would be necessary to combine the classic indicators of quality of life with new measures about the daily or seasonal level of exposure and integration or conflict of the local community in relation to transient populations. In particular, new indicators should reflect the imbalance between residents and non-residents in using local and finite resources. Where do service users come from? How often do they use these services? What is the level of satisfaction for different resources located in the cities but approached also by non-resident populations?

Official statistics regarding users for different services are not divided between residents and non-residents. Many problems also arise concerning the universes of the non-resident populations to look at in order to construct good samples for fruitful surveys.

Finally, in terms of public policies, it is also quite difficult to develop actions aimed to discover, counter pose or negotiate different interests for evanescent populations, with a low level of formal representation and self-consciousness but with a high level of role interchangeability. As a matter of fact, each of us is a real or at least a potential member of all these populations on the basis of his/her work or leisure activities, service utilization, and mobility paths at different daily times or periods.

\section{References}

Augé, M. (1992). Non-Lieux. Introduction à une anthropologie de la surmodernité. Paris: Seuil.

Balducci, A., Fedeli V., \& Pasqui, G. (2008). In movimento. Confini, popolazioni e politiche nel territorio milanese. Milano: Franco Angeli.

Bernareggi, G. M. (2007). L'onere dei non residenti per il Comune di Milano: una stima riveduta e aggiornata. Amministrare, 37(3), 333-422.

Boffi, M., \& Nuvolati, G. (2002). Time, mobility and urban governance: The case of the metropolitan area of Milan. In M. Dijst, W. Schenkel, \& I. Thomas (Eds.), Governing cities on the move. Aldershot: Ashgate. 
Burgess, E. (1925). The growth of the city: An introduction to a research project. In: R. E. Park, E. Burgess, \& R. McKenzie (Eds.), The city (pp. 47-62). Chicago: University of Chicago Press.

Casarin, M. (2002). Materiali per un Piano Strategico della Città di Venezia. Popolazione quotidiana e comunità: il caso di Venezia. Documento COSES 441.1. Venezia.

Castells, M. (1996). The rise of the network society. Oxford: Blackwell.

Cecchini, A., \& Cannaos, C. (2007). Secondo rapporto sul turismo ad Alghero. Alghero: Facoltà di Architettura di Alghero, Comune di Alghero.

Censis. (2008). Pendolari d'Italia, scenari e strategie. Roma: Censis.

Cicerchia, A. (1996). Indicators for the measurement of the quality of urban life: What is the appropriate territorial dimension? Social Indicators Research, 39(3), 321-358.

Cicerchia, A. (1999). Measures of optimal centrality: Indicators of city effect and urban overloading. Social Indicators Research, 46(3), 273-299.

Colleoni, M. (a cura di). (2008). La ricerca sociale sulla mobilità urbana. Metodo e risultati di indagine. Milano: Cortina.

Craglia, M., Leontidou, L., Nuvolati, G., \& Schweikart J. (1999). Evaluating quality of life in European regions and cities. COR-Studies E-3/99. Brussels: Committee of the Regions, European Union.

Cristaldi, F. (a cura di). (2003). Le "mille” popolazioni metropolitane. Un'analisi geografica dell'area romana. Roma: Centro Interdipartimentale di studi e ricerche sulla popolazione e la società di Roma, Università degli studi di Roma La Sapienza.

Duclos, D. (1999) La nascita dell'iperborghesia. In: Martinotti G (a cura di) La dimensione metropolitana: sviluppo e governo della nuova città (pp. 175-187). Bologna: il Mulino.

Ellin, N. (1996). Postmodern urbanism. Oxford: Blackwell.

Giddens, A. (1990). The consequences of modernity. Cambridge: Polity Press.

Goodchild, M. F., \& Janelle, D. G. (1984). The city around the clock: Space time patterns of urban ecological structure. Environment and Planning A, 16(6), 807-820.

Harvey, D. (1989). The condition of postmodernity. Oxford: Blackwell.

Leontidou, L. (1993). Postmodernism and the city: Mediterranean versions. Urban Studies, 30(6), 949-965.

Lynch, K. (1976). Managing the sense of a region. Cambridge: MIT Press.

Marceau, J. (1989). A family business? The making of an international business elite. Cambridge: Cambridge Univesity Press.

Mareggi, M. (2002). Innovation in urban policy: The experience of Italian urban time policies. Planning theory \& practices, 3(2), 173-194.

Mareggi, M. (2013). Planning times of the city: An overview on urban time policies. In M. Schrenk, V. V. Popovich, P. Zeile, \& P. Elisei (Eds.), Planning time. Proceedings REAL CORP 2013 (pp. 701-710).

Martinotti, G. (1993). Metropoli. La nuova morfologia sociale della città. Bologna: Il Mulino.

Martinotti, G. (1999). A city for whom? Transients and public life in the second-generation metropolis. In R. Beauregard \& S. Body-Gendrot (Eds.), The urban moment. Cosmopolitan essays on the late-20th-century city (pp. 155-184). London: Sage.

Mela, A., Davico, L., \& Conforti, L. (2000). La città, una e molte: Torino e le sue dimensioni spaziali. Napoli: Liguori.

Mingione, E., \& Nuvolati, G. (2003). Urban development programmes in Italy: National institutional innovation and European programmes. In P. De Decker, J. Vranken, J. Beaumont, \& I. Van Nieuwenhuyze (Eds.), On the origins of urban development programmes (pp. 101117). Antwerp: Garant.

Nuvolati, G. (2002). Popolazioni in movimento città in trasformazione. Abitanti, pendolari, city users, uomini d'affari, flâneur. Bologna: Il Mulino.

Nuvolati, G. (2003). Resident and non-resident populations: Quality of life, mobility and time policy. The Journal of Regional Analysis \& Policy, 33(2), 67-83.

Nuvolati, G. (2006). Commuting and quality of life: The Italian case. In R. Estes (Ed.), Advancing quality of life in a turbulent world (pp. 55-66). New York: Springer.

Nuvolati, G. (2007). Mobilità quotidiana e complessità urbana. Firenze: Fitrenze University Press. 
Nuvolati, G. (2009). Quality of life in cities: A question of mobility and accessibility. In V. Møller \& D. Huschka (Eds.), Quality of life and the millennium challenge (pp. 177-191). New York: Springer.

Nuvolati, G. (2011). Vivibilità nelle aree metropolitane contemporanee in evoluzione. In L. Struffi (Ed.), (a cura di) Crisi economica, crisi ambientale, nuovi modelli sociali (pp. 195-209). Trento: Università degli studi di Trento.

Pasqui, G. (2008). Città, popolazioni, politiche. Milano: Jaca Book.

Sassen, S. 1991. Global cities. New York, London, Tokyo. Princeton: Princeton University Press. Saunders, P. (1981). Social theory and the urban question. London: Hutchinson.

Sen, A. (1993). Capabilities and well-being. In M. Nussbaum \& A. Sen (Eds.), The quality of life (pp. 30-53). Oxford: Clarendon Press.

Toffler, A. (1980). The third wave: The classic study of tomorrow. New York: Bantam.

Tönnies, F. (1887). Gemeinschaft und Gesellschaft. Leipzig: Fues's Verlag.

Tornaghi, C. (2004). Mobilità e city users a Milano: individuazione e stima delle popolazioni non residenti. Amministrare, 34(1), 5-50.

Webber, M. (1963). Order in diversity: Community without propinquity. In L. Wingo (Ed.), Cities and spaces. Baltimore: Johns Hopkins Press.

Webber, M. (1968). Urban place and the non-place urban realm. In J. Dyckman, D. Foley, A. Guttenberg, M. Webber, W. Wheaton, \& C. Whurster (Eds.), Explorations into urban structure (pp. 79-153). Philadelphia: University of Pennsylvania Press. 


\section{Part IV \\ Mapping Mobility Practices}




\title{
Metropolitan Dynamics and Mobility Flows: A National Comparative Study (1991-2011)
}

\author{
Mario Boffi and Matteo Colleoni
}

\begin{abstract}
The first national interest in metropolitan areas dates back to the seventies stimulated by the strong growth in population around the main metropolitan conurbations in Italy and linked to the issue of constructing administrative bodies of a metropolitan nature. Since then, the presence of metropolitan areas has been covered by sector literature sharing, albeit from different disciplinary perspectives, the aim of identifying territorial collocation and socio-demographic structure. In a similar way to those in English in the fifties on metropolitan areas, Italian studies define metropolitan areas by combining criteria of homogeneity, interdependence and morphology. Similar attention to integration of the defining criteria is present in this study, which aims to identify metropolitan areas in Italy and study their evolution in the period from 1991 to 2011. Compared to studies carried out so far this proposal stands out for its choice to consider as metropolitan those areas that meet specific requisites of density of metropolitan functions, including special attention dedicated to mobility for work or study reasons. More than an accessory function that supports the other activities, mobility is considered a fundamental dimension of metropolitan areas, helping to define the shape of the area and draw its borders.
\end{abstract}

Keywords Metropolitan areas - Commuting - Mobility flows • Geographic information system (GIS) • Demographic dynamics • Meta cities

\section{Introduction}

From the mid-seventies on, the topic of escape from the city and return to the countryside received increasingly more attention in Italian literary journalism and, in many cases, also in scientific literature. This interest was due to the fact that, for the first time since the unification of Italy, big cities (with more than 250,000

M. Boffi · M. Colleoni ( $\square)$

University of Milan Bicocca, Milan, Italy

e-mail: matteo.colleoni@unimib.it 
inhabitants) were seeing their inhabitants move out to smaller towns. The growing demographic weight of medium-size cities then fuelled arguments about the appeal of towns where lower demographic pressure and better accessibility to services combine to give expectations of better quality of life.

Both explanations gave too much importance to the ability of the demographic dimension alone to explain urban change and did not sufficiently consider the role played by the territory in forming cities. As classic authors well knew, without the high territorial density and social heterogeneity of its components the numerousness of the population alone is not sufficient to turn a human settlement into a city (Wirth 1938). While demographic growth is only a clue to the urban presence, in the same way, its decrease is neither proof of its decline, nor is a return to the countryside of its inhabitants. The huge amount of literature on urban systems emphasises the importance that territorial relations have had in the formation of cities and of larger metropolitan areas. In the various stages of their growth cycle (Hall and Hay 1980; Van den Berg et al. 1982), metropolises have attracted and lost population, changing morphology but not, because of this, losing their urban characterisation. In this sense, reference to systems and metropolitan areas finds priority justification in the need to identify new urban conformations that take advantage of the dimensional and territorial limits of the municipalities that comprise them.

The first national interest in metropolitan areas dates back to the seventies stimulated by the strong growth in population around the main metropolitan conurbations in Italy and linked to the issue of constructing administrative bodies of a metropolitan nature (Martinotti 1993, p. 61). Since then, the presence of metropolitan areas has been covered by sector literature sharing, albeit from different disciplinary perspectives, the aim of identifying territorial collocation and socio-demographic structure. In a similar way to those in English in the fifties on metropolitan areas (American Standard Metropolitan Areas, or the English Functional Urban Regions), Italian studies define metropolitan areas by combining criteria of homogeneity, interdependence and morphology. Compared to the early Italian studies, which identified metropolitan areas using criteria based mainly on homogeneity (Acquarone 1961; Ardigò 1967; Cafiero and Busca 1970), those carried out after the eighties were the result of a combination of requisites of high demographic consistency and non-agricultural employment density (which refer to the already mentioned criteria of homogeneity) with requisites of a strong presence of commuter flows (which instead refer to criteria of interdependence). This was the direction taken by early studies by Cafiero and Cecchini (1989), Ercole and Zonta (1991) and, later, those carried out by ISTAT $(1994,2005)$ to define local systems and functional regions of work and the proposal by Boatti (2008) to delineate functional homogeneous areas and interconnected systems of locality. These studies share an attention to commuter flows, integrated with a more traditional attention to homogeneity dimensions and an equal disregard for morphological criteria, which are on the contrary the priority issue in analysis of the tradition of urban and metropolitan studies on urban environments (Boeri et al. 1993; Palermo 1997; Balducci 2006; Calafati and Veneri 2013). While only considering construction continuity, one of the many variables in the morphologic-territorial paradigm, the 
study into metropolitan areas by Bartaletti (2009) is the most attentive to integration of criteria of homogeneity and interconnection with those of morphology. Inspired by the identification method of the American Standard Metropolitan Areas, Bartaletti's identification of the central cities in metropolitan areas is based on numbers employed in manufacturing and a selection of metropolitan-vocation tertiary services, aggregating the municipalities that meet requisites of demographic increase, population density, commuting and continuity in built-up areas (Boffi et al. 2012). In this way, the study identifies 33 metropolitan areas in Italy, some of which are adjacent and grouped into a smaller number of consolidated areas.

Similar attention to integration of the defining criteria (homogeneity, interdependence and morphology) is present in this study, which aims to identify metropolitan areas in Italy and study their evolution in the period from 1991 to 2011. Compared to studies carried out so far this proposal stands out for its choice to consider as metropolitan those areas that meet specific requisites of density of metropolitan functions, including special attention dedicated to mobility for work or study reasons. A second element that characterises this study introduced here is the high territorial detail of the analysis, the municipality and - where possible - the section of census, which, compared to more aggregated units, allows a better description of a phenomenon like the metropolitan one, increasingly more transversal with regard to administrative borders. Based on figures from Population and Home Censuses and Industry, Service and Institution Censuses from 1991 to 2011, this study is introduced by analysis of long-term Italian urban demographic dynamics (the last century) and medium-term (the last forty years) with the aim of describing the socio-territorial processes that have led to the formation of Italian urban and metropolitan areas. The detailed presentation of the analysis method and techniques used to identify metropolitan areas and represent their collocation on the territory then leads to analysis of the structure and the Italian metropolitan dynamics over the last twenty years.

\section{Long- and Medium-term Italian Urban Demographic Dynamics}

Big Italian cities today have a lower demographic number than those of European metropolises; however, there was a moment in history when they were the most densely populated on the continent. At the beginning of the first millennium, Palermo was, together with Seville, the most densely populated city in Europe and Venice and Genoa held the title two centuries later. In the sixteenth century, Naples, Milan and Venice had doubled the inhabitants of London. From the seventeenth century, the barycentre of urban Europe shifted towards central-northern Europe, especially towards cities in England, the country that was the first to start the industrialisation process. In 1850, London had 2 million, 300 thousand inhabitants and was the most densely populated city on earth. While at lower levels than the 
biggest European cities, the unification of Italy marked the beginning of growth for Italian cities and they continued to grow until 1971. In 1871, the two most densely populated cities in the country (Naples and Milan) were home to around 752 thousand people out of a national total of around 22 million (3.4\%). One hundred years later, in 1971, the 14 cities with more than 250 thousand inhabitants totalled over 11 million out of a total of 54 million, 130 thousand (20.6\%). In this period, demographic growth of the most densely populated cities was more rapid than that in the rest of Italy and due mainly to expansion of their surface area. Furthermore, growth was everywhere due more to the appeal of the city that to the tendency of its inhabitants to reproduce, particularly in cities in the central and northern Italy. The great appeal of the big cities in the North, in particular of Turin, Milan and Genoa, was explained by the attraction of industry. In other cases, it was due instead to political factors; during its reign as the capital of the Kingdom of the Two Sicilies, until 1860, Naples was the most densely populated city in Italy, but already by 1931 it had been overtaken by Rome and Milan. From the end of the thirties, Rome became Italy's most densely populated city, thanks to the appeal of its concentration of political, administrative, religious and cultural functions (Barbagli and Pisati 2012).

Over the last forty years, the largest cities in Italy have lost inhabitants, reaching a total of 8 million, 791 thousand in 2011 out of a total of 59 million, 434 thousand (about $15 \%$ ). This demographic drop, whose causes are both natural (fewer births) and migratory (reduction in house moves into the cities and, in particular, from other Italian municipalities), has mainly affected the big cities in the North (26\% less population in 2011 than in 1971) and to a lesser extent those in southern $(-14 \%)$ and central Italy $(-7 \%)$. As we will see later, this had consequences on the formation and structure of urban and metropolitan areas, as the larger and more composite ones in northern Italy are the result of greater population movement out of metropolitan centres to sub- and peri-urban municipalities. Figures in essays on demographic variation in the last decade (2011-2001) show a reduction in the loss of population by the big municipalities compared to the medium period, albeit lower than a level that would qualify as re-urbanisation (in other words, growth in metropolitan hubs). The fact then that in almost all big cities in the South (with the exception of Bari) and those on northern coasts (Trieste, Genoa and Venice), demographic figures show consistent decreases over the past decade anticipates a second aspect, to which we will return later, regarding the collocation of Italian urban areas in different stages of the metropolitanisation process (more advanced in the Centre and North and more recent in the South).

The drop in population in big municipalities from the seventies on marked a turning point in the history of urban dynamics of Italian cities, up to that moment characterised by heavy urbanisation. The demographic numbers in municipalities with fewer than 30,000 inhabitants, constantly decreasing since the unification of Italy in favour of the big cities, began to level out, while that of medium-sized cities continued to grow but at a slower rate than the previous period. While in 2011, the majority of the Italian population continues to live in small municipalities, their 


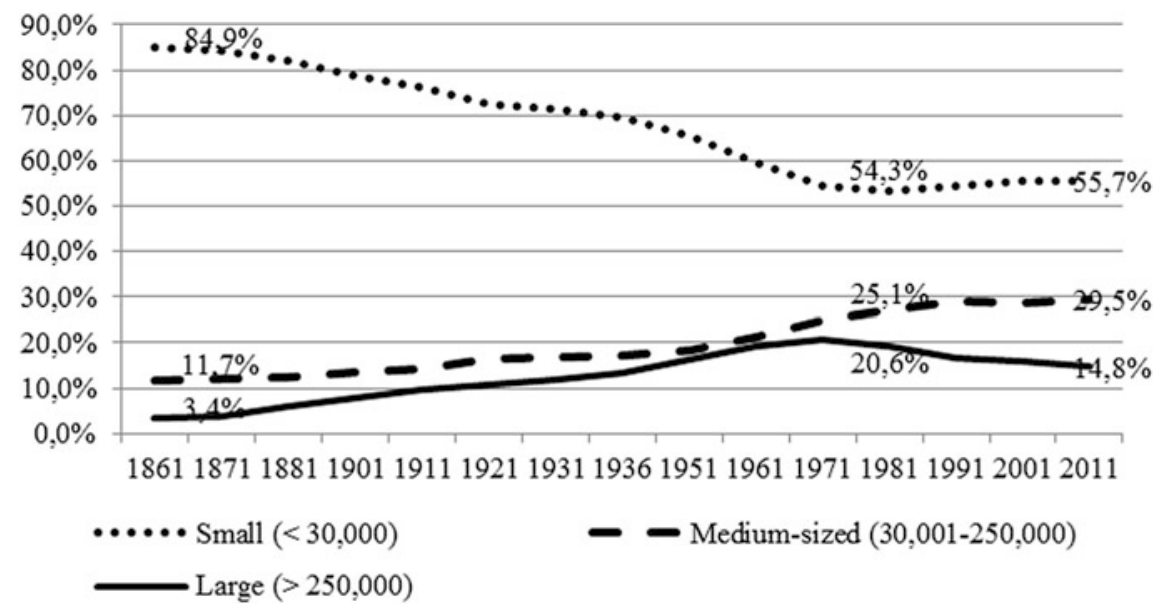

Fig. 1 Population size per type of area and year 1861-2011. Percentage values. Source Own elaboration on Population and Homes Censuses, Istat 1861-2011

demographic weight reached about $56 \%$, in favour of medium-sized municipalities, $29 \%$ and large ones (about $15 \%$, see Fig. 1).

Rather than an improbable escape in pursuit of non-urban environments, territorial analysis of demographic variation shows that the biggest increase regarded municipalities, of any size, located in the gravitation areas of the biggest cities of a metropolitan nature. Medium-term analysis of the variation in the demographic density shows the presence of uniform, rather than widespread, areas of increase and decrease (see Fig. 2). The increase affected suburban municipalities and, later, peri-urban ones that gravitate around not only metropolises but also around capital cities of provinces. Clearly visible around big Italian cities, these are municipality areas whose demographic increase is explained both by high birth rates (of the younger population living there) and also by the appeal to the population from metropolises or non-urban municipalities. Areas with big demographic increase are also to be found along the Adriatic coastal areas (from Romagna to Puglia), along the Tyrrhenian coast (from Rome to Salerno) and, to a lesser degree, in the South of Sicily.

This decrease, however, affected most of the suburban area of Italy including urban and metropolitan systems, regardless of the size of the municipalities. In first place were mountain and rural areas, but with significant differences depending on the territorial location. It is interesting, for example, to note that the drop in population affected the Apennine areas in the Centre and South of Italy more than the Alpine areas. Valle d'Aosta and, especially, Trentino Alto Adige, rich regions in the Alpine range with a strong tourist vocation, are characterised by a basically stable demographic situation and, in their biggest cities, even by an increase in population. Vice versa the Ligurian-Tuscan coast, the lower Po valley area and mountain areas 


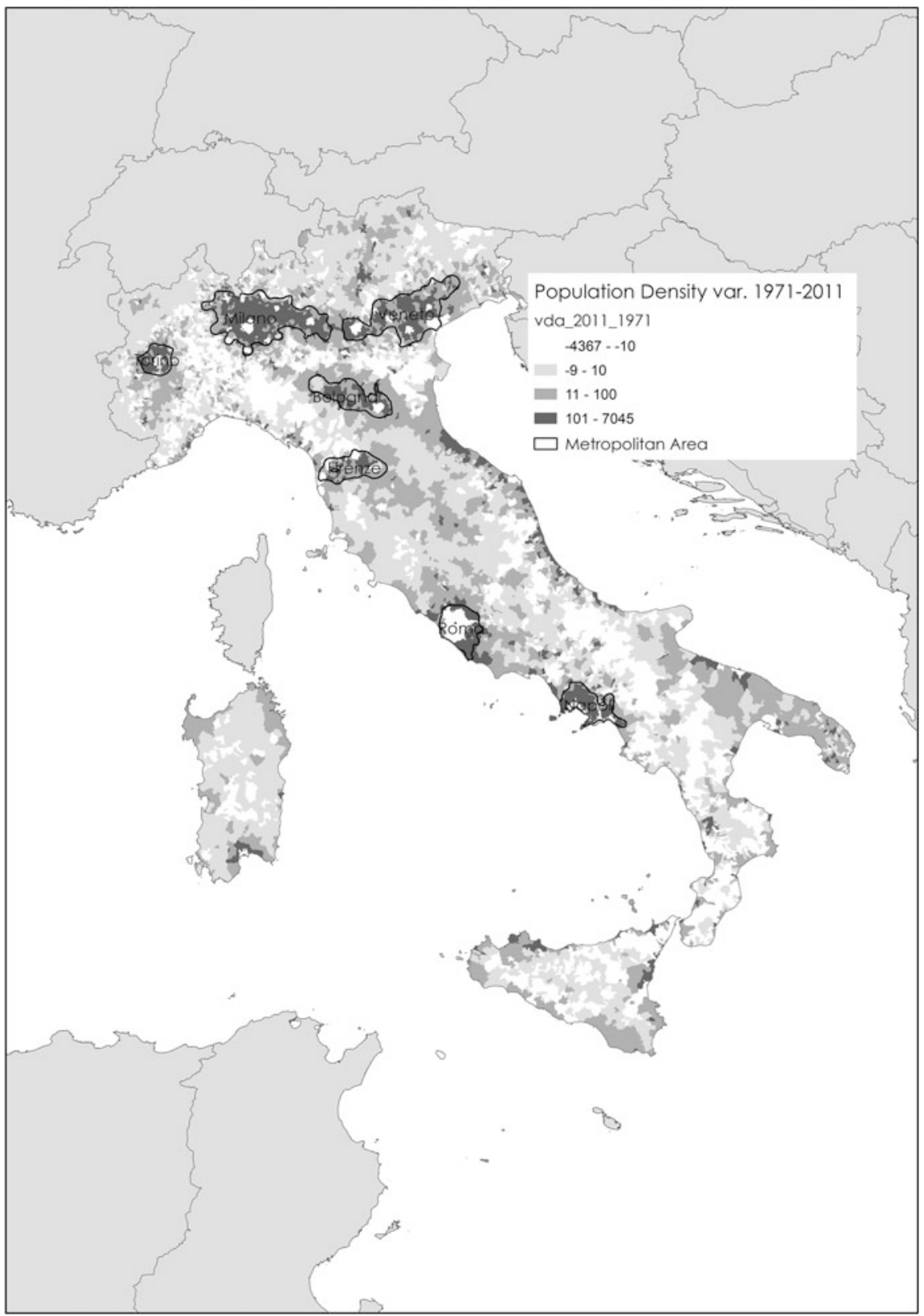

Fig. 2 Demographic density variation 1971-2011. Source Own elaboration on Population and Homes Censuses, Istat 1971-2011 
in the South of Italy and the islands all share a migration of population towards urban hubs (in the South) and urban areas (in the Centre and North).

In brief, the dynamics of long- and medium-term demographic increase unequivocally defines the borders of urbanised areas which gravitate around large cities that, despite a drop over the last forty years, continue to have a large demographic size and to fulfil their role as the centre of larger urban areas that we can call metropolitan (Vicari 2013). As the greatest consistency and demographic density inside them is the consequence of the concentration of functions linked to production, commerce, services and, consequently, movement flows that link the urban areas, we look at the latter when analysing the formation and dynamics of metropolitan areas in Italy.

\section{Metropolitan Dynamics over the Last Twenty Years (1991-2011)}

\subsection{Analysis Method}

Definitions of metropolitan area proposed by national and international literature all consider as such those settlements that have in common the same urban nature (homogeneity) and urban form (morphology), which gravitate around a metropolitan centre (core) and between which there is strong functional interaction (interdependence). The high consistency and concentration of population (size and density) around large Italian municipalities observed on the previous pages are therefore a good indicator but is not yet proof of the presence of a metropolitan area. In order to qualify as such, we need to look at the territorial distribution of the other factors that go to make up a city, work (the market in the Weber sense of the word as a place of production, consumption and, we add, service) and urban systems, flows of people, goods and information (mobility). Considering as metropolitan the area distinguished by the presence of functions that allow it to influence a vast territory, in continuity with other recent national and international studies, (Casacchia et al. 2006; Thurstain-Goodwin and Unwin 2000) the residential, productive, tertiary and mobility functions are defined as characterising (as a quality of factor of interconnection between the metropolitan functions). The size of metropolitan functions is monitored by constructing indicators of territorial density, respectively, of the number of residents, number of employees and movements for study and work.

The cited indicators were based either on Population Census (2011-1991) - demographic and mobility values — and Industry and Service Census (2011-1991) employees in the local units (see Table 1). While population data inputs were on the census tract scale, the employee and mobility values were on the municipal scale. The mobility data, based on origin/destination values, were transformed into straight lines connecting the cities, representing the geographic mobility network. The analysis 
Table 1 Metropolitan functions and indicators

\begin{tabular}{l|l|l}
\hline Metropolitan functions & Indicators (territorial density) \\
\hline Residential & 1. Dwelling & Number of residents \\
\hline Productive & 2. Manufacturing activities & Number of employees \\
\hline Tertiary & $\begin{array}{l}\text { 3. Commerce and services } \\
\text { 4. Finance and insurance activities } \\
\text { 5. Real estate activities } \\
\text { 6. Information and communication } \\
\text { 7. Health } \\
\text { 8. Social assistance } \\
\text { 9. Public administration } \\
\text { 10. Professional, scientific and technical } \\
\text { activities } \\
\text { 11. Secondary education } \\
\text { 12. University education and scientific } \\
\text { research } \\
\text { 13. Recreational, cultural and sports } \\
\text { activities } \\
\text { 14. Associationism } \\
\text { 15. Accommodation and catering } \\
\text { 16. Transport }\end{array}$ & \\
& $\begin{array}{l}\text { 17. Mobility of persons } \\
\text { Mobility }\end{array}$ & \\
\hline
\end{tabular}

Source Own elaboration on Population and Homes Census and Industry, Service and Institution Census, Istat 2011 and on Ateco 2007; classification of economic activities

process went through a transformation of vector inputs into a gridded surface of $1 \mathrm{~km}^{2}$, by means of a weighted KDE (Kernel Density Estimator) model; in particular the bandwidth, representing in the model the spatial outcome of the indicators, was derived from a modified Median Centre statistic, with the exception of the mobility network lines, transformed by a fixed bandwidth of $2.5 \mathrm{~km}$ (Boffi 2004).

While limited to movements for study or work reasons alone, the flow density indicator enables more accurate calculation of localisation and territorial concentration instead of just points of origin and destination, in the conviction that mobility is a constitutive and not just accessory element of metropolitan areas.

Calculation of the 17 indicators of metropolitan functions aims not only to analyse their distribution throughout Italy and observe their concentration in urban areas but also, first and foremost, to build a composite index of metropolitanism (or urban centrality, Thurstain-Goodwin and Unwin 2000).

The normalised gridded values were then reduced by means of a two-step Factor Analysis procedure, concerning first the fourteen indicators of the Tertiary Sector, and second the four general indicators. The resulting values were interpreted as the Spatial Metropolitan and Urban Indicator and the isolines built on it at the 0.4 value - representing a relevant statistical break of the distribution - made up the borders of the areas identified either as Metropolitan Areas-if totalling at least one million inhabitants - or Urban Areas - with a total of more than 250,000 inhabitants; higher values of the Metropolitan Indicator were used to identify the various subtype 
spatial classes inside the Metropolitan Areas, such as Core or Peri-urban. The spatial and statistical analyses were performed using packages from ESRI-Arcgis 10.3 and IBM-SPSS 22.

\subsection{Composition, Localisation and Morphology of Metropolitan and Urban Areas in 2011}

In 2011, there were seven metropolitan areas (four in the North, two in the Centre and one in the South) and seven urban areas with a population of over 250,000 (three in the North, four in the South and on the islands, see Table 2). While the former account for only $8.7 \%$ of the country's surface area, they include $18.3 \%$ of the municipalities and no less than $41.6 \%$ of the population (24 million, 732 thousand inhabitants). Considering also the population in the large urban areas, we can say that half of Italy's population lives in metropolitan and urban areas in an area equal to one-tenth of the country's total. Their demographic density therefore exceeds the national average (197.2 inhabitants per square kilometre) and, more importantly, that of the rest of Italy (109.6), equal in metropolitan areas to 941 inhabitants per square kilometre and in urban ones to 1137.1. The lowest demographic density of metropolitan areas compared to urban areas is explained by the greater size of the former, of peri-urban areas, medium urbanity and low-density demographics collocated on the fringes of metropolitan areas (Colleoni and Caiello 2013).

The metropolitan area of Milan is the largest and most densely populated in Italy, followed by the Veneto area (for size) and Naples (for density). Its 783 municipalities are home to no fewer than 8 million, 14 thousand people who, as we will see, fuel the very strong mobility flows into the metropolitan core (the city of Milan). The most compact metropolitan areas (normally characterised by the presence of a dominating core with a high level of metropolitanism) are those with the highest demographic density (Naples, Rome and Turin). The urban areas are different from metropolitan ones due to a lower demographic consistency and surface area, while some of these cover a large area (Rimini) and have a population density close to the threshold for inclusion in the metropolitan category (Bari with 955 thousand inhabitants). In the method section, we said that the metropolitan and urban areas are characterised by a high concentration of metropolitan functions and, consequently, by a high level of urban centrality (or metropolitanism). Considering the negative value of the index in the rest of the country $(-0.21$, see Table 3$)$ in metropolitan areas, this stands at 1.96 and in urban ones at 1.24. It is interesting to observe that in some urban areas (Palermo, Genoa and Catania) the index has values higher or closer to the average of metropolitan areas, confirming the presence of areas with a strong metropolitan vocation (despite not having a sufficiently numerous population to be included in the metropolitan category). 


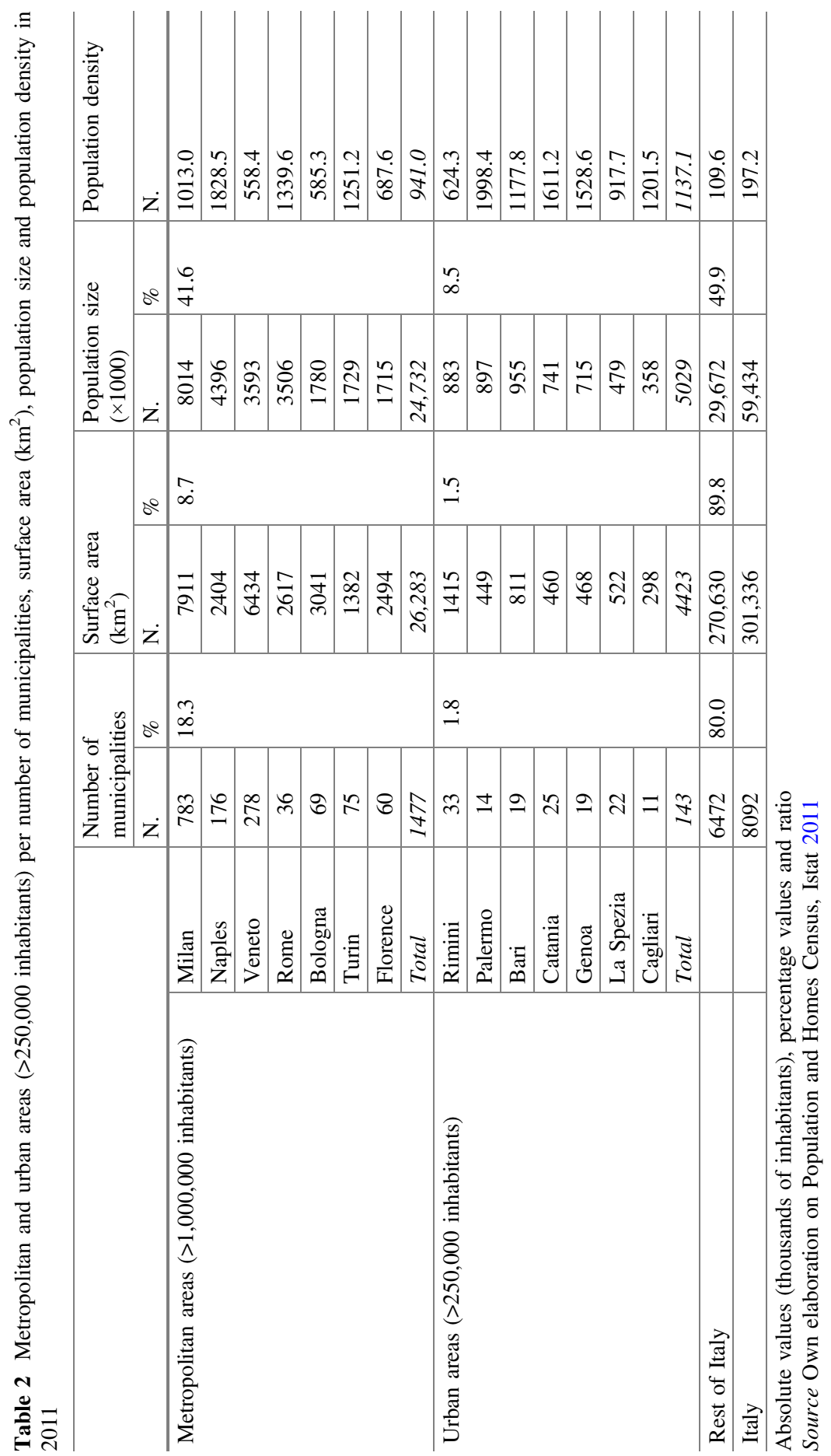


Table 3 Metropolitan and urban areas ( $>250,000$ inhabitants) per index of metropolitanism (threshold $>0.4$ ) in 2011. Ratio

\begin{tabular}{|c|c|c|c|c|c|}
\hline & & $\begin{array}{l}\text { Index of } \\
\text { metropolitanism }\end{array}$ & & & $\begin{array}{l}\text { Index of } \\
\text { metropolitanism }\end{array}$ \\
\hline \multirow{8}{*}{$\begin{array}{l}\text { Metropolitan } \\
\text { areas } \\
\text { (>1,000,000 } \\
\text { inhabitants) }\end{array}$} & Milan & 2.40 & \multirow{8}{*}{$\begin{array}{l}\text { Urban } \\
\text { areas } \\
(>250,000 \\
\text { inhabitants) }\end{array}$} & Rimini & 0.83 \\
\hline & Naples & 2.29 & & Palermo & 2.03 \\
\hline & Veneto & 1.14 & & Bari & 1.14 \\
\hline & Rome & 3.09 & & Catania & 1.64 \\
\hline & Bologna & 1.34 & & Genoa & 1.97 \\
\hline & Turin & 2.94 & & \begin{tabular}{|l} 
La \\
Spezia
\end{tabular} & 0.80 \\
\hline & Florence & 1.39 & & Cagliari & 1.31 \\
\hline & Total & 1.96 & & Total & 1.24 \\
\hline Rest of Italy & & -0.21 & & & \\
\hline Italy & & - & & & \\
\hline
\end{tabular}

Source Own elaboration on Population and Homes Census, Istat 2011

While Italian metropolitan areas share an equal high concentration of residential, productive and commercial functions (and of mobility flows), they however present different morphologies. The category of linear form areas includes those of Milan, Bologna, Florence and the Veneto area. As shown in Fig. 3, their borders do not coincide with those of their relative administrative bodies and their shape resembles a corridor, residential areas with metropolitan functions and increasingly more flow spaces (Castells 1996; Martinotti 1999). The linear shape of these areas, referred to as polycephalic in sector literature, is indicative of the presence of an articulated system of hubs that, with the core, have complex functional interactions that go beyond the traditional role of dependence. The low values of the indicator of inhabitant density may be explained by the existence of a widespread urban fabric, characterised by a greater dispersion of the towns. This is especially evident in the Veneto area, which stretches from Verona to Pordenone, reaching beyond the borders of the region, linking the Veneto cities situated along the eastern axis of the great flow corridor of the so-called sunbelt (which links countries in the East, via Italy and the South of France, with Portugal). Whereas the other linear areas have dominating cores that recall more traditional territorial hierarchies; especially that of Milan, which extends for almost $8000 \mathrm{~km}^{2}$ from Novara to Brescia, touching the western borders of the Veneto area. The metropolitan area of Bologna has an unequivocal linear shape, partially dominated by the capital municipality, which runs along the Via Emilia, almost touching the semi-coastal urban area of Rimini (and prefiguring the profile of a short-term single metropolitan area going from Parma to Pesaro). Processes of takeover are also visible between the linear area of Florence, which connects the capital city of this municipality with Pisa, (via Prato and Pistoia), to the coastal urban one of La Spezia.

Whereas the metropolitan areas of Turin, Rome and, in part, Naples belong to circular or monocephalic areas. The greater concentration of metropolitan functions, indicative of the presence of a strong dominating role of the core, is evident in the 


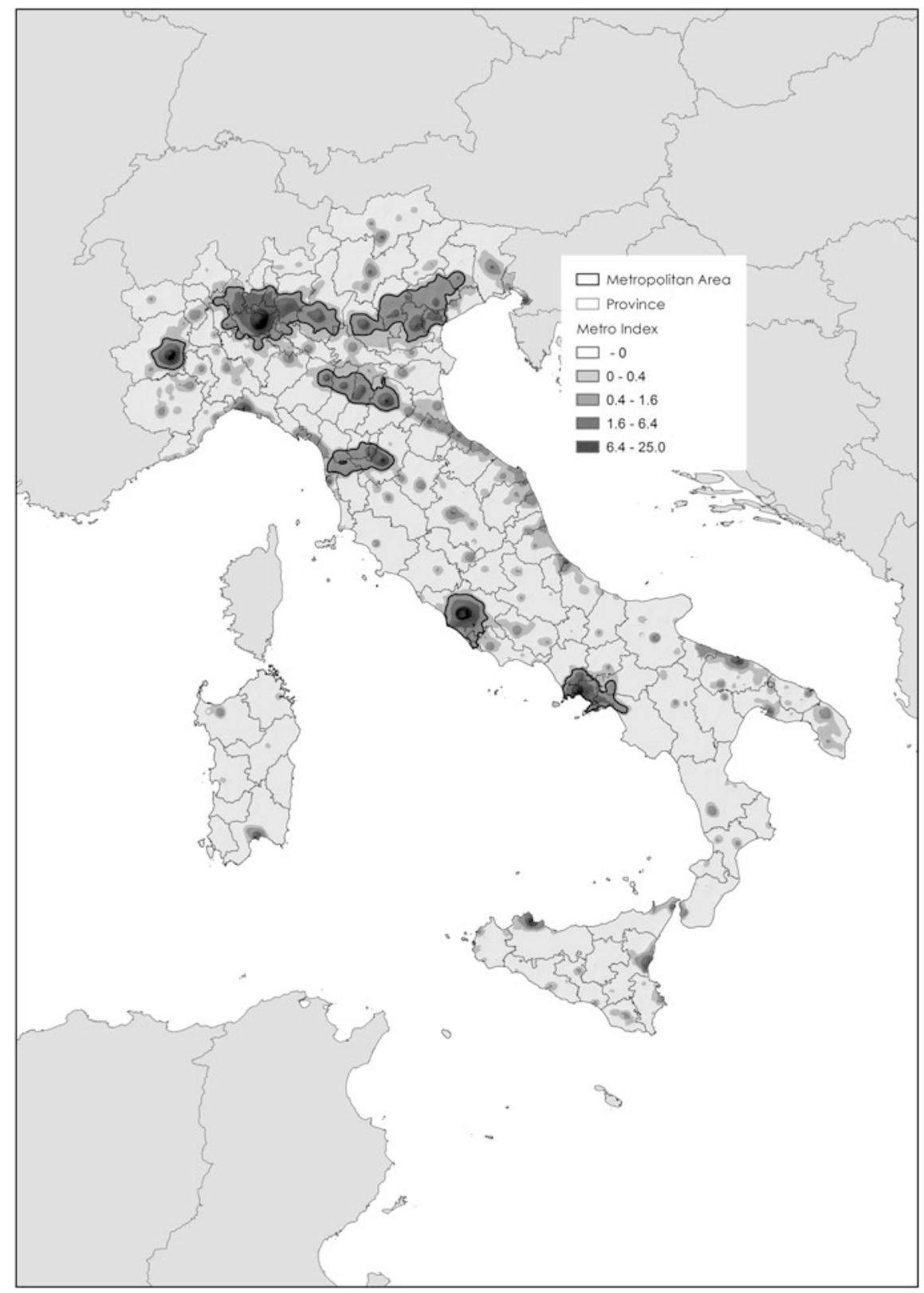

Fig. 3 Metropolitan and urban areas in Italy in 2011. Source Own elaboration on Population and Homes Census and Industry, Service and Institution Census, Istat 2011 
higher values of the index of urban centrality and residential density. Of the three, Naples is the most atypical, showing a greater articulation of hubs (albeit dominated by the capital city) and a coastal linear extension (that develops beyond the city of Salerno).

Against the background of a mainly non-urbanised territory (in blue in figure) urban areas are visible that, despite being isolated, in many cases have a significant concentration of functions. Special attention must be reserved for the Alpine areas in Trentino Alto Adige and the coastal ones in Puglia and on the bigger islands.

Over the past twenty years, against a national demographic increase of $4.7 \%$, metropolitan areas have seen an increase in population of $7 \%$ (see Table 4). The increase of urban areas was, meanwhile, lower (1.9\%) as was that of non-urban and non-metropolitan areas $(3.3 \%)$. Two variations in the areas deserve attention, the big demographic increase in the Veneto and Emilia-Romagna areas that, together with the Milan area, form the macro-region characterised by the most marked metropolitan development and noticeable reduction in demographic weight in the urban area of Genoa (unlike the general strengthening in urban areas along the coast). The twenty-year dynamics of Italian metropolitan areas shows the extension to the East of the Milan metropolitan area, the greater compactness of the Veneto area and the urban area of Rimini and, to the South, the increase in the Bari area.

Table 4 Metropolitan and urban areas (>250,000 inhabitants) per population size 1991-2011

\begin{tabular}{|c|c|c|c|c|c|}
\hline & & \multirow{2}{*}{$\begin{array}{l}2011 \\
\text { N. }\end{array}$} & \multicolumn{2}{|l|}{1991} & \multirow{2}{*}{$\begin{array}{l}\text { Percent variation } \\
(1991-2011)\end{array}$} \\
\hline & & & N. & $\%$ & \\
\hline \multirow{8}{*}{$\begin{array}{l}\text { Metropolitan areas } \\
(>1,000,000 \text { inhabitants })\end{array}$} & Milan & 8014 & 7306 & \multirow[t]{8}{*}{40.7} & 9.7 \\
\hline & Naples & 4396 & 4245 & & 3.6 \\
\hline & Veneto & 3593 & 3164 & & 13.5 \\
\hline & Rome & 3506 & 3389 & & 3.4 \\
\hline & Bologna & 1780 & 1612 & & 10.4 \\
\hline & Turin & 1729 & 1752 & & -1.3 \\
\hline & Florence & 1715 & 1655 & & 3.6 \\
\hline & Total & 24,732 & 23,122 & & 7.0 \\
\hline \multirow{8}{*}{$\begin{array}{l}\text { Urban areas }(>250,000 \\
\text { inhabitants) }\end{array}$} & Rimini & 883 & 776 & \multirow[t]{8}{*}{8.7} & 13.8 \\
\hline & Palermo & 897 & 884 & & 1.5 \\
\hline & Bari & 955 & 935 & & 2.2 \\
\hline & Catania & 741 & 700 & & 5.9 \\
\hline & Genoa & 715 & 807 & & -11.4 \\
\hline & $\begin{array}{l}\text { La } \\
\text { Spezia }\end{array}$ & 479 & 476 & & 0.6 \\
\hline & Cagliari & 358 & 359 & & -0.3 \\
\hline & Total & 5029 & 4937 & & 1.9 \\
\hline Rest of Italy & & 29,672 & 28,718 & 50.6 & 3.3 \\
\hline Italy & & 59,434 & 56,778 & & 4.7 \\
\hline
\end{tabular}

Absolute values (thousands of inhabitants) and percentage values

Source Own elaboration on Population and Homes Census, Istat 2011 
The other urban and metropolitan areas do not, however, show any significant morphological differences over the last twenty years.

Comparing the morphology of the metropolitan areas with that of the provinces and the regions, we can see that the former almost always include parts of different provinces (and in two cases, Milan and Veneto, also of different regions). The exceptions are Turin and Rome, which are completely included within the one province. In only three situations does the whole province belong to the metropolitan area-this is the case with Milan, Monza and Naples. This is a fact that must be given due consideration in light of the recent law for the constitution of metropolitan provinces.

\subsection{The Socio-demographic and Economic Structure of Metropolitan and Urban Areas in 2011}

Italian metropolitan areas have been formed in a process lasting many decades that has seen a considerable change in the territorial distribution of residential, productive and service hubs in the country. Dispersion of settlements in peri-urban areas, together with the increase in functional interaction between cities, has led to the formation of metropolitan areas characterised, as we have already seen, by the biggest increase in population. As this increase in population corresponds to positive dynamics in the migratory and natural totals it is, normally, held to be younger and more multi-ethnic than the rest of the country. This hypothesis is confirmed by figures from the latest Census, which in 2011 highlights the presence in metropolitan areas of higher percentages of minors (4.9\%), young people $(14.6 \%)$ and foreigners $(8.4 \%)$ and lower quotas of the elderly $(75+$ totally $9.6 \%)$. The same goes for work indicators, which in metropolitan areas show bigger quotas of graduates $(11.7 \%)$, employed persons $(89.8 \%)$ and lower figures for the unemployed (10.2\%, see Table 5).

The differences compared to the national averages and the non-urban rest of the country are, however, lower than expected due to the discrepancies that exist both between metropolitan areas and within them. Regarding the first point, albeit characterised by a common, high density of metropolitan functions, the socio-demographic structure of Italian areas is influenced by their different geographic location. Within them, at least four different kinds of areas are evident - the core, the sub-cores, suburban areas and peri-urban areas - in turn characterised by different socio-demographic and productive structures. The fact that, despite the differences that exist between and within these areas, they show values in line with expectations would tend to back the theories regarding the existence of a metropolitan identity. It is however, an identity with some differences, the entity of which, in particular within the specific areas, has not been discussed in this paper and will be a subject for interesting analysis in the future. 
Table 5 Metropolitan and urban areas (>250,000 inhabitants) per work indicators in 2011

\begin{tabular}{|c|c|c|c|c|c|}
\hline & & $\begin{array}{l}\text { Percentage } \\
\text { of } \\
\text { graduates }\end{array}$ & $\begin{array}{l}\text { Active } \\
\text { population }\end{array}$ & $\begin{array}{l}\text { Employment } \\
\text { rate }\end{array}$ & $\begin{array}{l}\text { Unemployment } \\
\text { rate }\end{array}$ \\
\hline \multirow{8}{*}{$\begin{array}{l}\text { Metropolitan areas } \\
(>1,000,000 \\
\text { inhabitants })\end{array}$} & Milan & 11.3 & 3792 & 93.0 & 7.0 \\
\hline & Naples & 9.3 & 1640 & 75.4 & 24.6 \\
\hline & Veneto & 10.3 & 1713 & 93.5 & 6.5 \\
\hline & Rome & 16.1 & 1637 & 89.7 & 10.3 \\
\hline & Bologna & 13.3 & 899 & 93.3 & 6.7 \\
\hline & Turin & 11.5 & 785 & 90.8 & 9.2 \\
\hline & Florence & 11.7 & 817 & 91.9 & 8.1 \\
\hline & Total & 11.7 & 11,281 & 89.8 & 10.2 \\
\hline \multirow{8}{*}{$\begin{array}{l}\text { Urban areas } \\
(>250,000 \\
\text { inhabitants })\end{array}$} & Rimini & 11.4 & 447 & 92.3 & 7.7 \\
\hline & Palermo & 10.0 & 351 & 74.4 & 25.6 \\
\hline & Bari & 9.9 & 383 & 82.7 & 17.3 \\
\hline & Catania & 10.1 & 306 & 75.3 & 24.7 \\
\hline & Genoa & 13.1 & 312 & 92.2 & 7.8 \\
\hline & $\begin{array}{l}\text { La } \\
\text { Spezia }\end{array}$ & 10.0 & 218 & 89.9 & 10.1 \\
\hline & Cagliari & 14.2 & 171 & 81.5 & 18.5 \\
\hline & Total & 11.0 & 2187 & 84.3 & 15.7 \\
\hline Rest of Italy & & 8.8 & 12.518 & 88.2 & 11.8 \\
\hline Italy & & 10.2 & 25.985 & 88.6 & 11.4 \\
\hline
\end{tabular}

Absolute values (thousands of inhabitants), percentage values and ratio Source Own elaboration on Population and Homes Census, Istat 2011

The metropolitan dimension is normally associated with a greater concentration of activity and, consequently, of work in economic sectors that have more need of the benefits offered by the presence of high-quality, specialist services and infrastructures. In turn, the latter are ideally located in those areas where the market is more active and better inserted into the system of production, commerce and services on a global level. Sectors such as not only finance and insurance, information and communication, professional, scientific and technological activities, but also hospitality and food services (to support the former) are normally considered to be cornerstones for the production structure of more economically dynamic areas, such as metropolitan ones. Italian metropolitan areas are fairly in line with these expectations, showing higher related percentages for employees in the advanced tertiary sectors with $20.7 \%$ (compared to a national average of $17.1 \%$, and that of the rest of the country of $12.6 \%$ and of urban areas of $18.1 \%$, see Fig. 4). Compared to the rest of the country there are, however, again in relative terms, fewer employees in the sectors of manufacturing (27.1\%), public administration (16.3\%) and, albeit by very little, commerce $(28.1 \%)$. Whereas the lower figures for those working in hospitality, food service, culture, recreation and sport do not meet expectations, with these sectors continuing to see higher figures in non-urban and metropolitan areas $(9.5 \%)$. 


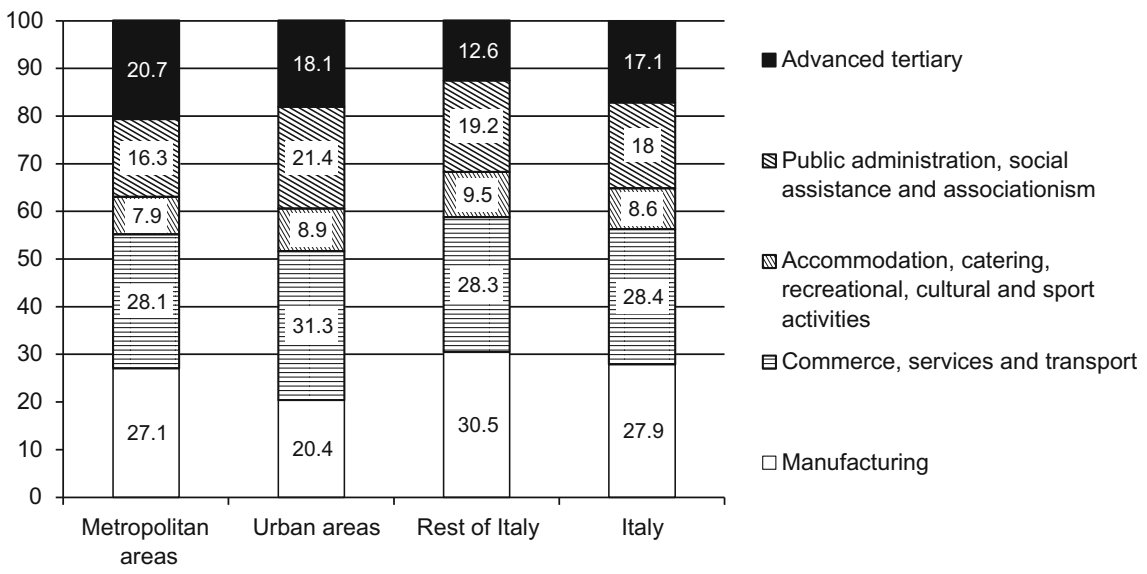

Fig. 4 Employees per macro-economic sector and type of area in 2011, percentage values. Source Own elaboration on Population and Homes Census and Industry, Service and Institution Census (Istat 2011). *Advanced tertiary: finance and insurance, information and communication, real estate, professional, scientific and technologic activities, scientific research

In the same way as for socio-demographic structure indicators, we are, however, referring to differences in economic structure lower than those expected due, once again, to the scarce homogeneity between Italian metropolitan areas. Advance tertiary sector activity, for example, involves $26.6 \%$ of employees in the Rome area, $23.6 \%$ in Turin and $22.3 \%$ in Rome (compared with figures in the metropolitan areas of Veneto and Naples that do not exceed $16 \%$ ). Again, public administration, which accounts for only $13.5 \%$ of employees in the metropolitan area of Milan, reaches the considerable figure of $22.6 \%$ in Naples and $21 \%$ in Rome. Manufacturing, finally, which as observed above has lower percentages of employees in metropolitan areas, however, totals $35 \%$ in the Veneto area. It would therefore seem possible to end by saying that on average, Italian metropolitan areas have an economic structure with more advanced tertiary activity than in the rest of the country, even though most of those in work in these areas are mainly employed in manufacturing and commerce. Furthermore, within metropolitan and urban areas, there is a division of employees that mirrors the traditional economic differences that exist between the country's different territorial divisions, not only between North and South, but also between Northwest and Northeast.

\subsection{Mobility in Metropolitan and Urban Areas 1991 and 2011}

The high concentration in metropolitan areas of the functions linked to production, commerce and services is translated into expected higher consistency of movement flows linking settlements. While theories about new urban systems are still lacking 
a shared term to describe their specificities compared to traditional metropolises, they do, however, share the conviction that they are places of residential, production and service settlement and, increasingly, flow spaces (Castells 1996; Martinotti 1999; Colleoni et al. 2012). Within them, the dispersion of settlements is considered to be the cause of increased movement of temporary populations: not only that of commuters, attracted by the greater supply of jobs in metropolises, but also that of city users, attracted by the concentration and better quality of goods and services in urban centres.

Data regarding movement for work and study given by the Census on population and inhabitants shows that in 2011, 28 million, 793 thousand Italian commuters travelled more than 129 million $\mathrm{km}$ in daily journeys $(13 \mathrm{~km}$ per commuter, see Table 6; Fig. 5). Compared to twenty years earlier, there has been an increase in both the number of commuters $(+5 \%)$ and the number of kilometres travelled $(+29 \%)$, and also the number of commuters per 100 inhabitants $(16.3 \%$ in 2011 and 13.2 in 1991, see Table 7). Over the last 20 years, there has also been an increase in flow density, in other words the relationship between the kilometres travelled by commuters and in the surface in square kilometres, which was equal to

Table 6 Metropolitan and urban areas (>250,000 inhabitants) per mobility indicators in 2011

\begin{tabular}{|c|c|c|c|c|c|}
\hline & & $\begin{array}{l}\text { Kilometres } \\
\text { travelled } \\
(\times 1000)\end{array}$ & $\begin{array}{l}\text { Kilometres } \\
\text { per } \\
\text { commuter }\end{array}$ & $\begin{array}{l}\text { Commuters } \\
\text { per } 100 \\
\text { inhabitants }\end{array}$ & $\begin{array}{l}\text { Flow } \\
\text { density* }\end{array}$ \\
\hline \multirow{8}{*}{$\begin{array}{l}\text { Metropolitan areas } \\
(>1,000,000 \\
\text { inhabitants })\end{array}$} & Milan & 25,815 & 12 & 27.7 & 3263 \\
\hline & Naples & 7352 & 11 & 15.4 & 3058 \\
\hline & Veneto & 10,328 & 12 & 24.2 & 1605 \\
\hline & Rome & 5858 & 20 & 8.2 & 2238 \\
\hline & Bologna & 4140 & 13 & 17.9 & 1361 \\
\hline & Turin & 3408 & 11 & 18.4 & 2466 \\
\hline & Florence & 4342 & 13 & 19.6 & 1741 \\
\hline & Total & 61,242 & 12 & 20.3 & 2330 \\
\hline \multirow{8}{*}{$\begin{array}{l}\text { Urban areas } \\
(>250,000 \\
\text { inhabitants })\end{array}$} & Rimini & 1246 & 12 & 12.2 & 881 \\
\hline & Palermo & 756 & 15 & 5.7 & 1683 \\
\hline & Bari & 1393 & 15 & 9.5 & 1718 \\
\hline & Catania & 1467 & 12 & 15.9 & 3190 \\
\hline & Genoa & 456 & 14 & 4.5 & 974 \\
\hline & $\begin{array}{l}\mathrm{La} \\
\text { Spezia }\end{array}$ & 638 & 9 & 14.3 & 1222 \\
\hline & Cagliari & 829 & 12 & 18.9 & 2782 \\
\hline & Total & 6786 & 13 & 10.7 & 1534 \\
\hline Rest of Italy & & 61,296 & 15 & 14.0 & 226 \\
\hline Italy & & 129,324 & 13 & 16.3 & 429 \\
\hline
\end{tabular}

Absolute values (thousands of inhabitants), percentage values and ratio

Source Own elaboration on Population and Homes Census (Istat 2011)

* Ratio between the kilometres travelled by commuters and the surface in square kilometres 


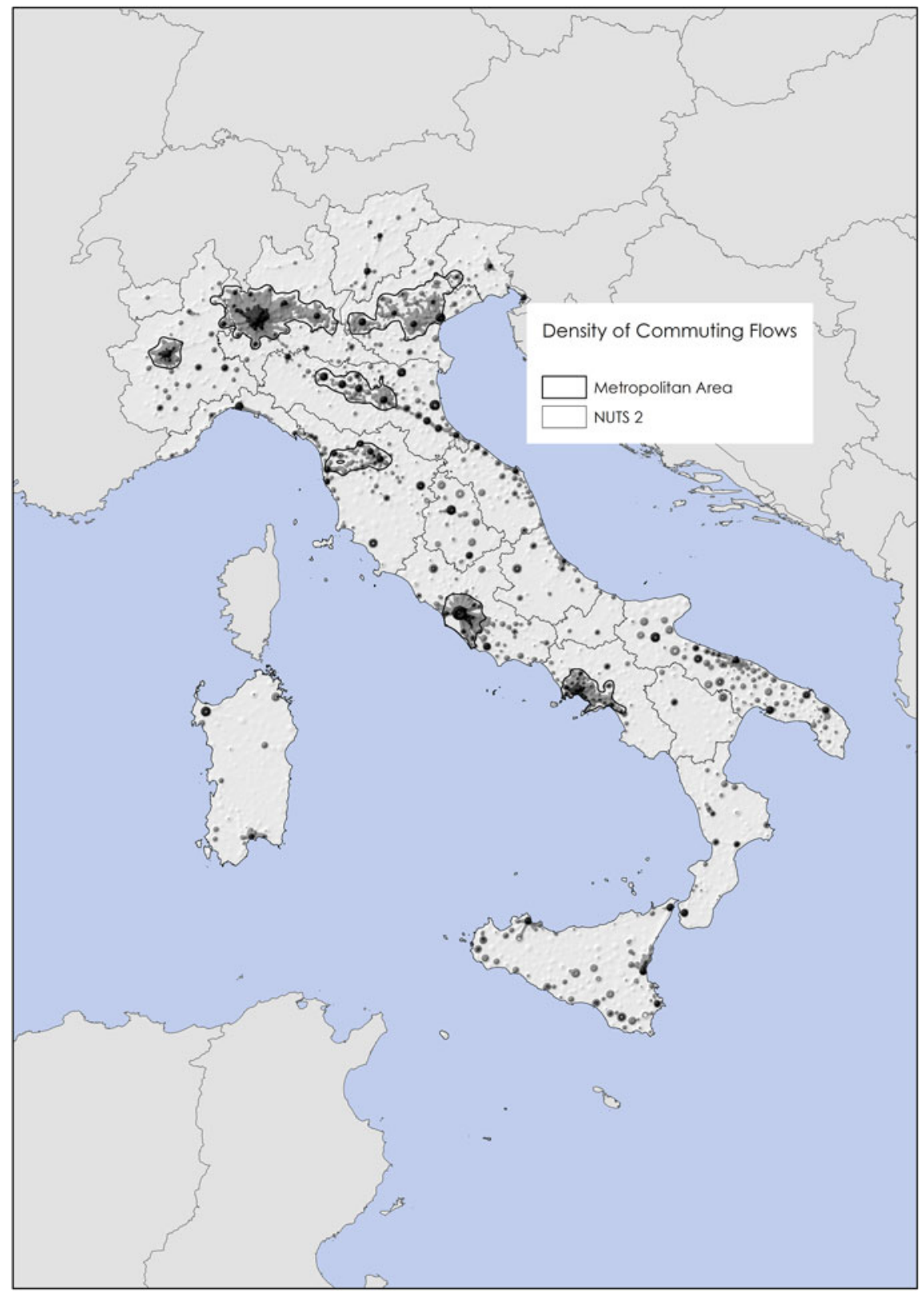

Fig. 5 Density of commuting flows in 2011. Source Own elaboration on Population and Homes Census and Industry, Service and Institution Census, Istat 2011 
Table 7 Metropolitan and urban areas (>250,000 inhabitants) per mobility indicators in 1991

\begin{tabular}{|c|c|c|c|c|c|c|}
\hline & & $\begin{array}{l}\text { Outside the } \\
\text { municipality of } \\
\text { residence }(\%)\end{array}$ & $\begin{array}{l}\text { Kilometres } \\
\text { travelled } \\
(\times 1000)\end{array}$ & $\begin{array}{l}\text { Kilometres } \\
\text { per } \\
\text { commuter }\end{array}$ & $\begin{array}{l}\text { Commuters } \\
\text { per } 100 \\
\text { inhabitants }\end{array}$ & $\begin{array}{l}\text { Flow } \\
\text { density* }\end{array}$ \\
\hline \multirow{8}{*}{$\begin{array}{l}\text { Metropolitan } \\
\text { areas } \\
\text { (> 1,000,000 } \\
\text { inhabitants) }\end{array}$} & Milan & 44.5 & 20,089 & 11 & 24.0 & 2539 \\
\hline & Naples & 30.1 & 6022 & 11 & 12.6 & 2505 \\
\hline & Veneto & 40.6 & 7992 & 12 & 20.7 & 1242 \\
\hline & Rome & 11.2 & 3514 & 20 & 5.3 & 1343 \\
\hline & Bologna & 30.5 & 3087 & 12 & 15.7 & 1015 \\
\hline & Turin & 35.8 & 3243 & 10 & 17.7 & 2347 \\
\hline & Florence & 34.0 & 3484 & 12 & 16.9 & 1397 \\
\hline & Total & 34.4 & 47,431 & 12 & 17.2 & 1740 \\
\hline \multirow{8}{*}{$\begin{array}{l}\text { Urban areas } \\
(>250,000 \\
\text { inhabitants })\end{array}$} & Rimini & 23.7 & 752 & 11 & 8.6 & 531 \\
\hline & Palermo & 8.8 & 400 & 15 & 3.1 & 891 \\
\hline & Bari & 20.4 & 1333 & 17 & 8.2 & 1644 \\
\hline & Catania & 28.7 & 1040 & 13 & 11.6 & 2261 \\
\hline & Genoa & 11.4 & 482 & 15 & 3.9 & 1029 \\
\hline & $\begin{array}{l}\text { La } \\
\text { Spezia }\end{array}$ & 29.8 & 507 & 10 & 10.6 & 970 \\
\hline & Cagliari & 27.6 & 665 & 15 & 12.4 & 2231 \\
\hline & Total & 20.2 & 5179 & 14 & 7.7 & 1171 \\
\hline Rest of Italy & & 30.9 & 47,579 & 15 & 10.9 & 176 \\
\hline Italy & & $31.5^{*}$ & 100,188 & 13 & 13.2 & 332 \\
\hline
\end{tabular}

Absolute values (thousands of inhabitants), percentage values and ratio

*In 1991 the number of commuters travelling inside the municipality of residence $(\times 1000)$ is 18,816 , the number of commuters travelling outside the municipality of residence is 8671 and the total number of commuters is 27,487

the national average of 332 in 1991 and equal to 429 in 2011. A good example of the growing functional interconnection that exists between Italian municipalities is given by the increase in the percentage of movement outside the municipality of residence, accounting for $31.5 \%$ of total commuter movement in 1991 and rising to $39.3 \%$ in 2011.

According to various sources, the increase in inter-municipality movements has not happened randomly but along the axes that connect areas characterised by high levels of functional interaction and, above all, towards the main metropolitan hubs (Censis 2008; Eurispes 2014; Colleoni and Boffi 2014). In effect, in both the years observed (1991 and 2011), Italian metropolitan areas show commuter per resident figures and flow density figures that are much higher than the national average. In 2011, in metropolitan areas, there were around 20 commuters for every 100 inhabitants, compared to a national average of 16.3 and 14 in the rest of the country. Looking at the number of kilometres travelled, metropolitan areas, which, we reiterate, cover just $9 \%$ of the surface of the country, are where around $50 \%$ of the total of national movements occur ( $47 \%$ to be precise). Metropolitan mobility is 
mainly characterised by a high flow density, totalling 2330 flows per square kilometre compared to a national average of 429 and 226 in the rest of the country. As flow density is the indicator that best measures the mobility load on the territory, this means that metropolitan areas see very high movement costs in terms of congestion of transport infrastructures, pollution and consumption of the territory. Inhabitants in metropolitan areas are also those who make more movement outside their municipality of residence, confirming the hypothesis regarding greater functional interdependence of the municipalities inside them. $41.8 \%$ of their commuters in fact travels outside their municipality of residence (compared to a national average of 39.3 and $27.4 \%$ in urban areas). The high functional compactness of metropolitan areas is also evident in a second indicator that measures the percentage of commuters who move to another municipality of the same kind of area. Compared to a national average of $78.4 \%$, in metropolitan areas no fewer than $93.7 \%$ movements link municipalities in the areas. Milan, which we reiterate is the most widespread and densely populated metropolitan area, has the highest number of commuters per 100 inhabitants (27.7) and the greatest flow density (3263). Not only, it is also the area with the greatest number of commuters moving outside the area $(52.9 \%)$ and with the highest density of movements between municipalities in the same area $(96.2 \%)$.

In conclusion, mobility in metropolitan areas is characterised not so much by a greater intensity or length of daily movements, as by a strong concentration in the space of the mobility itself. From this point of view, the spatial morphology of mobility takes on determining importance as an indicator for drawing the geographic borders of metropolitan areas.

\section{Conclusions}

As in the other western countries, Italian metropolitan areas are the outcome of a long-standing formation process that has led to a diverse countrywide distribution of functions, residential, production and service settlements, and of, as a consequence, relations between the metropolises and other cities in the urban system. These have formed around those metropolises where a concentration of jobs (both in industry and in public and private services) has attracted, over a century, around a fifth of the national population and they represent its core. From the early seventies the latter have lost their inhabitants to smaller municipalities in Italy country, not randomly but within their gravitation areas, to the suburban strips - at the startand to the peri-urban areas during the more advanced stage of the metropolitan growth cycle. Rather than a return of interest in smaller mountain or rural municipalities, which have seen a huge demographic decrease, we have seen an increase in the population in those, of any size, that are part of urban systems. The metropolitan specification of some of these systems is explained, not only by their great demographic consistency, but also by the presence of a dominating core and several sub-cores that have strong appeal for the rest of the territory due to the 
divers territorial distribution of metropolitan functions. Analysing the different territorial concentration of the latter, we have identified seven metropolitan areas, and we have studied their geographic collocation, morphology and dynamics over the past twenty years. Concentrated mainly in the North of Italy, they cover less than ten per cent of the country's surface, but are home, together with the seven complex urban areas, to around half the population in Italy. While sharing a significant concentration of metropolitan functions (translated into a high index of urban centrality), they are all different. In temporal terms, first and foremost, as those on the coasts and in the South are more behind with their metropolitan development process. But above from a spatial point of view, being either in the polycentric (or polycephalic linear areas) or monocentric (or monocephalic circular areas) category. Similar to corridors (or meta cities), the former have a more widespread urban fabric, a consequence of peri-urban development (less in monocephalic areas) and complex interaction between the hubs that goes beyond simple dependence. Apart from the spatial and temporal differences, however, the borders of all the metropolitan areas do not coincide with those of their administrative bodies. In almost all cases, these include parts of different provinces (and in two cases, even those of different regions) and only in three provinces do the metropolitan areas include the entire territory.

Despite complex urban areas having a lower demographic consistency than that needed for them to be included in the category above, urban areas have been noted with a strong metropolitan vocation (due to their demographic proximity or to their high urban centrality index value). Analysis of dynamics over this twenty-year period has also shown the presence of processes of metropolitan assimilation, in terms both of territorial expansion of some areas and also of their gradual coming closer. It will be interesting to observe from the next Census data if continuation of these processes leads to the formation of new metropolitan areas and if the latter are the result of expansion or of a union of existing areas.

Socio-demographic and economic analysis of the societies that live in metropolitan areas confirmed the hypothesis of the presence of a younger, educated, employed and advanced tertiary structure (and within this in the more economically dynamic sectors). Differences compared to the rest of the country were, however, smaller than expected due to the low level of homogeneity between and within the areas. Within the areas, first, due to the different socio-demographic and economic structure of their parts (core, sub-cores and sub- and peri-urban areas), the differences between which, not considered in this survey, open up the field to various interesting research topics. Between the areas, second, due to the effects that the traditional geographic differences continue to have on the social and economic structure of metropolitan areas.

Regardless of the geographic location, all the metropolitan areas are, however, characterised by the presence of heavy mobility flows. The high interdependence that exists between the functions in their territory is confirmed by the consistency of both flow density and inter-municipality mobility. More than an accessory function that supports the other activities, mobility is a fundamental dimension of metropolitan areas, helping to define the shape of the area and draw its borders. 
In order for this variable to offer explanations, knowledge is required about journeys for purposes other than work and study. The latter research topic is therefore added to those mentioned above as a means of producing a complete picture of the metropolitan reality in Italy.

\section{References}

Acquarone, A. (1961). Grandi città e aree metropolitane in Italia. Bologna: Zanichelli.

Ardigò, A. (1967). La diffusione urbana. Roma: AVE.

Balducci, A. (2006). Una visione per la Regione Urbana Milanese. In AA.VV. Milano nodo della rete globale. Un itinerario di analisi e proposte (pp. 231-264). Milano: Bruno Mondadori.

Barbagli, M., \& Pisati, M. (2012). Dentro e fuori le mura. Città e gruppi sociali dal 1400 a oggi. Bologna: Il Mulino.

Bartaletti, F. (2009). Le aree metropolitane in Italia e nel mondo. Il quadro teorico e i riflessi territoriali. Torino: Bollati Boringhieri.

Boatti, G. (2008). L'Italia dei sistemi urbani. Milano: Electa.

Boeri, S., Lanzani, A., \& Marini, E. (1993). Il territorio che cambia: ambienti, paesaggi e immagini della regione milanese. Milano: Abitare Segesta.

Boffi, M. (2004). Scienza dell'informazione geografica. Bologna: Zanichelli.

Boffi, M., Colleoni, M., \& Palvarini, P. (2012). A Gis methodology for defining the metropolitan areas. The Italian case study. In M. Campagna, A. De Montis, F. Isola, S. Lai, C. Pira, \& C. Zoppi (Eds.), Planning support tools: Policy analysis, implementation and evaluation proceedings of the seventh international conference on informatics and urban and regional planning INPUT (pp. 1847-1859).

Cafiero, S., \& Busca, A. (1970). Lo sviluppo metropolitano in Italia. Napoli: Giuffrè.

Cafiero, S., \& Cecchini, D. (1989). Un'analisi economico-funzionale del fenomeno urbano in Italia. In D. Martellato \& F. Sforzi (Eds.), Studi sui sistemi urbani (pp. 69-105). Milano: Franco Angeli.

Calafati, A. G., \& Veneri, P. (2013). Re-defining the boundaries of major Italian cities. Regional Studies, 47(5), 789-802. doi:10.1080/00343404.2015.1048976.

Casacchia, O., Nuvolati, G., Piroddi, E., \& Reynaud, C. (2006). La statistica per le aree metropolitane e sulle aree metropolitane: proposta per un sistema informativo integrato. Roma: Presidenza del Consiglio dei Ministri, Commissione per la Garanzia dell'Informazione Statistica.

Castells, M. (1996). The information age: Economy, society and culture. Oxford: Blackwell.

Censis (2008). I pendolari d'Italia. Scenari e strategie, Roma.

Colleoni, M., \& Boffi, M. (2014). Nuova morfologia della mobilità e politiche urbane. In A. Calafati (Ed.), Città tra sviluppo e declino. Un'agenda urbana per l'Italia (pp. 401-421). Roma: Donzelli Editore.

Colleoni, M., \& Caiello, S. (2013). Il peri-urbano e i suoi caratteri socio-territoriali. Una proposta analitica e empirica in Lombardia. Sociologia Urbana e Rurale, 102, 97-115. doi:10.3280/ SUR2015-106001.

Colleoni, M., Castrignanò, M., \& Pronello, C. (2012). Muoversi in città. Accessibilità e mobilità nella metropoli contemporanea. Milano: Franco Angeli.

Ercole, E., \& Zonta, M. (1991). Le dinamiche delle aree metropolitane italiane: le trasformazioni nel periodo 1961-1989. Amministrare, XXI(3), 447-470. doi:10.1442/78839.

Eurispes (2014). Libro bianco sulla mobilità e i trasporti. Osservatorio sulla mobilità e i trasporti, Roma.

Hall, P., \& Hay, D. (1980). Growth centres in the European system. London: Heinemann.

Istat (1994). I sistemi locali del lavoro in Italia 1991, Roma. 
Istat (2005). Distretti industriali e sistemi locali del lavoro 2001, Roma.

Istat (2011). Censimento della popolazione e delle abitazioni, Roma.

Martinotti, G. (1993). Metropoli. La nuova morfologia sociale della città. Bologna: Il Mulino.

Martinotti, G. (Ed.) (1999). La dimensione metropolitana. Bologna: Il Mulino.

Palermo, P. C. (1997). Linee di assetto e scenari evolutivi della regione urbana milanese. Atlante delle trasformazioni insediative. Milano: Franco Angeli.

Thurstain-Goodwin, M., \& Unwin, D. (2000). Defining and delineating the central areas of towns for statistical monitoring using continuous surface representations. Transactions in GIS, 4(4), 305-317.

van den Berg, L., et al. (1982). Urban Europe: A study of growth and decline. Oxford: Pergamon. Vicari, S. (Ed.). (2013). Questioni urbane. Caratteri e problemi della città contemporanea. Bologna: Il Mulino.

Wirth, L. (1938). Urbanism as a way of life. American Journal of Sociology, 44, 1-24. 


\title{
Mobility Practices in Peri-Urban Areas: Understanding Processes of Urban Regionalization in Milan Urban Region
}

\author{
Paola Pucci
}

\begin{abstract}
The paper focuses on mobility patterns as experienced in Lombardy peri-urban areas to investigate whether and if so how new processes of urban regionalization, (Soja in New companion to the city. Wiley-Blackwell, Cambridge, pp 679-689, 2011; Brenner in Towards a study of planetary urbanization. Iovis Verlage, Berlin, pp 14-27, 2013a; Brenner in Implosions/explosions: towards a study of planetary urbanization. Iovis Verlage, Berlin, 2013b; Young and Keil in Cities 27:87-95, 2010) can be better understood through a reorganization of mobility practices and the emergence of new geographies of movements. Some research evidence suggests that patterns linked to mobility, consumption and lifestyles in peri-urban areas are changing quickly, challenging the way we conceptualize the relationship that European city central areas entrain with their outer areas and suburbs. In the international literature on the subject, it is widely acknowledged that changing socio-economic conditions are calling for a parallel readjustment of the approaches adopted to assess such phenomena. This to a certain extent has been done; nonetheless, knowledge in the field remains fragmented and scattered across a number of disciplinary domains. In order to make sense of the evidence generated on mobility practices in peri-urban areas, this chapter investigates the diversity of mobility practices characterizing such areas in the Milan urban region (North Italy), highlighting possible transformative scenarios.
\end{abstract}

Keywords Peri-urban areas - Spatial mobility - Urban regionalization • Mobile phone data $\cdot$ Milan urban region

P. Pucci $(\square)$

DAStU, Politecnico Di Milano, Milan, Italy

e-mail: paola.pucci@polimi.it 


\section{The Peri-Urban Areas as Research Field on the Transformations in Contemporary City}

Peri-urban areas feature a multiplicity of spatial and social dynamics, which often differ from place to place. Such dynamics are the product of specific legislative, planning, cultural, economic, social and political traditions, and are hence closely bound up with their local histories. Here consolidated habits linked to our way of commuting, living and consuming are progressing, giving way to new practices, only partly comprehensible on the basis of some of the internationally available theories and conceptualizations. Also for this reason, various names have been proposed for these places in which traditional logics of urban space are reconfigured (Keil 2013; Brenner 2013b; Young and Keil 2010; Walks 2013).

At the same time, peri-urban areas tend to share some key features that have by now attracted the attention of researchers and policy analysts alike (Nilsson et al. 2013; Tosics 2013; Phelps and Wu 2011).

Mostly due to recent widespread decentralization processes, peri-urban areas are places where a considerable quantum of growth tends to occur, ${ }^{1}$ accompanied by socio-economic changes modifying their characteristics and transforming their relations with the central urban areas, with clear effects also on mobility practices in terms of "commuting transition" (Sultana and Weber 2014), with rapid increases in commuting time followed by gradual decreases, ${ }^{2}$ accompanied by a multi-skilled and hyper mobility, related to leisure and personal travels.

These spaces bring institutional boundaries into tension and highlight the need for more effective redefinition, offering a test ground to evaluate the effectiveness and impact of policies recently enacted to contain urban sprawl, ${ }^{3}$ to influence car dependency and the modal split in favour of more sustainable transport modes.

If considerable territorial and urban transformation processes could be observed in peri-urban areas, efforts to identify the key lines of this urbanization process, which covers a wide variety of situations both spatial and social, have led some authors to reconsider the concepts and notions commonly used to comprehend and study them.

Indeed, arguing in favour of the new definition of the "urban", some scholars (Sennet 2007; Keil 2013; Brenner 2013a) have inspired new conceptualization of the peri-urban spaces, conceived not simply as transitional areas located between town and country, but rather as new and emerging forms of 'urbanity', that bring into play new lifestyles, new mobility behaviours and new urban issues.

\footnotetext{
${ }^{1}$ See Intra Urban Dynamics in Espon FOCI Report 2010, Urban Audit.

${ }^{2}$ According to Sultana and Weber (2014) study on commuting patterns, peri-urban areas of recent residential growth in American cities have longer commuting times than other parts of the city; furthermore, and parallel with the ageing of this areas, commuting time will go through a predictable commuting transition.

${ }^{3}$ Among those, the "retrofitting" of suburbs through the densification of residential areas in and around existing or new public transport hubs.
} 
With the trans-scalar nature of the urban trends, centrality is becoming diffuse, and emancipation from distances results in the disappearance of boundaries between town and country, the centre-periphery model becomes obsolete, while new trends in lifestyles have allowed for the emergence of centralities diffused throughout all spaces. All this overturns the "peri-urban question", calling for a "new vision of urban theory without an outside" (...) "to supersede the urban/non urban divide that has long anchored the epistemology of urban research" (Brenner 2013a, p. 15).

In this direction, the post-metropolis concept brought in by Soja (2011) as a "new phase of multi-scalar regional urbanization" (p. 680), and the "in-between spaces" by Young and Keil (2010) in a re-conceptualisation of the Sieverts' work (2003) on the emerging patterns of urbanization and the connections between various aspects of urbanity in the urban regions, as well as the socio-spatial transformations in planetary urbanization (Brenner and Schmid 2013, p. 161) help to clarify the meaning and significance of these multidimensional evolving processes.

The multiplicity of "peri-urbanisms" is related to the diversity and plurality of peri-urban living (Dodier 2013), which are reflected in various practices of mobility.

In this "spatial turn" (Warf and Arias 2009), in which "density convergence plays a key role in the emergence of a distinctive new urban form" (Soja 2011, p. 684), peri-urban areas emerge as vectors of experimentations on the basis of their "mutability" (Dias et al. 2008), and their resilience related to an increasing complexity of homework mobility, overcoming the centre-periphery model and the dependency on one or several city centres.

Enhancing, on the one hand, the contribution of Italian and French research on peri-urbanism and its different forms, and on the other hand following in a line of studies on mobility ${ }^{4}$ as "part of the process of social production of time and space" (Cresswell 2006, p. 5), as useful fact-finding tool to describe urban transformations, this chapter proposes a comparative analysis of some peri-urban areas characterized by specific processes of urban sprawl, differentiated by age, morpho-functional features and settlements within the Milan urban region.

The hypothesis to investigate is whether and if so how the specificity and diversity of the processes of urban sprawl belonging to different "generations" of peri-urbanism in Lombardy affect the forms of mobility and lifestyles, showing different living habits and specific issues.

In our proposal, the international literature background is a framework taken critically on the basis of long research into the forms of peri-urban dispersion in Italy (Indovina 1990; Dematteis 1992; Secchi 1992, 1994; Lanzani 1991) and

\footnotetext{
${ }^{4}$ According to an established literature (Urry 2000; Kaufmann 2002; Cresswell 2006; Sheller and Urry 2006), presented also in the first chapter of this book, spatial mobility is a key to understand the transformations in contemporary city, as socio-spatial phenomenon capable of describing urban practices and their rhythms.
} 
indeed on the basis of interpretations of the different "generations" and "families" of peri-urban areas in Italy (Lanzani 2003; Clementi et al. 1996; Bianchetti 2000).

From the second half of the 1970s, these processes assumed in Italy, three different forms (Lanzani 2011):

- processes related to settlement growth in the most peripheral areas in metropolitan regions; marginal until the 1980s, they become significant in Italy, in the following years;

- a metamorphosis in the rural areas characterized by the presence of small and medium towns and medium-small factories, with strong integration between workplace and home places summarized also in specific forms of organization of the house (the so-called "casa-fabbrica") and major daily mobility dynamics related to the disarticulation of the industrial production cycle;

- reconstruction of a settlement system along the Adriatic coast (Marche and Abruzzo Regions) and the valley floor.

While these processes constitute the specificity of the Italian case, the 1990s mark a qualitative and quantitative transformation. New logics emerge from the principles of "minimum rationality" that had characterized the previous period: it is a matter of densification in spaces inside the metropolitan areas (minority part in 80 years), with a trivialization of the dispersion process, now linked to the dissemination of the single-plot house.

The "plural nature" of peri-urban areas in Italy and their evolution over time provide a specific framework for interpreting the changes in the urbanization process which, in other countries, can be mainly attributed to a shift from the typically monocentric dualism of dense city and sprawling low-density suburbanization to a polycentric network.

In this context, specific settlement conditions will be investigated through the transformations in mobility patterns. Our interest lies in visualizing the flows of mobility in the Milan urban region, but also in describing the experiential dimensions of commuting rhythms.

The argument is that commuting can be considered a mobile practice (Edensor 2011, p. 189) that exploits a rich variety of places of use in accordance with the temporal organization of a day, linked not only to fixed events (employment), but also to other activities.

Based on this, the transformations of peri-urban areas will be examined starting from the geographies of the mobility practices, and studied with quantitative data derived from official sources (surveys on systematic and unsystematic mobility, through the construction of synthetic indicators), as well as with mobile phone data provided by Telecom Italia.

These data enable us to describe the spatial and temporal variability of urban practices, in order to investigate how mobility practices are related to the transformations occurring in the peri-urban areas of the Milan urban region.

In these territories, through mobility patterns we seek to comprehend the "post-metropolis" plurality of forms and conditions, the relationships between 
mobility patterns and the urban, social and economic persistent divergences and specificities of the different settlement contexts.

Studied diachronically, the consolidated and the emerging mobility practices in peri-urban areas, reflecting upon specific thematic foci related to their geographic location, constitute an effective tool to highlight the scenarios of innovation which the mobility policy and transport services in peri-urban spaces are calling for. The mobility transition (namely new mobility patterns in commuter mobility) also allows to understand the fluidity of the boundaries, on the basis of the urban practices and their variability in space and time.

\section{A Kaleidoscope of Peri-Urban Spaces in the Milan Urban Region}

The various forms of peri-urbanization inside the new urban configurations emerging to increasing attention and prompting new debates in the international literature, have long been an object of study in the Italian literature. According to Bianchetti (2000), reflection on the sprawled settling in Italy followed three research perspectives:

- The "Città diffusa" model (Indovina 1990), in which dispersion is a direct result of processes of accumulation and distribution of wealth. The increase in residents' income led to the growth of residential and production buildings to improve individual conditions. In this perspective, the dispersion may become a "città diffusa" only if it is enriched with functions and services to improve its liveability;

- Urban Dispersion, analysed as the "shaping of individual rationality" (Secchi 2008), as individual responses to the problems of living and producing. In this interpretation, the dispersion reflects the degradation of the collective dimension of the common goods and the affirmation of the individual and private needs;

- Urban Dispersion as use-waste-redevelopment of the ground. According to this interpretation, the dispersion is a problematic condition for natural resources, as well as for the social capital.

Different interpretations of the phenomenon describe also the evolutionary forms of dispersion in Italy, leading to the superseding of the dichotomous centre-periphery model, because it was not able to explain the complexity of the urbanization forms and processes over the years.

In this context, also the Milan urban region, an extensive area which goes beyond the institutional borders of the metropolitan city of Milan ("Città Metropolitana di Milano"), is an alternative territorial organization to the metropolitan area, characterized by a more complex model of settlement, where a variety of places with socio-economical, functional and settling specifications emerge. 
This complex model of settlement has long been described by studies ${ }^{5}$ which have highlighted the presence of different urban systems, each with a distinct identity and then with a capacity of autonomous dynamics, governed by its own rules (Lanzani 1991). These interpretations have enabled us to overcome a hierarchical representation of the relationship between small/medium urban centres and Milan, in favour of a polycentric structure of the Milan urban region.

Indeed, the identification of a "territory in the plural" (Lanzani 1991) in the Milan urban region comes from research that, in the second half of the 1980s, studied the territorial transformations with analysis of socio-economic dynamics, urban settlement and open space morphologies, as well as of urban behaviours and practices of different populations who live, work and move in these territories.

These studies produce images with two different meanings: images as interpretations of urban transformation processes and images as "visions", useful for strategic spatial planning.

The result is a kaleidoscopic vision of the territory made up of following:

- Milano and the nearest municipal districts with high densities and the presence of important services and equipment for metropolitan populations;

- the rural South where the major urban dynamics in the last twenty years have changed the old agricultural vocation, following a sprawled settlement model;

- the West part (Magentino and Castanese) characterized by a polycentric and reticular settlement structure;

- the Brianza Milanese, in the Northern of Milan, with an historical and specialized industrial tradition (furniture district, textile system) which is now decreasing and characterized by dense urbanization, organized in the North-Western side of the region, along the historical infrastructure corridor constituting urban continuum (i.e. the Sempione road);

- the North-East part - the Vimercatese area - characterized by more recent settlement with low territorial density and extensive green open spaces, improving the environmental quality.

The complex geography of the territories in the Milan urban region, confirmed by the dynamics of daily mobility, eludes the institutional boundaries of urban and mobility policies (Fig. 1).

The daily mobility trends show a widened, dense and extensive use of the territories in the Milan urban region where the multi-directional mobility reflects a complex network of the relationships and places densely used: the increase in the transversal movements (orbital moves) defines a non-hierarchical system of relationships, even more in the dynamic areas (Fig. 2).

This dense and complex use of the territory is a consequence of a transformation in mobility behaviours: the obliged movements (work and study travel), characterized by fixed schedules and defined paths between an origin (home) and a

\footnotetext{
${ }^{5}$ About these: Boeri et al. (1993), Lanzani and Prusicki (1995), Clementi et al. (1996), Lanzani (2003), Balducci et al. (2011).
} 


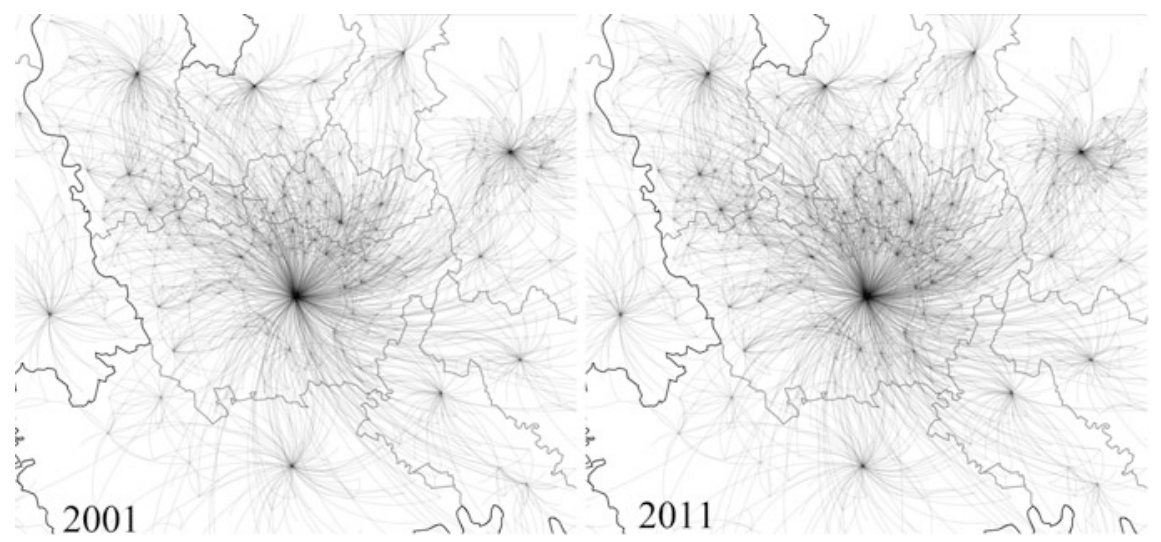

Fig. 1 Commuter flows $>100$. In gray the administrative boundaries (Source Dastu elaboration of Istat data)
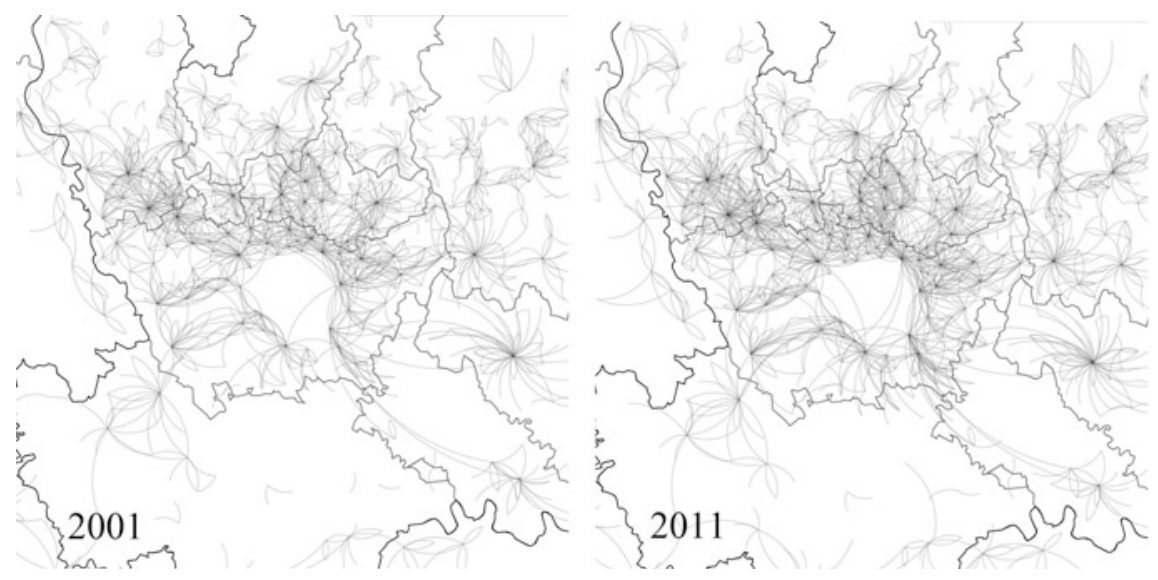

Fig. 2 Growing network of less hierarchical commuter flows inside dynamic places. Flows $>100$ have been mapped, excluding flows for and from regional cities (Source Dastu elaboration of Istat data)

destination (job/school), decrease in favour of growth in much more articulated movements in time and space, related to personal reasons, leisure time and purchases. $^{6}$

\footnotetext{
${ }^{6}$ Based on the Regional survey (2014) in Lombardy Region, the commuter flows are $22 \%$ of the daily mobility flows (they were $25 \%$ in 2002). In the last decade, the occasional displacements increased (24\% in 2002; $26 \%$ in 2014) (Regione Lombardia, 2002 and 2015).
} 
The chain of daily moves ${ }^{7}$ becomes more articulated; the daily rush hours are dilated ( $22 \%$ of the journeys are between 7 and 9 in the morning), and the average time of displacement increases ( $1 \mathrm{~h}$ and $6 \mathrm{~min}$ on average), due partly to traffic congestion.

If the difference of employment contracts, the diversification of the social time, as well as the weakening of the institutional ties (the timetables of work, school, public services and commercial concerns), produce an overlap between the time of the production, the time of the consumption and leisure time, the consequences of these transformations are recognizable in the daily mobility, describing "an archipelago" of places and relationships in Milan urban region.

At the same time, the economic crises have had repercussions on the commuting flows: mobility for work is growing faster than revenues. The density of movements increases more than the average income per capita, especially the outflows from the home municipalities. ${ }^{8}$

More than $50 \%$ of the employees work in a municipality where they do not live. This process of progressive estrangement between workplace and home place may be due to a residential migration from the Milan core area that has mainly affected towns in the South of the Milan urban region, where construction activity has been intense, with predominantly low-density settlements, characterized by marked functional specialization (residency), often accompanied by few or no services and by a standardized time of use. A further explanation may be sought in the effects of the economic crisis in the labour market that led to a lengthening of work-journeys, producing a growth in the average times of displacement, ${ }^{9}$ due to an increase in the average distances between work-place and home-place. This trend affects also some industrial districts and local production systems where the historic integration between residence and work ${ }^{10}$ dissolves, compared to growth in the job-dependence from other areas. ${ }^{11}$

A progressive weakening of local industrial system, characterized by a productive specialization and, up to now, with close integration between workplace and home place, is accompanied by dynamic trends in the surrounding areas of Milan where mobility increases in proportion to the attractiveness of the job supply. The stable equilibrium of the Milan-bound commuter flows, after a previous decade

\footnotetext{
${ }^{7}$ The daily average trips were 2.65 trips/day in 2002 and 2.5 trips/day in $2014.91 .2 \%$ of the sample performed two displacements sequentially (Regione Lombardia, 2002 and 2015).

${ }^{8}$ Commuter flows between 2001 and 2011 boost (+9.2\%), supported by a significant increase in outflows $(+19.8 \%)$, compared with a decline of internal flows in each municipality.

${ }^{9} 14 \%$ of the daily commuting in Milan urban region is characterized by a travel time over $60 \mathrm{~min}$ (Lombardy regional average is $8.9 \%$ ). Of these flows, $75.6 \%$ are outflows ( $88.2 \%$ in Lombardy). On the contrary, the flows under 15 min of travel time significantly decreased $(-42.6 \%)$.

${ }^{10}$ This is calculated with self-containment index, as ratio between internal flows and all the employed in each municipality.

${ }^{11}$ This trend affects especially the "Pedemontana" area in the North of Milan (along Varesina and Sempione roads), and in the North-East (as Magentino and Castanese), where, in the previous decade, there were high values of integration between home and work places.
} 


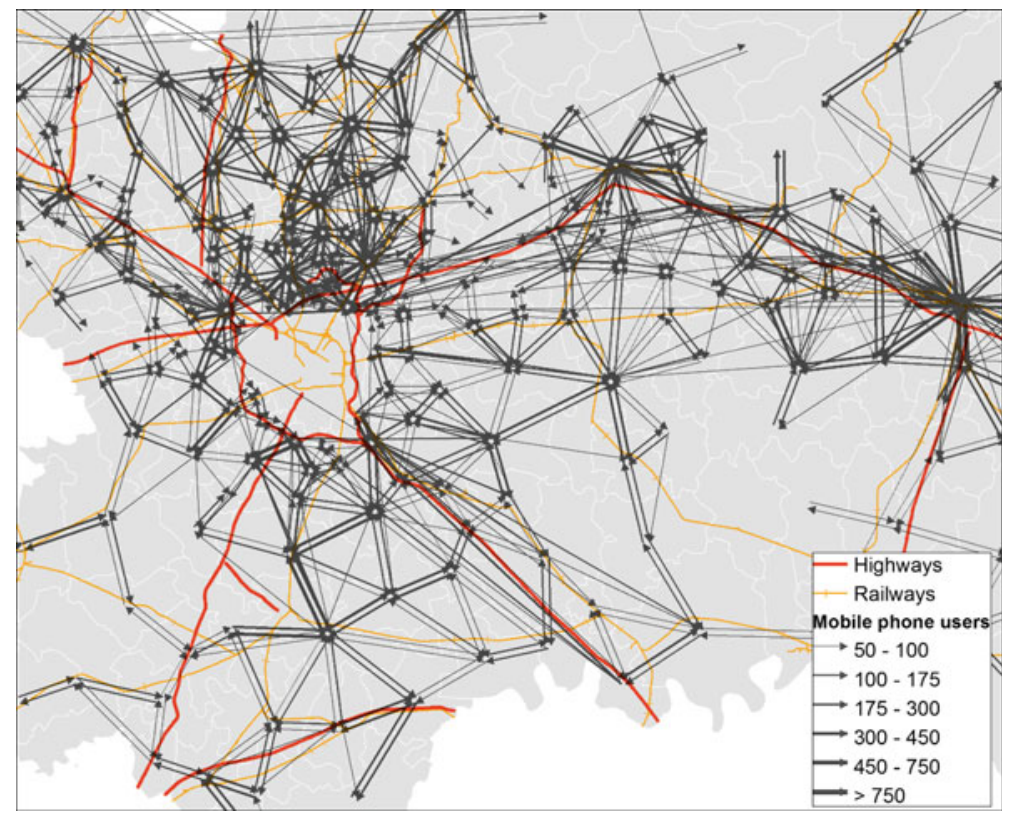

Fig. 3 Origin-destination flows of mobile phone users: 5 p.m., 19-10-2011 (Source Pucci et al. 2015)

(1991-2001) characterized by a reduction of the catchment area of the capital ${ }^{12}$ in favour of dynamic external territories, confirms a kind of faint "return to the centre". 13

Matching these results with the maps processed with mobile phone data (Pucci et al. 2015), we can observe the daily time in the density of flows (Fig. 3) related to individual habits as an effect of the diversified uses of the Milan urban region. These maps show how complex daily mobility patterns modify the hierarchical structure of the Milan urban region, revealing an increasing number of places frequented during the day as well as diversified ways of use reflecting daily life and job requirement transformations.

These general trends take on different forms and intensities, confirming multiple geographies in Milan urban region, out of the binary discourses centre/peripheries.

\footnotetext{
${ }^{12}$ The commuter flows attracted by Milan from the municipalities in Milan urban region were in decline between 1991 and $2001(-12.1 \%)$, and steady between 2001 and $2011(-0.04 \%)$.

${ }^{13}$ Milan catchment area - calculated as a percentage of commuter flows to Milan on total outflows generated by each municipality, excluding Milan - indicated in 2001 that $10.6 \%$ of outflows had as destination Milan, as compared with $8.13 \%$ in 2011.
} 


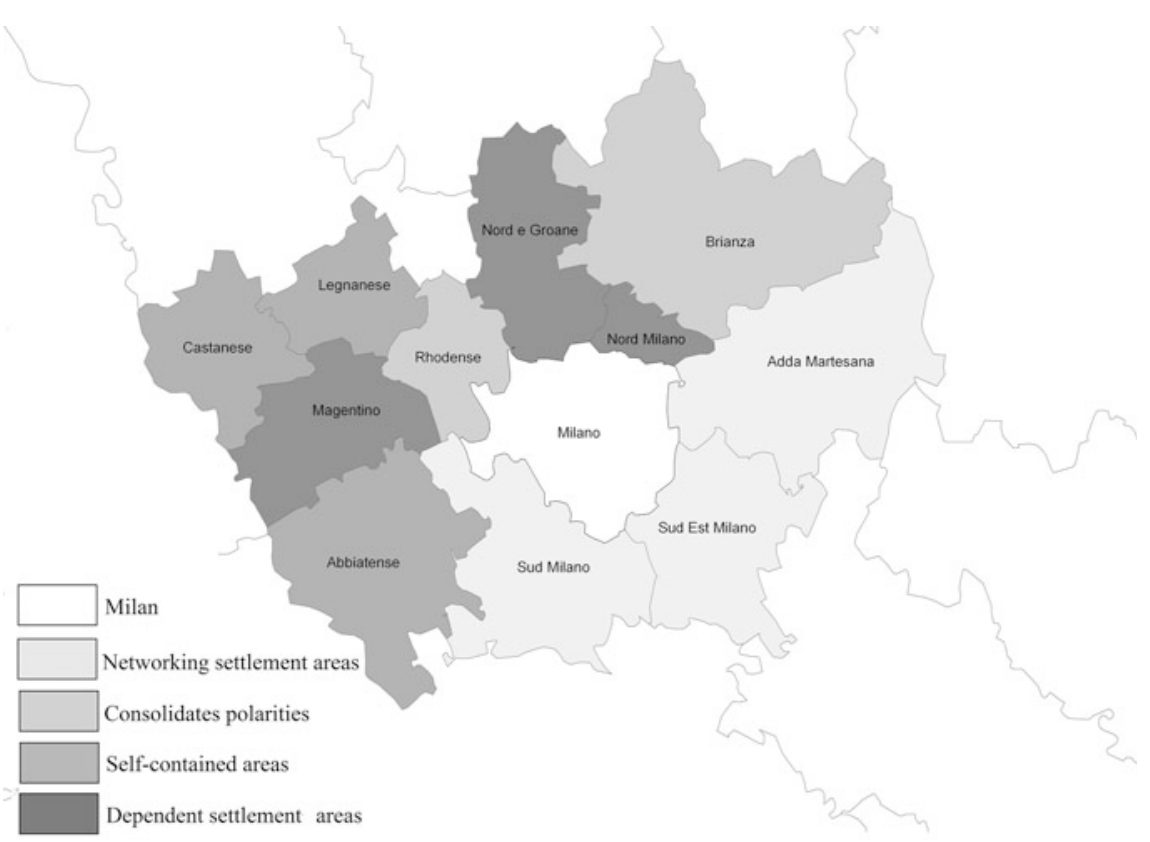

Fig. 4 Mobility profiles in the settlement areas of Milan urban region

Through correlations between mobility index at the municipal level ${ }^{14}$ emerge (Fig. 4):

- Networking settlement areas, characterized by attractiveness, not hierarchical and "orbital" movements (not Milan oriented), especially in the North-East;

- Consolidated polarities with the long-distance relationships near the standing out of secondary poles in the organization of the territorial settlements of the Milan urban region;

- "Self-contained" areas in terms of the job-related travel, in which the integration in the life spaces and between the residence and the workplaces is still good, even if it has been decreasing in the last decade, and where the territorial organization is characterized by a system of urban areas with qualified services;

\footnotetext{
${ }^{14}$ Processed index are: Self-containment index calculated as ratio between internal flows and the employee in each municipality; this index shows the level of integration between workplaces and home places at the municipality level. Mobility index is calculated as ratio between internal flows + outflows and the employees in each municipality. This index shows the density of displacements at the municipality level. Dependence index is calculated as ratio between the outflows and the employees in each municipality. This index shows the level of dependence for the offer of employment from other municipalities. The index of attraction is calculated as ratio between the inflows deducting the outflows and the employees in each municipality. This index shows the level of polarization and attraction for the supply of employment at municipality level (Pucci 2010).
} 
- Dependent settlement ambits where the employment depends on the other territories, notably on Milan city; they are well-connected areas in terms of public transports' networks to Milan and they have seen considerable transformation in the industrial activities as from the 1980s.

Among these different urban contexts, two generations of urban dispersion can be identified as characterized by different morphological, functional and socio-economic features, defined in distinct phases.

Brianza, the Northern area between the cities of Como, Lecco and Monza, due to its historical development, is characterized by an autonomous and flourishing industrial and economic sector. From their origin, these industrial districts have produced a peculiar industrial model with remarkable impacts on the urban settlement, distinguished by a network of urban centres without a single core. The peri-urban features in this territory are defined not only by a medium population density and scattered settlements with a high car dependence and commuting for studying and working, but also by close integration between services (health, education, infrastructures), housing, industrial and commercial plots. A large-scale widespread presence of urban facilities, enhancing closeness between dwelling, workplace and urban services, ensures everything a "city" can offer.

Therefore, this historical polycentric structure where a lot of transformations have occurred and are still in progress, ${ }^{15}$ is today marked by the effects of the decrease of production and unemployment, as well as the closure of many factories and commercial activities, with several urban and mobility changes. These transformations bring into crisis this integrated and networked system.

Another type of peri-urbanism, defined by recent urban settlement processes, is recognizable in the South of Milan urban region, where a widespread urbanization brought about by single-plot dwellings which occurred in the last 20 years, is transforming the rural profile of this area. This is a medium-density area where the urban sprawl has been generated by new inhabitants who mainly work in Milan.

The car mobility is reinforced by the lack of a public transport system and by a low density of railway stations, often inaccessible and poorly equipped (in terms of passenger services, public transport interchange and parking). This area, where agriculture was preserved by the creation of an Agricultural Park (Parco Agricolo Sud Milano), is under transformation through two contradictory processes: on the one hand, spontaneous processes and outstanding "overload" of metropolitan functions from the Milan urban core (housing, shopping malls and business districts), especially along the ring road and in the municipalities of the first belt; on the other hand, a rural landscape characterized by historical rural centres and farms continuing their activity in a more productive agricultural system, under significant pressure due to the growth in urban settlement over the past twenty years. The low urban density, the lack of services, together with an insufficient supply of public

\footnotetext{
${ }^{15}$ Industrial activities are being replaced by commercial and business settlement: big commercial centres, settlement of multinational labels and commercial parks, new shopping malls.
} 
transport make this area very similar to the more traditional models of suburbanization.

Given the diversity of their peri-urban contexts, due to urbanization processes occurring at different times and related to pre-existing structural conditions and to "path dependences", these two peri-urban areas represent a particularly promising field of analysis.

In these two "generations" of peri-urbanisms, we will study if, and if so how the "post-metropolitan regional model" (Soja 2000, 2011), characterized by new urban density gradients, transforming the relationships between peri-urban areas and metropolitan core, is recognizable and can be interpreted as "an accelerated re-organization and restructuring of the geography of movements that define the spatiality of human societies" (Soja 2004, p. 176).

\section{Methodology}

Based on the features of the process of regional urbanization by Soja (2011) density convergence, growing cultural and economic heterogeneity, social and political polarization - as well as the importance of the flows in the definition of in-between spaces (Young and Keil 2010), our study first tested correlations between housing density and mobility density, and then selected some micro-scale areas (e.g. neighbourhoods) to analyse the variability of the space-time practices, through mobile phone data.

The approach integrates traditional data (commuting national survey in 2001 and 2011, O/D matrix by the Lombardy Region in 2002 and 2014) with mobile data network provided by Telecom Italia company. ${ }^{16}$ With the construction of daily mobility indicators, ${ }^{17}$ it was possible to select some urban neighbourhoods to compare the density and variability of mobile phone traffic (Erlang date) with demographic and socio-economic data.

In these investigations, aggregated mobile phone data are the result of individual behaviours and habits. Hence, they offer information on the time space uses of the urban spaces. The processing of such data (Erlang and Origin/Destination flows by

\footnotetext{
${ }^{16}$ Two types of mobile phone data are processed: Erlang and O/D Matrix. Erlang is a dimensionless unit used in telecommunications as a measure of the average number of concurrent contacts in a time unit. In our case, the data is a measure of mobile phone traffic intensity every $15 \mathrm{~min}$. They were supplied by Telecom Italia in spatialized form; starting from the traffic recorded by each cell of the network, the provider distributed the measurements, by means of weighted interpolations, throughout a spatial tessellation of the Region in $250 \times 250 \mathrm{~m}^{2}$. O/D matrix is an origin-destination datum, derived from the Call Detail Record database provided by Telecom Italia derived from localized and aggregated tracks of anonymized mobile phone users (Pucci et al. 2015).

${ }^{17}$ The processed indices are self-containment index, mobility index, dependence index, index of attraction and housing density. For an explanation, see Footnote 14 in this chapter.
} 
mobile phone activity) allows for visualization of the spatial distribution of mobility flows, highlighting the places where urban practices occur recursively, but also reflects the experiential dimensions of mobility practices (Pucci et al. 2015).

\subsection{Correlation Between Mobility Index and Housing Density}

For some years, authors and scholars have investigated the correlation between urban density and mobility, showing positions very far from each other with respect to the role that settlement density plays in the intensity of the daily commuting (Newman and Kenworthy 1996; Naess 2005; Gordon et al. 1991; Gordon and Richardson 1997; Richardson and Gordon 2001; Ewing and Cervero 2001, 2010; Echenique et al. 2012).

On the evidence of the role covered by density for interpretation of the dynamics of urban regionalization, we investigate whether there is a correlation between housing density (calculated as percentage of buildings with one and two floors) and mobility index (calculated as ratio between inflows + outflows and employees) at the municipality level in the Milan urban region.

Calculations, carried out on the Milan urban region, have pointed to four situations characterizing the municipalities and summarized in Fig. 5.

The outcomes prove the relationship between high mobility and low housing density: most municipalities with low housing density have high values of mobility (C quarter). Most of them are localized in the North-West of Milan urban region
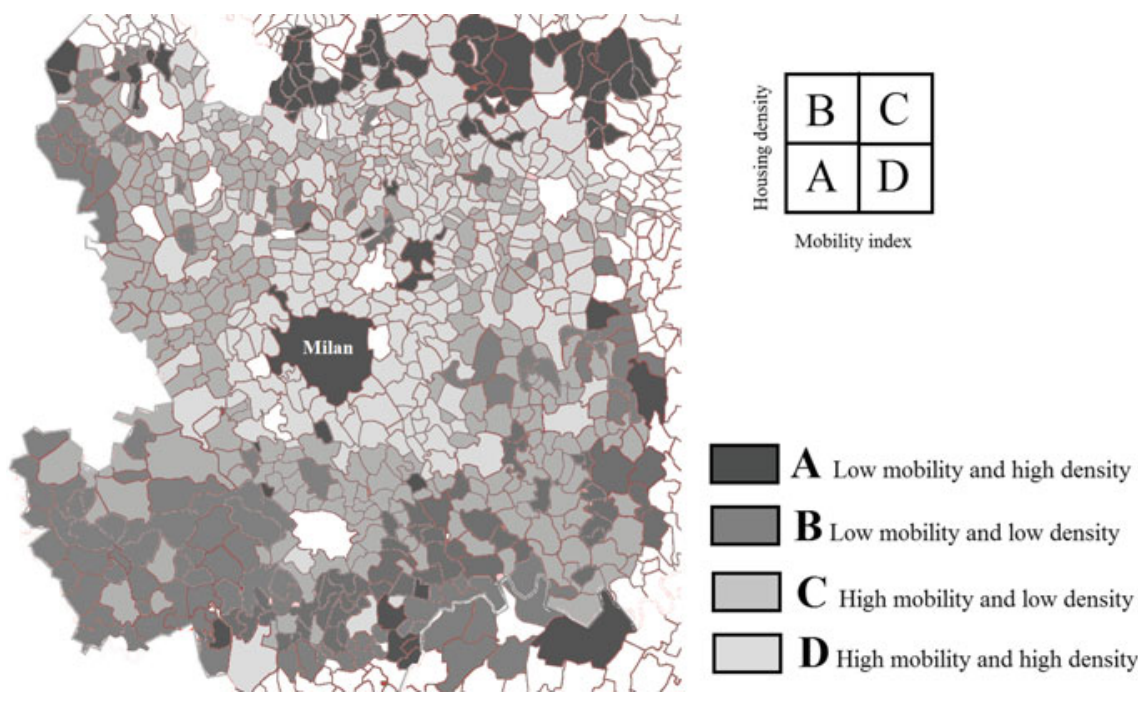

Fig. 5 Mobility index and density of housing settlement: four profiles 
(Castanese, Legnanese), and in the rural areas in the South-West (Abbiatense and South of Milan).

The municipalities with low urban density and low mobility (B quarter) are a few urban centres in the North of Milan (Brianza) characterized, in the last decade, by a stable trend in population and employees. The municipalities with high housing density and low mobility index (A quarter) show very different situations: there are attracting polarities like Milan, being characterized by a high internal mobility but a low value in outflows, and Monza, as well as Basiglio, a small municipality in the South of Milan with among the highest per capita incomes in Italy. This trend depends on the index of mobility, calculated as the sum of the internal and outflows from each municipality (ratio employees).

The municipalities with high values both in housing and mobility density (D quarter) are in the first belt around Milan and in the Western part of the Milan urban region (Magentino). In all of these territories, good road accessibility is provided by the motorways (except the municipalities in the North).

Going more in depth into the correlation between housing density and mobility, we considered as an indicator of mobility also the self-containment index (inflows/employees), with the aim of understanding if mobility generated by low housing density is attributable to internal mobility to each town, therefore related to a short-range mobility with good integration between workplace and home place.

The outcomes of these analyses enable us to identify different conditions, summarized in Fig. 6.

C quarter (high self-containment/low density) includes municipalities with low housing density and high short distance mobility, due to closeness between

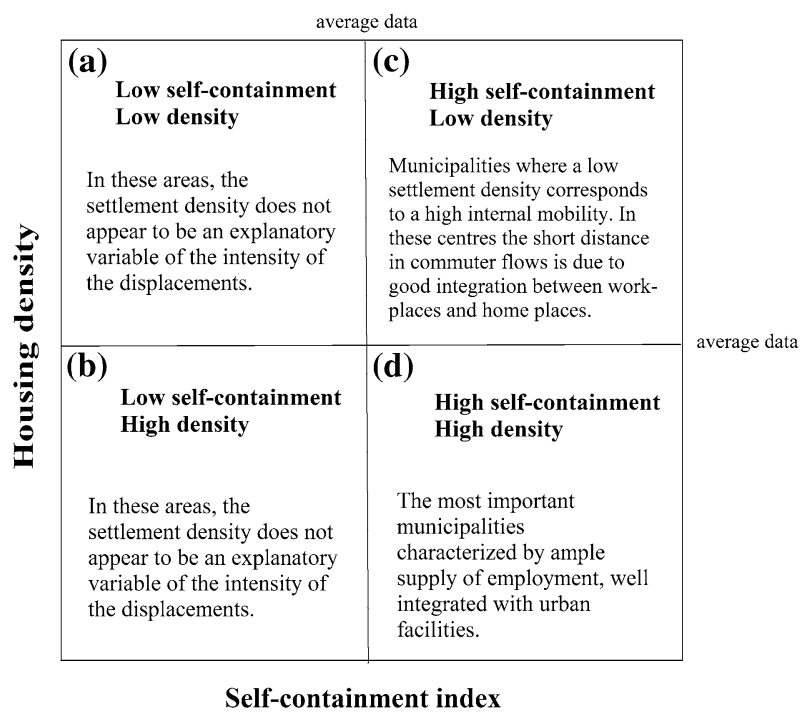

Fig. 6 Correlation between self-containment index and housing density 
workplace and home place. In this case, low housing density does not seem to be the reason for intensive work travel. This condition characterizes urban districts where historically the local production system has played an important role at the local and regional level (Castanese e Legnanese, and some municipalities in Brianza).

D quarter (high self-containment and density) regards municipalities with high settlement density as well as high density of internal flows. These are the main polarities in the Milan urban region, characterized by an ample supply of jobs and a high economic activity density, well integrated with the urban services (Milan, Monza, San Donato Milanese).

More complex situations are to be seen in A and B quarters, both characterized by a low density of internal flows, but different housing densities. In these cases, the settlement density does not appear to be an explanatory variable of the intensity of the displacements.

The analysis enables us to identify "several generations" of peri-urban areas in Milan urban region, with different evolutionary processes, even within the two areas of North and South Milan.

Both areas are now going through considerable transformation processes, related to the economic crisis and the restructuring of the local production system, reducing their urban and socio-economical complexity.

\subsection{Time-Space Variability of Urban Practices in Some Peri-Urban Neighbourhoods Through Mobile Phone Data}

Inside the municipalities characterized by low housing density and high values of mobility and belonging to different generations of peri-urbanism covering different periods of time, we selected some peri-urban neighbourhoods (Fig. 7), defined by various levels of integration between workplace and home place, influencing urban behaviour, life styles and the mobility practices of their inhabitants.

Within these different peri-urban neighbourhoods, using mobile phone data expressed in Erlang, we analysed the variability of trends on working days and during holidays. Elaborating the typical daily curves of mobile phone activity (Erlang from January to October 2009), the first hypothesis to verify was whether these areas, characterized by marked functional specialization (residency), often accompanied by few or no services and by a standardized time of use, showed specific and peculiar Erlang trends compared with other urban areas, in line with the profile of these contexts, almost exclusively residential and with a high percentage of working population.

The Erlang trends highlight in these peri-urban areas, different dynamics on weekdays (Wednesdays) and on Sundays, confirming the profile of these areas: they 


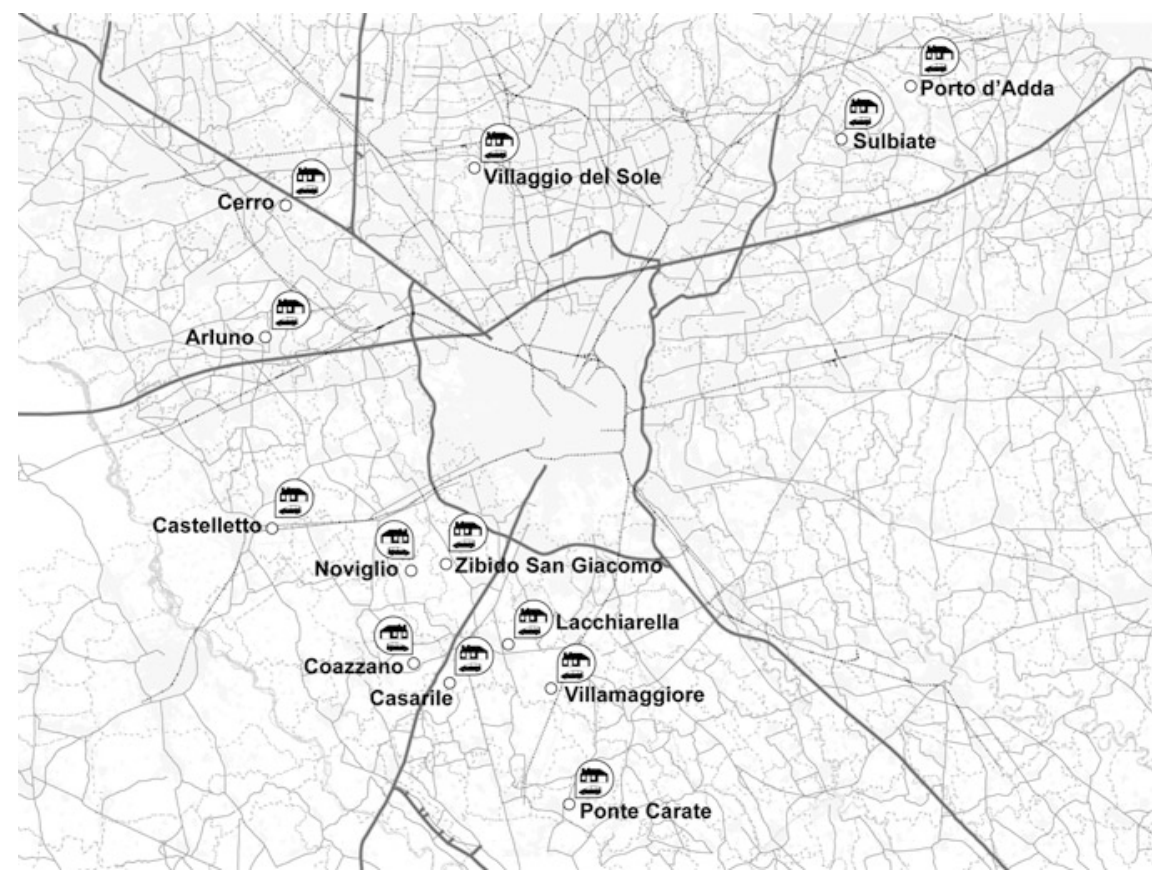

Fig. 7 Localization of the selected peri-urban neighbourhoods in Milan urban region

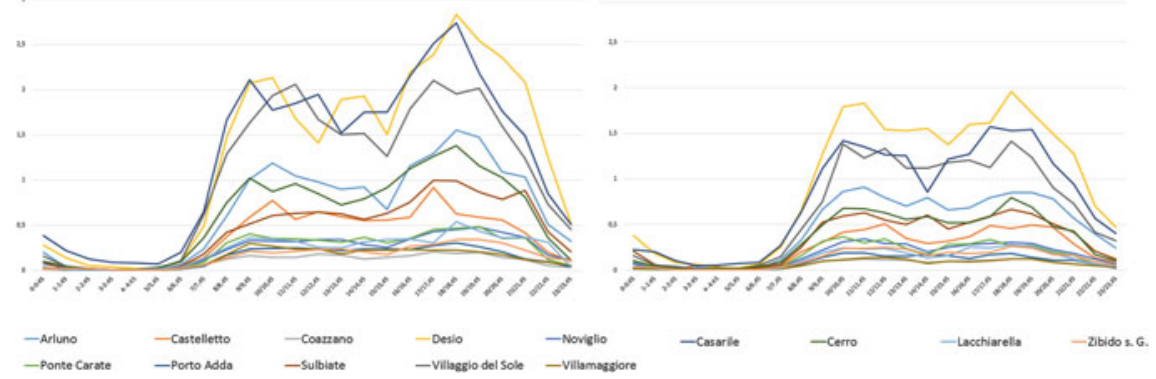

Fig. 8 Erland curves in weekday (Wednesday) and in holiday (Sunday)

are residential areas with a high percentage of the workers who, during the day, generally move to the workplace or school, and come back only in the evening.

The graphs (Fig. 8) clearly show similar trends in both the Southern and the Northern territories of the Milan urban region: the peak hours during morning and evening hours are more clearly visible during weekends when the amount of calling activity is much higher during the periods 9-12 a.m. and 7-10 p.m. Moreover, the 
different characters of the Northern and the Southern territories are also confirmed by the Erlang curves. For instance, calling activity in the Southern part of territory is much lower during weekdays and increases during holidays, whereas the North has strong calling activity throughout the week, implying that the population remains within their neighbourhoods; in other words, the selected areas in the Northern part of Milan urban region offer more choices in terms of urban facilities and services which keep the inhabitants around place of habitation.

During Sunday, higher values of mobile phone traffic are found, distributed fairly regularly throughout the day, although not related to the density of settlement. Comparing Erlang and statistical data, ${ }^{18}$ we see two extreme situations.

One of the least populous areas among those considered (Zibido in the South of Milan) is one that has a density of mobile phone traffic peaking on Sunday and falling on Wednesday. This trend may be related to the profile of this area, characterized more significantly than other areas by the presence of young population, by an equally high percentage of the population under 14 years, as compared to the residents over 55 years, who are under-represented. This area is a recent urban settlement characterized by single-plot houses and weak mixed land-uses.

The opposite situation - Cerro - is represented by the highest residential density in the urban context type considered, but with less intensity cell phone traffic on Sundays and indeed Wednesdays. These trends can be ascribed to the age profiles of residents (high density of population over 55 years).

Comparing the Erlang trend with the commuter out-flow data, in the areas with a strong dependence on other municipalities for the job market (i.e. with most significant commuter out-flow density during the working day), the density of the call activities always remains more intense on Wednesdays than on Sundays, although with different time profiles.

With socio-demographic profiles of the inhabitants, land-uses, as well as the age of buildings as the result of different processes of peri-urbanization, we can interpret the variability of the Erlang curves and relate them with different urban behaviours and lifestyles in our selected peri-urban areas.

The dynamics related to daily practices are ascribable to socio-economic and lifestyle transformations in peri-urban districts: the most recent urban settlement (Lacchiarella) is characterized by higher out-flow for work according to the inhabitants, which accounts for the low intensity of Erlang during working days compared with the other districts and with Sundays. On the contrary, the oldest urban settlement (Cerro) has the lowest value of outflows, confirming the "commuting transition paradigm" (Sultana and Weber 2014) due to the age of these areas (Fig. 9).

\footnotetext{
${ }^{18}$ The socio-economic data processed are: inhabitants by sex and age; socio-professional profile of population; foreign population; commuter flows; employees and economical activities. In addition: land-use and buildings uses, age of the buildings.
} 


\section{- Zibido San Giacomo}
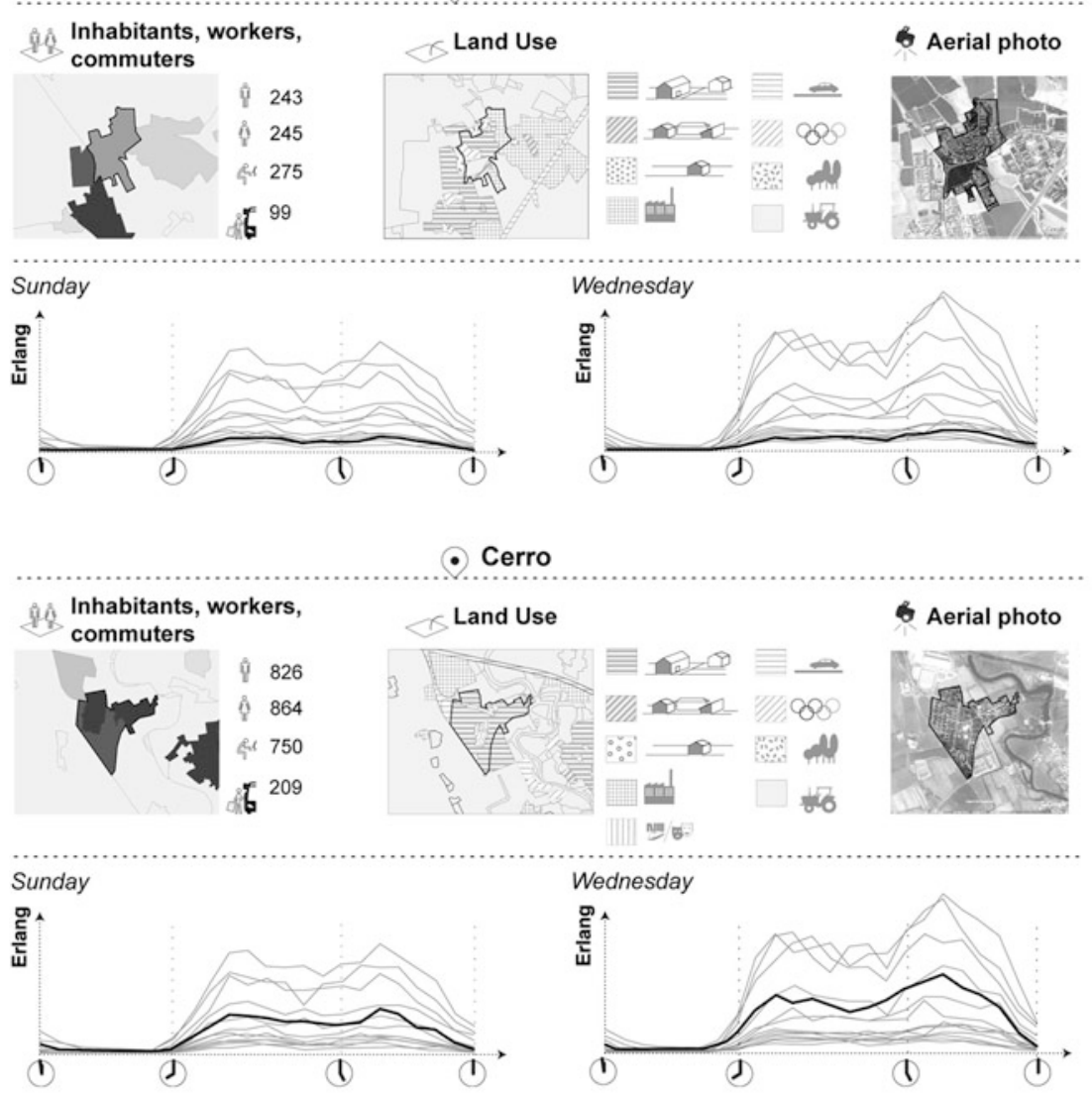

\section{- Lachiarella}
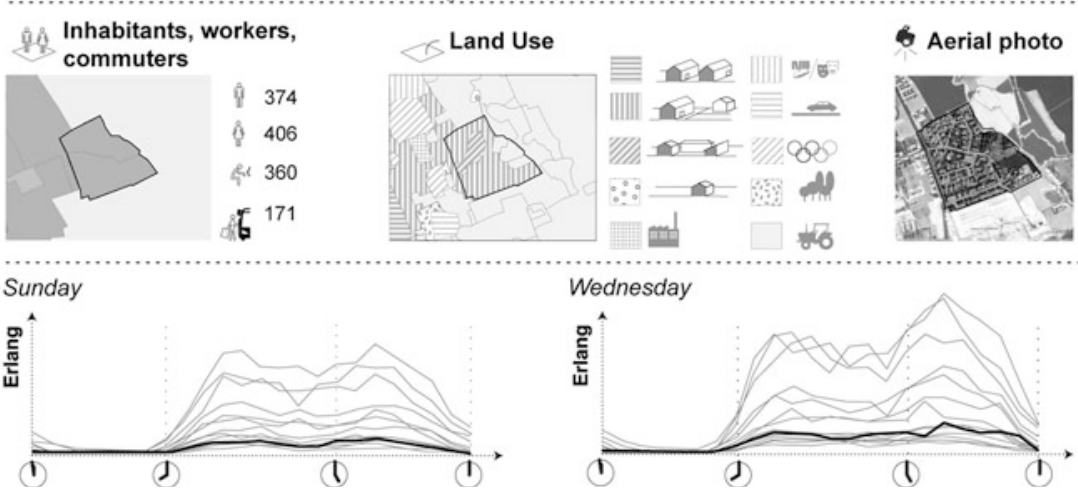

Fig. 9 Erlang and socio-demographical trends in some peri-urban neighbourhoods 


\section{In Perspective}

The as yet preliminary results of ongoing research show more complex dynamics, not related solely to the "post-metropolitan model". Probably, the economic crisis has played a part in influencing the evolutionary dynamics of these territories.

For these areas, we need not only new descriptions, but also the ability to understand the emerging needs and the issues relevant to the processes of structural crisis that some of these territories are going through and which overlap with important social changes and environmental problems. In this framework, testing research methods that work with different data sources and overlapping scales of study, is the challenge to understand the processes in place, avoiding homogenizing descriptions, without policy contents.

Additional analytical insights which involve an expansion of samples at the micro-scale as well as a more careful use of qualitative analysis create the possibility to:

- evaluate in depth whether the "post-metropolitan transformation model" (Soja 2000, 2011) is recognized even within the Lombardy context and can be read as a reorganization of the geography of movements;

- highlight the discrepancy between shifting boundaries of mobile practices and perimeters of the institutional policies as well as social polarization in peri-urban areas where access to communication and transport networks is often a key factor in redistribution of people, activities and land-use values, to produce significant effects on the social composition and distribution of the inhabitants;

- take the link between mobility and "new peri-urban issue" as main point of view on the new "urban question", but also as a device for renewing the lexicon, now inadequate, to explain the complexity of the phenomena and the nature of the post-urban transition;

- test how digital technologies (mobile phone data and social media) may be used within urban studies to integrate traditional data (O/D matrices, survey), with obvious benefits for both the heuristic (ability to read the space-time variability of the urban practices according to the resolution of the mobile phone data) and the operational dimensions (availability of the data with continuity over time, high spatial resolution, ability update in real time, etc.).

\section{References}

Balducci, A., Fedeli, V., \& Pasqui, G. (2011). Strategic planning for contemporary urban regions. London: Ashgate.

Bianchetti, C. (2000). Dispersione e città contemporanea. Percorsi, linguaggi, interpretazioni. Territorio, 14, 161-170.

Boeri, S., Lanzani, A., \& Marini, E. (1993). Il territorio che cambia. Ambienti, paesaggi e immagini della regione milanese. Aim, Abitare Segesta Cataloghi, Milano. 
Brenner, N. (2013a). Introduction: Urban theory without an outside. In N. Brenner (Ed.), Towards a study of planetary urbanization (pp. 14-27). Berlin: Iovis Verlage.

Brenner, N. (Ed.). (2013b). Implosions/explosions: Towards a study of planetary urbanization. Berlin: Iovis Verlage.

Brenner, N., \& Schmid, C. (2013). Planetary urbanization. In N. Brenner (Ed.), Implosions/explosions: Towards a study of planetary urbanization (Jov: 160-163).

Clementi, A., Dematteis, G., \& Palermo, P. C. (Eds.). (1996). Le forme del territorio italiano. Roma-Bari: Laterza.

Cresswell, T. (2006). On the move: Mobility in the modern western world. London: Routledge.

Dematteis, G. (Ed.). (1992). Il fenomeno urbano in Italia: interpretazioni, prospettive, politiche. Milano: Angeli.

Dias, D., Langumier, J., \& Demang, D. (2008). Mutabilité du périurbain. Le modèle pavillonnaire face aux crises énergétique et environnementale. Annales de la recherche urbaine., 104, 149-156.

Dodier, R. (2013). Modes d'habiter périurbains et intégration sociale et urbaine. EspacesTemps.net, Peer review, 06.05.2013. http://www.espacestemps.net/articles/modes-dhabiter-periurbains-etintegration/.

Echenique, M. H., Hargreaves, A. J., Mitchell, G., \& Namdeo, A. (2012). Growing cities sustainable. Does urban form really matter? Journal of the American Planning Association, $78(2), 121-137$.

Edensor, T. (2011). Commuter: Mobility, rhythm and commuting. In T. Cresswell \& P. Merriman (Eds.), Geographies of mobilities: Practices, spaces, subjects (pp. 189-204). Farnham: Ashgate.

Ewing, R., \& Cervero, R. (2001). Travel and the built environment: A synthesis. Transportation Research Record, 1780, 87-114.

Ewing, R., \& Cervero, R. (2010). Travel and the built environment. Journal of the American Planning Association, 76(3), 265-294.

Gordon, P., Richardson, H. W., \& Jun, M. J. (1991). The commuting paradox: Evidence from the Top Twenty. Journal of the American Planning Association., 57(4), 416-420.

Gordon, P., \& Richardson, H. W. (1997). Are compact cities a desirable planning goal? Journal of the American Planning Association, 63(1), 95-106.

Indovina, F. (1990). La città diffusa. Venezia: Daest.

Kaufmann, V. (2002). Re-thinking mobility contemporary sociology. Aldershot: Ashgate.

Keil, R. (Ed.). (2013). Suburban constellatio. Berlin: Jovia.

Lanzani, A. (1991). Il territorio al plurale. Milano: Angeli.

Lanzani, A. (2003). I paesaggi italiani. Roma: Meltemi.

Lanzani, A. (2011). In cammino nel paesaggio. Roma: Carocci editore.

Lanzani, A., \& Prusicki, M. (1995). Azioni a carattere strategico. Progetti e politiche sui sistemi territoriali e urbani. In A. Magnaghi (Ed.) Bonifica, riconversione e valorizzazione ambientale del bacino dei fiumi Lambro, Seveso e Olona. Linee orientative per un progetto integrato. Urbanistica Quaderni (Vol. 2, pp. 133-153).

Naess, P. (2005). Residential location affects travel behavior. But how and why? The case of Copenhagen metropolitan area. Progress in Planning, 63(1), 167-257.

Newman, P. W. G., \& Kenworthy, J. R. (1996). The land use-transport connection. Land Use Policy, 13(1), 1-22.

Nilsson, K., Pauleit, S., Bell, S., Aalbers, C., \& Nielsen, T. S. (Eds.). (2013). Peri-urban futures: Scenarios and models for land use change in Europe. Heidelber: Springer.

Phelps, N. A., \& Wu, F. (Eds.). (2011). International perspectives on suburbanization: A post-suburban world?. Basingstoke: Palgrave-MacMillan.

Pucci, P. (2010). Territoires et populations en mouvement. Pratiques de mobilité dans la région urbaine de Milan. Flux, 79-80, 101-111.

Pucci, P., Manfredini, F., \& Tagliolato, P. (2015). Mapping urban practices through mobile phone data. Heidelberg, New York, Dordrecht, London: Springer. (PolimiSpringerBrief). 
Richardson, H., \& Gordon, P. (2001). Compactness or sprawl: America's future vs. the present. In M. Echenique \& A. Saint (Eds.), Cities for the new millennium (pp. 53-64). London, UK: E. \& F. N. Spon

Secchi, B. (1992). Urbanistica descrittiva. Casabella. 588.

Secchi, B. (1994). Resoconto di una ricerca. Urbanistica, 103, 25-30.

Secchi, B. (2008). La città del XX secolo. Bari: Laterza.

Sennet, R. (2007). The open city. In R. Burdett \& D. Sudjic (Eds.), The endless city: The urban age project by the London School of Economics and Deutsche Bank's Alfred Herrhausen Society. London: Phaidon.

Sheller, M., \& Urry, J. (2006). The new mobilities paradigm. Environment and Planning A, 38, 207-226.

Sieverts, T. (2003). Cities without cities: An interpretation of the Zwischenstadt. London: Routledge.

Soja, E. W. (2000). Postmetropolis: Critical studies of cities and regions. Oxford: Basil Blackwell.

Soja, E. W. (2004). Le temps des nodalités post-métropolitaines. In S. Allemand, F. Ascher, \& J. Lévy (Eds.), Les sens du mouvement (pp. 175-181). Paris: Belin.

Soja, E. W. (2011). Regional urbanization and the end of the metropolis era. In G. Bridge \& S. Watson (Eds.), New companion to the city (pp. 679-689). Cambridge, MA: Wiley-Blackwell.

Sultana, S., \& Weber, J. (2014, February 1). The nature of urban growth and the commuting transition: Endless sprawl or a growth wave? Urban Studies, 51, 463-476.

Tosics, I. (2013). Sustainable land use in peri-urban areas: Government, planning and financial instruments. In K. Nilsson, S. Pauleit, S. Bell, C. Aalbers, \& T. S. Nielsen (Eds.), Peri-urban futures: Scenarios and models for land use change in Europe (pp. 373-404). Heidelberg: Springer.

Urry, J. (2000). Sociology beyond societies: Mobilities for the twenty-first century. London: Routledge.

Walks, A. (2013). Suburbanism as a way of life, slight return. Urban Studies, 50(8), 1388-1471.

Warf, B., \& Arias, S. (Eds.). (2009). The spatial turn: Interdisciplinary perspectives. London and New York: Routledge.

Young, D., \& Keil, R. (2010). Reconnecting the disconnected: The politics of infrastructure in the in-between city. Cities, 27, 87-95. 


\title{
Mobile Phone Data in Reading Mobility Practices
}

\author{
Fabio Manfredini, Paola Pucci and Paolo Tagliolato
}

\begin{abstract}
This chapter explores the potential of mobile phone data in reading urban practices and rhythms of usage of the contemporary city. Presenting the results of two researches, promoted by Telecom Italia and carried out by the authors, the chapter will show how new maps based on mobile phone data analysis can represent spatialized urban practices, providing new insights into space-time patterns of mobility practices. Mobile traffic data employed in the analysis of complex temporal and spatial patterns (Erlang, and origin-destination matrices) were treated as the effect of individual behaviours and habits, offering information about the features of usage of urban spaces that vary over time. Thanks to the processing of mobile phone data, it was possible to describe the intensity of use of the city (during the day, weekdays/holidays, seasons), linking them to the differences in the distribution of urban activities at different hours, day and weeks, as a useful tool to define urban policies regarding the supply of services; managing large and special events (inflow, outflow, monitoring), also estimating the mobility demand and the spatial-temporal variation in population density; describing time-dependent phenomena that are missing from traditional analysis; as well as tracing 'fuzzy boundaries' as perimeters of practices, as a tool for supporting and increasing the efficiency of urban policies and mobility services.
\end{abstract}

Keywords Erlang mobile phone data - Origin/destination mobile data - Treelet approach · Daily practices - Urban policy

Specific credits: Paolo Tagliolato paragraphs 1 and 2, Fabio Manfredini paragraph 3, Paola Pucci paragraph 4.

F. Manfredini $(\square)$ P. P. Pucci

DAStU, Politecnico di Milano, Milano, Italy

e-mail: fabio.manfredini@polimi.it

P. Pucci

e-mail: paola.pucci@polimi.it

P. Tagliolato

Istituto per il Rilevamento Elettromagnetico dell'ambiente CNR, Milano, Italy

e-mail: paolo.tagliolato@gmail.com

(C) Springer International Publishing Switzerland 2016

P. Pucci and M. Colleoni (eds.), Understanding Mobilities

for Designing Contemporary Cities, Research for Development,

DOI 10.1007/978-3-319-22578-4_14 


\section{Introduction}

In "The computer for the twenty first century" Weiser (1999), leader of the "ubiquitous computing" programme at Xerox Palo Alto Research Center, anticipated how a new generation of computers in the next few years would be so intimately interlaced in people's daily life as to become invisible to our perception. The main features of this kind of computers, according to Weiser, are their knowledge of their own location and their reduced size. At PARC, some prototypes of these devices were constructed and their resemblance to our smartphones and tablets is amazing.

The wide diffusion of smart devices that make the internet available "on the move" opened up new perspectives for information collected by people. This is the case of volunteered geographic information (Goodchild 2007), where citizens become "sensors" and can contribute to the collection of geographic data. Smartphone applications, open data portals, citizen science initiatives and social networks constitute the current scenario in this direction: with a few taps on a smart device, it is possible to enrich the current state of knowledge of places with regard to manifold topics, from the presence of biological species to leisure places in a city, from agronomy to road traffic.

Besides, crowdsourced big data suffer from the reliability of collected data: their accuracy is a fundamental issue. Coming to the possibility of exploiting this information for urban studies and mobility, whose appeal, given the costs of traditional surveys, undoubtedly emerges, the works in this direction must cope with the serious issue of the bias in the kind of people effectively using these technologies.

Despite this, in the same increasing trend of mobile communication, the so-called "next social revolution" (Rheingold 2002), a different source of data offered by people acting as sensors, but less prone to biases, has developed over the years: data are cellular network data, collected by providers for technical and accounting needs, a continuously updated source of information about the usage of mobile phones. In this case, with regard to the representativeness of cellular network data with respect to people, we can consider how mobile phone technology has been increasingly adopted by people in the past years: the average mobile penetration rate had increased from $0.4 \%$ in 1991 to $91.1 \%$ by 2010 worldwide (according to the World Bank) and in Italy in 2010 it was $146 \%$.

Mobile phone traffic data are promising sources for large-scale surveys. Users provide information about the (use of the) territories by simply using their mobile phone. Moreover, these data are automatically generated from the telecommunication networks, so there is no need for the huge investments necessary for acquisition of traditional data banks. 


\section{Analysis of Cellular Network Data}

In the context of a collaboration with Telecom Italia, ${ }^{1}$ one of the main cellular network providers in Italy, we carried out a project studying the potential and usefulness of cellular network data for urban studies and mobility. The main source maintained by cellular network providers is the "Call Detail Records" database. A call detail record reports, for each mobile phone call, the identifier of the mobile device (more precisely that of its SIM card), the cells in which the call occurred and timestamps of start and end of the call. The big issue, when exploiting these data, is privacy: it was proven (De Montjoye et al. 2013) that, even if anonymized (for instance obfuscating the ids of SIMs), these data can be used to identify people, being spatial traces of at least four spatio-temporal points, a unique fingerprint.

In the light of this consideration, we wish to point out that we only considered aggregated data, intrinsically and effectively characterized by anonymity, and hence, in our opinion, data that could be practically used for real applications.

In our study, the available data were processed following a methodological approach outlined in Fig. 1.

We present here just two data elaborations, given their particular relevance to spatial mobility.

The first data type regards the cellular network traffic intensity spatially distributed over the Lombardy region. It is expressed in Erlang, a dimensionless unit used in telecommunications as a measure of the average number of concurrent contacts in a time unit. Even if it can be derived from Call Detail Database, these data were directly collected at the antenna level, without relation to single users. It can be thought of as the work of the antenna, reporting the number of calls managed by it in a time unit. Starting from the traffic recorded by each antenna, the provider distributed the measurements, by means of weighted interpolations, throughout a spatial tessellation of the region in $250 \times 250 \mathrm{~m}^{2}$ areas ("pixels"). The data at our disposal covered the period 2009-2011. We used for the analyses the ratio between the amount of Erlang in each pixel and the total amount of traffic, at the same moment, in the "universe", represented in our case by the Lombardy Region. This relative measure indicates the amount of telephone traffic in a certain spatial region with respect to the total traffic. These data are more likely to provide indirect information about variations in the number of people. The information was statistically processed for comparison with the variables derived from consolidated data sources (census data, land use). These data were used to evaluate the possible relationships between variations in the intensity of cellular network phone calls and land-use characteristics.

Comparing Erlang data and data of people's presence in the Lombardy region derived from the latest official survey on mobility (Indagine O/D Regione

\footnotetext{
${ }^{1}$ Two research projects were financed by Telecom Italia during the year 2009 and 2011: "Utilizzazione dei dati di telefonia mobile per indagini territoriali" and "Stima di Matrici O/D con dati di traffico telefonico".
} 


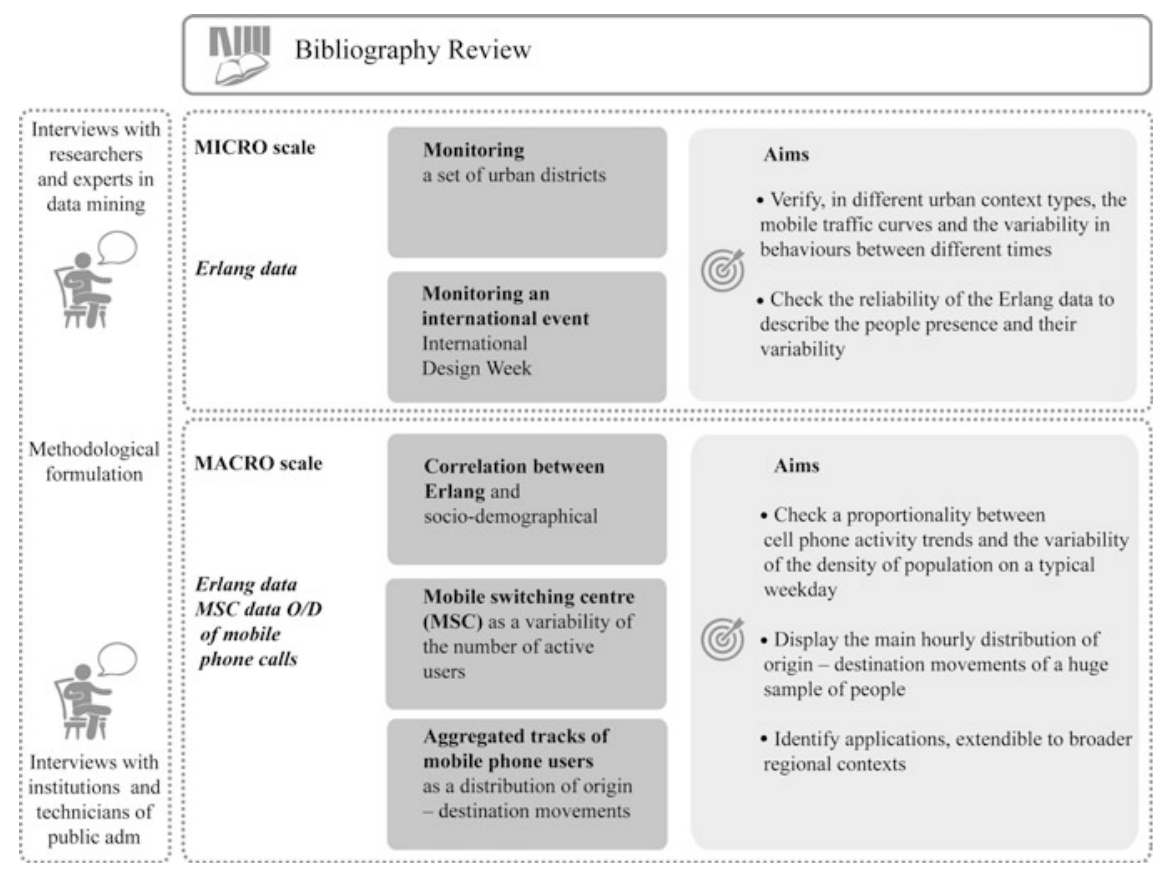

Fig. 1 The methodological approach (Source Pucci et al. 2015)

Lombardia 2002), we found a high correlation at the municipal scale (Pucci et al. 2015, Sect. 3.2.1 for a broader discussion), confirming the reliability of cell phone traffic data. The following table presents the correlation coefficient for the provincial capitals of the region (Table 1).

Erlang measures can give insights into various aspects of the urban area to which they refer, and analysis of them can be developed for various purposes, including selection of urban zones from the observed area with particular traffic intensity, identifying and measuring the attractiveness of the areas and their variability during the day; identification of "anomalies" occurring in the use of certain areas in reference to land uses, population and activity densities; monitoring of large events taking place in the city; segmentation of the area into districts characterized by homogeneous telephonic patterns; and identification of a set of reference signals able to describe the different patterns of utilization of the mobile phone network in time.

We discussed these topics and our results in (Pucci et al. 2015). Here, we only present one elaboration based on an analysis of the spatial and temporal variability of urban spaces during a large-scale event—called the "Salone Internazionale del Mobile"-which takes place not only in a specific part of Milan - the Rho-Pero exhibition district — but also in different parts of the city of Milan with various initiatives - going under the name of "Fuorisalone". 
Table 1 Linear correlation between the time series of cell phone traffic and those of people's presence in the provincial capitals of Lombardy region

\begin{tabular}{l|l|l|l}
\hline Municipality & $\begin{array}{l}\rho \text { (Pearson's correlation } \\
\text { coefficient) original } \\
\text { time series }\end{array}$ & $\begin{array}{l}\rho \text {-moving } \\
\text { average }(3 \text { terms) } \\
\text { smoothing of the } \\
\text { time series }\end{array}$ & $\begin{array}{l}\rho \text {-moving average } \\
\text { (3 terms) smoothing of } \\
\text { the time series, time range } \\
07: 00-23: 00\end{array}$ \\
\hline BERGAMO & 0.817281 & 0.916167 & 0.937125 \\
\hline BRESCIA & 0.845554 & 0.941575 & 0.968859 \\
\hline COMO & 0.670492 & 0.902546 & 0.930791 \\
\hline CREMONA & 0.783395 & 0.974567 & 0.986318 \\
\hline LECCO & 0.761152 & 0.891482 & 0.920895 \\
\hline LODI & 0.825717 & 0.928989 & 0.982498 \\
\hline MANTOVA & 0.483841 & 0.773677 & 0.939052 \\
\hline MILANO & -0.269416 & 0.453118 & 0.878923 \\
\hline MONZA & -0.321579 & 0.935640 & 0.978077 \\
\hline PAVIA & 0.292641 & 0.835625 & 0.874587 \\
\hline SONDRIO & 0.739026 & 0.862859 & 0.919483 \\
\hline VARESE & 0.895775 & 0.969681 & 0.986226 \\
\hline
\end{tabular}

Source Pucci et al. (2015)

This event attracted temporary populations that are difficult, if it not impossible, to measure with traditional data and surveys, but detected by mobile phone network data, as shown in Fig. 2, where the activity in the city of Milan in an average working day and the activity in a specific day during the International Design week are compared.

Values are ratios of telephone traffic among these days. Areas with events associated with the large event clearly emerge with values indicating an activity three times the normal. Such kinds of maps (specific day/average day) could easily be derived daily, and could be a tool for monitoring anomalous concentration of activities.

Figure 3 shows the outcome of a more sophisticated technique, Treelet decomposition (Lee et al. 2008) of Erlang signal, which can give insights into hidden patterns of mobile phone usage, caused by different usages of the city in time and in space which are related to individual mobility (Manfredini et al. 2012a, b, 2015; Vantini et al. 2012; Pucci et al. 2015).

In Fig. 3, each map in the set shows the intensity of specific patterns of both mobility and city usages (commuting, nightly activities, distribution of residences, non-systematic mobility), comparing them with the main urban facilities and services. ${ }^{2}$

In doing so, the Treelet approach shows the ability of mobile phone data to reflect the space-time variability of use of urban spaces, not necessarily due to the functional features, land use or the times of the activities, but rather to the ways in which people frequent some of these spaces.

\footnotetext{
${ }^{2}$ In each map, we added infrastructures (railways and main roads), railway stations, Linate city airport, main shopping centres and the fair trade centre.
} 


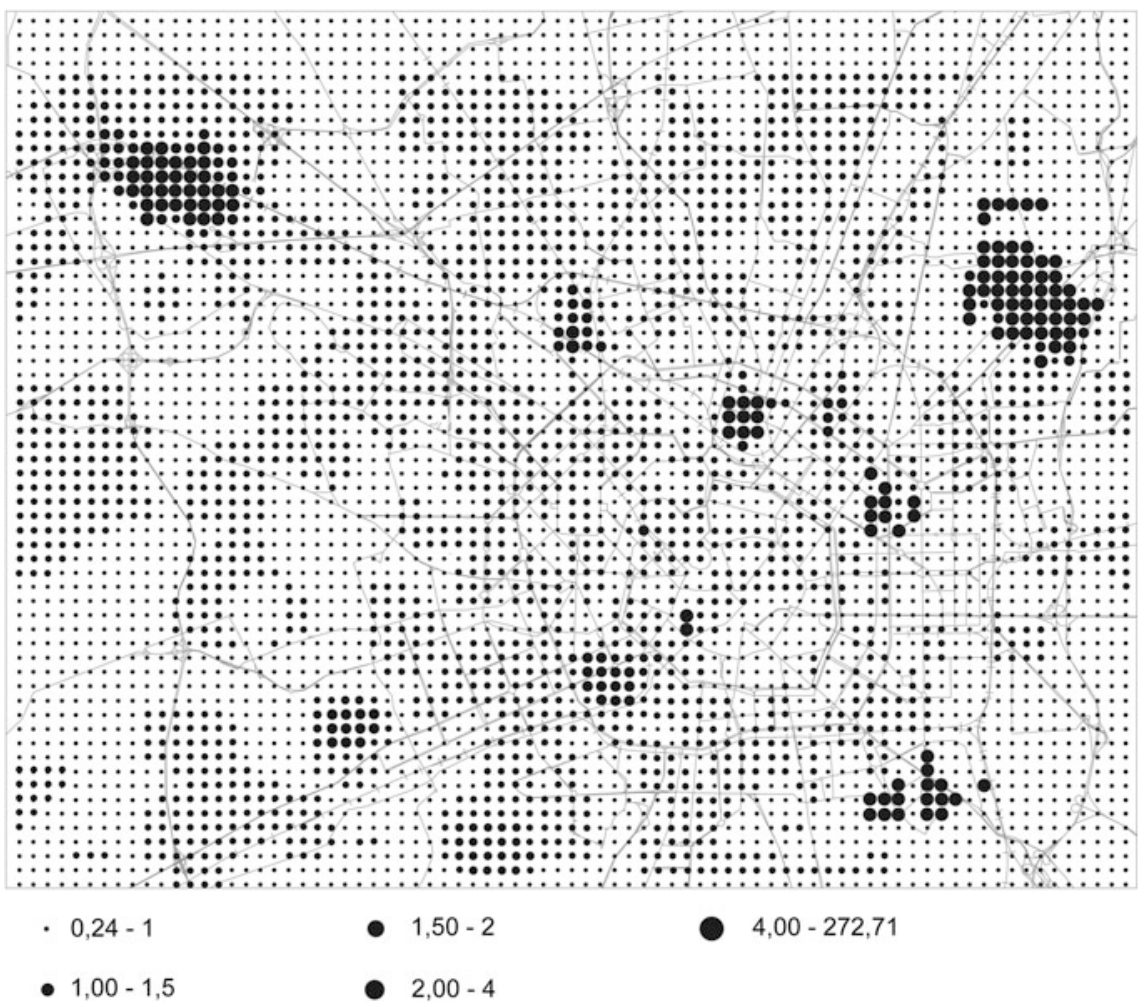

Fig. 2 Cell phone traffic intensity ratio between a day during the International Design Week, 2009 , and the average working day. The map highlights the parts of the city where the activity, during the International Design Week (April 24), was greater than during a typical weekday

This outcome is very promising for urban studies because it enables us to describe the "urban rhythms" generated by practices, rather than defined by opening/closing of activities, and to work with the actual uses of the urban spaces and services, as experienced in urban practices. ${ }^{3}$

The second typology of data is the aggregated origin-destination flows derived from the call detail records database. In the framework of our research and in collaboration with Telecom Italia (T-Lab), we arrived at a definition of a datum which was free from privacy restrictions, consisting in an aggregation of users' movements based on CDR records. Telecom Italia implemented a system for automatic, blind extraction of data of this kind, depicted in Fig. 4. Once fed with the CDR and a tessellation of a geographical region, it outputs time series of origindestination matrices (where origin and destination zones are the tessellation tiles), equivalent to a function $\mathrm{F}(\mathrm{o}, \mathrm{d}, \mathrm{t}) \rightarrow \mathrm{n}$ which, at time $\mathrm{t}$ ( $\mathrm{t}$ varying in the $24 \mathrm{~h}$ of a

${ }^{3}$ For more extensive discussion, we refer the interested reader to Pucci et al. (2015). 
Work and daily activities........
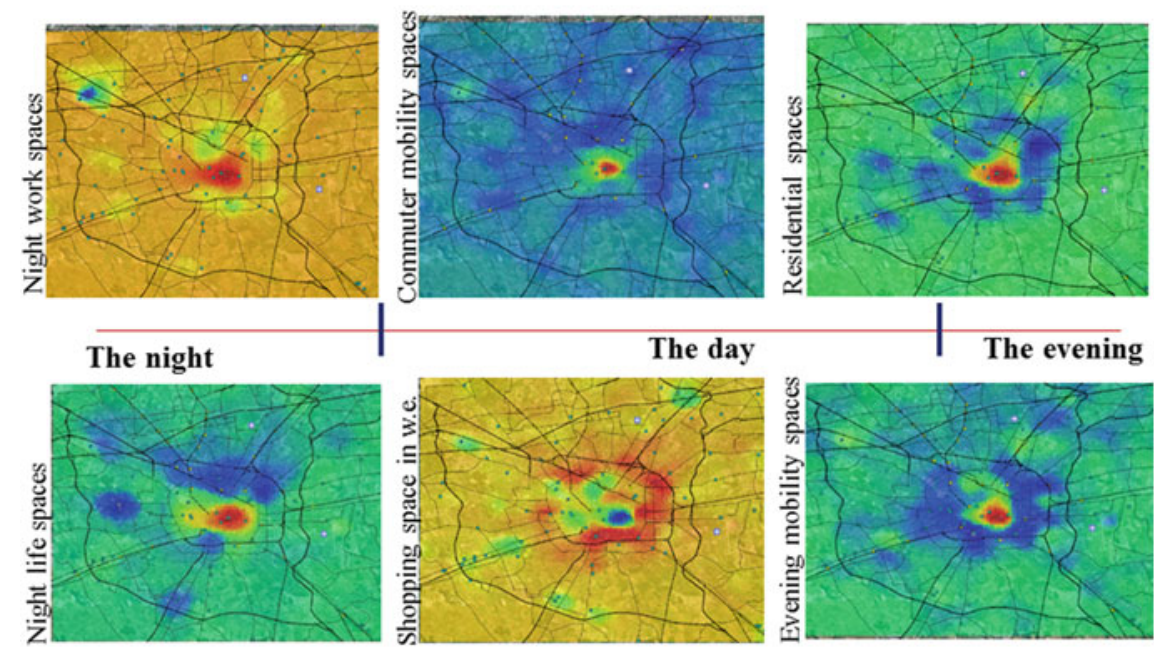

Leisure time, friendships and family activities.......

Fig. 3 Urban practices through mobile phone data. Source processing by DAStU (Dipartimento di Architettura e Studi Urbani) and MOX (Laboratorio di Modellistica e Calcolo Scientifico) Politecnico di Milano, on Telecom Italia data, 2013

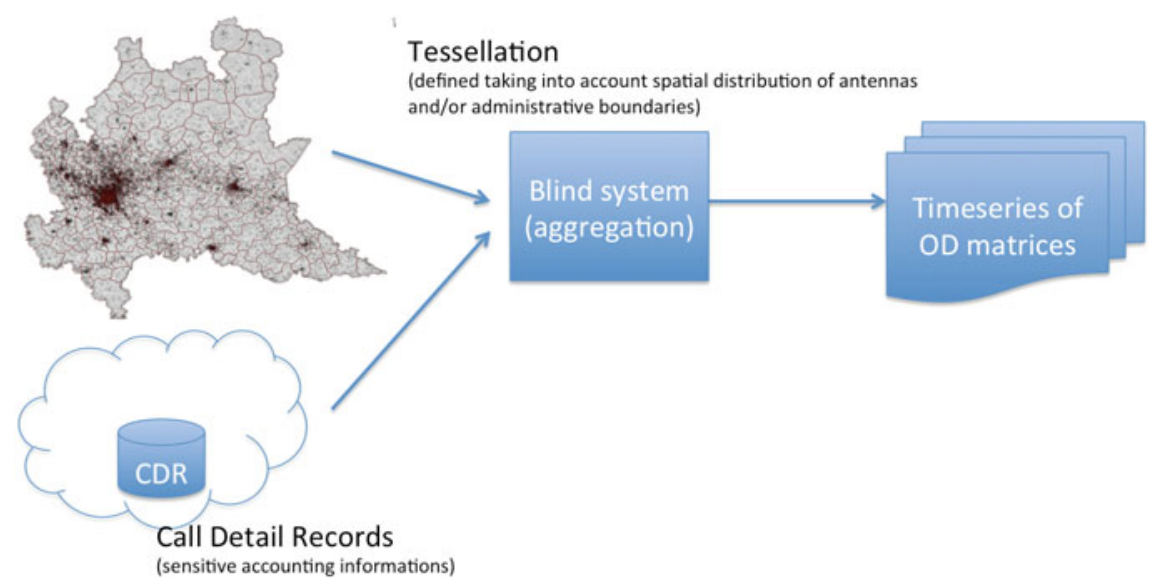

Fig. 4 Blind extraction of time series of aggregated origin-destination matrices

given day), assigns to origin o and destination $\mathrm{d}$ the number $\mathrm{n}$ of distinct users that performed some mobile phone activity within $\mathrm{o}$ at time $\mathrm{t}-1$ and a subsequent activity within $\mathrm{d}$ at time $\mathrm{t}$. 


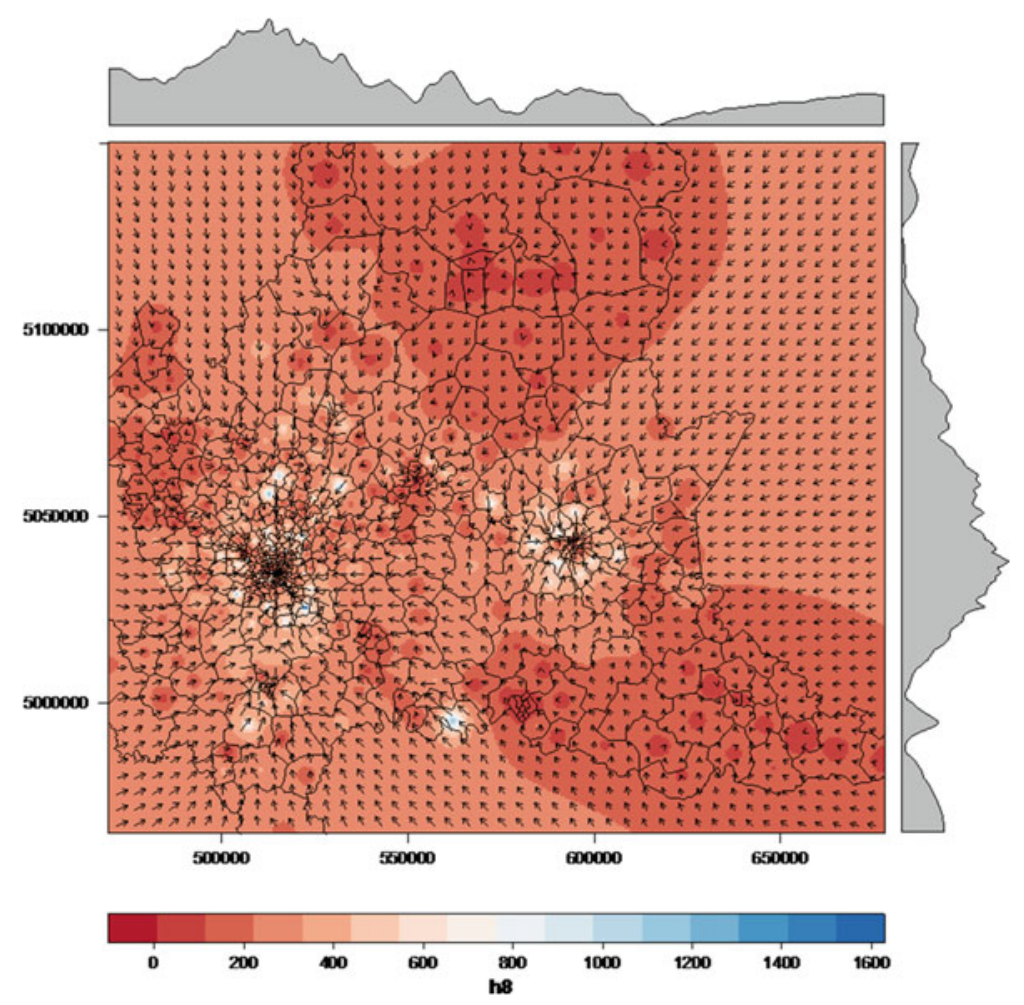

Fig. 5 Vector field of prevalent flows of mobility obtained through kriging

We proposed an overview of these data in terms of "prevalent flows" of mobility, defined as the sum vector of all the flows of people moving from each zone. Figure 5 shows the result of interpolating the sum vectors to obtain a regular vector field. In particular, the figure depicts the vector field for the morning rush hours in the Lombardy region. The polarization of movements towards the two cities of Milan and Brescia appears quite clearly.

Further, we showed by means of more sophisticated analysis (Tagliolato et al. 2014; Pucci et al. 2015), how this kind of aggregated OD matrices can be informative for. We identified pairs of zones with a high degree of regularity of movements between them. Public transport policies could benefit from identification of regular mobility practices: it could offer insight into the actual catchment area of an urban context, to which regulation measures and appropriate rates of the public transport service should correspond. 


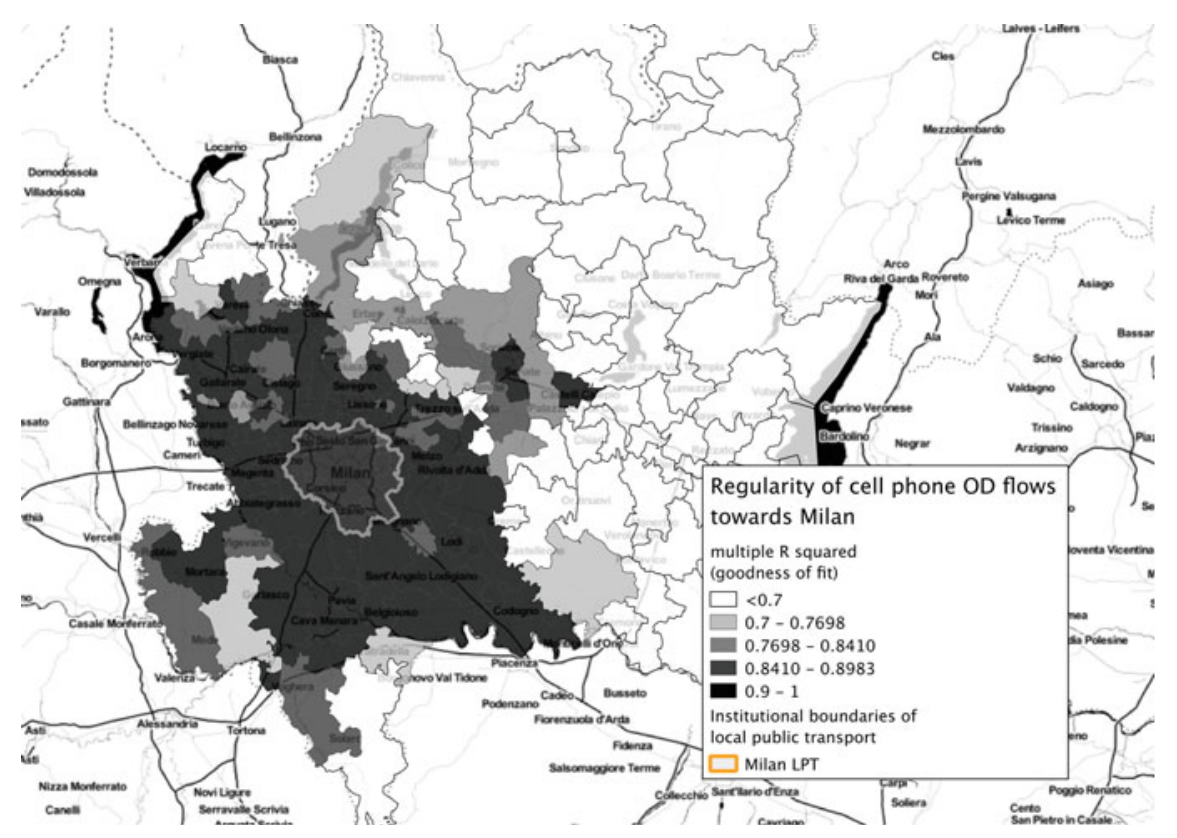

Fig. 6 Regularity of flows directed towards Milan. The perimeter of the institutional boundaries of the management of the local public transport is superimposed (Source Pucci et al. 2015)

We considered, for each origin-destination (od) pair, the seasonal process

$$
\operatorname{\Phi od}(t)=\Sigma \beta i D i(t)+\varepsilon(t)
$$

where the sums are taken on $i$ varying in $\{1, \ldots, 24\}$ and the $D i$ are seasonal (i.e. hourly) indicator variables, and we calculated the coefficient of determination (multiple $R 2$ ) that results from fitting ood to $F$ od. $R 2$ measures the quality of the model fit: we take it as a synthetic indication of the regularity of the signal.

Figure 6 represents in this perspective of regularity of movements a "catchment area" of Milan, alternative to the superimposed Local Public Transport institutional boundaries. Identification of the actual boundaries of the provenience of temporary populations of the city could contribute to the definition of fairer and more efficient policies (Pucci et al. 2014).

\section{Towards a Role of Mobile Phone Data in Official Statistics}

In our research, we demonstrated how different types of cell phone data can provide new knowledge about urban dynamics, which can be used in practical terms. 
These data, thanks to their spatial and temporal resolution, appear to have great potential in urban analysis and planning, in particular for recognition and identification of urban practices occurring in time and space. These phenomena are difficult to recognize through conventional data sources since they are rarely updated and since they are not able to intercept phenomena which change over time such as typically, mobility or the temporary presence of people in certain parts of the city, or the density of uses of territories.

Recent years have seen a growing debate on evaluation of the potential contribution of new sources of data based on information collected anonymously by users to official statistics.

In particular, the main question is definition of methods able to integrate them with conventional data sources to overcome the limitations of conventional data in describing and measuring phenomena occurring in urban spaces.

Among these urban phenomena, mobility in its spatial and temporal articulation appears to be one of the main issues that call for identification of new sources of data and methodologies able to describe it.

The perspective opened by mobile phone data in this field is particularly interesting if we consider, for example, the situation in the Lombardy region and focus on the following points (Pucci et al. 2015, p. 55):

- the spatial resolution of mobile phone data is, in urban areas, much finer than that of traditional surveys. Mobility practices can, then, be better visualized and studied;

- mobile phone data are continuously collected and their temporal resolution is very high; it could be possible to monitor different practices over time on an hourly, daily or seasonal basis;

- the transport mode is lacking in mobile phone data, which means that only indirect indications can be obtained for traffic on the main roads;

- we may reasonably assume that when information derived from mobile phone data becomes available on the market it will cost rather less than the outlay needed for conventional surveys, the mobile phone data having already been collected for accounting and for network monitoring (Table 2).

These mobile phone origin-destination data have much to offer for investigations into mobility and for urban analysis, in general.

If we consider mobility in a wider sense, not only related to origin-destination data, but also to the density of uses of the territories, we can compare other types of data (i.e. Erlang data) with conventional data sources in order to evaluate the potential of this kind of data in analysing urban phenomena (Table 3).

In origin/destination mobile data, information about users (user sociodemographic profiling, purpose of trips, modes of transports) is missing, and moreover there are sampling issues (data provided by one company, data on mobile phone activity, just to cite two major concerns).

The potential availability of these data opens new implications for the urban research community that needs to elaborate new strategies to integrate traditional data with user-generated data, such as mobile phone activity, in order to achieve a better comprehension of urban usages, in time and in space. 
Table 2 Comparison of the available sources on mobility in Lombardy

\begin{tabular}{|c|c|c|c|}
\hline & $\begin{array}{l}\text { Survey on mobility (OD) Lombardy } \\
\text { region } 2014\end{array}$ & $\begin{array}{l}\text { Census (on } \\
\text { commuting) } \\
\text { ISTAT 2011 }\end{array}$ & $\begin{array}{l}\text { Mobile phone } \\
\text { data (aggregated } \\
\text { O/D tracks) }\end{array}$ \\
\hline Sample & $30 \mathrm{~K}$ interviews & All residents & $\begin{array}{l}\text { Mobile phone } \\
\text { users } \sim 1.5 \mathrm{M} \text { per } \\
\text { day }\end{array}$ \\
\hline $\begin{array}{l}\text { Type of } \\
\text { movement }\end{array}$ & All & Study and work & All \\
\hline $\begin{array}{l}\text { Reference } \\
\text { period }\end{array}$ & $\begin{array}{l}\text { Average working day in } 2014 \\
\text { (February-May) }\end{array}$ & $\begin{array}{l}\text { Typical } \\
\text { working day }\end{array}$ & Everyday \\
\hline Updates & Expected on an yearly basis from 2016 & Every 10 years & Continuous \\
\hline $\begin{array}{l}\text { Information } \\
\text { on vehicle }\end{array}$ & Yes & Yes & No \\
\hline $\begin{array}{l}\text { Spatial } \\
\text { resolution }\end{array}$ & $\begin{array}{l}\text { Municipalities, aggregation of minor } \\
\text { municipal districts, subdivision of major } \\
\text { municipalities }\end{array}$ & Municipalities & $\begin{array}{l}\text { Variable } \\
\text { aggregation of } \\
\text { cells }\end{array}$ \\
\hline $\begin{array}{l}\text { Temporal } \\
\text { resolution }\end{array}$ & $24 \mathrm{~h}$ & 7-10 a.m. & $\begin{array}{l}\text { Hourly or } \\
\text { sub-hourly }\end{array}$ \\
\hline Cost & Expensive & Very expensive & Not known \\
\hline
\end{tabular}

Table 3 Comparison between conventional data sources and mobile phone data

\begin{tabular}{l|l|l|l}
\hline & $\begin{array}{l}\text { Conventional data } \\
\text { sources (municipal } \\
\text { statistical offices) }\end{array}$ & $\begin{array}{l}\text { Conventional data sources ISTAT } \\
\text { census }\end{array}$ & $\begin{array}{l}\text { Mobile phone } \\
\text { data (Erlang) }\end{array}$ \\
\hline Sample & All residents & All residents & $\begin{array}{l}\text { Mobile phone } \\
\text { active users }\end{array}$ \\
\hline $\begin{array}{l}\text { Spatial } \\
\text { resolution }\end{array}$ & Urban blocks & $\begin{array}{l}\text { Municipality boundaries (very } \\
\text { variable), urban blocks }\end{array}$ & $\begin{array}{l}\text { Pixel size } \\
250 \times 250 \mathrm{mt}\end{array}$ \\
\hline $\begin{array}{l}\text { Reference } \\
\text { period }\end{array}$ & Yearly & 2011 (census) & Everyday \\
\hline Updates & Yes (yearly) & Every 10 years (census) & Continuous \\
\hline $\begin{array}{l}\text { Available } \\
\text { information }\end{array}$ & $\begin{array}{l}\text { Number of inhabitants, } \\
\text { sex, age, nationality }\end{array}$ & $\begin{array}{l}\text { Number of inhabitants, sex, age, } \\
\text { nationality, workers, education, } \\
\text { employees, etc. }\end{array}$ & No \\
\hline $\begin{array}{l}\text { Temporal } \\
\text { resolution }\end{array}$ & Yearly & Yearly & $\begin{array}{l}\text { Hourly or } \\
\text { sub-hourly }\end{array}$ \\
\hline $\begin{array}{l}\text { Data } \\
\text { ownership }\end{array}$ & Public & Public & Private \\
\hline $\begin{array}{l}\text { Cost for the } \\
\text { production }\end{array}$ & Expensive & Very expensive & $\begin{array}{l}\text { Not known, } \\
\text { cheap }\end{array}$ \\
\hline $\begin{array}{l}\text { Cost for the } \\
\text { public }\end{array}$ & Free & Free & $\begin{array}{l}\text { Not known, } \\
\text { not free }\end{array}$ \\
\hline
\end{tabular}


At the same time, official statistics are therefore required to interact with this new kind of data, in order to evaluate if, and if so how mobile phone data can be used as new sources, able to describe phenomena for which official statistics do not collect data. In doing so, digital data as additional sources can be used as complement to conventional data sources or as alternative sources able to replace conventional ones (Barcaroli et al. 2014).

Questions that need to be addressed are the possibility and the expediency to replace existing data with mobile phone data or to improve/validate/integrate existing data with new sources and the possibility to collect completely new data about aspects of social life that are hard to capture with conventional data sources such as specific groups of populations, time-related information, etc.

In this direction, UNECE-United Nations Economic Commission for Europedecided to set up an internet inventory on the use of Big Data in national and international statistical organizations (http://www1.unece.org/stat/platform/display/ BDI/UNECE+Big+Data+Inventory+Home).

The inventory contains structured and searchable information about actual and planned use of Big Data in statistical organizations. This information is held in a standard template, searchable by statistical domain (using the Classification of Statistical Activities, an existing international standard), and the classification of type of Big Data (developed by the Big Data Task Team).

Among these, some are related to the use of mobile phone data, in particular concerning mobility issues and tourism. For each project, the major findings and problems are summarized. One of the main issues is privacy. While mobile phone operators have potentially access to all the information about their customers (mobile phone activity, location, direction of communications), they may not give the same access to researchers or official statistics institutions, depending on their company privacy policies and on the laws on protection of privacy in the country of application (Blondel et al. 2015).

The anonymization of mobile phone data is a growing field of research because the possibility to use these data for purposes other than those for which they are originally collected emerged only a few years ago. Moreover, the attention of public opinion to these topics must be kept in absolute consideration.

At the same time, the formats in which the data can be provided are many and there is not yet an established standard of mobile phone data free of privacy constraints. In general terms, the original raw data are acquired automatically by the network, processed directly by the company and finally provided to the scientific community in different formats, at different spatial and temporal resolutions, and it is not always possible to obtain precise information on the methodology used for producing the data.

The data refer to mobile phone activities, i.e. the number of interactions between the device and the network (calls, text messages, etc.). Therefore, the number of active users is lower than the number of mobile phone subscriptions. In our research, we found that in the Lombardy region the number of mobile phone users with more than 8 activities per day exceeded 1 million, which is in any case a value greater than the dimension of a standard statistical sample defined in the framework of a survey. 
Despite the limitations to the quality and nature of the data, we must stress that the sample size is comparable, if not greater, than that of many conventional surveys based on interviews.

There is a trade-off between the completeness of the sample achievable with census data versus the variability of the number of active users in mobile phone data. There is also another trade-off in the spatial and temporal resolution of mobile phone data, measurable, respectively, in hundreds of metres and in minutes/hours, in comparison with the spatial and temporal resolution of conventional data, measurable, respectively, according to the dimensions of administrative or statistical units and in years.

By choosing one source rather than another, we lose some information, gain some other information and the researcher has the responsibility to explain the limitations and the advantages to final users and urban stakeholders.

The census data output is usually coarse in resolution (e.g. local areas or counties rather than individuals or households). Moreover, the methods used to generate the data are quite inflexible (for example, once a census is being implemented, it is impossible to add/remove questions). Whereas the census seeks to be exhaustive, enumerating all the people living in a country, most surveys and other forms of data generation are samples, seeking to be representative of a population.

Mobile phone data have a very fine spatial and temporal resolution and are very flexible. It is therefore feasible to analyse customized areas depending on the aims of the research (urban blocks, linear infrastructures, etc.). Precise spatial accuracy is therefore one relevant aspect that creates greater possibilities for detailed research.

Another point to stress is that mobile phone data must be interpreted, even with the help of conventional data sources (e.g. mobility data, land use/land cover, sociodemographic data, census data) and other sources that have become available in recent years (open mapping websites, social media data and in general user-generated data). This is important because, thanks to a map of activities, land cover or urban facilities, it is possible to attribute a sense to concentrations and hot spots of mobile phone activity or anomalies in specific hours of the day, days of the weeks and seasons.

Mobile phone data are therefore important as corroborating evidence in explaining patterns of usage of the city by urban populations (Pucci et al. 2015, p. 75).

In this context, the official statistics institutions can play a relevant role in incorporating some of the methodologies and of these new sources of data in their own tasks. First, they can act as public interlocutors of telephone companies in order to define formats and conditions to obtain mobile phone data for the general interest. In fact, since mobile phone companies are private, no technical and scientific collaboration between them exists, with the exception of some humanitarian projects in Asia or Africa. In this framework, the definition of a public interest use of mobile phone data and the identification of a public agency (i.e. an official statistics institution) may lead companies to share some data for specific purposes.

Moreover, using data at high temporal and spatial resolution, it will be feasible to move from descriptive indicators to statistical modelling (nowcasting and forecasting) and to integrate, in the general framework provided by conventional data, the outcomes derived from the analysis of spatial and temporal patterns of mobile phone data. 
Selection of research experiments on the integration of different datasets, identification of replicable research methodologies and definition of a protocol to integrate heterogeneous information could be three relevant tasks for the development of applications of mobile phone data to specific case studies.

Statisticians, social scientists, urban planners and geographers should take advantage of this new data source. Due to their complexity, integration between different competences is needed to fully exploit the potential of this kind of data. Computation and quantitative analytical skills are therefore required, together with the capacity to read and visualize spatial-temporal dynamics deriving from the analysis of big data.

Analysing the spatial and temporal usage of cities in their contemporary daily-life practices requires integration between traditional data (land cover, town plans, spatial distribution of activities, etc.) and new sources of information, closer to users, such as mobile phone data activity or geolocated digital traces, with the aim of identifying the complexity and multiplicity of individual behaviours. Through the new data, we can define who we are by the places we go to, overcoming some limitations due to characteristics of traditional sources of data in describing contemporary city dynamics.

In this context, the real challenge for urban studies is the integration of available databases together with an innovative use of traditional sources, in order to capture the variety of changes in urban practices (Pucci et al. 2015, p. 76).

\section{Towards a Role for Mobile Phone Data in Urban Policy}

The processing of mobile phone data has an important role to play in both the analytical and the normative dimensions of urban policies, within two complementary perspectives.

The first perspective appraises the relevant real-time knowledge offered by mobile phone data in describing the intensity of urban activities and their evolution through space and time, as a framework for area-wide implementation of more effective urban and mobility policy.

This is because, as effect of individual behaviour and habits (Ahas and Mark 2005), mobile phone data enable us to detect the molecular daily practices and the emerging demands being made by populations using the city and its services, at varying rhythms and intensities.

These potentialities are related to the peculiar features of mobile phone data. Indeed, although "certain footprints have a personalised value (...), they indicate the presence of a person implied from the outset"4 (Ferraris 2009, p. 336), in our research these "idiom footprints" are not connected to an individual, but instead to

\footnotetext{
${ }^{4}$ My translation of "Certe tracce possiedono un valore individualizzante [...] ossia segnalano la presenza di una persona che ne è all'origine e che vi è implicata" (Ferraris 2009, p. 336).
} 
"groups of subjects that, temporarily and intermittently, share practices of daily life" (Pasqui 2008, p. 148). This is because the nature of the data provides aggregate behaviours related to the intensity of mobile phone use. In doing so, our research focused on the longitudinal activity patterns of network cells rather than individual users. Through geographical mapping of mobile phone usage at different times of the day, it was possible to verify the value of these data to ascertain the following:

- population distribution in cities and their variability, according to the density of call activity in mobile network cells;

- land-use classification according to mobile phone uses, in which different "basic" profiles of city usages can concur to identify different profiles of use and consumption without the burden of a direct survey; in this case, mobile phone data would allow for functional description of space in terms of effective uses instead of activities and equipment ${ }^{5}$;

- origin-destination tracks of mobile phone users in the form of an O/D matrix to monitoring different mobility practices over time, on an hourly, daily or seasonal basis.

Thanks to the potentialities of mobile phone data in explaining the spatial dimension of varying practices that have great impacts on the densities of use of the city and its services, we can propose several possible applications in terms of the following:

- recognizing specific (in time and space) situations of deficit in public transport supply related to the effective concentration of population and uses;

- supporting and increasing the efficiency of urban policies and transport services with more detailed knowledge of the intensity of the use of the city (during the day, weekdays/holidays, seasons) linking them to the differences in the urban activity distribution at different hours, days and weeks;

- managing environmental and industrial risk protection with information deduced from mobile phone data used as a "proxy" of the population exposed to specific risks;

- managing large and special events (inflow, outflow, monitoring), also estimating the mobility demand and the spatial-temporal variation in population density, to offer guidance for future decisions on the provision of new urban services;

- developing an integrated research protocol based on the comparable and available data (traditional and digital data) and starting from definition of the main indicators, measures and successful criteria to be implemented at the local scale for the Local Authorities.

Far from seeking a deterministic analysis that allows for continuous real-time calculation, referred to by Nigel Thrift as "qualculation" (Thrift 2004), we know that "research is needed to understand the policy implications of these data and how institutions should evolve to accommodate them. Methodologies and tools are

\footnotetext{
${ }^{5}$ See Chap. 3 in Pucci et al. (2015).
} 
needed for devising effective policies, combining them strategically and overcoming implementation barriers such as public and political acceptability" (Bruun and Givoni 2015, p. 31). In addition, the outputs must be comprehensible to elected officials and, indeed, to the public.

However, an essential condition that makes these data particularly interesting for urban policy is linked to the importance of taking the urban rhythms in exploring the complexity of the contemporary city where the increase of "polyrhythmic nature of everyday urban life" needs new analytical approaches.

If "the urban has an intrinsically rhythmic organization which, in turn, gives rise to specific forms, configurations and relations of space, time, interaction and mobility" (Smith and Hetherington 2013, p. 6), it is through more effective analytical tools such as mobile phone data that the rhythmic organization of the city can be read.

Our references take into account that the contemporary city is a "site of sociability" (Amin and Thrift 2002), understanding of which is made possible by the space-time variability of the practices that take place in it. Mobile and digital data take us beyond an approach to the city as configured by "enclaves" (fixed and bounded sites) and 'armatures' (infrastructure channels and transit spaces) (Shane 2005), providing real-time maps of a daily practices that bring out a rich variety of places of use in accordance with the temporal organization of everyday life. These places define new geographies that call into question urban policies and transport supplies.

In addition, through processing mobile and digital data, two myths are challenged: the "death of distance" caused by mobile technology and the borderless world through space-time compression, as well as the "erratic and nomadic behaviour of metropolitan populations". The data show a strong recursion path: while we move a lot during the day, we tend to do so along familiar and habitual paths ${ }^{6}$ (Gonzalez et al. 2008).

The second perspective concerns the valuable support offered by mobile phone data in "re-scaling" urban policy and assisting in the construction of geographies of partnerships between different stakeholders.

On the evidence of several researches (Ahas and Mark 2005; Ratti et al. 2006; Kwan at al. 2007; Reades et al. 2007), mobile phone data offer multi-scalar maps to deal with the variability of the relationships, with time-dependent phenomena, with the heterogeneous rhythms of urban practices that are missing from traditional analysis, becoming a support for tracing fuzzy boundaries as perimeters of practices, useful for a "re-territorialization" of urban policies.

\footnotetext{
${ }^{6}$ In this perspective, the work of Gonzales, Hidalgo and Barabasi, which examined the tracked positions of individuals, demonstrated that "human trajectories show a high degree of temporal and spatial regularity" (Gonzalez et al. 2008).

${ }^{7}$ This means a process of 'shaping' between shifting political boundaries, new geographies and structures of power, human landscapes, local/transnational communities and their everyday border experiences.
} 
The need to build relevant boundaries as a resource of institutional capital in Spatial Planning comes up against the difficulty of giving operational content to this issue as well as the practical impact of the shift on institutional boundaries and consolidated spaces of governmental activity corresponding to powers and strengthened responsibilities.

As we have already pointed out (Pucci et al. 2015, Chap. 5), a different articulation of skills and resources that will improve the regulation of practices and help to generate the new frameworks for institutional innovation, calls for tools to outlining relevant and shared variable boundaries. The challenge is posed in terms of interpretive tools able to recognize "soft spaces" (such as transversal spaces) and "fuzzy boundaries" (such as fluid perimeters) to manage "the permanent dissociation between citizens, inhabitants and city users characterizing all territorial gov-

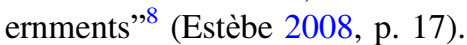

In Spatial Planning as well as in Borderscape Studies, ${ }^{9}$ many contributions-as pointed out by Parker and Vaughan-Williams (2012) — draw attention to the following:

- the need for an alternative paradigm for (re)thinking border politics' (...), thinking about alternative geopolitical visions in which novel approaches to borders are mobilized;

- the urgency to understand that borders are also not temporally fixed;

- interrogation of the link between bordering practices and 'the various forms of contestation and resistance' border practices give rise to;

- the relationship between bordering processes and the 'where' of the border, that is to say its shifting and changing location (Parker and Vaughan-Williams 2012, pp. 727-733).

All these points are of great interest for urban planning in a project-oriented viewpoint, highlighting the main features of the borders as dynamic social processes, useful to deal with the governance process, to interpret and regulate the transformation processes in times, places, social life and work programmes in the contemporary city.

Indeed, in different experiences, 'informal boundaries' may become part of an 'institutional landscape', generating new models of public involvement and actions capable of intercepting and responding more effectively to the emerging social demands.

The debate on "soft spaces" as "representative of a deliberate attempt to generate new thinking and insert new models of public engagement $[\ldots]$; as part of the changing institutional landscape of Spatial Planning (...) and predominately defined (or not) in a fluid fashion, and with reference to fuzziness, in order that they are

\footnotetext{
${ }^{8} \mathrm{My}$ translation from "Tous les gouvernements territoriaux vivent sous un régime permanent de dissociation entre les citoyens, les habitants et les usagers de la ville" (Estèbe 2008, p. 17).

${ }^{9}$ According to Brambilla (2014), Borderscape studies focus on the conceptual evolution of borders offering new perspectives to dealing with processes of 'shaping' between shifting political boundaries, new geographies and structures of power, human landscapes, local/transnational communities and their everyday border experiences.
} 
more amenable to a shifting range of issues and actors involved in Spatial Planning projects" (Haughton and Allmendinger 2008) confirms this orientation.

The contents and key dimensions of these notions are gaining consensus, also in view of their fundamental characteristics, which express "the new post-devolution spaces of planning" (Haughton et al. 2010), but, at the same time, they leave open the matter of the operational impacts in terms of relationships with the formal hard spaces of governmental activity.

In the relationship between fuzzy boundaries, as new spaces of governance, and institutional spaces, the problems related to the temporal variability of the practices at the origin of the fuzzy perimeters, such as the mechanisms of political representation of communities of practice, remain unresolved.

An important aspect to drawing relevant boundaries in Spatial Planning is the capacity building of shared perimeters to promote forms of cooperation and new geographies of partnerships.

In this way, a different articulation of skills and resources, such as will improve the regulation of practices and help to generate new frameworks for institutional innovation, requires identification of flexible as well as shared boundaries.

According to Peck and Theodore (2010, p. 171), “(...) there is an inescapable need to confront new methodological challenges. Spatially demarcated forms of policy evaluation certainly will not do. New methodological strategies must be developed to expose and critically interrogate the interconnectedness of policy regimes between places and across scales".

In this perspective and considering the main features of mobile phone data, they can contribute in supporting the cross-scalar approaches (i.e. how the variability of borders changes the social and political configurations), and indeed the nexus between everyday life-worlds, power relations and social borders.

Time-space variability of urban practices and their relevance in terms of density and repetitiveness, detected by mobile phone data, can provide a useful contribution, not only to the recognition and naming of the territories of urban practices deforming institutional boundaries, but also to a "re-scaling" of the hierarchies of intervention, and thus to the governance of dynamic processes.

In our research (Pucci et al. 2015, Chap. 5), we demonstrate the relevance of the maps produced with mobile phone data and representing the territories made by "communities of practice", which generate contingent boundaries with a relational and variable value, on the evidence of the dynamics we plan to capture and regulate.

\section{References}

Ahas, R., \& Mark, U. (2005). Location based services: New challenges for planning and public administrations? Futures, 37, 547-561.

Amin, A., \& Thrift, N. (2002). Cities. Reimagining the urban. Cambridge: Polity.

Barcaroli, G., De Francisci, S., Scannapieco, M., \& Summa, D. (2014). Dealing with big data for official statistics: IT issues. Meeting on the Management of Statistical Information Systems, Dublin, Ireland and Manila, Philippines, 14-16 April, 2014. 
Blondel, V., Decuyper, A., \& Krings, G. (2015). A survey of results on mobile phone datasets analysis. Arxiv. http://arxiv.org/abs/1502.03406.

Brambilla, C. (2014). Exploring the critical potential of the borderscapes concept. Geopolitics, . doi:10.1080/14650045.2014.884561.

Bruun, E., \& Givoni, M. (2015). Six research routes to steer transport policy. Nature, 523, $29-31$.

De Montjoye, Y.-A., Hidalgo, C. A., Verleysen, M., \& Blondel, V. D. (2013). Unique in the crowd: The privacy bounds of human mobility. Scientific Reports, 3, 1376. doi:10.1038/ srep01376.

Estèbe, P. (2008). Gouverner la ville mobile: la ville en débat. Paris: Puf.

Ferraris, M. (2009). Documentalità. Perché è necessario lasciar tracce. Bari: Laterza.

Gonzalez, M. C., Hidalgo, C. A., \& Barabasi, A. L. (2008). Understanding individual human mobility patterns. Nature, 453(7196), 779-782.

Goodchild, M. (2007). Citizens as sensors: The world of volunteered geography. GeoJournal, 69 (4), 211-221. Retrieved from http://dx.doi.org/10.1007/s10708-007-9111-y.

Haughton, G., \& Allmendinger, P. (2008). The soft space of local economic development. Local Economy, 23(2), 138-148.

Haughton G. et al. (2010). The new spatial planning: Territorial management with soft space and fuzzy boundaries, London: Routledge.

Kwan, M. P., Dijst, M., \& Schwanen, T. (2007). The interaction between ICT and human activity-travel behaviour. Transportation Research Part A: Policy and Practice, 41(2), 121-124. Available at: http://linkinghub.elsevier.com/retrieve/pii/S0965856406000255 Accessed in May 9, 2012.

Lee, A. B., Nadler, B., \& Wasserman, L. (2008). Treelets. An adaptive multi-scale basis for sparse unordered data. The Annals of Applied Statistics, 2(2), 435-471.

Manfredini, F., Pucci, P., Secchi, P., Tagliolato, P., Vantini, S., \& Vitelli, V. (2012a). Treelet decomposition of mobile phone data for deriving city usage and mobility pattern in the Milan urban region. MOX Report 25. http://mox.polimi.it/it/progetti/pubblicazioni/view.php?id= 345\&en=, 25 June, 2012.

Manfredini, F., Pucci, P., Secchi, P., Tagliolato, P., Vantini, S., \& Vitelli, V. (2015). Treelet decomposition of mobile phone data for deriving city usage and mobility pattern in the Milan urban region. In A. M. Paganoni \& P. Secchi (Eds.), Advances in complex data modeling and computational methods in statistics (pp. 133-148). Heidelberg, New York, Dordrecht, London: Springer.

Manfredini, F., Pucci, P., \& Tagliolato, P. (2012b). Mobile phone network data: New sources for urban studies? In G. Borruso, et al. (Eds.), Geographic information analysis for sustainable development and economic planning: New technologies (pp. 115-128). Hershey: IGI Global.

Parker, N., \& Vaughan-Williams, N. (2012). Critical border studies: Broadening and deepening the lines in the sand agenda. Geopolitics, 17(4), 727-733.

Pasqui, G. (2008). Città, popolazioni, politiche. Milano: Jaca Book.

Peck, J., \& Theodore, N. (2010). Mobilizing policy: Models. Methods and Mutations. Geoforum, 41(2), 169-174.

Pucci, P., Manfredini, F., \& Tagliolato, P. (2014). A new map of the Milan urban region through mobile phone data. In A. Contin, P. Paolini, \& R. Salerno (Eds.), Innovative technologies in urban mapping. Built Space and Mental Space (pp. 83-92). Cham: Springer.

Pucci, P., Manfredini, F., \& Tagliolato, P. (2015). Mapping urban practices through mobile phone data. PoliMI SpringerBriefs. Heidelberg, New York, Dordrecht, London: Springer.

Ratti, C., et al. (2006). Mobile landscapes: Using location data from cell phones for urban analysis. Environment and Planning B: Planning and Design, 33, 727-748.

Reades, J., Calabrese, F., Sevtsuk, A., \& Ratti, C. (2007). Cellular census: Explorations in urban data collection. IEEE Pervasive Computing, 6(3), 30-38.

Rheingold, H. (2002). Smart mobs: The next social revolution. Cambridge, MA: Basic Books.

Shane, D. G. (2005). Recombinant urbanism. Conceptual modelling in architecture, urban design, and city theory. Wiley: Chichester. 
Smith, R. J., \& Hetherington, K. (2013). Urban rhythms: Mobilities, space and interaction in the contemporary city. The Sociological Review, 61(S1), 4-16.

Tagliolato, P., Manfredini, F., \& Pucci, P. (2014). Discovering regularity patterns of mobility practices through mobile phone data. International Journal of Agricultural and Environmental Information Systems, 5(3), 38-56.

Thrift, N. (2004). Movement-space: The changing domain of thinking resulting from the development of new kinds of spacial awareness. Economy and Society, 33(4), 582-604.

Vantini, S., Vitelli, V., \& Zanini, P. (2012). Treelet analysis and independent component analysis of Milan mobile-network data: investigating population mobility and behaviour. In Analysis and Modeling of Complex Data in Behavioural and Social Sciences-Joint Meeting of the Italian and the Japanese Statistical Societies.

Weiser, M. (1999). The computer for the 21st century. SIGMOBILE Mobile Computing and Communications Review, 3(3), 3-11. doi:http://doi.acm.org/10.1145/329124.329126. 


\section{Index}

A

Accessibility, 7, 24, 30, 40, 78, 103, 153, 162, 172, 174, 177, 181, 183, 186, 197, 208, 244

Autostrada Pedemontana Lombarda, 93, 95, 98, 104, 105

C

Car dependence, 172, 179, 180, 182-185

City users, 15, 29, 52, 53, 59, 110, 193, 199, 223,269

Commuters, 29, 37, 39, 51, 52, 56, 59, 60, 130-132, 135, 146, 192-195, 199, 223, 226

Commuting, 9, 37, 38, 42, 44, 51, 110, 117, 157, 177, 181, 183, 192, 209, 232, 238, 241, 242, 247, 257

Creative Industries, 114

D

Daily mobility, 25-28, 40, 236, 238, 242

Daily practices, 5, 50, 61, 247, 266, 268

Demographic dynamics, 209

E

Efficiency, 15, 30, 58, 68, 113, 123, 125, 153, 154, 156, 159, 161, 164-166, 168, 267

Environmental integration, 87

Erlang, 242, 245, 247, 255-257, 262

F

Future of mobility, 67, 68, 75, 77, 78, 81

G

Geographic Information System (GIS), 213

Governing mobilities, 71

I

Infrastructure project, 88, 91, 93, 101

Infrastructures, 5, 18, 36, 44, 69, 70, 78, 80, $105,110,119,155,197,226,241,265$

\section{$\mathbf{J}$}

Justice, 30, 153-155, 164, 166, 168

$\mathbf{L}$

Local networks, 117, 121

M

Meta cities, 29, 227

Metropolitan areas, 29, 58, 179, 182-184, 186, 192, 208-210, 214, 215, 217, 219-222, 225-227, 234

Milan Urban Region, 88, 233-236, 238-241, 243-246

Mobile methods, 131

Mobile phone data, 14, 234, 239, 242, 245, 249, 257, 262, 264-268, 270

Mobile risk society, 78

Mobilities, 6, 8-11, 15-17, 47, 70-73, 82, 131, 137

Mobility flows, 215, 217, 227, 243

Mobility policy, 14, 15, 62, 71, 76, 235, 266

Mobility practices, 4, 5, 7, 9, 11-13, 15, 17, 49, $51,73,130,133,135,136,139,147,232$, 234, 243, 245, 260, 262, 267

Mobility time, 161

Motorised means of transport, 23, 172

Multilocality, 110, 115, 116, 118, 120, 124, 126

O

Origin/destination matrix, 6, 41, 213, 237, 242, 258, 261, 262, 267

$\mathbf{P}$

Peri-urban areas, 215, 220, 226, 227, 232-234, 242, 245, 247, 249

Place attachment, 110, 113, 126

Plug\&play places, 111, 122, 124-126

Pluralization, 54

P. Pucci and M. Colleoni (eds.), Understanding Mobilities

for Designing Contemporary Cities, Research for Development,

DOI 10.1007/978-3-319-22578-4 
Q

Quality, 6, 10, 16, 18, 24, 28-30, 37, 58, 72, $73,75,79,82,88,92,95,96,106,113$, 155-158, 162, 164, 208, 213, 221, 223, 236, 261, 265

$\mathbf{R}$

Resident populations, 195, 197

$\mathbf{S}$

Smart urbanism, 68, 73

Social Capital, 5, 10, 11, 30, 91, 165, 175, 185, 235

Social exclusion, 29, 30, 172-174, 176, 178, 179, 183, 185, 186, 194, 198

Sociology, 6, 17, 27, 28, 30, 41, 131, 200

Socio-spatial transformations, 3, 233

Spatial mobilities, 5

Standardization of places, 110, 112-114, 124-126

\section{T}

Territorialisation, 5, 7, 17

Territory, 5, 9, 18, 27, 36, 43, 45, 46, 55, 88, 92-95, 97, 98, 103-105, 130, 134, 135, 137, 139, 144, 146, 163, 208, 209, 213, 219, 226, 227, 236, 241, 247
Time, 3, 4, 6, 7, 9-11, 14, 15, 17, 25, 26, 28, $36-39,42,45,47,49,51-54,56,57,68$, $71,73,75,76,78,89,90,101,102,113$, $115,118,121-123,125,126,130-132$, $137,138,142,144,146,147,152-161$, 163-166, 168, 174, 178-181, 197, 198, 200, 233, 237, 238, 245, 249, 259, 267

Time policies, 144, 166, 197

Tourists, 72, 193, 194, 197, 199

Transport disadvantage, 30, 172-186

Transport policy, 186

Treelet approach, 257

$\mathbf{U}$

Urban conflicts, 191, 194

Urban form, 13, 44, 53, 172, 179, 184, 213, 233

Urban mobility, 3, 15, 60, 72, 73, 81, 82, 153, $154,156,168$

Urban morphology, 28

Urban policy, 13, 15, 58-61, 266, 268

Urban populations, 5, 8, 28, 51-62, 265

Urban regionalization, 243

Urban rhythms, 4, 8, 49, 51, 56, 144, 146, 147, $151-153,168,258,268$ 